\title{
From Scotland to New Scotland: Constructing a Sectoral Marine Plan for Tidal Energy for Nova Scotia
}

\author{
by \\ Stephen Joseph Sangiuliano \\ supervised by \\ Dr. Mark S. Winfield
}

\begin{abstract}
A Major Paper
submitted to the Faculty of Environmental Studies

in partial fulfillment of the requirements for the degree of Master in Environmental Studies

York University, Toronto, Ontario, Canada
\end{abstract}

May 17, 2017 
The marine environment has historically played a significant role in sustaining coastal economies, with $44 \%$ of the global population living within $150 \mathrm{~km}$ of the coast. Projections of exponential population growth and an increase in living standards in the near future suggest that economic activity linked to the marine environment will grow, thereby giving rise to an increase in marine spatial usage in finite marine space. This materialization can exacerbate user - user conflicts, while placing further stress on the ecological functions of the marine environment, thereby contributing to enhance user - environment conflict. In order to solve such dilemmas, coastal nations have advocated for the implementation of marine spatial planning (MSP). A narrative running in parallel with MSP is that of climate change as a product of the excessive combustion of fossil fuels for purposes of energy provision. This climate change dilemma has prompted politicians around the world to advocate for the implementation of renewable energy systems. For geographical areas with high tidal current velocities, tidal current turbines (TCTs) offer a way to meet renewable energy capacity and greenhouse gas (GHG) emissions reductions targets. However, TCTs become another player operating within a finite and already stressed marine environment. Therefore, Scotland, whose marine environment hosts an abundance of tidal current resources, has become the first and only nation to construct and implement a sectoral marine plan for tidal energy (SMPTE) in order to facilitate the commercial-scale development of TCTs to meet national renewable energy deployment and GHG emissions reductions targets while accounting for potential industry and environmental conflicts. Nova Scotia is another geographical area with similar tidal resource potential. However, a plethora of factors have seemed to inhibit the deployment of TCTs in provincial waters. While Nova Scotia demonstrates a substantial industry cluster, capacity building, and supply chain, the province lacks a comprehensive MSP to manage uses of the marine environment in conjunction with TCT deployment.

This paper constructs a draft SMPTE for Nova Scotia. The paper overviews the operation and timeline of tidal energy development internationally and compares it to the Nova Scotia context. Due to the complexities associated with the multiplicity of federal and provincial governmental departments delegated with legislative jurisdiction over various aspects of the marine environment, an analysis of legislation and policies is undertaken in conjunction with best practices in Europe in order to establish jurisdictional boundaries and authorities in relation to the proposed SMPTE. The SMPTE process and outputs are then detailed and a map of suitable plan option areas that take into consideration ecological, technological, social, cultural, political, and economic factors is presented and compared to the marine renewable-energy areas legislated under the Marine Renewable-energy Act 2015. A quality management review of the SMPTE is undertaken in relation to the ICES Marine Spatial Planning Quality Management System and compared against the quality management review undertaken for Scotland's SMPTE. Research and data gaps are identified and key recommendations are made for the province of Nova Scotia and its tidal energy industry. 
The content of this major paper is the culmination of the work I have undertaken during my enrollment in York University's Master in Environmental Studies (MES) degree in the Faculty of Environmental Studies. My Plan of Study (PoS) concentration is renewable energy planning for sustainable settlements. The components of my PoS are energy planning, climate change, and renewable energy. The objective of my major paper was to construct a sectoral marine plan for tidal energy (SMPTE) for the province of Nova Scotia. In fulfillment of the renewable energy component of my PoS, I have researched the operational parameters, ecological impacts, societal perceptions, and economics of tidal current turbines (TCTs), a renewable energy technology (RET) which utilizes the kinetic energy emanating from the lateral movement of the tides to produce electricity. TCTs are advantageous in comparison to other RETs given their predictability, reliability, high capacity factors, and ability to easily accommodate energy storage to provide base-load power. In fulfillment of the climate change component of my PoS, I researched the detrimental ecological implications on societies emanating from the excessive combustion of fossil fuels for purposes of energy provision. Finally, in fulfillment of the energy planning component of my PoS, I have completed the Planning checklist in the MES degrees planning stream in order to obtain an in depth comprehension of the technical and theoretical aspects of planning. In relation to my major paper, I had focused on marine spatial planning (MSP), an area of concentration which serves to identify industry and environmental conflicts within marine environments with the intent of spatially allocating users of the marine environment in a sustainable manner. MSP provides a strategic siting methodology for TCTs which takes into account technological, ecological, political, social, economic, and legal factors. In this MSP field, I had worked for Marine Scotland Science, the epicenter of the TCT industry and associated MSP practices, to undertake and publish a quality management review of their SMPTE. It is with all this knowledge and experience from which I have obtained during my two years in the MES degree which has allowed me to construct a SMPTE for Nova Scotia in fulfillment of my major paper, the MES planning stream checklist, and the overall MES requirements. Upon starting my MES degree at York University, I hadn't the slightest clue about renewable energy systems and/or what "planning" even meant. In a coordinated effort to educate myself, I downloaded every article available off of the first 10 pages of search results of Google Scholar for every renewable energy type I had read existed on Wikipedia. One day I opened and article entitled Modeling the Operation and Maintenance Costs of a Large Scale Tidal Current Turbine Farm, written by Ye Li and H. Keith Florig, and this was the first time I saw a tidal current turbine (page iv). I thought it was the most majestic site, a piece of technology that can concur the vast and dangerous ocean in an attempt to save the planet. After learning about the technology I was instantly hooked, and immediately dropped all other focuses in my life and told myself that I would go through hell and high water (no pun intended) to put these devices in the ocean. 
There are many people I would like to thank, but the word count might constitute as a thesis in and of itself, so I apologize in advance if anyone has been excluded, just know that it was so in text only but not it thought. This paper is dedicated to my late aunt, Nina Viera, who passed away on February of 2017 after a long battle with cancer. She was the strongest person I have ever met and never complained once about the suffering imposed upon her by her condition. If you could do that Nina, then a Masters degree is nothing to fret about. I would like to thank my colleague Stan Mastrantonis who completed all of the Geographical Information System (GIS) work in this major paper - whenever there was a technical issue that would have discouraged most, Stan always said he would find a way, and this paper is proof of that. I hope we can continue our professional relationship as our careers proceed. I would like to thank the Canadian Maritime Region Department of Fisheries and Oceans (DFO) in Dartmouth, Nova Scotia who provided a huge quantity of the data used in the analysis and were helpful from the moment I met with them and until the end of the project. I would like to thank Peter Mulvihill, for supporting me in my Independent Directed Study (IDS) and field experience which allowed me to pursue this field; Mark Winfield, for providing me with guidance pertaining to my long-term career goals; and Dr. Liette Gilbert, for just about every single thing you could possibly ask for in an advisor. I would like to extent a special thanks to Lily Piccone, who encouraged me when others had initially told me I wouldn't fit into the Masters degree; Joseph Cesario, whose continued patience has helped me finance my degree; and Ann Tsirgielis - I came to campus two months before the semester with the intention of looking for a job, Ann had encouraged me to enroll in the MES degree, I imagine I would still be working 12 hour night shifts if it wasn't for you Ann, thanks from the bottom of my heart. Of course I would like to thank every single member of my family, after standing on Pier 21 where many of my relatives immigrated from Italy with not a penny to their name to a strange land in order to provide me with a better life. I would like to thank my dad for making me strong, my brother for providing me with footsteps to follow towards success, my uncles, aunts, and grandmother for showing me the value of family, and my little cousin for showing me to enjoy is in the simplest of things of life when I am lost in my work. A special thanks to my mother and my best friend, Nancy Sangiuliano - without whom I would be lost. Last but certainly not least, I would like to thank Dr. Ian M. Davies, Manager of Renewables and Energy for Marine Scotland. Ian is the truest embodiment of the word philanthropist, and he provided me with the greatest gift of all - an opportunity. I will not let it go to waste... bill me for all of your ongoing consultation when I get one of these turbines in the water. 


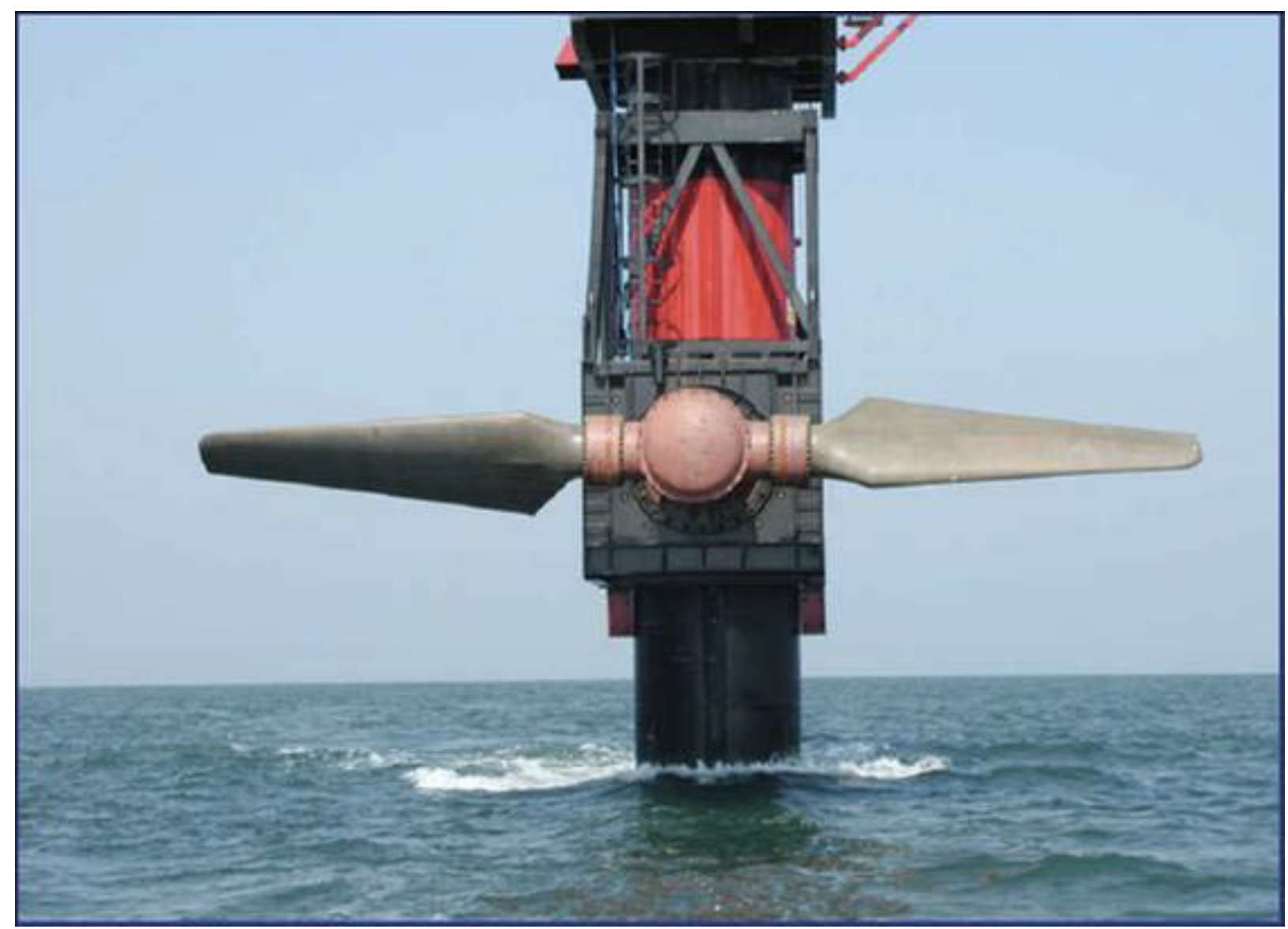

(Li and Florig, 2006,1)

"Only those who will risk going too far will find out how far one can go"

(Charlier, 2003, 516) 


\section{TABLE OF CONTENTS}

Abstract

Foreword

Acknowledgements

Table of contents

1. Introduction

2. Tidal current energy overview

2.1. Tidal physics

2.2. Tidal current turbine operation

2.3. Timeline of tidal energy development

3. The Nova Scotia context

4. Marine spatial planning

4.1. Scotland's national marine plan

4.2. Scotland's sectoral marine plan for tidal energy

4.2.1. Phase 1 - Initial plan framework

4.2.2. Phase 2 - Draft plan option areas

4.2.3. Phase 3 - Final plan option areas

4.2.4. Phase 4 - Licensing

ii

iii

iv

vi

1

3

3

4

4

5

8

8

11

12

13

14

14

15

16

16

19

21

22

26

26

26

28

36

37

$\begin{array}{cc}\text { 5.2.2. Phase } 2 \text { - Draft plan option areas } & 39 \\ 5.2 .2 .1 \text { Sustainability appraisal } & 39\end{array}$

5.2.2.1.1. Mi'kmaq ecological knowledge study $\quad 39$

$\begin{array}{ll}\text { 5.2.2.1.2. Socioeconomic assessment } & 44\end{array}$

5.2.2.1.3. Strategic environmental assessment 45

$\begin{array}{ll}5.2 .2 .2 \text {. Sustainability appraisal review } & 50\end{array}$

$\begin{array}{ll}\text { 5.2.3. Phase } 3 \text { - Final plan option areas } & 50\end{array}$

$\begin{array}{ll}\text { 5.2.3.1. Ministerial adoption } & 50\end{array}$

5.2.3.2. Marine renewable energy areas vs. plan option areas 51

5.2.4. Phase 4 - Licencing $\quad 54$

$\begin{array}{ll}\text { 5.3. Quality management review } & 55\end{array}$

5.3.1. The establishment of the external context $\quad 57$

5.3.2. The establishment of the internal context 57

5.3.3. Risk identification $\quad 59$

$\begin{array}{ll}\text { 5.3.4. Risk analysis } & 60\end{array}$

$\begin{array}{ll}\text { 5.3.5. Risk evaluation } & 61\end{array}$

$\begin{array}{ll}\text { 5.3.6. Risk treatment } & 61\end{array}$

5.3.7. Monitoring and review $\quad 62$

$\begin{array}{ll}\text { 5.3.8. Summary } & 63\end{array}$

6. Key recommendations $\quad 69$

References

Appendix A: Nova Scotia sectoral marine plan for tidal energy consultation draft 78

Appendix B: Quality management review $\quad 94$

$\begin{array}{lr}\text { Appendix C: Acronyms and abbreviations } & 117\end{array}$ 


\section{List of Figures}

Figure 1: Scottish sectoral marine planning process 11

Figure 2: Scottish adopted plan option areas 14

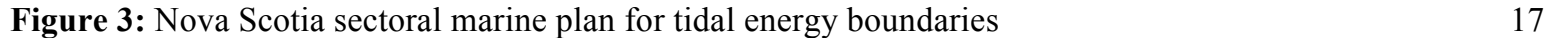

Figure 4: Primary suitability parameter spatial modeling results $\quad 32$

Figure 5: Scottish national marine plan regional boundaries $\quad 36$

Figure 6: Nova Scotia environmental density map 37

Figure 7: Nova Scotia sectoral marine plan for tidal energy regional boundaries $\quad 38$

Figure 8: Nova Scotia sectoral marine planning process 38

$\begin{array}{ll}\text { Figure 9: Socio-cultural data projection } & 40\end{array}$

Figure 10: Socio-cultural restriction model $\quad 40$

Figure 11: Industry data projection $\quad 41$

Figure 12: Industry restriction model $\quad 41$

Figure 13: Non-technical exclusion data projection $\quad 42$

Figure 14: Environmental restriction model $\quad 42$

Figure 15: Initial plan framework aggregate scoping model including opportunity data layers 43

Figure 16: Initial plan framework and sustainability appraisal aggregate environmental data projection 48

Figure 17: Initial plan framework and sustainability appraisal aggregate opportunity data projection $\quad 48$

Figure 18: Sustainability appraisal aggregate constraint model $\quad 49$

Figure 19: Final plan option areas $\quad 51$

Figure 20: Marine renewable energy areas $\quad 52$

\section{List of Tables}

Table 1: Tidal modeling cycle $\quad 3$

Table 2: Tidal energy development timeline $\quad 6$

Table 3: Scotland's national marine plan structure 9

Table 4: Scottish and Nova Scotia sectoral marine plan for tidal energy public policy agendas 23

Table 5: Scottish and Nova Scotia sectoral marine plan for tidal energy stakeholder list 24

Table 6: Scottish and Nova Scotia ideal list of data layers 27

Table 7: Nova Scotia tidal current energy resources $\quad 29$

Table 8: Primary suitability parameters 31

Table 9: Tidal current turbine shipping clearance $\quad 32$

Table 10: List of data layers refined 33

Table 11: Weightings of data layers for the initial plan framework 35

Table 12: Sustainability appraisal data layers $\quad 45$

Table 13: Sustainability data layer weightings 46

Table 14: Marine renewable energy areas vs plan option areas $\quad 54$

Table 15: One-window standing committee governmental bodies $\quad 55$

Table 16: Scottish sectoral marine plan for tidal energy quality management review recommendations 56 adapted from Sangiuliano (2016)

Table 17: ICES Marine Spatial Planning Quality Management System conformity comparison $\quad 63$

Table 18: ICES Marine Spatial Planning Quality Management System public policy agenda 65 conformity comparison

Table 19: Scottish sectoral marine plan for tidal energy quality management review recommendations $\quad 67$ 


\section{Introduction}

The marine environment has historically played a significant role in sustaining coastal economies, as can be witnessed through the evolution of global super powers from Greece to France to the United States. This relationship of large human societies strategically positioning themselves within close proximity to large water bodies, thereby proliferating access to the marine environment and the natural resources encompassed within them, is one that continues to modern times, with $44 \%$ of the global population living within $150 \mathrm{~km}$ of the coast (UN, 2010). In 2012, Europe's Blue Economy supported 5.4 million jobs, producing $€ 500$ billion (EU, 2012) through such traditional marine industries such as fishing, shipping, dredging, mineral extraction, recreation and tourism.

Running in unison with this congregation of economic activity within the marine environment are future projections of global population growth, the majority of which is expected to intensify in the $82.3 \%$ of mega cities situated on a coastline (Tibbetts, 2002), with an increase in living standards expected to accompany such population growth projections (Pelc and Fujita, 2002). It therefore follows suit that the very same economic activity linked to the marine environment will grow exponentially, thereby giving rise to an increase in marine spatial usage in finite marine space, which ultimately gives rise to an increase in the potential for marine spatial conflict. Such a dilemma is referred to as user - user conflict (Douvere, 2008).

The intensification of various industries operating in the marine environment, and the subsequent concentration of the extraction of natural marine resources for purposes of economic exploitation, places stress on the ecological functions of the marine environment in question, which can result in the decline of the health of the overall ecosystem. This reduction in ecological functions and the associated availability of natural capital can produce adverse implications for the economic sectors that depend on marine resources (Deutsch, Folke and Skånberg, 2003). Such a dilemma is referred to as user - environment conflict (Douvere, 2008).

If adequate management is not applied to the marine environment, the proliferation of user - user and user - environment conflicts will inevitably result in the degradation of the marine environment and the associated services provided by its ecological functions that sustain coastal and global economies. Such dilemmas have triggered political support for the application of marine spatial planning (MSP) in order to effectively manage spatial activity in areas experiencing multiple uses of the marine environment. Comprehensive MSPs are being constructed and implemented in nations such as Germany, the Netherlands, Belgium, and Scotland in response to an increase in marine spatial conflicts perpetuated by the North Sea basin's status as a leading international hub of economic activity (OSPAR, 2010).

However, the construction and implementation of a comprehensive MSP in and of itself will not suffice as a measure to stabilize the marine-based economies of coastal cities and nations. Global climate change instigated by the excessive combustion of fossil fuels for purposes of energy provision stemming from the advent of the industrial revolution have altered the Earth's natural planetary functions, and thus its capacity to sustainably provide ecosystem services is increasingly deteriorating (IPCC, 2014). Such increases in global warming of 0.65 $1.06^{\circ}$ from 1880 to 2012 have had substantial adverse implications on the ecological functions of the oceans at a greater pace than any other in human history (World Resource Institute, 2005).

This climate change dilemma has prompted support from all levels of government globally from municipal to regional to international to curtail the release of greenhouse gas (GHG) emissions into the atmosphere via the promotion of renewable energy systems 
deployment in public policy agendas. While renewable energy technologies such as solar photovoltaic (PV), onshore wind turbines, and various sources of biomass production are well researched and economically competitive for the most part (Timmons, Harris and Roach, 2014), competing uses for terrestrial space in an ever-densifying civilization (Tibbetts, 2002), in conjunction with the need to conserve natural terrestrial ecosystems, the deployment of offshore renewable energy technologies are gaining momentum in the public policy agendas of progressive governments with suitable resources (Johnson, Kerr and Side, 2012).

One such offshore renewable energy technology that is showing promise with regards to the transition from pre-commercial status to commercial implementation are tidal current turbines (TCTs). TCTs operate to produce electricity by harnessing the kinetic energy dissipated from the lateral movement of tidal flows in coastal waters where current speeds reach a mean spring peak tidal flow velocity (Vmsp) of $1.5 \mathrm{~m} / \mathrm{s}$ (Davies, Gubbins and Watret, 2012). By employing the kinetic energy from the tides, TCTs become advantageous in comparison to other renewable energy technologies due to their predictability, reliability, high capacity factors, favorable overall systems efficiency, and ability to easily accommodate energy storage (Bryden and Macfarlane, 2000), as tidal flows are nearly constant and can be modeled down to the second for centuries in advance (Elghali, Benbouzid and Charpentier, 2007).

Scotland is one such nation that possesses economically viable tidal current velocities, with availability resource estimates demonstrating 32TWh/yr (Crown Estate, 2012), 25\% of Europe's tidal energy resource (Marine Scotland, 2014). Therefore, Scotland has heavily invested in the deployment of TCT arrays within its territorial waters in order to meet GHG emissions mitigation targets of $42 \%$ below 1990 levels by 2020 and $80 \%$ below 1990 levels by 2050, as stated in the Climate Change (Scotland) Act 2010, while providing 30\% of its energy demand from renewables by 2020 , with $100 \%$ renewably generated electricity (Marine Scotland, 2013).

However, in attempting to solve this climate change dilemma, Scotland recognizes that TCTs essentially become another industry within their national economy that demands usage of marine space. Therefore, anticipating user - user and user - environment conflicts, Scotland has become the first and only nation to construct and implement a sectoral marine plan for tidal energy (SMPTE) to strategically identify suitable sites for TCT deployment, thereby assisting their national marine plan (NMP) in effectively managing industry conflict and ecosystem health while meeting GHG emissions reduction and renewable energy deployment targets, subsequently protecting the national economy (Sangiuliano, 2016).

Across the Atlantic Ocean resides another geographical region with substantial tidal current resource potential. The Canadian province of Nova Scotia is home to the highest tidal range fluctuations in the world, measuring in at a maximum of $16 \mathrm{~m}$ between lowest astronomical tide (LAT) and highest astronomical tide (HAT) (Grabbe et al., 2009), subsequently forcing 160 billion tonnes of water through the Bay of Fundy with every flow of the current, approximately four times more volume that every fresh water river in the world combined (Energy, 2012). This extreme flow of the tides has been estimated to produce approximately $7.4 \mathrm{GW}$ of power in the Bay of Fundy alone, $2.1 \mathrm{GW}$ of which are considered extractable with only a 5-10\% reduction in tidal flow dependent on four high energy sites (Karsten, 2012), which has been modeled to be acceptable without detrimental impacts on marine ecosystem functions (Bryden et al., 2007).

However, despite substantial provincial and federal investments into the Nova Scotia tidal energy sector, including research and development (R\&D) organizations such as the Acadia Tidal Energy Institute (ATEI), Marine Renewables Canada (MRC), Offshore Energy Research 
Association of North America (OERA), and Fundy Ocean Research Centre for Energy (FORCE) (Department of Energy, 2010a), there is currently only one TCT deployed in Nova Scotia waters, which was coupled by extensive litigation both prior to and following implementation. As a plethora of tidal resource, economic, and social studies are pumped out by such organizations in a collaborative effort, there remains a missing piece to the puzzle, perhaps the key stone which is present in the vast majority of European nations who have successfully deployed renewable energy systems in their national waters, and that is the construction and implementation of a MSP.

This paper provides an overview of tidal current energy development and TCT operation. The current status of MSP is touched upon to frame marine spatial management initiatives around the world, and the subsequent resulting benefits. The tidal energy development context for the Province of Nova Scotia is discussed and Scotland's SMPTE process is examined. The paper then constructs a SMPTE process for Nova Scotia loosely based off of Scotland's SMPTE, with specifications detailed in regards to the establishment of the public policy agenda, and enhancements made to the SMPTE process and outputs from a quality management perspective based on recommendations made in Sangiuliano's (2016) quality management review of the Scottish SMPTE to ICES's Marine Spatial Planning Quality Management Review document, identified as applicable. Final plan option areas (POAs) most suitable for the sustainable deployment of TCTs within provincial waters is then be identified and a planning document is attached within appendix A.

\section{Tidal Current Energy Overview}

\subsection{Tidal physics}

The movement of tidal currents are governed by the gravitational and centrifugal forces of the moon and sun enacted upon the Earth (Clark, 2007), 68\% of which is attributable to the moon and $32 \%$ to the sun as a result of the dynamics of their respective masses and distances from the Earth (Elghali et al., 2007). Such gravitational and centrifugal forces interact to produce two budges in the oceans on opposite sides of the planet, which, when combined with over one hundred harmonic constituents (Tarbotton and Larson, 2006), produce flood and ebb tides, materializing in the rising and falling of oceanic water bodies. These flood and ebb tides are constrained within lunar days, measuring 24 hours, 50 minutes and 28 seconds (Clark, 2007). Depending on the site specific dynamics of a geographical location, such tidal cycles can be categorized as diurnal, with flood and ebb tides occurring once in a lunar day, semi-diurnal, occurring twice every lunar day, or a variation between the two (Elghali et al., 2007).

Such lunar day tidal cycles are further encompassed within a lunar orbit cycle consisting of conjunction, first quartile, opposition, third quartile, and back to conjunction (Bryden and Melville, 2004). At conjunction and opposition, the moon and sun are oriented parallel to one another with respect to the position of the Earth, thereby producing spring tides, which are periods characterized by higher velocity tidal flows (O'Rourke, Boyle and Reynolds, 2010b). At first and third quartile, the moon and sun are oriented perpendicular to one another with respect to the position of the Earth, thereby producing spring tides, which are periods characterized by lower velocity tidal flows. Each lunar orbit cycle takes place within 29.5 days (Everett et al., 2006), which, when considering all the harmonic dynamics involved in both lunar days and lunar orbits, repeat themselves every 18.6 years (Tarbotton and Larson, 2006). Thus, when taking into account the operation of TCTs that rely on such predictable and reliable principals of tidal physics as a 
fuel source, the electricity produced from an array of TCTs can be modeled down to the second for the total estimated 25 year operational lifespan of the devices ( $\mathrm{Li}$ and Florig, 2006), thereby allowing grid operators to match electricity input to societal demand while reducing the amount of storage installation capacity required to provide renewable base load electricity (Sangiuliano, 2016).

Table 1: Tidal modeling cycle

\begin{tabular}{|l|l|l|}
\hline \multicolumn{3}{|c|}{ Tidal Current Modeling Cycle } \\
\hline \multicolumn{1}{|c|}{ Tidal Cycle } & \multicolumn{1}{c|}{ Duration } & \multicolumn{1}{c|}{ Citation } \\
\hline Lunar day & $24 \mathrm{~h}, 50 \mathrm{~m}, 28 \mathrm{~s}$ & Clark, 2007 \\
\hline Lunar cycle & 29.5 days & Everett et al., 2012 \\
\hline Full harmonic cycle & 18.6 years & Tarbotton \& Larson, 2006 \\
\hline
\end{tabular}

\subsection{Tidal current turbine operation}

While a number of mechanical devices have been constructed to employ tidal current energy to produce electricity, including horizontal and vertical axis turbines, corkscrew configurations, oscillating hydrofoil devices, tidal kites, and venturi-type shrouded models (O'Rourke, Boyle and Reynolds, 2010b), the only design that has been developed in full-scale, tested in real sea high-flow environments, and scheduled for commercial implementation are horizontal axis configurations (MeyGen, 2016).

TCTs operate to produce electricity by harnessing the kinetic energy dissipated via the lateral movement of tidal flows, typically magnified via the passage of large bodies of water through narrow corridors such as headlands, estuaries, channels, and sea lochs (Bryden and Melville, 2004) which act to accelerate the flow of the current to a Vmsp of $1.5 \mathrm{~m} / \mathrm{s}$ or greater fast enough to maximize the output of electricity from a TCT to provide desirable economic return (O'Rourke, Boyle and Reynolds, 2010a). The tidal flow passes through turbine rotors consisting typically of a bladed-propeller configuration that is connected to a gearbox, which turns a generator (O'Rourke, Boyle and Reynolds, 2009a). In order to maximize energy output, many TCTs are equipped with a $180^{\circ}$ pitch system in order to strategically orient the rotor parallel to the changing directionality of the tidal current dictated by flood and ebb tides (Khan, Bhuyan, Iqbal and Quaicoe, 2009).

While many configurations have been engineered to stabilize TCTs in the optimal sited direction of incoming tidal currents, the majority of TCT devices have been secured in place via pile driving monopoles into the seabed (Fraenkel, 2002) or anchoring the turbine rotor to a large concrete gravity base heavy even to hold the devise in place (Tougaard, 2003). The electrical energy produced by the TCTs is then transmitted to consumers by either connecting individual TCT transformers to an onshore transformer station, preferable for near-shore arrays, or by connecting individual transformers to an offshore transformer station, preferable for far-shore arrays, which would then transmit electricity through a single cable to an onshore station to manipulate the output voltage to grid accommodation specifications (Myers and Bahaj, 2005).

\subsection{Timeline of tidal energy development}

Despite the advantages of harnessing tidal currents as an energy resource, the TCT industry still resides in the pre-commercial phase (Li and Florig, 2006). Despite the current status of TCTs, the concept of extracting kinetic tidal energy is not a new development, as the use of 
tidal mills to grind cereals can be traced back millennia to the Roman era, such as the Eling tidal mill, which is still preserved in part to this day in Hampshire, England (Bryden and Melville, 2004). However, the application of tidal current energy to produce electricity can be dated back much more recently to the early 1990s, where the first mechanical device constructed to convert kinetic energy from the tides into electrical energy took place in Loch Linnhe, in the Western Highlands of Scotland (Esteban and Leary, 2012). The years that followed saw a gaining in momentum of tidal energy conversion $R \& D$ via the development of $1 / 100$ scale conversion devices placed in test tanks that were designed to emulate real sea conditions.

It was not until 2003 that the very first full-scale TCT was installed and monitored in a real sea, high current velocity environment, with Marine Current Turbine Ltd.'s (MCT) deployment of their $300 \mathrm{~kW}$ SeaFlow model off the coast of the village of Lynmouth, Devon, England (Fraenkel, 2006). Shortly after, the European Marine Energy Centre (EMEC), located in the Orkney Islands, northeastern Scotland was constructed and became operational in May of 2005 (O'Rourke, Boyle and Reynolds, 2010b). To this day, EMEC remains the largest TCT test center in the world, currently hosting eight grid-connected test births (EMEC, 2016). The next milestone along the timeline of tidal energy development was the implementation of the first commercial-scale grid-connected TCT, once again developed by MCT, with their $1.2 \mathrm{MW}$ twinrotor SeaGen model deployed in the Strangford Narrows off of the coast of Northern Ireland in July of 2008 (Fraenkel, 2010). Approximately one year later in 2009, the FORCE TCT test center was constructed in Parrsboro, Nova Scotia, adjacent to the high-energy tidal current waters of the Minas Passage (FORCE, 2013).

In 2010, the UK Crown Estate awarded a seabed lease to MeyGen to develop the world's first commercial TCT array capped at 389MW of installed capacity in the Pentland Firth and Orkney Waters (PFOW). With the devolution of powers from the UK Crown Estate to the Scottish Government's Marine Scotland division to plan and manage the Scottish territorial zone (TZ - 0-12nm from LAT) via the Marine Scotland Act 2010, and the exclusive economic zone (EZZ - 12-200nm), via the Marine and Coastal Access Act 2009, the latest step to facilitate progression towards commercial implementation of TCTs was Scotland's development of the world's first and currently only SMPTE. With the draft plan released in July of 2013, the SMPTE was constructed and implemented with the intent of streamlining the consenting and licensing regime of TCT implementation in Scottish waters (Marine Scotland, 2013a). Finally, this summer of 2016, phase 1 of the MeyGen project was scheduled to be implemented with the deployment of four 1MW TCTs in the PFOW region, representing the installment of the world's first commercial TCT array (MeyGen, 2016).

\section{The Nova Scotia context}

Situated in the southeastern most region of Canada, Nova Scotia prides itself on its historical relationship to the marine environment, dating back to the mid-1 $7^{\text {th }}$ century, where Acadian settlers built dykes around the bulk of the Minas Basin to irrigate the land and cultivate crops (Griffiths, 1992). With 7,579kms of coastline (Department of Energy, 2016), Nova Scotia's economy continues to hold strong ties to the marine environment, touting the largest conglomeration of ocean R\&D private and public firms in all of North America at approximately 300 , diversified in the fields of natural and social sciences, engineering, and economics (Department of Energy, 2012). With marine industries accounting for $1 / 3$ of all R\&D business in Nova Scotia, the approximately 60 innovator technological organizations generated an estimated 
over $\$ 500$ million in revenue in 2009 , with projections suggesting an increase in the decades to follow (Department of Energy, 2016).

Nova Scotia is also home to the world's highest tides, measuring in at $16 \mathrm{~m}$ at HAT, the range fluctuations of which result in comparative impressive tidal current velocities when forced through narrow passages (Grabbe et al., 2009). Such tidal current velocities of sites identified in the Bay of Fundy including Minas Passage, Grand Passage, Petit Passage, and Digby Gut have been estimated to produce 7,429MW of power, 2,095MW of which has been deemed sustainably extractable by the scientific community (Karsten 2012), while the Cape Breton Region of Nova Scotia hosts two areas of tidal energy interest, including the Great Bras d'Or Channel and the Barra Straight which have been estimated to produce $6.8 \mathrm{MW}$ of power, $1.7 \mathrm{MW}$ of which are considered sustainably extractable. In addition to such sites, resource estimates are scheduled to be undertaken in other areas in the northern portion of the province, with the Bras d'Or area designated as a marine renewable energy priority area under the Marine Renewable-energy (MRE) Act 2015 along with the Bay of Fundy.

Table 2: Tidal energy development timeline

\begin{tabular}{|l|l|l|l|l|}
\hline \multicolumn{5}{|c|}{ International TCT Development Timeline } \\
\hline Event/Structure & Year & Location & Significance & Citation \\
\hline Eling tide mill & $1086 ?$ & Hampshire, England & Oldest tidal mill preserved & Bryden and Melville, 2004 \\
\hline Loch Linnhe TCT & 1994 & Loch Linnhe, Scotland & First TCT device testing & Esteban and Leary, 2012 \\
\hline SeaFlow & 2003 & Devon, England & First full-scale TCT deployed & Fraenkel, 2006 \\
\hline EMEC & 2005 & Orkney Islands, Scotland & First TCT test center & $\begin{array}{l}\text { O'Rourke, Boyle and } \\
\text { Reynolds, 2010b }\end{array}$ \\
\hline $\begin{array}{l}\text { *Race Rocks Tidal } \\
\text { Project }\end{array}$ & 2006 & $\begin{array}{l}\text { Vancouver Island, British Columbia, } \\
\text { Canada }\end{array}$ & $\begin{array}{l}\text { First TCT tested in Canadian } \\
\text { waters }\end{array}$ & $\begin{array}{l}\text { Department of Energy, } \\
2012\end{array}$ \\
\hline $\begin{array}{l}\text { *Roosevelt Tidal } \\
\text { Energy Project }\end{array}$ & 2006 & East River, New York, USA & $\begin{array}{l}\text { First TCT array deployed in } \\
\text { North America }\end{array}$ & $\begin{array}{l}\text { Department of Energy, } \\
2012\end{array}$ \\
\hline $\begin{array}{l}\text { SeaGen } \\
\text { *FORCE }\end{array}$ & 2008 & Strangford Narrows, Northern Ireland & $\begin{array}{l}\text { First commercial-scale grid- } \\
\text { connected TCT }\end{array}$ & Fraenkel, 2010 \\
\hline MeyGen seabed lease & 2010 & Minas Passage, Nova Scotia, Canada & First Canadian TCT test center & FORCE, 2013 \\
\hline Scottish SMPTE & 2013 & PFOW, Scotland & $\begin{array}{l}\text { First commercial-scale } \\
\text { development lease awarded }\end{array}$ & MeyGen, 2016 \\
\hline MeyGen Phase 1 & 2016 & Edinburgh, Scotland & First and only SMPTE & Marine Scotland, 2013 \\
\hline
\end{tabular}

* denotes the North American development timeline

In order to capitalize upon this vast energy resource, the Nova Scotia provincial and Canadian federal governments partly funded the development of a large-scale TCT test center off of the Minas Passage in Parrsboro known as FORCE, which became operational in 2009 (Natural Resources Canada, 2016). From FORCE's early conception, it hosted an Open Hydro TCT device from September 2009 to January 2011 where it underwent extensive environmental effects monitoring (FORCE, 2013). Five years later, the installation of four $24.5 \mathrm{kV}$ subsea power cables have made FORCE (2016) capable of accommodating four 16MW TCT arrays, reaching an aggregate installed capacity of 64MW in the Minas Passage (Department of Energy, 2012), with projections of $110 \mathrm{MW}$ of TCT generated electricity around the province becoming online by 2020 , accounting for $5 \%$ of the current installed electrical capacity, and creating 340 personyears of employment during installation and 550 person-years over the 25 year lifespan of TCTs (Department of Energy, 2010a). An economic assessment undertaken by Pinfold (2015) suggest 
that the tidal energy industry can provide $\$ 1.7$ billion in GDP, which is currently $34 \%$ of Nova Scotia's GDP resulting from the entire ocean industry combined (Department of Energy, 2016).

With such a vast resource potential of $7.4 \mathrm{GW}$, political backing from the governments of Nova Scotia and Canada, financial support of over \$100 million (Natural Resources Canada, 2016), capacity building via the 450 ocean related PhDs (Department of Energy, 2016), supply chain industries amounting in $\$ 5$ billion in GDP, a world class TCT test facility, regulatory legislation in the MRE Act 2015, and favorable long-term economics of 30,000 direct employment opportunities, Nova Scotia could play an integral role in the emerging tidal energy industry. The province has the potential to act as a global industry cluster, providing physical, technical, and scientific resources to other nations with similar tidal current energy potential such as Italy, France, Argentina, Brazil, Korea, China, and Australia, to name a few (O'Rourke et al., 2010b).

Despite such a favorable climate, in 2016, there is not a single TCT in provincial waters. This unto itself represents a backwards step from the deployment of the Open Hydro TCT seven years ago. Furthermore, intense lobbying by other marine industry organizations, such as the Bay of Fundy Inshore Fishermen's Association over environmental, social, and cultural concerns have put a hold on Cape Sharp Tidal's deployment of a commercial-scale TCT in the Bay of Fundy this summer (CBC Radio, 2016). However, support for the industry overall does continue in the province, which begs the question, what piece of the puzzle is missing from Nova Scotia's tidal energy development agenda in order to successfully facilitate the commercial implementation of TCTs? Examining best practices from the international leader in the tidal energy industry in Scotland, the one component that is absent in Nova Scotia, let alone Canada as a whole, is the construction and implementation of a comprehensive MSP, particularly to the industry, a SMPTE.

In a review of the Rio Declaration on Environment and Development, Doelle et al. (2006) identify three principles of sustainable development that are very much in line with tidal energy development, these are Principle 10 - public participation, Principle 15 - the precautionary approach, and Principle 22 - Indigenous people and local community management/development. These principles of sustainable development have indeed occurred within the Nova Scotia tidal energy development agenda in the undertaking of three strategic environmental assessments (SEAs), two on the Bay of Fundy and one on Cape Breton waters (Daborn, 2016), a socioeconomic impact scoping assessment (Howell and Drake, 2012), and a Mi'kmaq ecological knowledge study (MEKS) (Membertou Geomatics Consultants, 2009).

However, in contrast to best practices cited in the Copenhagen Strategy on Offshore Wind Power Deployment (Danish Energy Authority, 2005), such outputs of sustainable development for the tidal energy industry in Nova Scotia have occurred in a disaggregated manner with the absence of a cohesive regulatory regime (Fournier, 2011), thus hindering the capacity to discern areas of pre-planned optimal site selection that reduce financial risk to developers and communities as well as reducing the complexity of obtaining consents and licenses (Doelle, 2006). Fournier (2011), in Marine Renewable Energy Legislation: A Consultative Process, puts forth 27 recommendations on how to develop an efficient and sustainable tidal energy industry in Nova Scotia, with his primary key recommendation being the need to develop and implement a strategic plan for the deployment of TCTs. This strategic plan can be embodied in construction of a provincial MSP, and more specifically a SMPTE. While much work has been undertaken in the last seven years in the absence of a SMPTE, Fournier 
believes that this is only a minor setback that can be quickly resolved with the implementation of a strategic plan.

\section{Marine spatial planning}

MSP construction and implementation is driven by the necessity to coordinate the estimated 382 existing and emerging activities occurring within a given marine environment (Lester et al., 2013) in order to reduce user - user and user - environment conflicts (Douvere, 2008), thereby enhancing and sustaining the operational effectiveness of the marine economy while supporting the interests of industry and community stakeholders (Marine Scotland, 2013a). Several European nations that have constructed and implemented national MSPs included The Netherlands' Integrated Management Plan for the North Sea 2015 (IMPNS2015, 2005), Germany's coastal Lander, Territorial Sea Plan and EEZ plan (Gee et al., 2004), Belgium's Master Plan for the Belgium Part of the North Sea (BPNS) (Douvere et al., 2007), and Scotland's NMP (Marine Scotland, 2014).

However, in relation to more mature global land use planning practices, the advent of MSP is comparatively immature, and thus no single best practice approach on which to draw from currently exists, with different regulatory regimes and permitting process often times stifling the consenting of offshore renewable energy projects. However, progress is being made, and one such nation with a comprehensive MSP who have successfully deployed TCTs in their national waters is Scotland.

\subsection{Scotland's national marine plan}

Scotland implemented their NMP in 2014 in accordance to principles of sustainable marine planning and development set out in the EU Directive 2014/89/EU (Marine Scotland, 2014). Powers to plan in Scottish waters were devolved from the UK Crown Estate to Scottish Parliament via the enactment of the Marine Scotland Act 2010, which delegates authority of marine planning matters to the Scottish Government's Marine Scotland division as the acting sole competent authority (CA) within the Scottish TZ, and the Marine and Coastal Access Act 2009, which delegates authority of marine planning matters to Marine Scotland within the Scottish EEZ. Policies put forth in Scotland's NMP must be compatible with the higher-level policies set out in the UK Marine Policy Statement (MPS).

The NMP provides a vision statement of "clean, healthy, safe, productive and diverse seas; managed to meet the long-term needs of nature and people" (Marine Scotland, 2014, pp. 10). The NMPs vision is then supported by strategic objectives establishing an ecosystem approach framework to achieve good environmental status (GES), as set out in the 11 GES descriptors which encompass all policies within the plan, and high-level marine objectives (HLMOs), organized under the five guiding principles of the UK's shared framework for sustainable development, with HLMOs underpinned by 21 general policies (GENs). The NMP then identifies 11 key sectors, consisting of sea fisheries, aquaculture, wild salmon and diadromous fish, oil and gas, carbon capture and storage (CCS), offshore wind and marine renewable energy, recreation and tourism, shipping, ports, harbors and ferries, submarine cables, defense, and aggregates, with the intent of reducing potential spatial competition and conflict by emphasizing the requirement for sustainable development and use, allocating statutory weight to spatial outputs of planning policy on marine renewables development, prescribing general spatial guidance where possible, emphasizing the need for consultation and adaptive management, and detailing the specific factors that should be considered within each sector. Each individual sector 
is then defined by its own objectives which identify their conformity with the NMP's strategic objectives in relation to economic, social, marine ecosystem, and climate change contexts.

Table 3: Scotland's national marine plan structure

\begin{tabular}{|c|c|c|c|c|c|}
\hline \multicolumn{6}{|c|}{ Scotland's National Marine Plan } \\
\hline \multicolumn{6}{|c|}{$\begin{array}{c}\text { Vision: } \\
\text { "clean, healthy, safe, productive and diverse seas; managed to meet the long-term needs of nature and people" }\end{array}$} \\
\hline \multicolumn{6}{|c|}{ Strategic Objectives } \\
\hline \multicolumn{2}{|c|}{$\begin{array}{l}\text { Ecosystem Approach: } \\
11 \text { Descriptors of Good Environmental } \\
\text { Status (GES) }\end{array}$} & \multicolumn{4}{|c|}{$\begin{array}{l}\text { UK's Five Guiding Principles for Sustainable Development: } \\
\text { High Level Marine Objectives (HLMOs) \& General Policies (GENs) }\end{array}$} \\
\hline \multirow[t]{3}{*}{ GES 1} & \multirow{3}{*}{$\begin{array}{l}\text { Biological diversity is } \\
\text { maintained }\end{array}$} & \multicolumn{4}{|c|}{ Achieving a sustainable marine economy } \\
\hline & & \multirow[t]{2}{*}{ HLMO 1} & \multirow[t]{2}{*}{$\begin{array}{l}\text { Infrastructure is in place to support } \\
\text { and promote safe, profitable and } \\
\text { efficient marine businesses }\end{array}$} & GEN 1 & $\begin{array}{l}\text { General planning principle: There is a } \\
\text { presumption in favor of sustainable } \\
\text { development and use of the marine } \\
\text { environment when consistent with the } \\
\text { policies and objectives of this Plan. }\end{array}$ \\
\hline & & & & GEN 2 & $\begin{array}{l}\text { Economic benefit: Sustainable development } \\
\text { and use which provides economic benefit to } \\
\text { Scottish communities is encouraged when } \\
\text { consistent with the objectives and policies of } \\
\text { the Plan. }\end{array}$ \\
\hline \multirow[t]{3}{*}{ GES 2} & \multirow{3}{*}{$\begin{array}{l}\text { Non-indigenous } \\
\text { species introduced by } \\
\text { human activities are } \\
\text { at levels that do not } \\
\text { adversely alter the } \\
\text { ecosystems }\end{array}$} & \multirow[t]{2}{*}{ HLMO 2} & \multirow{2}{*}{$\begin{array}{l}\text { The marine environment and its } \\
\text { resources are used to maximize } \\
\text { sustainable activity, prosperity and } \\
\text { opportunities for all, now and in the } \\
\text { future }\end{array}$} & GEN 3 & $\begin{array}{l}\text { Social benefit: Sustainable development and } \\
\text { use which provides social benefits is } \\
\text { encouraged when consistent with the } \\
\text { objectives and policies of the Plan }\end{array}$ \\
\hline & & & & GEN 4 & $\begin{array}{l}\text { Co-existence: Proposals which enable } \\
\text { coexistence with other development sectors } \\
\text { and activities within the Scottish marine area } \\
\text { are encouraged in planning and decision } \\
\text { making processes, when consistent with } \\
\text { policies and objectives of this Plan. }\end{array}$ \\
\hline & & \multirow[t]{2}{*}{ HLMO 3} & \multirow[t]{2}{*}{$\begin{array}{l}\text { Marine businesses are taking long-term } \\
\text { strategic decisions and managing risks } \\
\text { effectively. They are competitive and } \\
\text { operating efficiently }\end{array}$} & GEN 5 & $\begin{array}{l}\text { Climate change: Marine planners and } \\
\text { decision makers must act in the way best } \\
\text { calculated to mitigate, and adapt to, climate } \\
\text { change. }\end{array}$ \\
\hline \multirow[t]{3}{*}{ GES 3} & \multirow{3}{*}{$\begin{array}{l}\text { Populations of all } \\
\text { commercially } \\
\text { exploited fish and } \\
\text { shellfish are within } \\
\text { safe biological limits, } \\
\text { exhibiting a } \\
\text { population age and } \\
\text { size distribution that } \\
\text { is indicative of a } \\
\text { healthy stock }\end{array}$} & & & GEN 6 & $\begin{array}{l}\text { Historic environment: Development and use } \\
\text { of the marine environment should protect } \\
\text { and, where appropriate, enhance heritage } \\
\text { assets in a manner proportionate to their } \\
\text { significance. }\end{array}$ \\
\hline & & \multirow[t]{2}{*}{ HLMO 4} & \multirow[t]{2}{*}{$\begin{array}{l}\text { Marine businesses are acting in a way } \\
\text { which respects environmental limits } \\
\text { and is socially responsible. This is } \\
\text { rewarded in the marketplace. }\end{array}$} & GEN 7 & $\begin{array}{l}\text { Landscape/seascape: Marine planners and } \\
\text { decision makers should ensure that } \\
\text { development and use of the marine } \\
\text { environment take seascape, landscape and } \\
\text { visual impacts into account }\end{array}$ \\
\hline & & & & GEN 8 & $\begin{array}{l}\text { Coastal process and flooding: Developments } \\
\text { and activities in the marine environment } \\
\text { should be resilient to coastal change and } \\
\text { flooding, and not have unacceptable adverse } \\
\text { impact on coastal processes or contribute to } \\
\text { coastal flooding }\end{array}$ \\
\hline \multirow[t]{3}{*}{ GES 4} & \multirow{3}{*}{$\begin{array}{l}\text { All elements of the } \\
\text { marine food webs, to } \\
\text { the extent that they } \\
\text { are known, occur at } \\
\text { normal abundance } \\
\text { and diversity and } \\
\text { levels capable of } \\
\text { ensuring the long- } \\
\text { term abundance of the } \\
\text { species and the } \\
\text { retention of their full } \\
\text { reproductive capacity. }\end{array}$} & \multicolumn{4}{|c|}{ Ensuring a strong, healthy and just society } \\
\hline & & HLMO 5 & $\begin{array}{l}\text { People appreciate the diversity of the } \\
\text { marine environment, its seascapes, its } \\
\text { natural and cultural heritage and its } \\
\text { resources and act responsibly. }\end{array}$ & GEN 1 & $\begin{array}{l}\text { General planning principle: There is a } \\
\text { presumption in favor of sustainable } \\
\text { development and use of the marine } \\
\text { environment when consistent with the }\end{array}$ \\
\hline & & HLMO 6 & $\begin{array}{l}\text { The use of the marine environment is } \\
\text { benefiting society as a whole, } \\
\text { contributing to resilient and cohesive } \\
\text { communities that can adapt to coastal } \\
\text { erosion and flood risk, as well as } \\
\text { contributing to physical and mental } \\
\text { wellbeing }\end{array}$ & & policies and objectives of this Plan. \\
\hline \multirow[t]{2}{*}{ GES 5} & \multirow{2}{*}{$\begin{array}{l}\text { Human-induced } \\
\text { eutrophication is } \\
\text { minimized, especially }\end{array}$} & HLMO 7 & $\begin{array}{l}\text { The coast, seas, oceans and their } \\
\text { resources are safe to use. }\end{array}$ & & \\
\hline & & HLMO 8 & The marine environment plays an & & \\
\hline
\end{tabular}




\begin{tabular}{|c|c|c|c|c|c|}
\hline & \multirow{2}{*}{$\begin{array}{l}\text { adverse effects } \\
\text { thereof, such as losses } \\
\text { in biodiversity, } \\
\text { ecosystem } \\
\text { degradation, harmful } \\
\text { algal blooms and } \\
\text { oxygen deficiency in } \\
\text { bottom waters }\end{array}$} & & $\begin{array}{l}\text { important role in mitigating climate } \\
\text { change. }\end{array}$ & & \\
\hline & & HLMO 9 & $\begin{array}{l}\text { There is equitable access for those who } \\
\text { want to use and enjoy the coast, seas } \\
\text { and their wide range of resources and } \\
\text { assets, and recognition that for some } \\
\text { island and peripheral communities the } \\
\text { sea plays a significant role in their } \\
\text { community. }\end{array}$ & & \\
\hline \multirow[t]{3}{*}{ GES 6} & \multirow{3}{*}{$\begin{array}{l}\text { Sea-floor integrity is } \\
\text { at a level that ensures } \\
\text { that the structure and } \\
\text { functions of the } \\
\text { ecosystems are } \\
\text { safeguarded and } \\
\text { benthic ecosystems, } \\
\text { in particular, are not } \\
\text { adversely affected. }\end{array}$} & HLMO 10 & $\begin{array}{l}\text { Use of the marine environment will } \\
\text { recognize, and integrate with, defense } \\
\text { priorities, including the strengthening } \\
\text { of international peace and stability and } \\
\text { the defense of the United Kingdom } \\
\text { and its interests. }\end{array}$ & & \\
\hline & & \multicolumn{4}{|c|}{ Living within environmental limits } \\
\hline & & \multirow[t]{2}{*}{ HLMO 11} & \multirow[t]{2}{*}{$\begin{array}{l}\text { Biodiversity is protected, conserved } \\
\text { and, where appropriate, recovered, and } \\
\text { loss has been halted }\end{array}$} & GEN 1 & $\begin{array}{l}\text { General planning principle: There is a } \\
\text { presumption in favor of sustainable } \\
\text { development and use of the marine } \\
\text { environment when consistent with the policies } \\
\text { and objectives of this Plan. }\end{array}$ \\
\hline \multirow[t]{3}{*}{ GES 7} & \multirow[t]{3}{*}{$\begin{array}{l}\text { Permanent alteration } \\
\text { of hydrographical } \\
\text { conditions does not } \\
\text { adversely affect } \\
\text { marine ecosystems }\end{array}$} & & & GEN 9 & $\begin{array}{l}\text { Natural heritage: Development and use of the } \\
\text { marine environment must: } \\
\text { (a) Comply with legal requirements for } \\
\text { protected areas and protected species. } \\
\text { (b) Not result in significant impact on the } \\
\text { national status of Priority Marine Features. } \\
\text { (c) Protect and, where appropriate, enhance } \\
\text { the health of the marine area. }\end{array}$ \\
\hline & & \multirow[t]{2}{*}{ HLMO 12} & \multirow[t]{2}{*}{$\begin{array}{l}\text { Healthy marine and coastal habitats } \\
\text { occur across their natural range and are } \\
\text { able to support strong, biodiverse } \\
\text { biological communities and the } \\
\text { functioning of healthy, resilient and } \\
\text { adaptable marine ecosystems }\end{array}$} & GEN 10 & $\begin{array}{l}\text { Invasive non-native species: Opportunities to } \\
\text { reduce the introduction of invasive non- } \\
\text { native species to a minimum or proactively } \\
\text { improve the practice of existing activity } \\
\text { should be taken when decisions are being } \\
\text { made. }\end{array}$ \\
\hline & & & & GEN 11 & $\begin{array}{l}\text { Marine litter: Developers, users and those } \\
\text { accessing the marine environment must take } \\
\text { measures to address marine litter where } \\
\text { appropriate. Reduction of litter must be taken } \\
\text { into account by decision makers. }\end{array}$ \\
\hline \multirow[t]{3}{*}{ GES 8} & \multirow[t]{3}{*}{$\begin{array}{l}\text { Concentrations of } \\
\text { contaminants are at } \\
\text { levels not giving rise } \\
\text { to pollution effects }\end{array}$} & \multirow[t]{3}{*}{ HLMO 13} & \multirow[t]{3}{*}{$\begin{array}{l}\text { Our oceans support viable populations } \\
\text { of representative, rare, vulnerable and } \\
\text { valued species. }\end{array}$} & GEN 12 & $\begin{array}{l}\text { Water quality and resource: Developments } \\
\text { and activities should not result in a } \\
\text { deterioration of the quality of waters to which } \\
\text { the Water Framework Directive, Marine } \\
\text { Strategy Framework Directive or other } \\
\text { related directives apply. }\end{array}$ \\
\hline & & & & GEN 13 & $\begin{array}{l}\text { Noise: Development and use in the marine } \\
\text { environment should avoid significant adverse } \\
\text { effects of man-made noise and vibration, } \\
\text { especially on species sensitive to such } \\
\text { effects. }\end{array}$ \\
\hline & & & & GEN 14 & $\begin{array}{l}\text { Air quality: Development and use of the } \\
\text { marine environment should not result in the } \\
\text { deterioration of air quality and should not } \\
\text { breach any statutory air quality limits. }\end{array}$ \\
\hline \multirow[t]{4}{*}{ GES 9} & \multirow{4}{*}{$\begin{array}{l}\text { Contaminants in fish } \\
\text { and other seafood for } \\
\text { human consumption } \\
\text { do not exceed levels } \\
\text { established by } \\
\text { Community } \\
\text { legislation or other } \\
\text { relevant standards }\end{array}$} & \multicolumn{4}{|c|}{ Promoting good governance } \\
\hline & & HLMO 14 & $\begin{array}{l}\text { All those who have a stake in the } \\
\text { marine environment have an input into } \\
\text { associated decision making. }\end{array}$ & GEN 1 & $\begin{array}{l}\text { General planning principle: There is a } \\
\text { presumption in favor of sustainable } \\
\text { development and use of the marine } \\
\text { environment when consistent with the policies } \\
\text { and objectives of this Plan. }\end{array}$ \\
\hline & & HLMO 15 & $\begin{array}{l}\text { Marine, land and water management } \\
\text { mechanisms are responsive and work } \\
\text { effectively together for example } \\
\text { through integrated coastal zone } \\
\text { management and river basin } \\
\text { management plans. }\end{array}$ & GEN 15 & $\begin{array}{l}\text { Planning alignment A: Marine and terrestrial } \\
\text { plans should align to support marine and land } \\
\text { based components required by development } \\
\text { and seek to facilitate appropriate access to the } \\
\text { shore and sea. }\end{array}$ \\
\hline & & HLMO 16 & $\begin{array}{l}\text { Marine management in the UK takes } \\
\text { account of different management } \\
\text { systems that are in place because of } \\
\text { administrative, political or } \\
\text { international boundaries }\end{array}$ & GEN 16 & $\begin{array}{l}\text { Planning alignment B: Marine plans should } \\
\text { align and comply where possible with other } \\
\text { statutory plans and should consider } \\
\text { objectives and policies of relevant non } \\
\text { statutory plans where appropriate to do so. } \\
\text { <applies to inshore waters only> }\end{array}$ \\
\hline
\end{tabular}




\begin{tabular}{|c|c|c|c|c|c|}
\hline \multirow[t]{3}{*}{ GES 10} & \multirow{3}{*}{$\begin{array}{l}\text { Properties and } \\
\text { quantities of marine } \\
\text { litter do not cause } \\
\text { harm to the coastal } \\
\text { and marine } \\
\text { environment }\end{array}$} & HLMO 17 & $\begin{array}{l}\text { Marine businesses are subject to clear, } \\
\text { timely, proportionate and, where } \\
\text { appropriate, plan-led regulation }\end{array}$ & GEN 17 & $\begin{array}{l}\text { Fairness: All marine interests will be treated } \\
\text { with fairness and in a transparent manner } \\
\text { when decisions are being made in the marine } \\
\text { environment. }\end{array}$ \\
\hline & & HLMO 18 & $\begin{array}{l}\text { The use of the marine environment is } \\
\text { spatially planned where appropriate } \\
\text { and based on an ecosystems approach } \\
\text { which takes account of climate change } \\
\text { and recognizes the protection and } \\
\text { management needs of marine cultural } \\
\text { heritage according to its significance. }\end{array}$ & GEN 18 & $\begin{array}{l}\text { Engagement: Early and effective engagement } \\
\text { should be undertaken with the general public } \\
\text { and all interested stakeholders to facilitate } \\
\text { planning and consenting processes. }\end{array}$ \\
\hline & & \multicolumn{4}{|c|}{ Using sound science responsibly } \\
\hline \multirow[t]{4}{*}{ GES 11} & \multirow[t]{4}{*}{$\begin{array}{l}\text { Introduction of } \\
\text { energy, including } \\
\text { underwater noise, is } \\
\text { at levels that do not } \\
\text { adversely affect the } \\
\text { marine environment }\end{array}$} & HLMO 19 & $\begin{array}{l}\text { Our understanding of the marine } \\
\text { environment continues to develop } \\
\text { through new scientific and socio- } \\
\text { economic research and data collection. }\end{array}$ & GEN 1 & $\begin{array}{l}\text { General planning principle: There is a } \\
\text { presumption in favor of sustainable } \\
\text { development and use of the marine } \\
\text { environment when consistent with the policies } \\
\text { and objectives of this Plan. }\end{array}$ \\
\hline & & \multirow[t]{2}{*}{ HLMO 20} & \multirow[t]{2}{*}{$\begin{array}{l}\text { Sound evidence and monitoring } \\
\text { underpins effective marine } \\
\text { management and policy development. }\end{array}$} & GEN 19 & $\begin{array}{l}\text { Sound evidence: Decision making in the } \\
\text { marine environment will be based on a sound } \\
\text { scientific and socio-economic evidence. }\end{array}$ \\
\hline & & & & GEN 20 & $\begin{array}{l}\text { Adaptive management: Adaptive } \\
\text { management practices should take account of } \\
\text { new data and information in decision making, } \\
\text { informing future decisions and future } \\
\text { iterations of policy. }\end{array}$ \\
\hline & & HLMO 21 & $\begin{array}{l}\text { The precautionary principle is } \\
\text { applied consistently in accordance } \\
\text { with the UK Government and } \\
\text { Devolved Administrations' } \\
\text { sustainable development policy }\end{array}$ & GEN 21 & $\begin{array}{l}\text { Cumulative impacts: Cumulative impacts } \\
\text { affecting the ecosystem of the marine plan } \\
\text { area should be addressed in decision-making } \\
\text { and plan implementation }\end{array}$ \\
\hline
\end{tabular}

\subsection{Scotland's SMPTE}

Scotland's SMPTE is subsumed within the offshore wind and marine renewable energy sector identified within Scotland's NMP, with all policies and regulations set out in the SMPTE in conformity with the strategic objectives designated within the NMP (Marine Scotland, 2013a). The SMPTE was informed by and contributes to Scotland's Marine Energy Action Plan, National Renewables Infrastructure Plan (N-RIP), and Securing the Benefits from Scotland's Next Energy Revolution. The SMPTE was constructed and implemented in response to key drivers consisting of the development of a marine planning agenda, the establishment of marine licensing, to mitigate the impacts of climate change by assisting the Scottish Government in meeting GHG emissions mitigation targets via commercial-scale TCT, and to help facilitate Scotland's transition to a low-carbon economy, thereby making them a global leader in the marine renewable energy market. The framework set out the SMPTE is comprised of the strategic aims of identifying preferred development areas for tidal energy developments in Scotland, facilitating enhanced economic development, investment, and employment, and minimizing adverse implications on people, other sectors, and the environment.

The primary output of Scotland's SMPTE is the identification of 10 POAs, based on the prime suitability of sustainable commercial-scale TCT deployment measuring at an accommodating capacity of 30MW or greater (Marine Scotland, 2013a). With the intent of developing a streamlined licensing and consenting regime to further enhance the implementation of large TCT arrays, the identification of final POAs where based on the acknowledgment of potential conflicts arising from planning, regulatory, legislative, social, economic, environmental, ecological, and cultural constraints, with the first two phases of the four-phase SMPTE process identifying, analyzing, evaluating, and revamping the weighting of such constraints, and the third phase accepting the proposed POAs. The forth phase can be considered the immediate output of the SMPTE process as the establishment of the project licensing regime. 
The following subsections further detail the individual components of Scotland's SMPTE process.

Figure 1: Scottish sectoral marine planning process

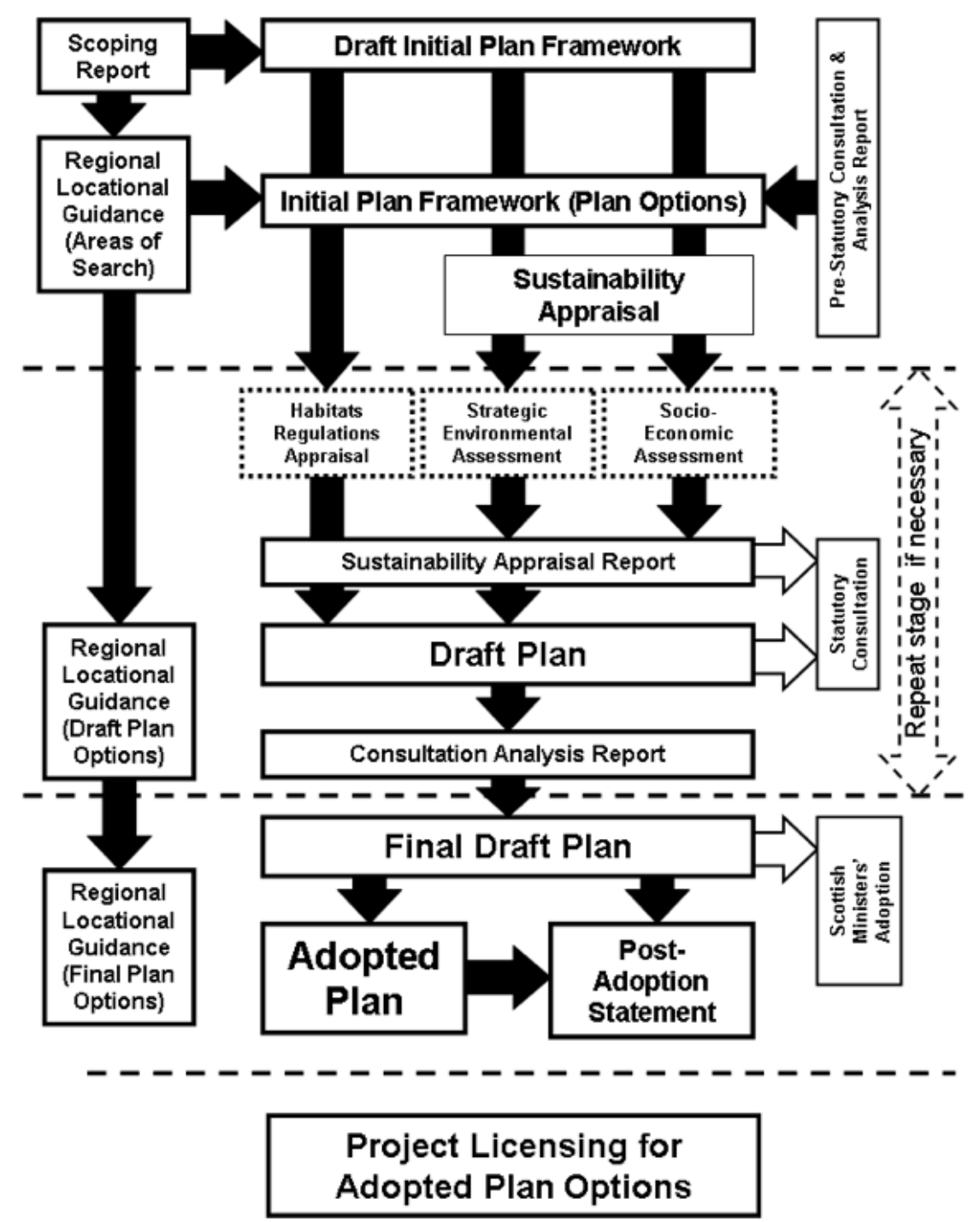

\subsubsection{Phase 1-Initial plan framework}

The preliminary identification of POAs is undertaken during the scoping stage by selecting spatial data layers consisting of presently occurring and future designated uses of Scottish waters (e.g. existing or pending aquaculture leases), as well as culturally and ecologically significant areas, all of which were categorized as socio-cultural, environmental, industry, commercial fishing, and non-technical (Davies et al., 2012). Through informed consultation within Marine Scotland, weightings regarding the level of constraint are attributed to spatial data layers and then compiled into the UK Crown Estate's spatial modeling tool MaRS, which then produced maps suggesting the most suitable sites for tidal energy development. Following the production of maps from the scoping exercise, regional locational guidance (RLG) is employed by scientific and technical advisors of Marine Scotland to further identify areas of 
suitable deployment based on constraint and also opportunity (e.g. proximity to grid connection access) that are site specific to regions identified in the SMPTE, and thus more detailed (Marine Scotland, 2013c).

Running in unison with RLG, pre-statutory consultation is undertaken by engaging key stakeholders identified in the SMPTE, and categorized under fishing, shipping/navigation, natural environment, local government, grid, national/devolved government, industry, community, and tourism/recreation, are consulted and encouraged to contribute local knowledge and provide their opinion into the siting process (Marine Scotland, 2013a). The outcome of prestatutory consultation is then organized into a report and made publically available to provide for a transparent planning process. The outputs of the pre-statutory consultation and analysis report, together with the outputs of RLG, feed into the initial plan framework (IPF). The POAs produced for the IPF are then put forward to Scottish Ministers' in order to obtain approval and subsequently commence the formal planning process.

\subsubsection{Phase 2 - Draft plan option areas}

In compliance with the Environmental Assessment (Scotland) Act 2005 and the UK Marine Policy Statement, the second phase of the SMPTE process is to undertake a sustainability appraisal comprised of a SEA, socio-economic assessment, and habitats regulation appraisal (HRA) in order to further analyze and evaluate potential environmental, ecological, cultural, and socio-economic spatial conflicts and compatibilities specific to each site identified as a POA in the IPF (Marine Scotland, 2013b). The SEA identifies key environmental receptors that are likely to display degrees of sensitivity resulting from stressors produced from tidal energy developments, as well as quantifying potential impacts and exploring potential mitigation measures (Marine Scotland, 2015c). The socio-economic assessment establishes a framework for measuring, both quantitatively and qualitatively, the user - user and user - environment conflicts that tidal energy development may have on a community in economic and social contexts (Marine Scotland, 2015a). The HRA identifies spatial conflicts between tidal energy developments in purposed POAs with areas designated either currently, or have the potential to be designated in the future as special areas of conservation (SACs) under the Habitats Directive and special protection areas (SPAs) under the Birds Directive, as specified under the EU-wide biological conservation legislation Natura 2000 (Marine Scotland, 2015a).

The results of the SEA, socio-economic assessment, and HRA are documented and published in a sustainability appraisal report and subject to consultation with key stakeholders for a minimum of 16 weeks (Marine Scotland, 2013a). As in Phase 1, running in unison of stakeholder engagement is the second phase of RLG where scientific and technical experts within Marine Scotland provide site specific advice on areas of constraint and opportunity within identified SMPTE regions based off of the findings presented in the sustainability appraisal report. During this period, the SEA and HRA reports used to inform the sustainability appraisal undergo statutory consultation with the appropriate governance bodies, consisting of Scottish Natural Heritage (SNH), Scottish Environmental Protection Agency (SEPA), Historic Scotland (HS), and the Joint Nature Conservation Committee (JNCC) reviewing the results of the SEA, and $\mathrm{SNH}$ reviewing findings from the HRA report.

Running in parallel with statutory consultation, the results of stakeholder engagement and RLG with regards to the findings presented in the sustainability appraisal report inform the development of formal draft POAs, which are subject to consultation with key stakeholders for a

minimum period of 16 weeks (Marine Scotland, 2013a). These draft POAs are also then fed into 
the statutory consultation process and, if deemed sustainable, the appropriate statutory authorities will approve the draft POAs and produce a consultation analysis report demonstrating how issues raised by key stakeholders were accounted for throughout the sustainability appraisal report and draft plan. However, in conformity with the Environmental Assessment (Scotland) Act 2005, if statutory consultation had determined that the results from the sustainability appraisal were environmentally, ecologically, economically, and socially unacceptable, Phase 2 would have to repeat itself until and unless the outcome of the process can be deemed sustainable in conformity to the strategic objectives of establishing an ecosystem approach framework to marine planning and applying the five shared UK guiding principals for sustainable development set out in the NMP.

\subsubsection{Phase 3 - Final plan option areas}

The output of Phase 2 carries over to Phase 3 as final POAs in the SMPTE suitable for the sustainable deployment of TCT arrays with an installed capacity of 30MW or greater. A final round of RLG consultation is undertaken to inform any further levels of constraint or suitability for the identified final POAs, which are then put forward for formal legislative adoption by applicable Scottish Ministers (Marine Scotland, 2013a). If the plan is adopted, demonstrating compliance with various EU Directives pertaining to MSP, including the SEA Directive, Habitats Directive (92/43/EEC), Birds Directive (2009/147/EC), MSP Directive, and the Marine Strategy Framework Directive (MSFD), the final POAs are contained within the SMPTE. In conformity with the Environmental Assessment (Scotland) Act 2005, the Scottish Ministers produce a post-adoption statement detailing the reasons for for formally adopting the SMPTE and how key stakeholder concerns arising from all phases of the SMPTE process were either taken into consideration or not and why.

\subsubsection{Phase 4 - Licensing}

Once the SMPTE is drafted, published, and implemented, proponents can obtain project licenses to for POAs through Marine Scotland's Licensing Operations Team (MS-LOT), who operate as a one-stop shop to issue permits, consents, and licenses, as well as provide advice and guidance on the regulatory hurtles associated with project development, acting as a sort of continuous exercise of RLG (Marine Scotland, 2013a). However, although POAs within the SMPTE are identified through the extensive three-phase SMPTE process presented above due to their determined resource availability and planning, social, economic, environmental, ecological, and cultural sustainability suitable for commercial-scale TCT deployment, given the complexity of the marine environment in conjunction with the distinct risks associated with different project developments, there is no guarantee that a proponent will receive consent to obtain a license for a POA. If Marine Scotland deemed necessary, a conditional tender to undertake project-level environmental impact assessment (EIA) will be drafted.

Similarly, there are a number of sites that were excluded from being identified as POAs within the SMPTE solely based on their resource capacity being estimated as under 30MW, however, these sites can also be granted licenses for development by MS-LOT if there is development interest and the appropriate conditions for consent are met by the proponent. Once the SMPTE is implemented and the licensing regime is in place, strategic monitoring and review of the interactions of commercial TCT deployment on the indicators identified in the sustainability appraisal are undertaken by a sectoral plans review group (SPRG), thereby further informing future iterations of POAs identified in the SMPTE. 
Figure 2: Scottish adopted plan option areas

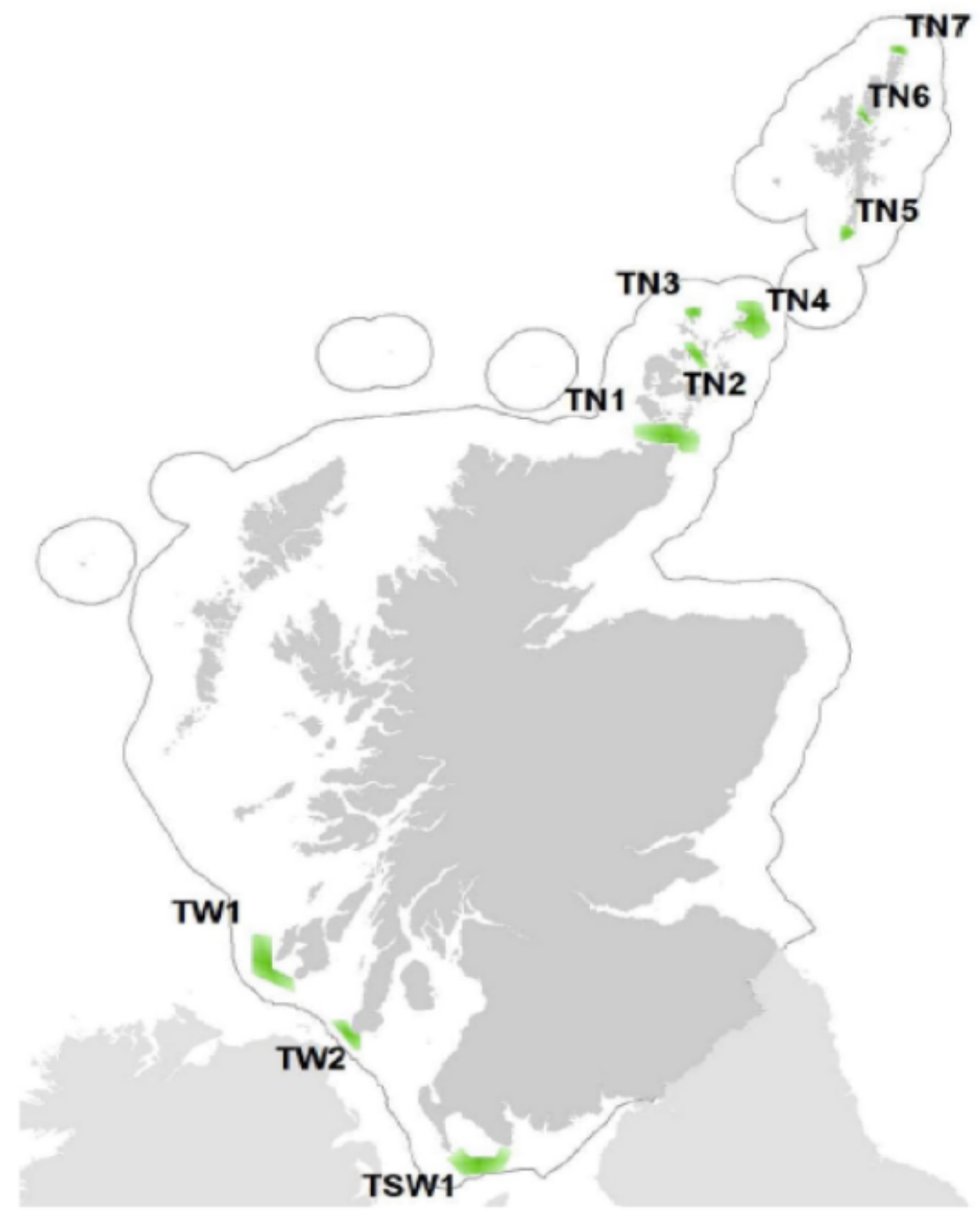

\section{Constructing a sectoral marine plan for tidal energy for Nova Scotia}

The remainder of this paper constructs a SMPTE for the province of Nova Scotia. Given that Scotland is the only nation to have constructed and implemented a SMPTE, this exercise is particularly unique from a governance structure point-of-view as the proposed SMPTE would be provincial in nature, therefore requiring a slue of joint federal and provincial policies, legislation, and regulatory authorities in order to establish the regulatory regime of the SMPTE. Via a series of email chains and formal meetings, members of ATEI, OERA, MRC, FORCE, DoE, World Wildlife Foundation (WWF), and Fundy Tidal Inc. (FTI) had agreed to participate in the development of the SMPTE for this paper, and whose technical, scientific, policy, and industry expertise will be employed primarily for RLG in an advisory capacity and here on out referred to as the scientific and technical advisory panel (STAP). Since there is no solidified governance structure to employ for RLG as is the case in Scotland, the STAP participants are also stakeholders in Nova Scotia's tidal industry, and therefore can act not only as governance advisory but stakeholder consultation as well, thereby fulfilling the two primary means of 
consultation utilized in the SMPTE process. While the STAP can not replace community stakeholder involvement, given the scope and timeframe of this paper, the STAP will suffice as not to stir up the socio-political climate in a research paper whose outputs are not being employed by the province directly or in its entirety.

The paper first establishes the public policy agenda framing the SMPTE, inclusive of jurisdictional boundaries, authorities, purpose, and stakeholders. The SMPTE process is then detailed specific to the Nova Scotia context with outputs generated at each stage within each phase of the process and the methodology employed to achieve such outputs detailed, with the final output of process producing adopted POAs. The immediate output of the SMPTE process, the establishment of the project licensing regime, as currently constructed and implemented by the DoE, will be overviewed. Final POAs emanating from the SMPTE process undertaken in this paper will be compared to the marine renewable-energy areas legislated in the MRE Act 2015 which didn't not undergo a formally structured planning framework. Drawing from criteria established in the MSP best practice guideline document, the International Council for the Exploration of the Sea's (ICES) Marine Spatial Planning Quality Management System (ICES MSP QMS) (Cormier et al., 2015), a quality management review will be undertaken for the Nova Scotia SMPTE in comparison to the Scottish SMPTE quality management review detailed in Sangiuliano's (2016) A Quality Management Review of Scotland's Sectoral Marine Plan for Tidal Energy. Finally, key recommendations will be made on gaps in the Nova Scotia context in relation to the TCT development framework currently in place.

\subsection{Public policy agenda}

In order to build an effective MSP process, a public policy agenda must be organized to discern both the economic development and ecosystem protection goals to come into fruition once the plan is implemented, here on out referred to as the marine development agenda and ecosystem protection agenda, respectively (Cormier et al., 2015). In developing this process, the vision, key drivers, and strategic aims of the plan have to be identified, as well as the planning boundaries in which they will be applied, the CAs delegated with powers to plan within this boundary, and the legislation that provides for the CA's powers. Furthermore, it is imperative to identify the internal and external actors associated to the development of the MSP process so that cultural, social, political, legal, regulatory, financial, technological, economic, and environmental factors that may impede the ability for the plan to achieve the strategic aims set out in the plan are incorporated into the planning process to provide for a transparent and inclusive development framework with minimal regulatory risk.

\subsubsection{Establishing jurisdictional boundaries}

Due to the absence of a solidified cohesive regulatory governance structure for MSP both federally and provincially (Fournier, 2011), Nova Scotia's marine boundaries in which the framework of a SMPTE would be developed and implemented can not draw from currently delineated and legislated margins (Doelle et al., 2006), as is the case for Scotland's SMPTE as provided by the Marine Scotland Act 2010 and the UK Marine and Coastal Access Act 2009, which delegates planning authorities of Scottish waters to Marine Scotland as the sole appointed CA from 0-12nm and 12-200nm from LAT, respectively (Marine Scotland, 2013a). While Article 56 of the Law of the Sea Convention (LOSC) 1982 designates rights for States to regulate marine environments out to the 200nm EEZ, the notion of which level of government lays claim to particular waters has been thoroughly debated, specifically with regards to the Bay of Fundy 
due to the federal government's claim of the bay being an internal historic water basin of Canada in contrast with Atlantic provinces, inclusive of Nova Scotia, claiming that their historical and cultural relationship with the marine environment is not limited to waters inter fauces terrae(within the jaws of the land - including bays, estuaries, and straits).

In order to discern provincial marine planning boundaries for Nova Scotia for the purposes of the construction of a SMPTE, one would have to turn to Section 92A (1)(c) of the Constitution Act 1982 which stipulates that provinces can create legislation with regards to the development, conservation, and management of sites and facilities in the province for the generation and production of electrical energy, thereby delegating jurisdiction of TCT implementation to the province conditional on demonstration of territorial claim prior to confederation in 1867 (Doelle et al., 2006). In the case of Nova Scotia, this claim can be traced back to the the royal instructions issued by Governor Carlton "upon the separation of what is now the province of New Brunswick from the province of Nova Scotia, the southern boundary of the new province was defined as 'a line in the center of the Bay of Fundy from the River Saint Croix aforesaid to the mouth of Musquat (Missiquash) River' clearly indicating the claim of Great Britain at the time to the whole Bay of Fundy as a portion of her territory" (Doelle et al., 2006, pp. 10), thereby solidifying as clearly as possible in the absence of concrete legislation Nova Scotia's territorial claim to jurisdiction to the Bay of Fundy, and subsequent western planning boundaries of the proposed provincial SMPTE at hand.

In order to determine the Eastern boundaries of the SMPTE, many scholars have suggested that Atlantic provinces such as Nova Scotia can claim historical $3 \mathrm{~nm}$ TZ boundaries to pre-confederation (Doelle et al., 2006). However, the absence of legislated federal and provincial jurisdiction, in conjunction with potentially conflicting claims by Atlantic provinces of rights over the marine environment inter fauces terrae, in some cases extending as far as the continental shelf beyond the 200nm EEZ as may be the case with Newfoundland and Labrador if contested, and federal legislative claims under Section 8(1) of the federal Oceans Act 1996 vesting the seabed and subsoil of the territorial sea and internal waters outside of provincial boundaries to the federal Crown, a healthy compromise can be met for the purposes of a provincial SMPTE by extending the TZ to $12 \mathrm{~nm}$ from LAT as is uniform amongst European North Sea situated member states (Douvere and Ehler, 2009).

However, conflictions amongst the provincial and federal governments over jurisdictional boundaries of a SMPTE on Nova Scotia's east coast would not be an area of high contention as economically viable tidal current speeds of a minimum Vmsp of $1.5 \mathrm{~m} / \mathrm{s}$ suitable for TCT implementation typically occur in areas where large bodies of water are forced through narrow corridors such as headlands, estuaries, channels, and sea lochs (Bryden and Melville, 2004), and thus there is no resource potential beyond the $3 \mathrm{~nm}$ mark of the province. Finally, to discern the rest of the SMPTE provincial planning boundaries, best practices shared amongst European nations with delineated MSP boundaries of evenly splitting the distance of the marine environment between their respective LATs should be employed for Nova Scotia's western and northwestern boundaries adjacent to New Brunswick, and northern boundary adjacent to Prince Edward Island.

Prior to initiating the first stage of Phase 1, scoping areas for search, Marine Scotland had defined six offshore renewable energy regions (north, northwest, northeast, east, west, and southwest) in order to further identify, analyze, and evaluate potential constraints and opportunities to determine POAs through RLG exercises (Marine Scotland, 2013a). A common consensus amongst scholars is that, in order to employ an effective ecosystem approach to MSP, 
identified by the NMP as a strategic objective, ecosystem boundaries must be accounted for and incorporated into the MSP regions (Douvere, 2008).

Figure 3: Nova Scotia sectoral marine plan for tidal energy boundaries

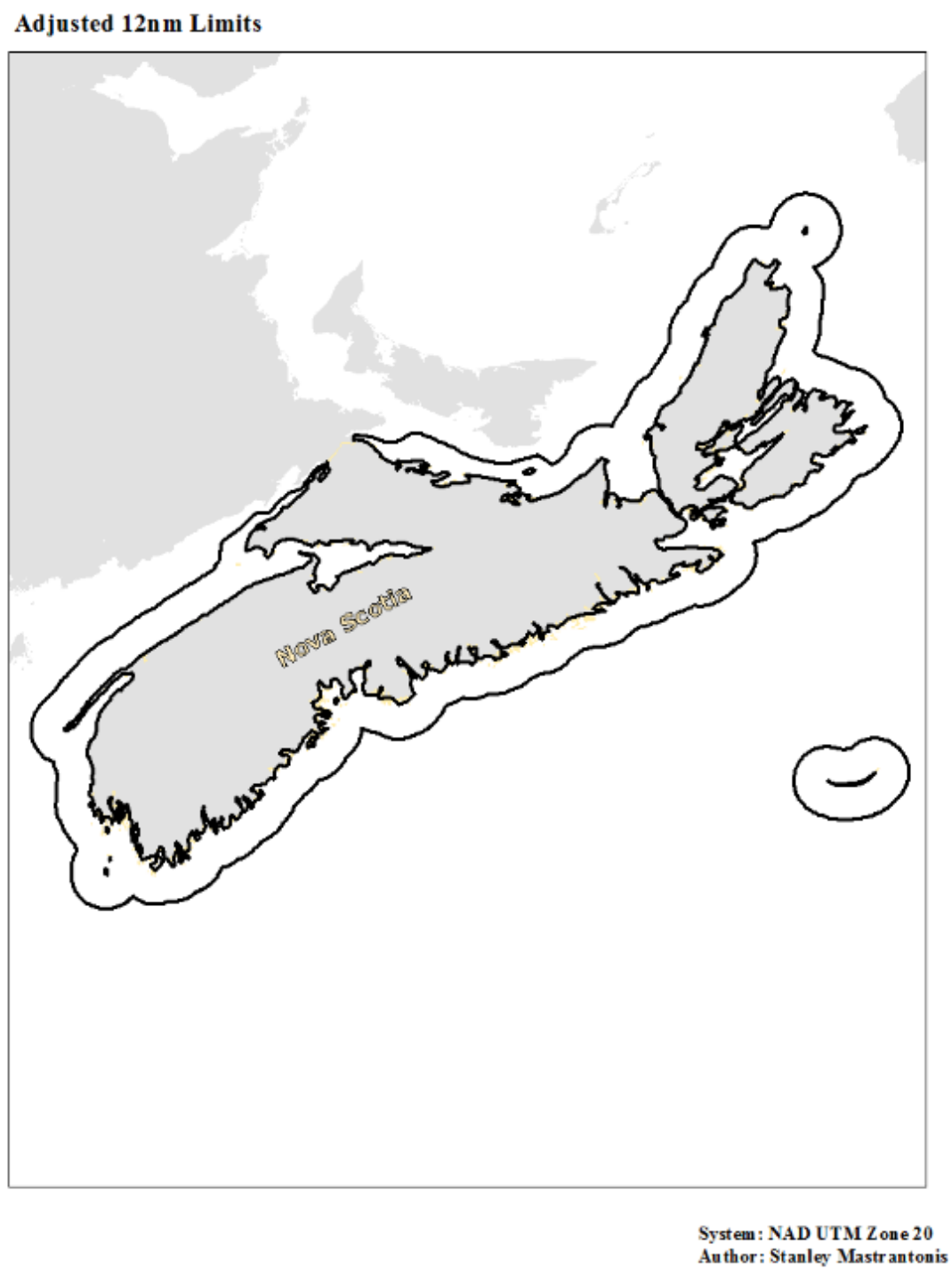

The Scottish SMPTE delineated the six offshore renewable energy regions without a published structured methodology and without consideration to ecosystem boundaries, resulting in Sangiuliano's (2016) third quality management review recommendation in A Quality Management Review of Scotland's Sectoral Marine Plan for Tidal Energy of establishing ecosystem boundaries in order to account for far-field impacts resulting from commercial-scale TCT array implementation in relation to the potential alteration of natural hydrology patterns and sediment deposition affecting the larger marine ecosystem up and downstream, thus jeopardizing ecosystem services within and outside the SMPTE management boundaries. Therefore, the delineation of regional boundaries incorporating natural oceanographic, hydrological, and prevailing ecosystem boundaries determined by an analysis of marine species occupation patterns with be withheld until maps are produced incorporating ecosystem-based data layers and put forth to the STAP for review during the RLG stage of Phase 1 of the SMPTE process. 


\subsubsection{Establishing jurisdictional authority}

Although the existing federal legislative framework discussed above, in conjunction with the adoption of best practice from European nations who have constructed and implemented MSPs can offer some guidance into establishing what the SMPTE provincial jurisdictional boundaries would be, this does not answer the question of what jurisdictional bodies, whether federal or provincial, would have jurisdictional legislative and administrative authority to regulate planning efforts within these established boarders. In order to decipher what governing body would act as the CA for the construction and implementation of a provincial SMPTE, under which public policy agenda, either the marine development agenda, ecosystem protection agenda, or both, and under what legislation, one must overview the legislative authorities currently in place to regulate other users of the marine environment.

The federal government agency Transport Canada is the only regulatory authority, as delegated by the Navigable Waters Protection Act (NWPA) 1985, who can issue permits regarding a development that may impede or obstruct marine transport both within and outside provincial boundaries (Fournier, 2011). Similarly, the federal government agency the Department of Fisheries and Oceans Canada (DFO) is the only regulatory authority, as delegated by the Fisheries Act 1985, who can issue permits regarding a development that may disrupt the public right to fish both within and outside provincial boundaries. However, the Nova Scotia Department of Natural Resources (DNR) has proprietary rights over the seabed within provincial jurisdictional boundaries as delegated by the Crown Lands Act 2012 (ATEI, 2013), thereby authorizing the province the right to issue seabed leases for the development, conservation, and management of sites and facilities within provincial jurisdiction for the generation and production of electrical energy as mirrored by Section 92A (1)(c) of the Constitution Act 1982 (Doelle et al., 2006).

When taking all the legislation listed above into consideration, the current regulatory regime of the SMPTE public policy agenda would permit the issuance of leases for TCT implementation under provincial authority, specifically that of the Nova Scotia DNR under the Crown Lands Act 2012, while all regulatory and legislative authority would remain in the realm of the federal government, specifically Transport Canada under the NWPA 1985 and the DFO under the Fisheries Act 1985. While this system is technically feasible, and currently forms a portion of the even more complex One-Window Standing Committee (OWSC) comprised of five federal and six provincial regulatory authorities (Acadia, 2013) garnered to coordinate the similarly complex permitting and approvals process, a complex regulatory system and governance framework often deters developers who believe that such a large conglomeration can slow the eventual consenting and licensing of projects, thereby increasing financial risk (Fournier, 2011). Therefore, in order to mitigate the deterrence of attracting TCT project proponents into Nova Scotia waters, as few regulatory authorities as possible should be delegated powers to plan.

It is recommended that the federal government delegate administrative authority with regards to TCT projects to the province via the establishment of prescribed regulations under the Oceans Act 1996, which provides a platform for the federal government to attribute legitimacy to provincial legislation governing internal waters of Canada and provincial TZs (Doelle et al., 2006). In essence, this would provide for a single figurehead provincial authority, thereby reducing regulatory complexity within the governance structure and as perceived by project proponents and the community, while allotting statutory weight via federal legislation to provincial administration, thereby potentially deterring litigation stemming from fisherman with 
concerns surrounding displacement. For purposes of this paper, this will be the legislative framework of the SMPTE, with the delegation of powers to plan for the marine environment from federal to provincial in ways similar to the devolution of powers from the UK to Scotland in the Scottish EEZ via the Marine and Coastal Access Act 2009 (Marine Scotland, 2013a).

However, unlike the Canadian framework proposed above, the Scottish Government created new legislation via the Marine Scotland Act 2010 that mirrored the UK Marine and Coastal Access Act 2009 in that powers to plan for the marine environment were delegated to Marine Scotland, with the Marine Scotland Act 2010 providing for legislative authority within the Scottish TZ (Marine Scotland, 2014). It therefore prompts the recommendation that the Nova Scotia and Canadian government eventually enact similar legislation to provide for a more solidified legislative regulatory governance structure which, although may take some time, the industry is still in the pre-commercial stage and therefore allots time for the industry to decipher its economic viability (Fournier, 2011).

It terms of which provincial body would be designated the CA for Nova Scotia's SMPTE, the MRE Act 2015 clearly delegates legislative administrative authority to the Minister of Energy, here on out referred to as the Minister, with the general management and supervision duties of the Minister under the Act provided by Section 5(1), (2) (a)-(g). However, the Minister does not have the right to issue a lease of the seabed to a project proponent as submerged Crown Land within provincial waters is within the jurisdictional realm the Nova Scotia DNR under the Crown Lands Act 2012, and therefore, while Section 5(d) of the MRE Act 2015 provides for the Minister to consult and co-ordinate activities with other government bodies, full administrative authority over TCT implementation regulations from Phase $1-4$ of the SMPTE process and outputs is not explicitly legislated to the DoE. Thus, the role of CA for the construction and oversight of the planning process of the marine development agenda for the Nova Scotia SMPTE is enshrined upon the DoE, with the stipulation of mandatory consultation for site selection with the DNR, acting as an other CA to some extent.

In conformity with the ecosystem approach to MSP advocated by scholars (Douvere, 2008), structuring best practice MSP guideline documents (Cormier et al., 2015), and implemented by the Scottish Government in their NMP and SMPTE (Marine Scotland, 2014), which provides for a slue of interrelated policies, visions, and objectives pertaining to sustainable development with regards to industry - environment interactions, an analysis of the legislation suggests that the CA for Nova Scotia's SMPTE ecosystem protection agenda is shared jointly both between the DoE and the Nova Scotia Department of Environment (NSE) and the Canadian Environmental Assessment Agency (CEAA).

While Section 5(2)(g) explicitly provides that the Minister may measure and analyze the environmental effects of marine renewable-energy activities and develop programs to enhance any benefits and mitigate any concerns associated with these activities, such as SEAs, and Section 58(1)(a) explicitly providing that the Minister may issue an order to cease work, the Nova Scotia Environment Act (NSEA) 1995 deems that tidal energy projects over 2MW are listed as Class 1 undertakings and must undergo an environmental assessment (EA), with the NSE delegated with the legislative authority to grant approval of the completion of said EA (Fournier, 2011). Furthermore, tidal energy projects over 50MW require joint federal and provincial review by the CEEA and the NSE under the Canadian Environmental Assessment (CEA) Act 2012 (Marine Renewable-energy Act, 2015). Therefore, the title of CA for the ecosystem protection agenda of the SMPTE is solely attributed to the DoE with projects $<2 \mathrm{MW}$, 
split with the DoE and NSE in projects $>2 \mathrm{MW}-<50 \mathrm{MW}$, and split with the DoE, NSE, and CEEA in projects $>50 \mathrm{MW}$.

\subsubsection{Establishing purpose}

Scotland's SMPTE sets out the vision, key drivers, and strategic aims which are in conformity with the policies set out in the NMP in order to establish the purpose and outcomes of the SMPTE itself within the public policy agenda and broader national political context (Marine Scotland, 2013a). In order to determine the vision, strategic aims, and key drivers for the Nova Scotia SMPTE, a review of the most prominent and reoccurring themes put forward in Marine Renewable Energy Legislation: A Consultative Process (Fournier, 2011), the MRE Act 2015, the Environmental Goals and Sustainable Prosperity Act (EGSPA) 2007, Nova Scotia's Electricity Plan (Department of Energy, 2010b), and the Marine Renewable Energy Strategy (Department of Energy, 2012) were analyzed and chosen in relation to the themes set out in Scotland's SMPTE. Since there is no standardized international definition for visions, drivers, strategies, aims, goals, and objectives, with different academics, experts, sectors, and governments assigning their own meaning to such words, for this paper the Scottish definition for vision, key drivers, and strategic aims will be employed. A vision acts as a mission statement for the long-term aspirations of what the government believes it can achieve as a whole for the nation. Key drivers are the political and governance context which is pushing the actions of the government through the construction of a plan to fulfill their vision. Strategic aims refer to the goals that the government has set out to achieve in response to the key drivers and towards the path to the government's vision.

Nova Scotia is one of the worst GHG emitters in Canada, with fossil fuels contributing to $90 \%$ ( $80 \%$ coal, $10 \%$ natural gas) of the province's energy generation for the greater part of the last two decades (Fournier, 2011), with the electricity sector being the largest contributor to such GHG emissions (Department of Energy, 2010b). Due to the substantial tidal current resources of the province, the employment of TCT derived electricity generation can become a major contributor to lowering Nova Scotia's GHG emissions. Nova Scotia has already exceeded the then nearest-term provincial renewable electricity generation target set out in the 2010 Electricity Plan of $25 \%$ generation by 2015 , achieving $26.6 \%$ renewable electricity generation, thereby putting the province on track to support the principals of sustainable development and economic prosperity set out in the EGSPA 2007 of becoming an international leader in environmental sustainability while achieving economic prosperity above the Canadian average by 2020 . The interest in having TCT technology becoming a large contributor to then loner-term generation targets set out in the Electricity Plan of 40\% renewable electricity generation by 2020 is due to the potential for capacity building within the province, becoming a major supply chain provider, and a global scientific and technical industry cluster, as discussed in section 3 .

However, in order to promote such aspirations of the province and make them come into fruition, Fournier's (2011) key recommendation out of the 27 listed in the Marine Renewable Energy Legislation: A Consultative Process report was the development of a strategic plan to address any cultural, social, political, legal, regulatory, financial, technological, economic, and environmental factors associated with the development of the industry in Nova Scotia. Furthermore, Fournier's report also mentions the construction of legislation specific to the tidal energy sector, which partly has materials in the MRE Act 2015. The purpose of the Act, as prescribed in Section 2, is to provide for the responsible, efficient, and effective development of 
marine renewable-energy resources through (a) a regulatory system that (i) is staged, collaborative, consultative and adaptive, and (ii) integrates technical, environmental and socioeconomic factors; and (b) programs and initiatives that promote the sustainable growth and management of the marine renewable-energy sector in the province.

The development of a strategic plan recommended by Fournier (2011), in the context of this paper, a SMPTE, can fulfill the purpose set out in the MRE Act 2015 as the SMPTE provides for a regulatory process composed of four overarching phases with internal scientific and technical, and community and industry stakeholder consultation and input throughout every phase in order to address cultural, social, political, legal, regulatory, financial, technological, economic, and environmental factors to identify POAs for TCT deployment based off of their sustainability. Therefore, the vision of Nova Scotia's SMPTE could be pulled from the Marine Renewable Energy Strategy's vision of Nova Scotia becoming a global leader in the development of technology and systems that produce environmentally sustainable, competitively priced electricity from the ocean (Department of Energy, 2012, pp. 2).

The key drivers that influence the construction of the SMPTE to realize the stated vision are marine planning - to assist with the development of a comprehensive policy framework for future decisions made at the project level (Fournier, 2011; Doelle et al., 2006); reduction of GHG emissions - contribute to federal targets of $30 \%$ in GHG emissions by 2030 over a 2005 baseline, contribute to provincial targets of $80 \%$ GHG emissions reductions by 2050 over a 2009 baseline, and contribute to G7 commitments of a carbon-free economy by 2100 (Department of Energy, 2010b); price stability - to reduce provincial reliance on coal and inherent volatile prices and exchange it for indigenous resources, with TCTs contributing to a $40 \%$ renewable energy generation portfolio by 2020 (Fournier 2011; Department of Energy, 2010b; 2012); and marine licensing - to streamline the licensing and consenting process of TCT testing and development. The strategic aims influenced by key drivers to realize the stated vision are reducing imported electricity to increase the wealth within the province, creating a skilled labor force with industry expertise to be exportable internationally, and maximizing the aggregate installed capacity of tidal energy in Nova Scotia, contributing to a more environmentally, economically, and socially sustainable Nova Scotia (Fournier 2011; Department of Energy, 2010b; 2012).

\subsubsection{Establishing key stakeholders}

The inclusion of industry and community stakeholders within the construction of any plan is essential in order to provide for a transparent, inclusive, and participatory planning process (Cormier et al., 2015). The concept of stakeholder participation is further emphasized as a necessity when examining the implementation of new technologies such as TCTs (Bronfman, Jiménez, Arévalo and Cifuentes, 2012), and new methods of structuring the implementation of technologies, such as that of MSPs and SMPTEs (Pomeroy and Douvere, 2008). Stakeholder engagement can mean the success or failure of the implementation of renewable energy systems, and in the case of Nova Scotia, TCTs, as the disaggregation of society predicated on the reliance on the expertise of others attributable to the shear size of modern communities and international interconnectivity of economies tends to prompt public and industry distrust in regulators (Bronfman et al., 2012). In order to gain this trust, it is suggested that regulators consult the public as early and as often in the planning process as possible in order to decrease public backlash and promote public acceptance of TCT adoption within Nova Scotia.

In order to include stakeholders within the SMPTE process, such stakeholders must first be identified based on their relationship with the SMPTE boundaries, regardless of whether they are 
located within them or not (Cormier et al., 2015). Pulling from Scotland's SMPTE, the identification of key stakeholders was not constrained to immediate geographical occupation, rather environmental, social, economic, ecological, and cultural factors concerning the relationships between people and organizations within the immediate planning boundary and the far-field impacts that commercial TCT implementation could potentially have prompted Marine Scotland to comprise a list of affected key stakeholders which they would contact for consultation, engagement, and feedback into the SMPTE process (Marine Scotland, 2013a).

Table 4: Scottish and Nova Scotia sectoral marine plan for tidal energy public policy agendas

\begin{tabular}{|c|c|c|c|c|}
\hline \multicolumn{5}{|c|}{ SMPTE Public Policy Agenda } \\
\hline \multicolumn{3}{|r|}{ Scotland } & \multicolumn{2}{|r|}{ Nova Scotia } \\
\hline Vision & \multicolumn{2}{|c|}{$\begin{array}{l}\text { The Scottish Government believes that Scotland can lead the } \\
\text { world in the development and deployment of offshore } \\
\text { renewable energy technologies }\end{array}$} & \multicolumn{2}{|c|}{$\begin{array}{l}\text { The Nova Scotia Government believes that Nova Scotia can } \\
\text { become a global leader in the development of technology and } \\
\text { systems that produce environmentally sustainable, } \\
\text { competitively priced electricity from the ocean }\end{array}$} \\
\hline \multirow[t]{4}{*}{$\begin{array}{l}\text { Key } \\
\text { Drivers }\end{array}$} & Marine planning: & $\begin{array}{l}\text { To inform the national and future regional } \\
\text { marine plans with regards to the strategic } \\
\text { siting of TCTs. }\end{array}$ & Marine planning: & $\begin{array}{l}\text { To assist with the development of a } \\
\text { comprehensive policy framework for } \\
\text { future decisions made at the project level }\end{array}$ \\
\hline & Marine licensing: & $\begin{array}{l}\text { To streamline the licensing and consenting } \\
\text { process of TCT testing and development. }\end{array}$ & Marine licensing: & $\begin{array}{l}\text { To streamline the licensing and } \\
\text { consenting process of TCT testing and } \\
\text { development }\end{array}$ \\
\hline & $\begin{array}{l}\text { Climate change } \\
\text { and Energy: }\end{array}$ & $\begin{array}{l}\text { To assist the SG in achieving GHG } \\
\text { emissions reduction targets } \\
\text { of } 42 \% \text { below } 1990 \text { levels by } 2020 \text { and } \\
80 \% \text { below } 1990 \text { levels } \\
\text { by } 2050 \text {, as stated in the Climate Change } \\
\text { (Scotland) Act } 2010 \text {. } \\
\text { Furthermore, to assist the SG in achieving } \\
\text { its commitment of providing } 30 \% \text { of its } \\
\text { energy demand from renewables by } 2020 \text {, } \\
\text { with an interim embedded target of } 100 \% \\
\text { renewably generated electricity }\end{array}$ & $\begin{array}{l}\text { GHG emissions } \\
\text { reductions: }\end{array}$ & $\begin{array}{l}\text { Contribute to federal targets of } 30 \% \text { in GH } \\
\text { emissions by } 2030 \text { over a } 2005 \text { baseline, } \\
\text { contribute to provincial targets of } 80 \% \mathrm{GH} \\
\text { emissions reductions by } 2050 \text { over a } 2009 \\
\text { and contribute to } \mathrm{G} 7 \text { commitments of a } \\
\text { carbon-free economy by } 2100\end{array}$ \\
\hline & $\begin{array}{l}\text { Transition to a } \\
\text { low carbon } \\
\text { economy: }\end{array}$ & $\begin{array}{l}\text { To exploit Scotland's tidal current } \\
\text { resource in a sustainable manner in order } \\
\text { to position Scotland as a world leader in } \\
\text { the low carbon economy transition in the } \\
\text { resulting four decades }\end{array}$ & Price stability: & $\begin{array}{l}\text { To reduce provincial reliance on coal and } \mathrm{i} \\
\text { inherent volatile prices and exchange it for } \\
\text { indigenous resources, with TCTs } \\
\text { contributing to a } 40 \% \text { renewable energy } \\
\text { generation portfolio by } 2020\end{array}$ \\
\hline \multirow{4}{*}{$\begin{array}{l}\text { Strategic } \\
\text { Aims }\end{array}$} & \multicolumn{2}{|c|}{$\begin{array}{l}\text { Maximizing the aggregate installed capacity of tidal energy in } \\
\text { Scotland }\end{array}$} & \multicolumn{2}{|c|}{$\begin{array}{l}\text { Maximizing the aggregate installed capacity of tidal energy in } \\
\text { Nova Scotia }\end{array}$} \\
\hline & \multirow{2}{*}{\multicolumn{2}{|c|}{$\begin{array}{l}\text { Facilitating enhanced economic development, investment, and } \\
\text { employment }\end{array}$}} & \multicolumn{2}{|c|}{$\begin{array}{l}\text { Reducing imported electricity to increase the wealth within the } \\
\text { province }\end{array}$} \\
\hline & & & \multicolumn{2}{|c|}{$\begin{array}{l}\text { Create a skilled labor force with industry expertise to be } \\
\text { exportable internationally }\end{array}$} \\
\hline & \multicolumn{2}{|c|}{$\begin{array}{l}\text { Minimizing adverse implication on people, other sectors, and } \\
\text { the environment }\end{array}$} & \multicolumn{2}{|c|}{$\begin{array}{l}\text { Contribute to a more environmentally, economically, and socially } \\
\text { sustainable Nova Scotia }\end{array}$} \\
\hline \multirow{3}{*}{$\begin{array}{l}\text { Competent } \\
\text { Authorities }\end{array}$} & \multirow{3}{*}{\multicolumn{2}{|c|}{ Marine Scotland }} & MSP CA & NS Department of Energy (DoE) \\
\hline & & & Ecosystem CA & $\begin{array}{l}\text { NS DoE }<2 \mathrm{MW} ; \\
\text { NS DoE \& NSE }>2 \mathrm{MW}-<50 \mathrm{MW} ; \\
\text { NS DoE, NSE, \& CEEA }>50 \mathrm{MW}\end{array}$ \\
\hline & & & Other CA & NS Department of Natural Resources \\
\hline \multirow[t]{2}{*}{$\begin{array}{l}\text { Legislative } \\
\text { Authority }\end{array}$} & \multirow{2}{*}{\multicolumn{2}{|c|}{$\begin{array}{l}\text { Marine Scotland Act 2010; } \\
\text { Marine and Coastal Access Act } 2009\end{array}$}} & $\begin{array}{l}\text { Marine } \\
\text { Development } \\
\text { Agenda }\end{array}$ & $\begin{array}{l}\text { MREA 2015; Oceans Act 1996; Crown } \\
\text { Lands Act } 2012\end{array}$ \\
\hline & & & $\begin{array}{l}\text { Ecosystem } \\
\text { Protection Agenda }\end{array}$ & $\begin{array}{l}\text { MRE Act 2015; NSEA 1995; CEA Act } \\
2012\end{array}$ \\
\hline
\end{tabular}

In order to initially identify key stakeholders for the Nova Scotia SMPTE, a list of Scottish stakeholders used in Scotland's SMPTE process was lifted from the draft plan and disseminated to the STAP. The stakeholders from the Scottish process were categorized under fishing, shipping/navigation, local government, industry, and community. A column was placed 
beside the Scottish stakeholder list with initial key stakeholders identified for the Nova Scotia context, informed by a literature review of Acadia's (2013) Community and Business Toolkit for Tidal Energy Development as a reference guideline, and send to the STAP in order to build upon. During this exercise, the STAP was asked to think about what it means to be a stakeholder in relation to tidal energy development in the Nova Scotia? Are there the geographical limitations? What are there cultural, historical, social, economic, and environmental relationships to the area? Furthermore, the STAP were encouraged to suggest alterations to the stakeholder categories listed in the Scottish SMPTE. In suggesting alterations, the STAP were asked to consider what advantages may come about the categorization of stakeholders for internal members of an overarching governance structure tasked with creating an SMPTE for the province? Is specificity or simplicity of categorization a better strategic approach? The aggregate results produced from the exercise are presented in table 5.

It is worthy to note that the "Local Government" category employed by Scotland was changed to "Government" upon suggestions proposed by the STAP, while trans-provincial and trans-national government stakeholders were included due to the adjacent suggested $12 \mathrm{~nm} \mathrm{TZ}$ marine planning boundary, as is the case for New Brunswick and Prince Edward Island, as well as identified relation to oceanographic processes, as is the case for Maine due to the Gulf of Maine's proximity to the Bay of Fundy. It is also worthy to note that the list of key stakeholders is by no means exhaustive or inclusive to those identified throughout the entirety of the SMPTE process as participation is encouraged by all for any stage of the SMPTE.

Table 5: Scottish and Nova Scotia sectoral marine plan for tidal energy stakeholder list

\begin{tabular}{|c|c|c|}
\hline \multicolumn{3}{|c|}{ List of Stakeholders for Consultation in the SMPTE Process } \\
\hline & Scotland & Nova Scotia \\
\hline Fishing & $\begin{array}{l}\text { Scottish Fishermen's Federation; National Federation } \\
\text { of Fishing } \\
\text { Organizations; Scottish Inshore Fishery Groups; } \\
\text { Local Fishing Organizations; Regional Advisory } \\
\text { Committees; Fishermen's Association Ltd (FAL); } \\
\text { Scottish Whitefish Producers' Association; Scottish } \\
\text { Pelagic Fishermen's Association; Northern Ireland } \\
\text { Fish Producers Organization; Manx Fish Producers' } \\
\text { Organization }\end{array}$ & $\begin{array}{l}\text { Bay of Fundy Inshore Fishermans Association; Fundy Fixed Gear } \\
\text { Council; Full Bay Scallop Association; Striped Bass Association; } \\
\text { Aquaculture Association of Nova Scotia; Canadian Aquaculture } \\
\text { Industry Alliance; } 1688 \text { Professional Lobster Fishermen Assocation; } \\
\text { 4Wd Gulf Tuna Association; 4Wd (Atlantic) Tuna Association; Acadia } \\
\text { First Nation; Annapolis County Clam Management Assoc; Area 18 } \\
\text { Crab Fishermen's Assoc; Area 19 Crab Fishermen's Association; Area } \\
\text { 22 Offshore Crab; Area 23 Crab Fishermen's Association; Area 24 } \\
\text { Crab Fishermen's Association; Area 29-30 Fishermen's Association; } \\
\text { Area 30 Fishermen's Association; ASPANS Affiliation of Seafood } \\
\text { Producers Association of Nova Scotia; Atlantic Canadian } \\
\text { Mobile Shrimp Association; Atlantic Elver Fishery Association; } \\
\text { Atlantic Groundfish Association; Atlantic Herring Co-op; Atlantic } \\
\text { Policy Congress of First Nations Chiefs; Atlantic Shark Association; } \\
\text { Bay of Fundy Inshore Fishermen's Association; Bay of Fundy Marine } \\
\text { Resource Centre; Big Bras D'Or Fishermen's Group; Canadian } \\
\text { Association of Prawn Producers; Clam Harvesting Area Two } \\
\text { Clammers Association; Cold Water Lobster Association; Commercial } \\
\text { Fishers Holders of Yarmouth Co. Eel Licences Assoc.; Cumberland } \\
\text { North Fisherman's Assoc.; Digby/Annapolis/Kings Sea Urchin Mgmt } \\
\text { Board; Digby County Clam Diggers Association; East Cape Breton } \\
\text { Fisherman's Association; East Cape Breton Fishers Association; } \\
\text { Eastern NS Mobile Gear Association; Eastern Shore Protective } \\
\text { Fishermans Assoc; Eastern Fishermen's Federation; ENS4X; Eskasoni } \\
\text { Fish \& Wildlife Commission; False Bay Fishermen's Association; } \\
\text { Federation of Gulf NS Groundfishermen; Fisheries Safety Association } \\
\text { of Nova Scotia; Full Bay Scallop Association; Fundy Fixed Gear } \\
\text { Council; Gabarus Fishermen's Association; Gaspereau Fishermen's } \\
\text { Association; Groundfish Enterprise Allocation Council; Glace Bay } \\
\text { Inshore Fishermen's Association; Groundfish Generalist Fishermen's } \\
\text { Association; Gulf NS Bonafide Fishermen's Association; Gulf NS } \\
\text { Fishermen's Coalition; Gulf NS Fishermen's Coalition; Gulf of NS } \\
\text { Fishermen's Coalition; Gulf NS Fleet Planning Board; Gulf NS } \\
\text { Herring Federation; Gulf NS Shellfish; Gulf NS Tuna Association; } \\
\text { Guysborough County Inshore Fishermen's Assoc; Halifax West }\end{array}$ \\
\hline
\end{tabular}




\begin{tabular}{|c|c|c|}
\hline & & 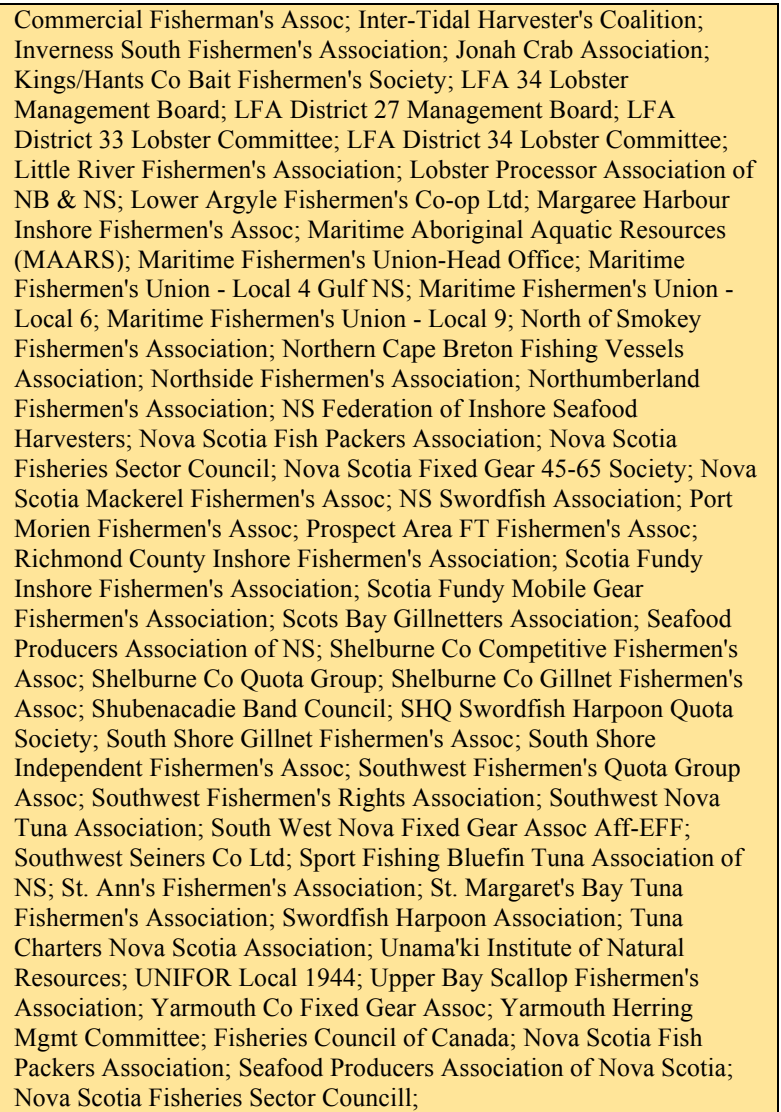 \\
\hline Shipping/Navigation & $\begin{array}{l}\text { UK Chamber of Shipping; Northern Lighthouse } \\
\text { Board; Royal Yachting Association; British Ports } \\
\text { Association; Forth Ports plc; } \\
\text { MCA; UK Major Ports; Associated British Ports; } \\
\text { Calmac; P\&O Ferries; Northlink Ferries; Pentland } \\
\text { Ferries; individual harbors } \\
\text { Natural Environment - Scottish Environment Link; } \\
\text { SNH; JNCC; RSPB; WWF; Whale and Dolphin } \\
\text { Conservation Society; SEPA; Northern Ireland } \\
\text { Environment Agency; Met Office }\end{array}$ & $\begin{array}{l}\text { Nova Scotia Boat Builders Association; Canadian Coast Guard; } \\
\text { Transport Canada; Saint John Port Authority (biggest port in the Bay } \\
\text { of Fundy), Halifax Port Authority (if this is province wide), other port } \\
\text { authorities }\end{array}$ \\
\hline Government & $\begin{array}{l}\text { CoSLA; All Scottish Local Authorities Grid - } \\
\text { Scottish and Southern Power Distribution; National } \\
\text { Grid; Scottish Power Systems Ltd National / } \\
\text { Devolved Government - DECC; MoD; Defra; Welsh } \\
\text { Assembly Government; Northern Ireland Assembly; } \\
\text { European Member States; Isle of Man }\end{array}$ & $\begin{array}{l}\text { NS Department of Energy (DoE); NS Department of Agriculture; NS } \\
\text { Department of Communities, Culture, and Heritage; Nova Scotia } \\
\text { Environment (NSE); NS Department of Fisheries and Aquaculture; NS } \\
\text { Department of Justice; NS Department of Labor and Advanced } \\
\text { Education; NS Department of Natural Resources (DNR); NS } \\
\text { Department of Intergovernmental Affairs; Municipality of Digby; } \\
\text { Department of Fisheries and Oceans Canada (DFO); Natural Resources } \\
\text { Canada; Environment Canada, New Brunswick (NB) Department of } \\
\text { Aboriginal Affairs; NB Department of Agriculture, Aquaculture, and } \\
\text { Fisheries; NB Emergency Measures Organization; NB Department of } \\
\text { Energy and Resource Development; NB Department of } \\
\text { Intergovernmental Affairs; NB Department of Justice and Public Safety; } \\
\text { NB Office of the Attorney General; NB Department of Post-Secondary } \\
\text { Education, Training, and Labor; NB Department of Tourism, Heritage, } \\
\text { and Culture; Prince Edward Island (PEI) Department of Agriculture and } \\
\text { Fisheries; PEI Department of Communities, Land, and Environment; } \\
\text { PEI Department of Economic Development and Tourism; PEI } \\
\text { Department of Education, Early Learning, and Culture; PEI Department } \\
\text { of Justice and Public Safety; PEI Department of Transportation, } \\
\text { Infrastructure, and Energy; PEI Department of Workforce and Advanced } \\
\text { Learning; Maine Department of Aquaculture, Conservation, and } \\
\text { Forestry; Maine Department of the Attorney General; Maine } \\
\text { Department of Economic and Community Development; Maine } \\
\text { Emergency Management Agency (MEMA); Maine Governor's Office of } \\
\text { Maine Department of Environmental Protection; Maine Library of } \\
\text { Geographic Information; Maine Geological Survey; Maine Historic } \\
\text { Preservation Commission; Maine Department of Inland Fisheries and }\end{array}$ \\
\hline
\end{tabular}




\begin{tabular}{|c|c|c|}
\hline & & $\begin{array}{l}\text { Wildlife (IFW); Maine Department of Resources; USA National } \\
\text { Oceanic and Atmospheric Association (NOAA) - U.S. Department of } \\
\text { Commerce; Municipality of the County of Cumberland; Cumberland } \\
\text { Energy Authority }\end{array}$ \\
\hline Industry & $\begin{array}{l}\text { Scottish Renewables; SR Wave and Tidal Developers } \\
\text { Group; SR } \\
\text { Offshore Wind Developers Group; EMEC; The } \\
\text { Crown Estate; Renewable UK; Oil \& Gas UK; } \\
\text { Aquaculture Industry (Scallop Association; } \\
\text { Association of Scottish Shellfish Growers); } \\
\text { Freshwater Fishing Industry (Assoc. of Salmon } \\
\text { Fishery Boards; Rivers and Fisheries Trusts of } \\
\text { Scotland; Salmon Net Fishermen's Association of } \\
\text { Scotland; Atlantic Salmon Trust; Scottish Salmon } \\
\text { Producers' Organization; Salmon and Trout } \\
\text { Association; British Trout Association); Highlands } \\
\text { and Islands Enterprise; Scottish Enterprise; SDI; } \\
\text { Federation of Small Businesses; CBI; Scottish } \\
\text { Chamber of Commerce; local chambers of } \\
\text { commerce; crofting organizations }\end{array}$ & $\begin{array}{l}\text { Fundy Tidal Inc. (FTI); Fundy Ocean Research Association for Energy } \\
\text { (FORCE); Marine Renewables Canada (MRC); Nova Scotia Tourism } \\
\text { Human Resource Council; Offshore Energy Research Association } \\
\text { (OERA); Cape Sharp Tidal; DP Energy; Atlantis Resources; Minas } \\
\text { Tidal; Black Rock Tidal; WWF, Ecology Action Center, Oceana, } \\
\text { CPAWS }\end{array}$ \\
\hline Community & $\begin{array}{l}\text { Local Community and Parish Councils; Local Trusts } \\
\text { and other interested parties/groups; Scottish Coastal } \\
\text { Forum, Planning Authorities Tourism / Recreation - } \\
\text { Visit Scotland; Sportscotland; RYA; Scottish Boating } \\
\text { Alliance; Kayak Associations; Scottish Canoe } \\
\text { Association; Ramblers Scotland; Surfing (Scottish } \\
\text { Surfing Federation; Orkney Surfers Association, } \\
\text { Riders of the West); Diving (Scottish Sub Aqua Club; } \\
\text { British Sub Aqua Club; PADI); Angling (Scottish } \\
\text { Sea Angling Conservation Network; Real Sea } \\
\text { Anglers; Scottish Federation of Sea Anglers) }\end{array}$ & $\begin{array}{l}\text { Mi'kmaq Conservation Group; Native Council of Nova Scotia; Acadia } \\
\text { Tidal Energy Institute (ATEI); Assembly of First Nations (AFN); } \\
\text { Native Women's Assoc. of Canada (NWAC); Inuit Tapiriit Kanatami } \\
\text { (ITK); Metis National Council (MNC); Congress of Aboriginal People } \\
\text { (CAP); Atlantic Policy Congress of First Nation Chiefs Secretariat } \\
\text { (APC); Ulnooweg Development Group (Financial/Business); Mi'kmaq } \\
\text { Grand Council; Mi'kmaq Rights Initiative (KMKNO); Confederacy of } \\
\text { Mainland Mi'kmaq (CMM); Union of Nova Scotia Indians (UNSI); } \\
\text { Mi'kmaw Kina'matnewey (Education); Nova Scotia Native Women's } \\
\text { Association; Native Council of Nova Scotia (Non-status/off-res.); } \\
\text { Mi'kmaw Native Friendship Centre (Urban); Unama'ki Institute of } \\
\text { Natural Resources; Mi'kmaq Assoc. of Cultural Studies; Mi’kmaq } \\
\text { Family \& Children's Services (Social); Mi'kmaq Legal Support } \\
\text { Network (Justice); Native Alcohol \& Drug Abuse Counselling Assoc. } \\
\text { (Addictions); Mi'kmaq Employment \& Training Secretariat } \\
\text { (Employment); Mi'kmaw Economic Benefits Office } \\
\text { (Training/Employment); Aboriginal Affairs Working Group (National: } \\
\text { FPT+NAO); Mi'kmaq-Nova Scotia-Canada Tripartite Forum; Made- } \\
\text { in-Nova Scotia Process (Negotiations); Mi'kmaq Rights Initiative }\end{array}$ \\
\hline
\end{tabular}

\subsection{Nova Scotia sectoral marine plan for tidal energy process and outputs}

\subsubsection{Phase 1 - Initial plan framework}

\subsubsection{Compilation of data}

In order to commence the scoping stage for the most suitable areas for deployment of TCTs based on the identification of spatial areas demonstrating the least environmental, ecological, social, industry, economic, and cultural constraint within established provincial waters, a list of ideal data layers to be employed was compiled. In order to develop the list of data layers, constraint layers employed in Scotland's SMPTE scoping stage were analyzed, with data layers demonstrating similarities to the Nova Scotia context lifted and compiled for the purposes of this paper. For example, SACs and SPAs apart of the European Natura 2000 biological conservation belt are not applicable to Nova Scotia, thus they were omitted, while areas of importance to marine mammals such as harbor porpoises are, and therefore were utilized for the Nova Scotia SMPTE scoping exercise. The Nova Scotia data layer list was then added to based on work completed by ATEI (2016) in their construction of the Nova Scotia Tidal Energy Atlas, which hosts a plethora of data on marine spatial usages within provincial waters. At this stage, RLG/pre-statutory consultation was employed through engagement with the STAP in order to identify possible constraint layers that may have been overlooked in the initial analysis based on the methodology detailed above. In order to facilitate this exercise, a chart was constructed which detailed all the layers used in Scotland's SMPTE scoping process, categorised 
under headings used in the Scottish process - socio-cultural, environmental, industry, commercial fishing, and non-technical restriction (Davies et al., 2012). Similar to the identification of stakeholders detailed in section 5.1.4., a column was attached directly adjacent to the listed data layers utilized in the Scottish context for the Nova Scotia process, with ideal data layers identified for Nova Scotia in the previous compilation listed under the same categories.

Table 6: Scottish and Nova Scotia ideal list of data layers

\begin{tabular}{|c|c|c|}
\hline \multicolumn{3}{|c|}{ List of Data Layers for the Scoping Process } \\
\hline & Scotland & Nova Scotia \\
\hline Socio-Cultural & $\begin{array}{l}\text { National scenic areas; Royal Yachting Association cruising } \\
\text { routes; Royal Yachting Association racing areas; Scheduled } \\
\text { Ancient } \\
\text { Monuments; Surfing beaches; World Heritage sites; Wrecks; } \\
\text { Protected wrecks; Potential for marine archaeological remains }\end{array}$ & $\begin{array}{l}\text { Provincial Parks - NS; Provincial Parks - NB; National Parks; } \\
\text { Recreational boating traffic; Yachting traffic; Ancient monuments; } \\
\text { Surfing beaches; World heritage sites; Protected shipping wrecks; } \\
\text { Potential marine archeological remains; Recreational fishing areas; } \\
\text { Cultural fishing grounds; NB Aboriginal land; NS Aboriginal land; } \\
\text { First Nation/Premiere Nation Canada; }\end{array}$ \\
\hline Environmental & $\begin{array}{l}\text { Bird reserves; Important Bird Areas; Local nature reserves; } \\
\text { Special Areas of Conservation (SACs); Special Protection Areas } \\
\text { (SPAs); Sites of Special Scientific Interest; Offshore candidate } \\
\text { SACs and SPAs; Offshore draft SACs and SPAs; Offshore } \\
\text { possible SACs and SPAs; RAMSAR sites; Possible sea haul out } \\
\text { sites; Areas of importance to basking sharks; Nursery areas for } \\
\text { commercial fish species; Spawning areas for commercial fish } \\
\text { species; Areas of search for potential Marine Protected areas } \\
\text { (MPAs); Areas of search for seabird Aggregations; Areas of } \\
\text { importance to breeding sea birds; Areas of importance to sea } \\
\text { birds in winter; Areas of importance to marine mammals }\end{array}$ & $\begin{array}{l}\text { National Wildlife Areas; Important Bird Areas; Migratory Bird } \\
\text { Sanctuaries; Special Protection Areas; Areas of importance to } \\
\text { waterfowl; Areas of importance to shorebirds; Areas of importance } \\
\text { to Atlantic salmon; Areas of importance to American eel; Areas of } \\
\text { importance to Atlantic sturgeon; Areas of importance to lobster; } \\
\text { Areas of importance to yellow breadcrumb sponge; Areas of } \\
\text { importance to bloodstar; Areas of importance to northern red } \\
\text { anemone; ecologically and biologically significant areas; Heat map } \\
\text { of Atlantic White-sided dolphin sightings; heat map of fin whale } \\
\text { sightings; heat map of grey seal sightings; heat map of harbor } \\
\text { porpoise sightings; heat map of harbor seal sightings; heat map of } \\
\text { humpback whale sightings; heat map of north Atlantic right whale } \\
\text { sightings; ocean tracking network, animals - Canada; right whale } \\
\text { critical habitat - NS; significant habitat - NS; Striped bass } \\
\text { movement - Minas Passage; fish hatcheries; land-based } \\
\text { aquaculture; lobster fishing areas; marine finfish aquaculture; } \\
\text { marine finfish lease boundaries; marine shellfish aquaculture; } \\
\text { marine shellfish lease boundaries; U-Fish sites; bathymetry; } \\
\text { sediments; }\end{array}$ \\
\hline Industry & $\begin{array}{l}\text { Offshore cables in UK waters (not active); Pipelines in UK } \\
\text { waters (not active); Potential gas and CO2 storage sites; Carbon } \\
\text { capture and gas storage infrastructure; Current Licensed Areas } \\
\text { for } \\
\text { Hydrocarbons; Closed waste disposal sites; Military Practice } \\
\text { and } \\
\text { Exercise Areas; Shipping density; Commercial fisheries } \\
\text { Landings; Dredging }\end{array}$ & $\begin{array}{l}\text { Offshore cables in Provincial waters (not active); Pipelines in } \\
\text { Provincial waters (not active); Potential gas and CO2 storage sites; } \\
\text { Carbon capture and gas storage infrastructure; Current Licensed } \\
\text { Areas for Hydrocarbons; Closed waste disposal sites ; Military } \\
\text { Practice and Exercise Areas; Shipping density; Commercial } \\
\text { fisheries landings; Dredging areas }\end{array}$ \\
\hline $\begin{array}{l}\text { Commercial } \\
\text { Fishing }\end{array}$ & $\begin{array}{l}\text { Commercial fisheries landings from mobile gear in inshore } \\
\text { waters; Commercial fisheries landings from static gear in } \\
\text { inshore waters; Commercial landings from fishing vessels }>15 \mathrm{~m} \\
\text { using mobile gears; Commercial landings from fishing vessels } \\
>15 \mathrm{~m} \text { using static } \\
\text { gears }\end{array}$ & $\begin{array}{l}\text { Commercial fisheries landings from mobile gear in inshore waters; } \\
\text { Commercial fisheries landings from static gear in inshore waters; } \\
\text { Commercial landings from fishing vessels using mobile gears; } \\
\text { Commercial landings from fishing vessels using static gears }\end{array}$ \\
\hline Non-Technical & $\begin{array}{l}\text { All Offshore Cable inside UK Waters; All Pipeline in UK Waters; } \\
\text { Anchorage Areas; Aquaculture Leases - Current; Aquaculture } \\
\text { Leases - Pending; Waste disposal sites (open); IMO Routeing - } \\
\text { excluding ABTAs; Munitions Dumps; Offshore Shipping Zones; } \\
\text { Operational Anemometers in UK Waters; Protected Wreck } \\
\text { Exclusion Buffers; UK offshore wind activity; Shipping Density - } \\
\text { Exclusion Areas; Tidal Leases - Live; UK Deal oil and gas Safety } \\
\text { Zones; UK Deal oil and gas Surface features; UK Deal oil and } \\
\text { gas Subsurface features; UKCS Exclusion Buffer - 500 m; Wave } \\
\text { Leases - Live; UK Detailed Coastline - not including Isle of Man } \\
\text { (Polygon) }\end{array}$ & $\begin{array}{l}\text { All Offshore Cable inside Provincial Waters; All Pipeline in } \\
\text { Provincial Waters; Anchorage Areas; Aquaculture Leases - } \\
\text { Current; Aquaculture Leases - Pending; Waste disposal sites; } \\
\text { Heavy shipping navigation areas; Munitions Dumps; Offshore } \\
\text { Shipping Zones; Operational Anemometers in Provincial Waters; } \\
\text { Tidal Leases - Live; Tidal Leases - Planned; Provincial /federal oil } \\
\text { and gas Safety Zones; Provincial /federal oil and gas Surface } \\
\text { features; Provincial /federal oil and gas Subsurface features; } \\
\text { Provincial Detailed Coastline; lighthouses; wharves and slipways; } \\
\text { ports; Existing Crown lease areas; proposed wind energy } \\
\text { COMFITs; }\end{array}$ \\
\hline
\end{tabular}

This chart was then disseminated to the STAP, where they were asked to add to the list by thinking about what other spatial uses do Nova Scotia waters host? What marine 
environmental species or processes may negatively interact with deployed TCTs and associated infrastructure? What industries may be negatively affected via the deployment of TCTs and associated infrastructure? What spatial areas may be viewed in high esteem from communities both within and outside management boundaries? What is the relationship between marine and terrestrial usages that may impede the deployment of TCTs and associated infrastructure? The STAP were then encouraged to suggest alterations to the data layer constraint categories listed in the Scottish SMPTE.

In suggesting alterations, the STAP was asked to consider what advantages may come about the categorization of constraints for internal members of an overarching governance structure tasked with creating an SMPTE for the province? Is specificity or simplicity of categorization a better strategic approach? These questions were asked while reminding the STAP that maps were to be produced under the different genres of categorization suggested as an intermediate output for the scoping process to help better visualize the different overall spatial usages of Nova Scotia provincial waters, eventually producing an aggregated map of all combined categories as a final output of the IPF. The aggregate results produced from the exercise are presented in table 6. At this stage in the process, it is imperative to note that, unfortunately, due to a dismal $13.3 \%$ response rate for the first two out of ideally eight RLG/stakeholder consultation exercises formally agreed upon by the STAP, and the miniscule alterations in which such a low response rate contributed to informing the SMPTE process, it was determined that the STAP had informally withdrawn from the SMPTE process, and therefore no further exercises were conducted from here on out.

\subsubsection{Exclusion, constraint, and opportunity parameters}

In order to begin the primary analysis to identify exclusion areas where TCT implementation is not plausible, a list of parameters was established in relation to tidal current resource, technological components of TCTs, and bathymetry. Karsten's (2012) resource assessment of the province demonstrates that $7.2 \mathrm{GW}$ of power resides within the Minas Channel area, including the Minas Passage. Of this $7.2 \mathrm{GW}$, a 5\% reduction of tidal flow was suggested as a sustainable limit given that the Minas Channel forms one interconnected system with the Minas Basin, therefore, any effects concerning the alteration of natural hydrology and sediment transport due to excessive tidal flow reduction in the Minas Channel will impact the greater ecosystem of the Minas Basin. In light of such dynamics, the 5\% of extractable energy suggested equates to $2 \mathrm{GW}, 1.6 \mathrm{GW}$ of which reside directly in the Minas Passage. The same principal of potentially adverse far-field effects due to excessive energy extraction is applicable to the Digby Neck and its interrelation to Digby Gut/Annapolis Basin, therefore, the acceptable 5\% flow reduction equates to $67 \mathrm{MW}$ of the total $180 \mathrm{MW}$ of available power.

When analyzing Petit Passage and Grand Passage, their geographical location between two large bodies of water suggests that the rate of flow through the passages have little relation to the greater tidal dynamics of the region, and therefore a $10 \%$ reduction in flow was estimated to be sustainable, allowing 19MW of the available 33MW to be extracted for Petit Passage, and 8.9MW of the available 16MW to be extracted for Grand Passage (Karsten, 2012). With regards to the two potential tidal energy sites identified in Cape Breton, the Great Bras d'Or Channel and the Barra Straight are heavily intertwined with coastal regional ecology via complex oceanic processes, and therefore a 5\% reduction in tidal flow was estimated to be sustainable, allowing $1.1 \mathrm{MW}$ of the available $4.6 \mathrm{MW}$ to be extracted for the Great Bras d'Or Channel, and $0.6 \mathrm{MW}$ of the available $2.2 \mathrm{MW}$ to be extracted for Barra Straight. 
While such power density figures act as a good indicator to identify potential areas suitable for TCT deployment, power densities do not demonstrate a direct linear correlation to current speeds. TCT designs operate on a set of parameters, with current speed being the most important. The Cape Breton 2012 background SEA report devised a chart of the technical operating parameters of TCTs, categorized as small-scale and large-scale (AECOM, 2012). Amongst the parameters, it was suggested that mean spring peak velocity (Vmsp) must measure in at $>1 \mathrm{~m} / \mathrm{s}$ for small-scale TCTs and $>1.2 \mathrm{~m} / \mathrm{s}$ for large-scale TCTs to be economically viable. However, the slow pace of development in accordance to public expectations from 2008 have led to frustrations amongst community stakeholders (AECOM, 2014), and therefore, it is suggested by this paper that the province utilize parameters of current industry leading TCTs that are ready for deployment, addressing TCT devices that can operate at lower current speeds as the technology develops through future iterations of the SMPTE. With this in mind, Verdant Power's (2008) Kinetic Hydropower System (KHPS) devises deployed in New York's East River offer the parameters of an economically viable array of small-scale TCTs. The cut-in speed of the $35 \mathrm{~kW}, 5 \mathrm{~m}$ rotor diameter KHPS TCTs is $1 \mathrm{~m} / \mathrm{s}$, producing electricity between $1-2.1 \mathrm{~m} / \mathrm{s}$. In light of this, and in conformity to the parameters employed by Scotland (Davies et al., 2012), a Vmsp of $1.5 \mathrm{~m} / \mathrm{s}$ will be the minimum speed required to avoid exclusion in the weighted overlay scoping model.

Table 7: Nova Scotia tidal current energy resources

\begin{tabular}{|c|c|c|c|c|c|}
\hline \multicolumn{6}{|c|}{ Nova Scotia Tidal Current Resource } \\
\hline Area & Site & $\begin{array}{l}\text { Maximum } \\
\text { Available } \\
\text { Resource }\end{array}$ & $\begin{array}{l}\text { Sustainably } \\
\text { Extractable } \\
\text { Resource }\end{array}$ & $\begin{array}{l}\text { Acceptable } \\
\text { Reduction in } \\
\text { Tidal Flow (\%) }\end{array}$ & $\begin{array}{l}\text { Current Speed } \\
(\mathrm{m} / \mathrm{s})\end{array}$ \\
\hline \multirow{3}{*}{ Minas Basin } & & 7200 & 2000 & & \\
\hline & Minas Passage & 5800 & 1600 & 5 & $2.5 \mathrm{Vmsp}$ \\
\hline & $\begin{array}{l}\text { Greater Minas } \\
\text { Basin }\end{array}$ & 1400 & 400 & 5 & $1-1.5 \mathrm{Vmsp}$ \\
\hline \multirow[t]{4}{*}{ Digby Neck } & & 229 & 94.9 & & \\
\hline & Digby Gut & 180 & 67 & 5 & $1 \mathrm{Vmsp}$ \\
\hline & Petit Passage & 33 & 19 & 10 & $2-2.5 \mathrm{Vmsp}$ \\
\hline & Grand Passage & 16 & 8.9 & 10 & $1.5-2 \mathrm{Vmsp}$ \\
\hline \multirow[t]{3}{*}{$\begin{array}{l}\text { Cape Breton } \\
\text { Region }\end{array}$} & & 6.8 & 1.7 & & \\
\hline & $\begin{array}{l}\text { Great Bras d'Or } \\
\text { Channel }\end{array}$ & 4.6 & 1.1 & 5 & $\begin{array}{l}\text { 1(-2?; current } \\
\text { measurement) }\end{array}$ \\
\hline & Barra Straight & 2.2 & 0.6 & 5 & $\begin{array}{l}1 \text { (current } \\
\text { measurement) }\end{array}$ \\
\hline Total & & 7435.8 & 2096.6 & & \\
\hline
\end{tabular}

Karsten's (2012) resource assessment report calculated Vmsps using statistical analysis and modelling for the two potential tidal current areas and six sites encompassed within those areas for the Bay of Fundy. For the Minas Channel area, the Minas Passage site demonstrated a Vmsp of $2.5 \mathrm{~m} / \mathrm{s}$, with the greater Minas Channel site demonstrating a Vmsp of $1.5 \mathrm{~m} / \mathrm{s}$. For the Digby Neck area, the Digby Gut site demonstrated a Vmsp of $1 \mathrm{~m} / \mathrm{s}$, with Petit Passage demonstrating a Vmsp of $2.25 \mathrm{~m} / \mathrm{s}$, and Grand Passage demonstrating a Vmsp of $1.75 \mathrm{~m} / \mathrm{s}$. The Cape Breton Region is comparatively a much less researched tidal energy site, and therefore, building off of the baseline information and resources available, power extraction theory was 
employed to determine current speeds as opposed to numerical modelling. The Great Bras d'Or Channel routinely exceeds $1 \mathrm{~m} / \mathrm{s}$, with little evidence of speeds exceeding $2 \mathrm{~m} / \mathrm{s}$, while the current speeds in Barra Straight rarely exceed $1 \mathrm{~m} / \mathrm{s}$. Given the Vmsps and current speeds provided above, it is clear that Digby Gut, Great Bras d'Or Channel, and Barra Straight will rank as exclusion areas in the weighted overlay model as Vsmps fall short of the $1.5 \mathrm{~m} / \mathrm{s}$ inclusionary cutoff.

Although current speeds in the Great Bras d'Or Channel may measure between $1-2 \mathrm{~m} / \mathrm{s}$, which may very loosely suggest a possible Vmsp of $1.5 \mathrm{~m} / \mathrm{s}$, greater research is required in order to provide financial security and good relations to developers and communities alike who may wish to invest in feed-in tariffs (FITs) or community feed-in tariffs (COMFITs). If the CA accepts payment towards a FIT or COMFIT without investigating the economic viability of a tidal energy site, as is the case for the MRE Act 2015 in relation to the resource exclusion sites listed above, a lack of confidence in the regulatory authority will build amongst community stakeholders and investors alike (Bronfman et al., 2012), thereby slowing down or halting the deployment of TCTs in Nova Scotia waters all together.

Due to the absence of tidal current speed spatial data layers to input into the spatial modelling tool for the initial scoping exercise of the IPF, correlations between a power density layer obtained from Karsten's Finite Volume Community Ocean Model (FVCOM) created for the Nova Scotia Tidal Energy Atlas, Tarbotton and Larson's (2006) Canada Ocean Energy Atlas, O'Rourke, Boyle, and Reynolds' (2010b) Tidal Energy Update 2009, and current speeds proposed in Karsten's (2012) Tidal Energy Resource Assessment Map for Nova Scotia were determined and modelled accordingly. Following the creation data layer accounting for current speed, Digby Gut still remained a viable area given the high power densities. However, due to the sites Vmsp assessed by Karsten as lower than $1.5 \mathrm{~m} / \mathrm{s}$, the area was excluded from the data set using a $0.45 / 1$ suitability ranking cut off, thereby establishing the suitability cut off gradient for the remainder of data layers employed in the spatial weighted overlay analysis. Ideally, the availability of tidal current data would have been attributed suitability ranking on a gradient with an increase in current speed.

Another two technical parameters to take into consideration are depth of deployment and distance from shore. Taking into consideration two different TCT technologies from different manufacturers, deployed in different environments, and developed at different scales, the $35 \mathrm{~kW}$, $5 \mathrm{~m}$ rotor diameter, small-scale KHPS TCT and the $1 \mathrm{MW}, 18 \mathrm{~m}$ rotor diameter, large-scale Andritz Hydro Hammerfest (AHH) HS1000 TCT being deployed in the MeyGen (2016) Project in Scotland's PFOW, both designs demonstrate a support structure which measures $60 \%$ in length from the base to the lowest point of a rotor blade. Therefore, the KHPS design stands $8 \mathrm{~m}$ high, and the HS1000 stands 28.5m high. These parameters justify AECOMs (2014) parameters of average depth of deployment for small-scale TCTs being between 10-30m, but do not necessarily support the $20-80 \mathrm{~m}$ average deployment depths for large-scale TCTs, as only one out of the eight TCT designs available for commercial development can be deployed in water depths less than 25m (Zhou et al., 2014). Therefore, this paper will utilize a $30-80 \mathrm{~m}$ depth of deployment for large-scale TCTs. AECOMs (2014) maximum distance of TCT deployment from the coast based on distance of AC export cables of $5 \mathrm{~km}$ for small-scale TCTs and $100 \mathrm{~km}$ for large-scale TCTs will be utilized for this paper. 
Table 8: Primary suitability parameters

\begin{tabular}{|l|l|l|}
\hline \multicolumn{2}{|c|}{ Primary Suitability Parameters } \\
\hline $\begin{array}{l}\text { Current Speed } \\
(\mathbf{m} / \mathbf{s})\end{array}$ & Depth & Maximum Distance from Shore $\mathbf{( k m / n m )}$ \\
\hline$>=1.5 \mathrm{Vmsp}$ & Small - scale $=10-30 \mathrm{~m}$ & $5 / 2.7$ \\
\cline { 2 - 3 } & Large-scale $=30=80 \mathrm{~m}$ & $100 / 54$ \\
\hline
\end{tabular}

The initial primary suitability exercise demonstrated that no small-scale TCT development could occur based on the methodology employed as areas demonstrating depths between $10-30 \mathrm{~m}$ did not host economically viable tidal current speeds of $=>1.5 \mathrm{~m} / \mathrm{s}$. The resulting analysis can be visualized in figure 4 . Following the results of the primary suitability modeling exercise, a set of parameters were put forth to determine whether large-scale TCT arrays could be deployed in shipping areas without causing spatial conflicts that would either result in a high constraint weightings being placed upon the resource area within the initial scoping stage, and/or demonstrating full exclusion from development in conformity to rights of way in favor of shipping lanes legislated under the NWPA 1985.

The Scottish SMPTE process attributed a weighting of constraint to shipping density areas of 800 out of a possible 1,000 scoring within the industry restriction model, while allocating offshore shipping zones and heavy shipping density areas as non-technical exclusion layers. However, these scoring were attributed in the absence of any published quantifiable methodology. For purposes of determining shipping interaction with potential tidal energy suitability areas, this paper has defined parameters based on the specs of leading commercially viable large-scale TCT designs in conjunction with best practices devised for safety clearance distances between TCTs and vessel traffic put forth in the UK.

As demonstrated in the current methodology utilized in the primary suitability parameters, large-scale TCTs can be deployed between 30-80m deep. However, the largest commercially viable TCT, the Atlantis Resources Ltd. (2015) AR1500 TCT model, has an 18m diameter rotor (in unison with the AHH HS1000), with a $60 \%$ seabed clearance from the base of its support structure to the bottom tip of the rotor diameter, thereby standing at $28.8 \mathrm{~m}$ high, advocating for a suggested operating clearance of 8 additional meters from LAT (MeyGen, 2016), all together requiring $36.8 \mathrm{~m}$ of the vertical water column. The UK government released a policy paper aimed towards providing guidance to TCT developers in assessing minimum water depth required for safe under keel clearance (UKC) of overhead operating vessels (NOREL, 2014). The paper suggested that a minimum vertical distance above a TCT (M) be established, and a charted vertical depth (CVD) consisting of M, UKC, and a safe vessel clearance depth (Dc) be determined in order to assess the total depth of TCT deployment required to allow for multiple-use zoning compatibility (MuZC) of vessel traffic and TCT deployment. The M value has already been established as $8 \mathrm{~m}$, and therefore the largest TCT available for commercial deployment has a maximum devise design height $(\mathrm{Dh})$ of $36.8 \mathrm{~m}$, given the maximum rotor diameter (Rd), devise seabed clearance (DSC), and $\mathrm{M}$, as expressed in equation (EQ) 1 . The Saint John, New Brunswick Harbor Master has confirmed, for the purposes of this paper, that the largest tanker vessels operating in the Bay of Fundy can have a draught of up to $21 \mathrm{~m}$, although this is a very infrequent occurrence, and therefore will be utilized as the full Dc inclusive of dynamic draught (Dd) and 30\% safety clearance, rather than just draught (Ds). 
Figure 4: Primary suitability parameter spatial modeling results

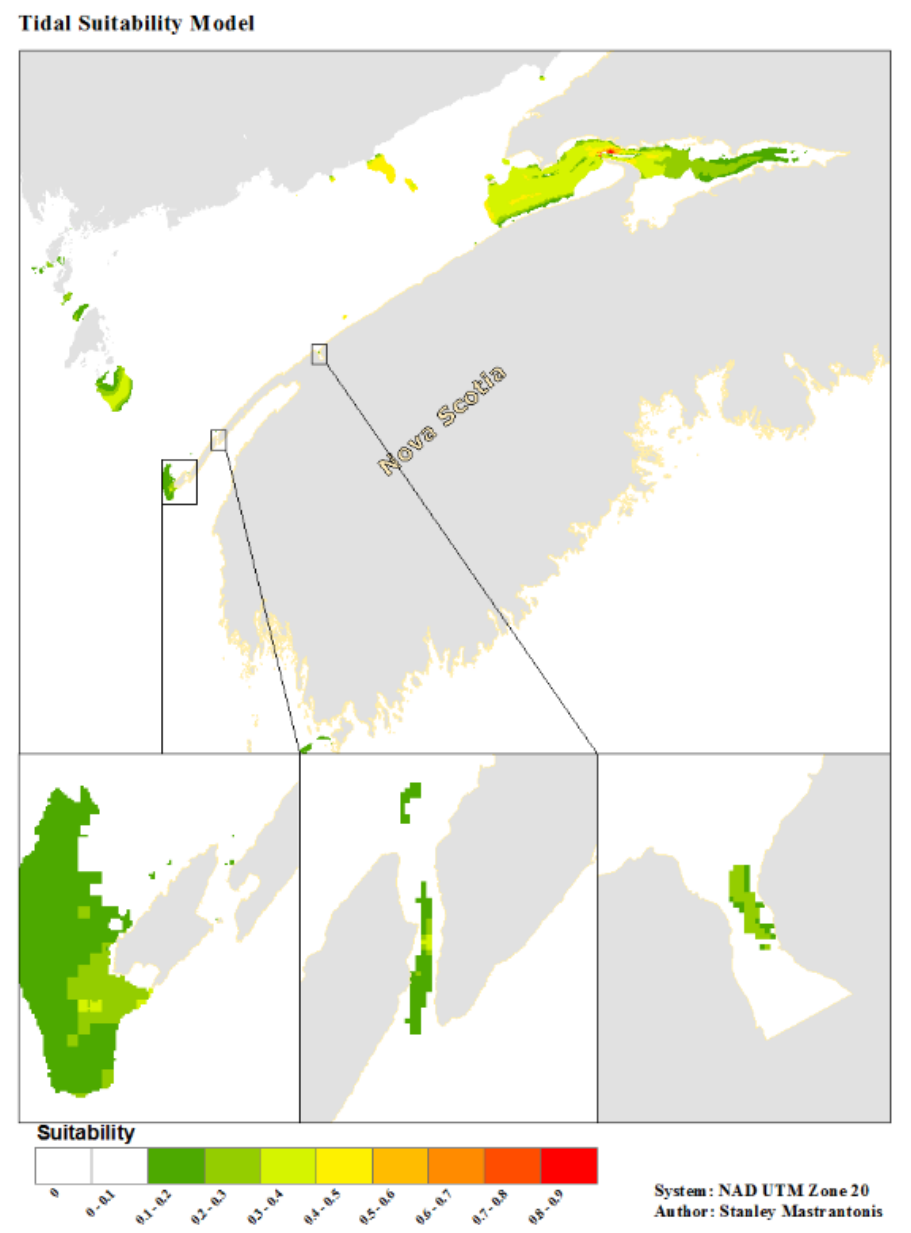

Table 9: Tidal current turbine shipping clearance

\begin{tabular}{|c|c|c|c|c|c|c|c|c|c|c|}
\hline \multicolumn{11}{|c|}{ Shipping Clearance Parameters } \\
\hline \multirow{4}{*}{$\begin{array}{l}\text { TC' } \\
\text { Dh }\end{array}$} & Vertic & $10 \mathrm{Occu}$ & ation & \multicolumn{4}{|c|}{ Vessel Safety Clearance } & \multicolumn{2}{|c|}{ Zoning Compatibility Value } & \multirow{4}{*}{$\begin{array}{l}\text { Weighting } \\
\text { Exclusion }\end{array}$} \\
\hline & \multirow{3}{*}{36.8} & $\mathrm{Rd}$ & 18 & & & & & \multirow[b]{5}{*}{ MuZC } & \multirow[b]{5}{*}{65.8} & \\
\hline & & $\mathrm{DSC}$ & 10.8 & & & & & & & \\
\hline & & $\mathrm{M}$ & 8 & & & \multirow[t]{3}{*}{ CVD } & \multirow[t]{3}{*}{37} & & & \\
\hline & & & & $\mathrm{UKC}$ & 8 & & & & & \\
\hline & & & & Dc & 21 & & & & & 400 \\
\hline
\end{tabular}

The one missing factor to the equation suggested by the UK UKC policy paper is a standard UKC measurement. However, no standard UKC measurements are in place in Nova Scotia, while extreme technology and vessel sizes have been employed, and therefore this paper will attribute a calculation of Mx2 + Dc to account for standard UKC in the total CVD as expressed in EQ2. When determining the CVD in conjunction with the Dh value, and subtracting $\mathrm{M}$ from the aggregate value, a measurement of $65.8 \mathrm{~m}$ of bathymetry would suggest a safe clearance to allow for MuZC between fully submerged TCT deployment and overhead vessel 
traffic as expressed in EQ3. In summation, a large-scale TCT deployed in heavy shipping areas $30-<65.8 \mathrm{~m}$ will be excluded from development while a TCTs operating in $=>65.8 \mathrm{~m}$ will be attributed a constraint weighting of half of the Scottish ranking, equaling 400, reducing on a normalized gradient as depth increases.

$$
\begin{gathered}
\mathrm{EQ} 1: \mathrm{Dh}=\mathrm{Rd}+60 \%+\mathrm{M} \\
\mathrm{EQ} 2: \mathrm{CVD}=\mathrm{Dc}+\mathrm{Mx} 2 \\
\mathrm{EQ} 3: \mathrm{MuZC}=\mathrm{Dh}+\mathrm{CVD}-\mathrm{M}
\end{gathered}
$$

\begin{tabular}{|c|c|c|}
\hline \multicolumn{3}{|c|}{ Refined List of Data Layers Identified in the IFP } \\
\hline \multirow[b]{2}{*}{ Socio-Cultural } & Scotland & Nova Scotia \\
\hline & $\begin{array}{l}\text { National scenic areas; Royal Yachting Association } \\
\text { cruising routes; Royal Yachting Association racing } \\
\text { areas; Royal Yachting Association sailing areas; } \\
\text { Scheduled Ancient Monuments; Surfing beaches; World } \\
\text { Heritage sites; Wrecks; Protected wrecks; Potential for } \\
\text { marine archaeological remains }\end{array}$ & $\begin{array}{l}\text { Provincial Parks - NS; Provincial Parks - NB; National Parks; } \\
\text { Recreational boating traffic; Yachting traffic; Legacy Sites; } \\
\text { Recreational Beaches; World heritage sites; Shipping wrecks; } \\
\text { Recreational fishing areas; Cultural fishing grounds; NB } \\
\text { Aboriginal land; NS Aboriginal land; First Nation/Premiere } \\
\text { Nation Canada; }\end{array}$ \\
\hline Environmental & $\begin{array}{l}\text { Bird reserves; Important Bird Areas; Local nature } \\
\text { reserves; Special Areas of Conservation (SACs); } \\
\text { Special Protection Areas (SPAs); Sites of Special } \\
\text { Scientific Interest; Offshore candidate SACs and SPAs; } \\
\text { Offshore draft SACs and SPAs; Offshore possible SACs } \\
\text { and SPAs; RAMSAR sites; Possible sea haul out sites; } \\
\text { Areas of importance to basking sharks; Nursery areas } \\
\text { for commercial fish species; Spawning areas for } \\
\text { commercial fish species; Areas of search for potential } \\
\text { Marine Protected areas (MPAs); Areas of search for } \\
\text { seabird Aggregations; Areas of importance to breeding } \\
\text { sea birds; Areas of importance to sea birds in winter; } \\
\text { Areas of importance to marine mammals }\end{array}$ & $\begin{array}{l}\text { National Bird Sanctuaries; Important Bird Areas; Special } \\
\text { Protection Areas; Areas of importance to sea birds; Areas of } \\
\text { importance to waterfowl; Areas of importance to shorebirds; } \\
\text { Areas of importance to Atlantic salmon; Areas of importance } \\
\text { to American eel; Areas of importance to Atlantic sturgeon; } \\
\text { Areas of importance to lobster; Areas of importance to yellow } \\
\text { breadcrumb sponge; Areas of importance to bloodstar; Areas } \\
\text { of importance to northern red anemone; ecologically and } \\
\text { biologically significant areas; Atlantic White-sided dolphin } \\
\text { sightings; whale sightings; grey seal sightings; harbor } \\
\text { porpoise sightings; harbor seal sightings; humpback whale } \\
\text { sightings; north Atlantic right whale sightings; ocean tracking } \\
\text { network, animals - Canada; right whale critical habitat - NS; } \\
\text { significant habitat - NS; Striped bass movement - Minas } \\
\text { Passage; fish hatcheries; sediments; RAMSAR sites; Migratory } \\
\text { Bird Sanctuaries; National Wildlife Areas; }\end{array}$ \\
\hline Industry & $\begin{array}{l}\text { Offshore cables in UK waters (not active); Pipelines in } \\
\text { UK waters (not active); Potential gas and CO2 storage } \\
\text { sites; Carbon capture and gas storage infrastructure; } \\
\text { Current Licensed Areas for } \\
\text { Hydrocarbons; Closed waste disposal sites; Military } \\
\text { Practice and } \\
\text { Exercise Areas; Shipping density; Commercial fisheries } \\
\text { Landings; Dredging }\end{array}$ & $\begin{array}{l}\text { Potential gas and CO2 storage sites; Carbon capture and gas } \\
\text { storage infrastructure; Current Licensed Areas for } \\
\text { Hydrocarbons; Closed waste disposal sites ; Military Practice } \\
\text { and Exercise Areas; Shipping density ; Commercial fisheries } \\
\text { landings; Dredging areas; }\end{array}$ \\
\hline Commercial Fishing & $\begin{array}{l}\text { Commercial fisheries landings from mobile gear in } \\
\text { inshore waters; Commercial fisheries landings from } \\
\text { static gear in inshore waters; Commercial landings from } \\
\text { fishing vessels }>15 \mathrm{~m} \text { using mobile gears; Commercial } \\
\text { landings from fishing vessels }>15 \mathrm{~m} \text { using static } \\
\text { Gears }\end{array}$ & $\begin{array}{l}\text { Commercial fisheries Landings (entire fleet, all gears); U-Fish } \\
\text { sites; lobster fishing areas; }\end{array}$ \\
\hline $\begin{array}{l}\text { Non-Technical } \\
\text { Exclusion }\end{array}$ & $\begin{array}{l}\text { All Offshore Cable inside UK Waters; All Pipeline in UK } \\
\text { Anchorage Areas; Aquaculture Leases - Current; Aquacul } \\
\text { Leases - Pending; Waste disposal sites (open); IMO Route } \\
\text { excluding ABTAs; Munitions Dumps; Offshore Shipping } \\
\text { Operational Anemometers in UK Waters; Protected Wrecl } \\
\text { Exclusion Buffers; UK offshore wind activity; Shipping D } \\
\text { Exclusion Areas; Tidal Leases - Live; UK Deal oil and ga } \\
\text { Zones; UK Deal oil and gas Surface features; UK Deal oil } \\
\text { Subsurface features; UKCS Exclusion Buffer - 500 m; Wa } \\
\text { - Live; UK Detailed Coastline - not including Isle of Man } \\
\text { (Polygon) }\end{array}$ & $\begin{array}{l}\text { All Offshore Cable inside Provincial Waters; All Pipeline in } \\
\text { Provincial Waters; Small craft harbors; Aquaculture Leases; } \\
\text { Waste disposal sites; Heavy shipping navigation areas; } \\
\text { Explosive testing sites; Offshore Shipping Zones; Operational } \\
\text { Anemometers in Provincial Waters; Tidal Leases parcels; Oil } \\
\text { and gas offshore wells, All oil and gas development sites and } \\
\text { exploratory areas; Provincial Detailed Coastline; Tidal } \\
\text { Resource; bathymetry; Wind turbines; Existing Crown lease } \\
\text { areas; marine shellfish aquaculture; marine finfish aquaculture; } \\
\text { land-based aquaculture; marine finfish boundaries; marine } \\
\text { shellfish lboundaries; }\end{array}$ \\
\hline Opportunity Layers & & lighthouses; wharves and slipways; ports; electricity grid; \\
\hline
\end{tabular}

Table 10: List of data layers refined 
A final primary suitability parameter that should ideally be implemented into the initial scoping exercise is sediment type and slope. Optimal TCT deployment requires a hard and flat bedrock seabed surface both for device anchoring and electricity cables (AECOM, 2014). In response to such parameters, the slope of the seabed was modelled, however, while sediment data was available, it was largely limited to immediate coastal regions of Nova Scotia, and therefore it was determined that attributing a weighting to the data layers would represent a bias to the overall established provincial marine planning boundaries, which ultimately lead to the exclusion of such data layers in the weighted overlay model. Ideally, suitability ranking on a gradient dependent on the type of substrate present would have been attributed, while sediment and slope data would have been comprised into one layer to account for the overall morphology of the seabed. Future work would require either comprehensive grab samples or remote sensing which would allow for the desired morphology layer. The final refined aggregate data for each restriction, exclusion, or opportunity model that were either listed as repeating in different categories in the Scottish context or not applicable have been altered as such and redisplayed, and desired data layers that could not be obtained listed in red text.

In unison with the Scottish SMPTE scoping exercise, constraint weightings were attributed to each layer based on the level of constraint that such activities and process are perceived to have. Ideally, the delegation of weightings would be a product of internal government consultation, as was the case in the Scottish context (Marine Scotland, 2013a). This methodology could further be informed by quantifying ecosystem services in conjunction with a magnitude matrix of cumulative interactions. Although, public input directly into the allocation of weightings to data layers should be avoided due to the potential for industry and sector bias. Regardless, due to current political sensitivities in relation to TCT deployment in the province, it was determined that Scottish weighting criteria would be employed for this exercise, with similar and interrelated features receiving the same weighting of constraint for the Nova Scotia SMPTE. These weightings are detailed in table 10.

Given that the weighted overlay model utilized for this paper employs a suitability gradient approach (0-99\%), rather than a simple overlay analysis as utilized in the Scottish exercise which relied primarily on GIS RASTER layer calculations, thereby limiting numerical modelling capabilities, the Nova Scotia SMPTE analysis can quantitatively justify the determination of spatial suitability of eventual POAs. Based on this quantitative methodology, relative percentile rankings have been deciphered for every data layer relative to each separate model. This makes the spatial analysis even more unique given that it is the first time such methodology has been employed with regards to the strategic siting of TCTs within a plan. Furthermore, due to the informal withdrawal of the STAP, the identification of further constraints as well as opportunities (e.g. the data proximity to grid) was not plausible through RLG. Therefore, a new model was devised from the Scottish model where opportunities received positive weightings. These opportunity data layers and associated weightings are also presented in table 10. It is worthy to note however, that technological modelling systems should be used as decision support tools only and can not replace governance consultation (Stelzenmüller et al., 2013), as decisions being made for people and the places in which they live should be made by people with relations to that area. 
Table 11: Weightings of data layers for the initial plan framework in Nova Scotia

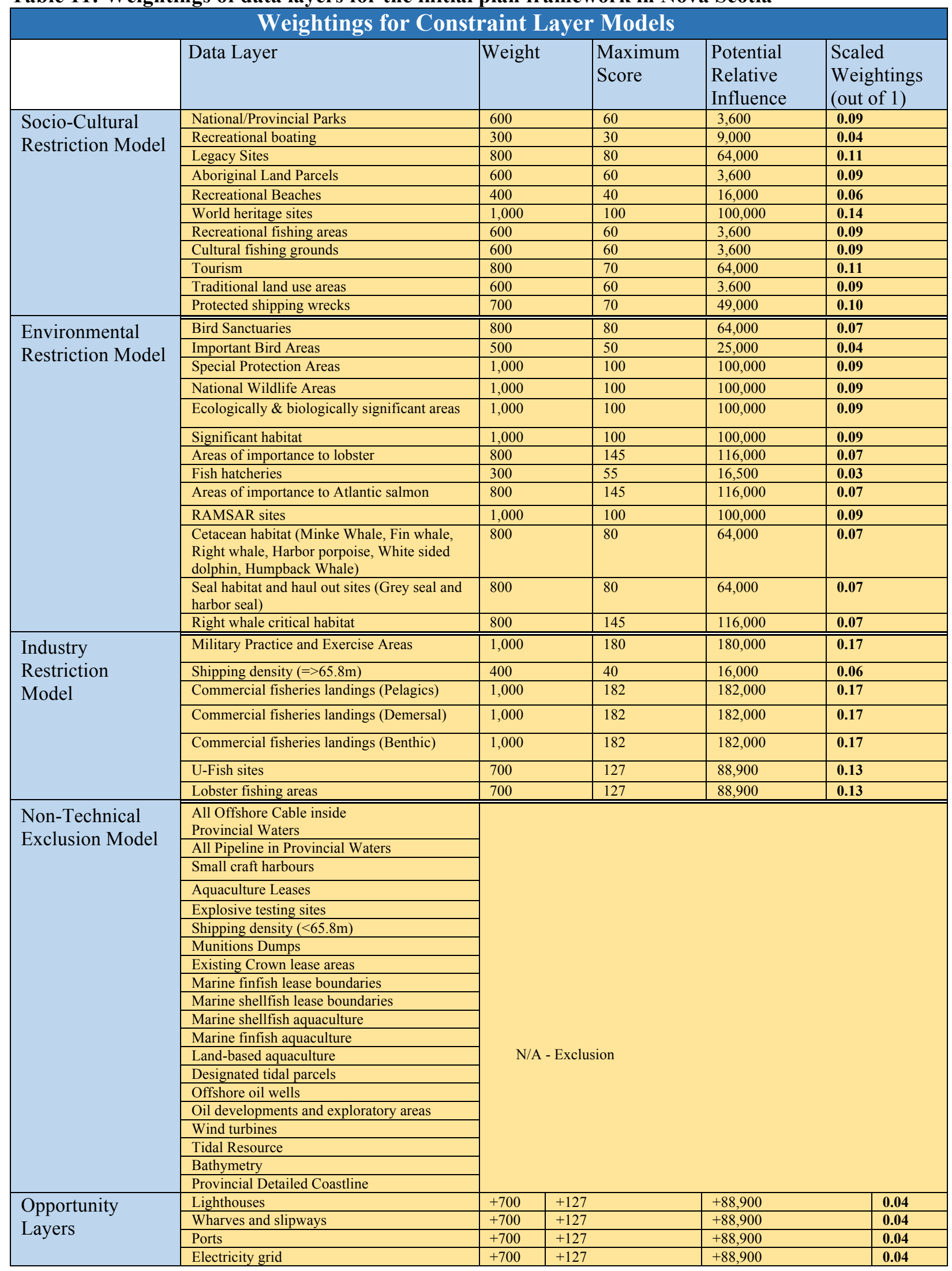




\subsubsection{Sectoral marine plan for tidal energy ecosystem regions}

In applying the ecosystem approach to MSP advocated for amongst leading scholars (Douvere, 2008) and solidified in the policies of MSPs of European nations (Douvere and Ehler, 2009), regional planning boundaries for Nova Scotia's marine environment should be constructed based on a set of spatial analysis criteria that identifies persistent themes related to ecosystem regions (Foley et al., 2010), therefore taking into account both near and far-field effects of not only TCT deployment, but all drivers operating in the marine environment, as regional planning boundaries would ideally be imposed in a national or provincial basis rather than a sectoral context specific to a plan such as a SMPTE.

The Scottish NMP identified six marine planning regions for purposes of further detailed evaluation in relation to sectoral planning initiatives specific to the environmental, social, and economic context of the regions (Marine Scotland, 2014). However, Scottish NMP regional boundaries follow no set criteria for their establishment in relation to the dynamic ecological complexities of the natural marine environment. This paper set out to establish ecosystem boundaries based on the identification of spatially persisting occurrence rates of various flora, fauna, and oceanographic processes within and outside the established provincial marine management boundaries. These parameters are intrinsically intertwined to the economic, social, and cultural contexts of the province given that natural capital derived from ecosystem services that are dependant on natural ecosystem functions support coastal economies and therefore the social make-up of coastal communities, while adhering to the cultural rights to such ecosystem services to traditional uses of the Mi'kmaq peoples in relation to the duty to consult and accommodate under the Constitution Act 1982.

In order to achieve delineate SMPTE boundaries predicated on the establishment of ecosystem regions, the data layers comprised within the environmental restriction model were aggregated into a density map to demonstrate areas of outstanding occurrence rates of the marine environment. Following the production of the environmental density map, presented in figure 6 , an analysis suggested that seven different marine planning boundaries be established in relation to the SMPTE and a broader provincial MSP if it were to be constructed and implemented, presented in figure 7 .

Figure 5: Scottish national marine plan regional boundaries

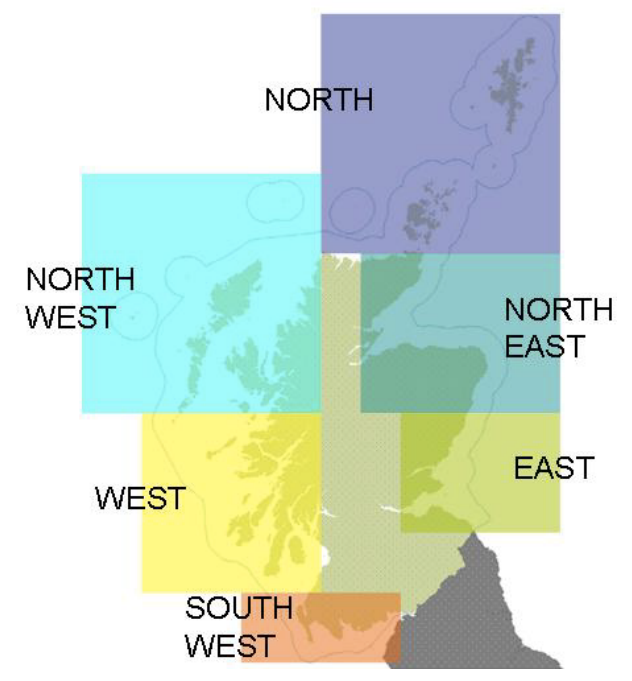




\subsubsection{Initial scoping results}

The initial scoping exercise produced weighted overlay maps of the data aggregated in the socio-cultural, environmental, and industry restriction models (including commercial fishing data). In order to demonstrate a lack of bias towards any particular category, the aggregate IPF constraint map comprised of all models utilized equal weightings for each of the restriction models employed, running in unison with the final approach adopted by the Scottish scoping exercise (Davies et al., 2012). Furthermore, data emanating from the non-technical exclusion model where TCT deployment was not possible based on prior allocated and incompatible spatial uses, while data emanating from the opportunity model was inputted to attach positive values concerning areas where TCT implementation could be streamlined through a $100 \mathrm{~km}$ buffer to lighthouses, ports, wharves and slipways, and electricity grids based off of visibility and operational AC cable logistics utilized in the initial exclusion parameters (AECOM, 2014). The results of the combination of all spatial factors are presented in figure 15. It is recommended that the DoE as the MSP CA produce and publish a report of the methodology employed in the initial scoping exercise, as well as the results, and be made publically available for comment for a minimum period of 16 weeks, in accordance with best practices demonstrated in Scotland's initial scoping exercise.

Figure 6: Nova Scotia environmental density map

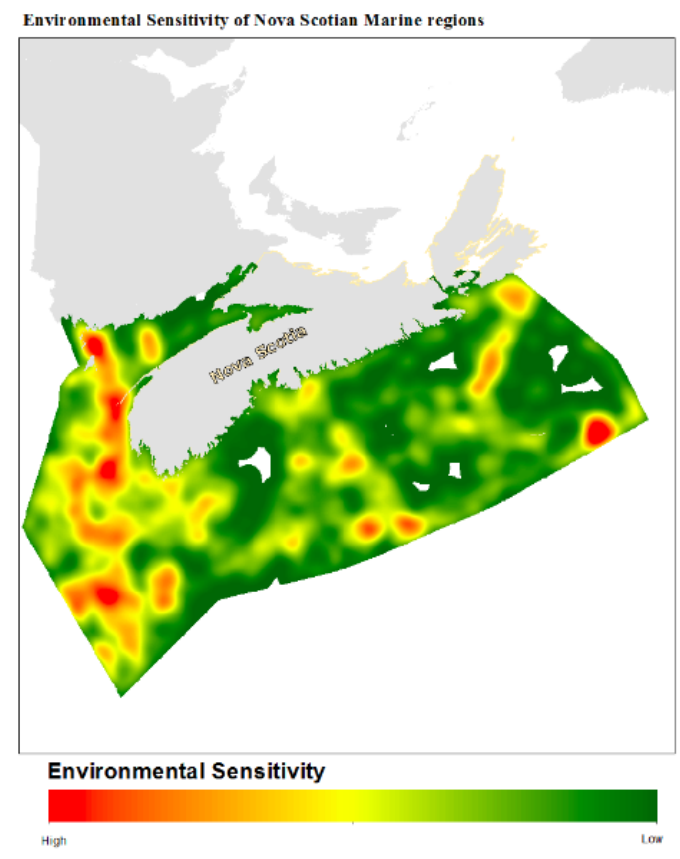

System: NAD UTML Zoae 20
Anthor: Stanley Mastrantonis 
Figure 7: Nova Scotia sectoral marine plan for tidal energy regional boundaries

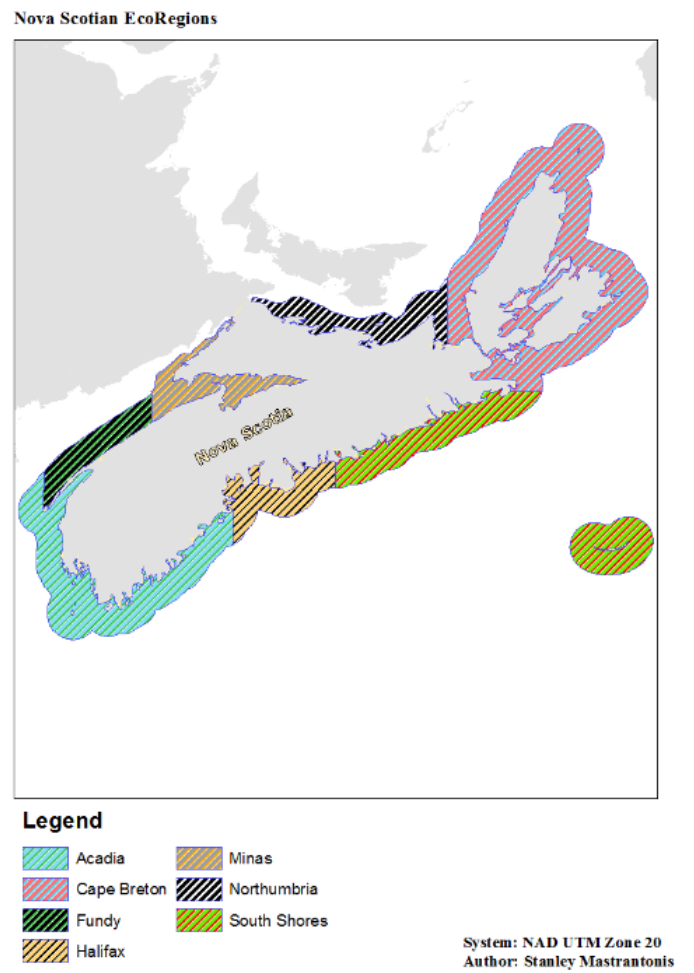

Figure 8: Nova Scotia sectoral marine planning process

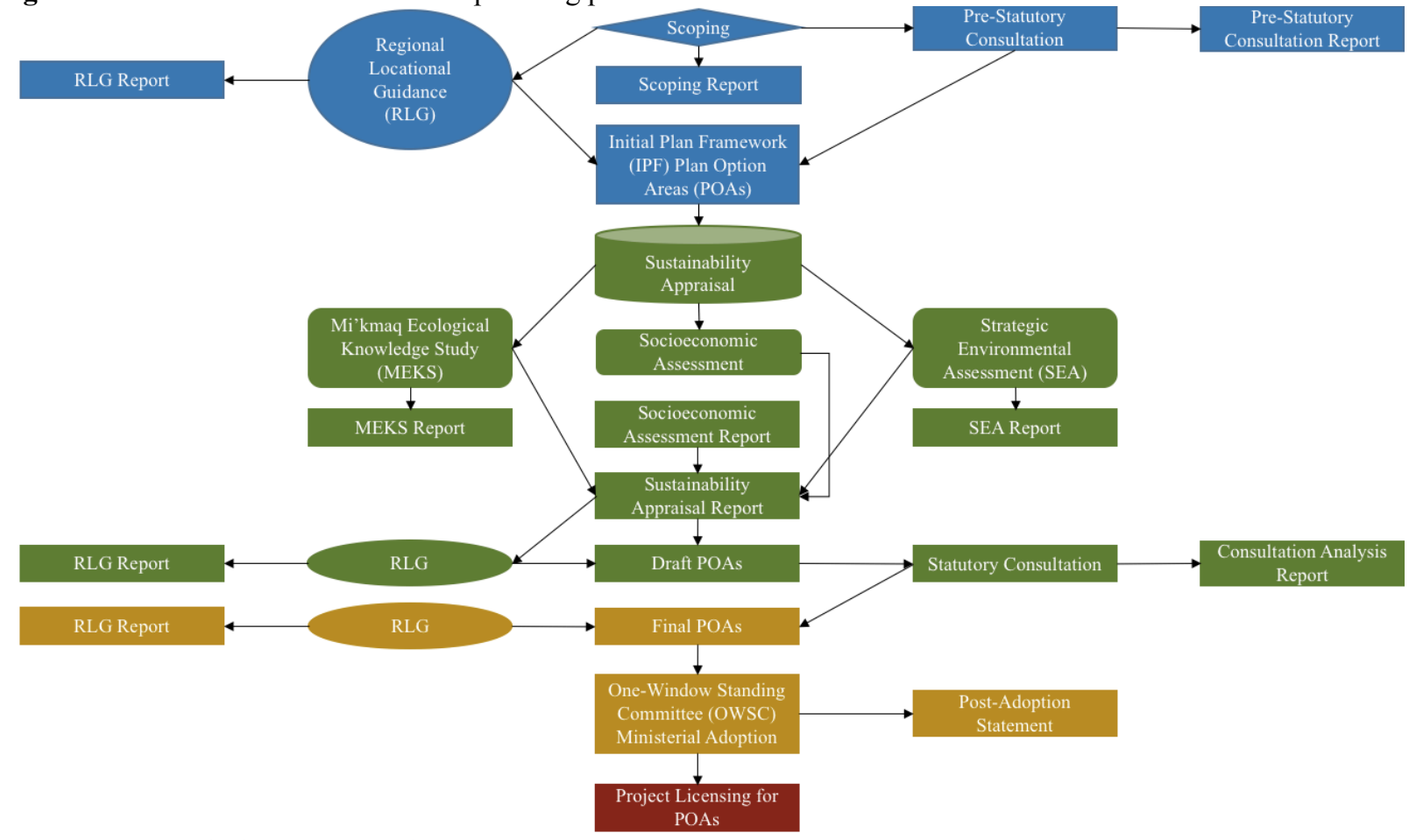

Phase 1 - Initial Plan Framework (IPF)

Phase 2 - Draft Plan Option Areas (POAs)

Phase 3 - Final POAs

Phase 4 - Licensing 


\subsubsection{Phase 2 - Draft plan option areas}

\subsubsection{Sustainability appraisal}

As a part of the sustainability appraisal for the Nova Scotia SMPTE based on the application of the Scottish framework, a SEA and socioeconomic assessment would ideally be undertaken following Phase 1 of the SMPTE process. However, for the purposes of this project, the three SEAs (two for the Bay of Fundy and one for Cape Breton/Bras d'Or) and the socioeconomic assessment already produced for the DoE in relation to tidal energy development will be utilized in order to further inform potential user - user and user - environment conflicts occurring within provincial waters.

A third component to the Scottish sustainability appraisal was the injection of a HRA in order to decipher potential interactions of tidal energy development in relation to European Natura 2000 biological conservation sites (Marine Scotland, 2013a). Since this is not applicable to the Nova Scotia context, it is excluded from the sustainability appraisal. However, given Nova Scotia's commitment to "encourage the sustainable development of marine renewable energy in a manner consistent with the recognition and affirmation of existing Aboriginal and treaty rights in section 35 of the Constitution Act, 1982, including the duty to consult" (Fournier, 2011, 29), the two MEKSs previously undertaken by Membertou Geomatics Consultants (MGC) will be injected into the Nova Scotia SMPTE sustainability appraisal in order to spatially incorporate traditional ecological knowledge of aboriginal peoples within the province. All new spatial information emanating from the sustainability appraisal will be weighted and incorporated into a second iteration of the overlay model in addition to previously incorporated data layers.

\subsection{Mi'kmaq ecological knowledge study}

The purpose of the MEKSs were to ensure that traditional knowledge and use of the tidal energy development study area were incorporated in environmental management and monitoring plans (Membertou Geomatics Consultants, 2009). The two key components of the MEKSs were to determine Mi'kmaq traditional land and resource use activities, both past and present, and conduct a Mi'kmaq significance species analysis, considering the resources that are important to Mi'kmaq use. For Phase 1 of the MEKS, published in 2009, the study area in question covered a portion of the Chignecto Bay, the Bay of Fundy, Greville Bay, Minas Channel, and the majority of the Minas Basin. The methodology behind obtaining traditional knowledge data consisted of consulting with four Mi'kmaq communities in order to identify traditional land uses and activities, as well as identifying other people who possess such knowledge and undertake such activities, eventually materializing in 20 interviews with 33 individuals.

An analysis of Phase 1 of the MEKS demonstrated a number of factors not previously considered in the initial scoping stage of the IPF. All of this data falls under the environmental restriction category of the scoping model, including 17 fish species (mackerel, flounder, herring, clam, cod, gaspereau, haddock, halibut, mussel, perch, periwinkle, pollock, scallop, shad, shrimp, smelt, and trout), 11 terrestrial and/or subaquatic mammals (bear, beaver, bobcat, deer, lynx, muskrat, otter, partridge, pheasant, rabbit, and raccoon), and one plant species (dulse). Lobster, flounder, mackerel, and herring were identified as the most harvested species, therefore, the later two will be inputted into the overlay model with the same weighting as lobster at 800 , which was previously accounted for during the initial scoping stage of the IPF, while flounder data could not be found. Of the 14 remaining fish species, data was only found on clam, cod, haddock, halibut, pollock, scallop, and shrimp, which will receive a weighting of 700, in line with other commercial fish species and in accordance with the rankings utilized in the Scottish 
SMPTE previously applied to Phase 1. For the animals, deer, partridge, and rabbit were identified as the most hunted, however, none of this data could be obtained, in line with dulse plant data.

Figure 9: Socio-cultural data projection Socio-Cultural Data Regions

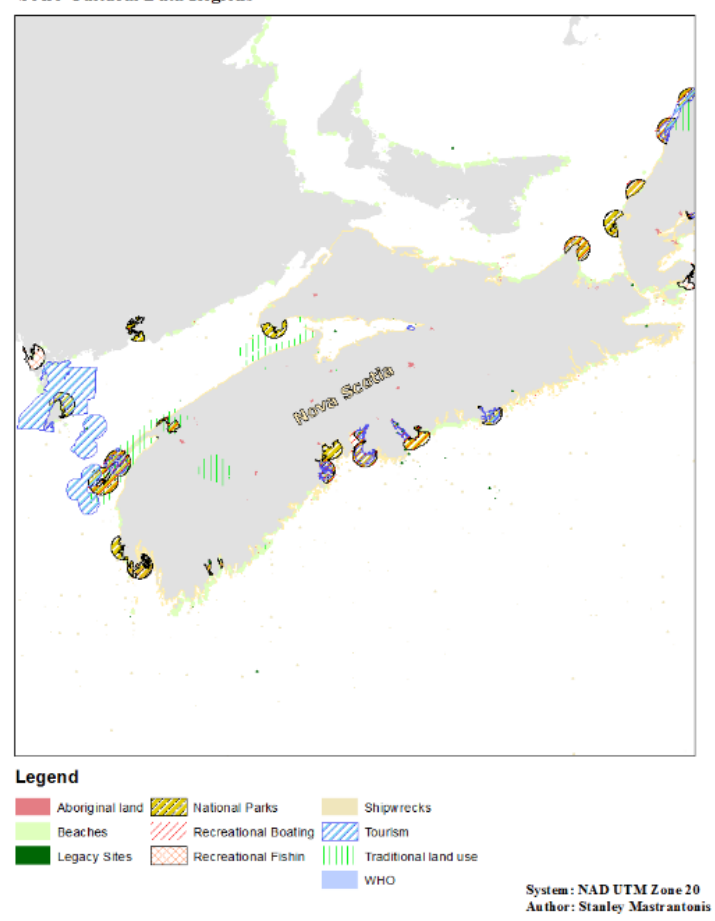

Figure 10: Socio-cultural restriction model

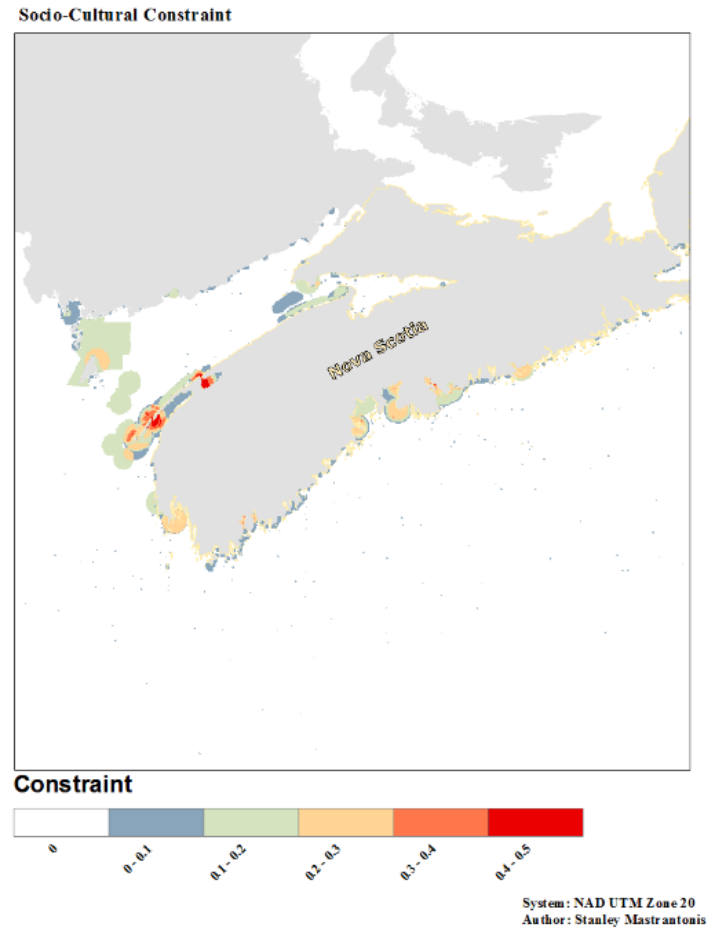


Figure 11: Industry data projection

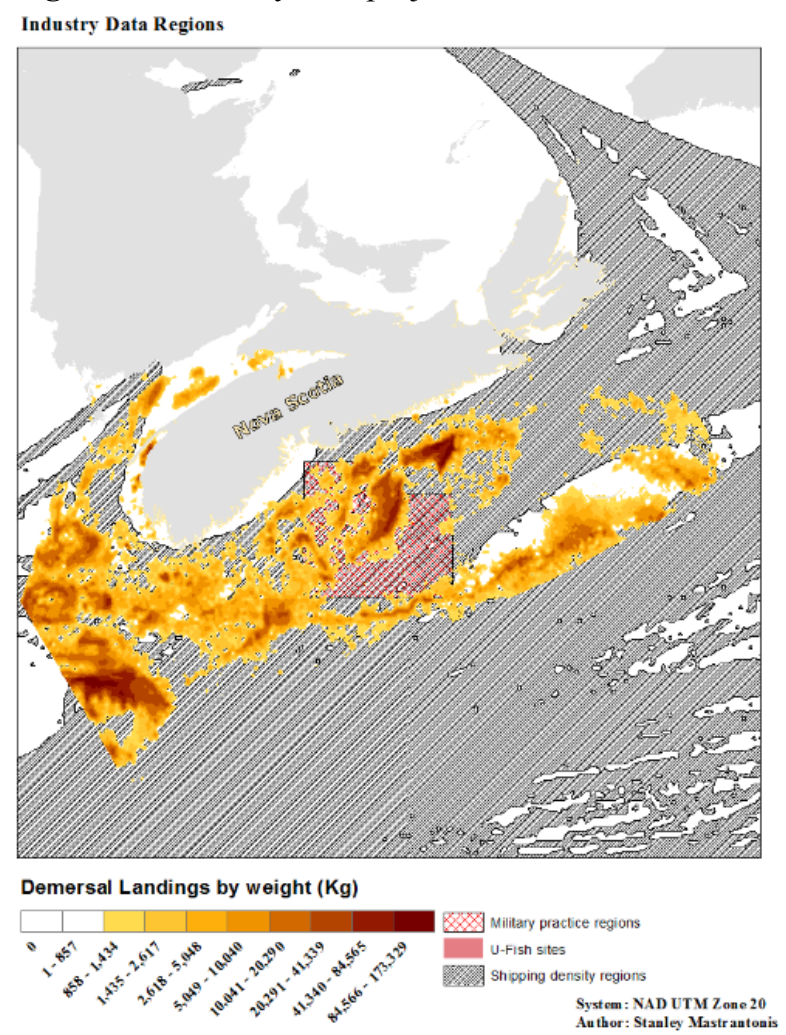

Figure 12: Industry restriction model

Industry Constriant Model

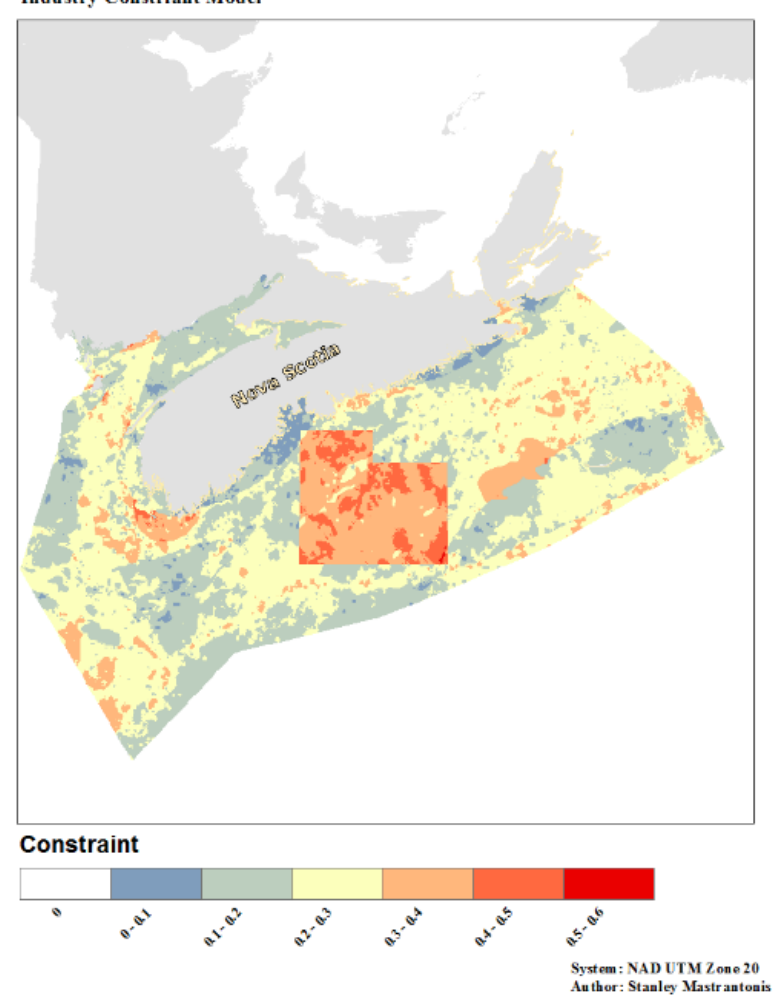


Figure 13: Non-technical exclusion data projection

Exclusion Data Regions

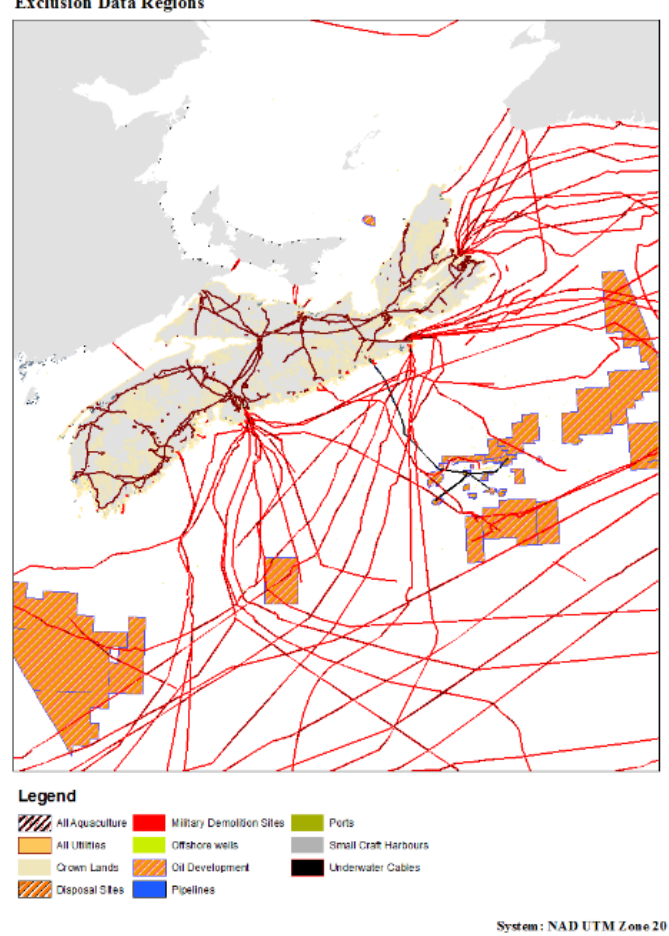

System: NAD UTM Zome 20

Figure 14: Environmental restriction model Environmental Constraint Model

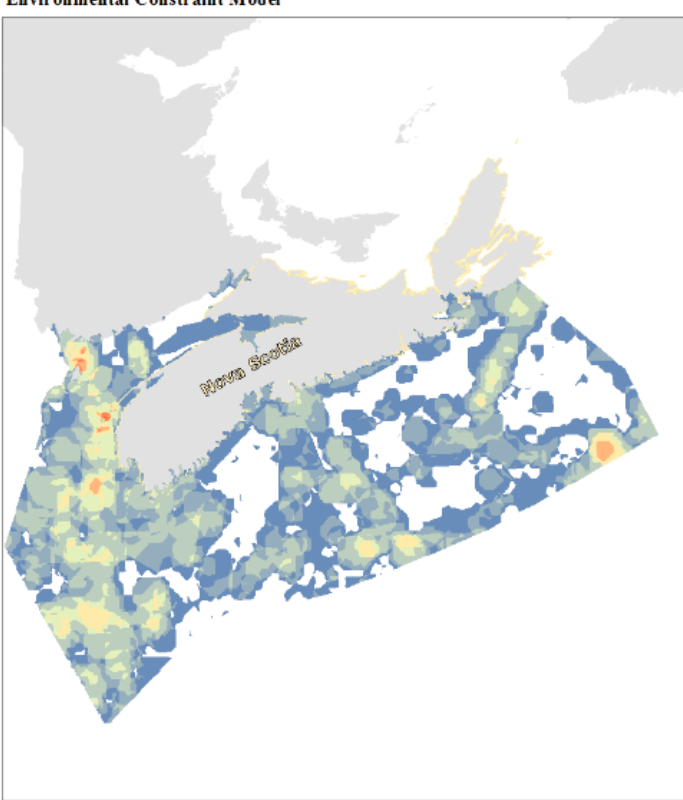

Constraint

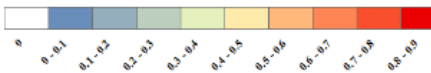

System: NAD UTM Zone 20
Author: Stanley Mastranton 
Figure 15: Initial plan framework aggregate scoping model including opportunity data layers

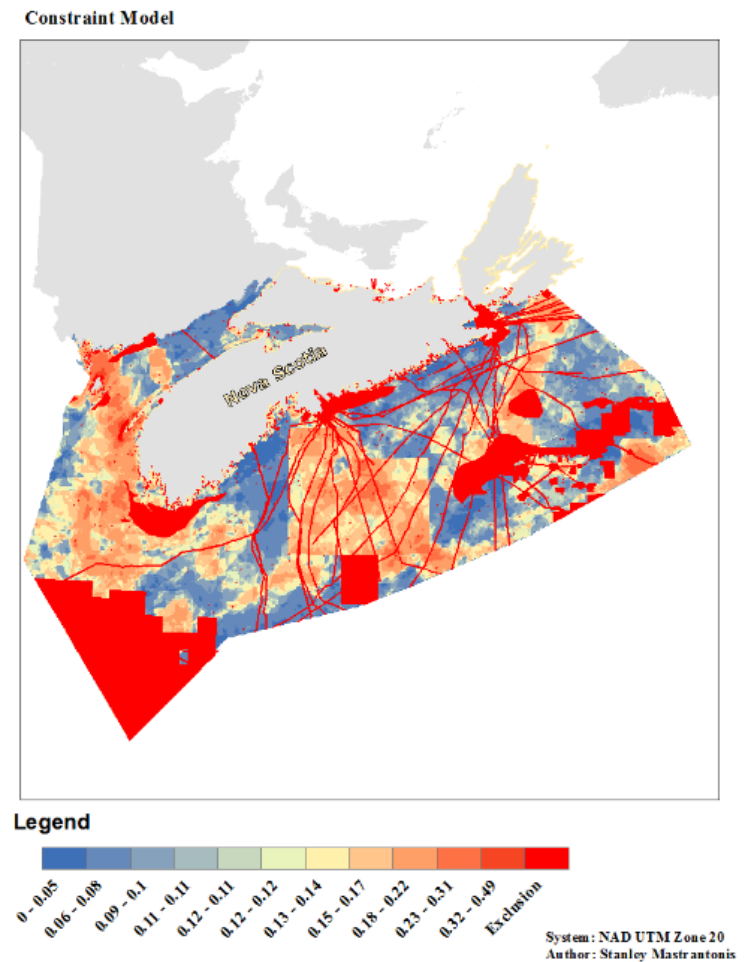

Phase 2 of the MEKS, published in 2012, was also conducted by MGC, and employed the same purpose, components, and methodology, with three Mi'kmaq communities being consulted with this time in order to identify traditional land uses and activities and others who possess such knowledge and undertake such activities, materializing in 16 interviews with 26 individuals (Membertou Geomatics Consultants, 2012). The study area for Phase 2 incorporated portions of Digby Gut around Bay View, and Victoria Beach, the southern tip of Digby Neck, including East Ferry, Petit Passage, and a northern portion of Long Island including Tiverton to just northeast of Central Grove, the southern tip of Long Island, including Freeport, a northeastern part of Brier Island, including Westport and Peter Island, as well as Grand Passage, and a southwest portion of Brier Island, extending into the Bay of Fundy and Gulf of Maine.

An analysis of Phase 2 of the MEKS also demonstrated a number of factors not previously considered in the initial scoping stage of the IPF phase, as well as Phase 1 of the MEKS. In line with the results emanating from Phase 1 of the MEKS, all of this data falls under the environmental constraint category of the scoping model, including three fish species (quohog, dogfish, crab), and 7 plant species (sweetgrass, mayflower, apple, blueberry, cranberry, golden thread, sweet flag). However, none of this data could be obtained. Furthermore, the report referred to Canadian Species at Risk Areas (SARA), which will be inputted into the overlay model with the same weighting as 1,000 , in unison with ecologically and biologically significant areas and significant habitat previously taken into consideration in the initial scoping stage of the IPF.

Ideally, it is recommended that a single MEKS with a study area incorporating the entirety of provincial planning boundaries established in this paper be undertaken by the DoE as the MSP CA following Phase 1 of the SMPTE, identifying criteria in greater depth in relation to the established regional marine planning areas, with the DoE producing a published report of the 
provincial MEKS which would be made publically available for comment for a minimum period of 16 weeks, in accordance with best practices of the HRA, socioeconomic assessment, and SEA demonstrated in Scotland.

\subsection{Socioeconomic assessment}

The socioeconomic assessment for tidal energy development in Nova Scotia, entitled Scoping Study on Socio-Economic Impacts of Tidal Energy Development in Nova Scotia: A Research Synthesis \& Priorities for Future Action, was undertaken by Howell and Drake (2012) on behalf of the Fundy Energy Research Network (FERN) for the Nova Scotia DoE and the then Offshore Energy Environmental Research Association (OEERA) in 2012. The purpose of the socioeconomic assessment was to identify socio-economic issues related to tidal energy development and reference best practices that have been employed internationally in order to help facilitate positive socio-economic benefits within communities. The key issues the report attempted to illuminate included technology development, supply chain development, workforce development, and knowledge transmission and research collaboration.

While the assessment had shed some light on crucial factors pertaining to sustainable tidal energy development scenarios, particularly locations of industry clusters, proximity to electrical grids, and access to suitably sized wet ports (Howell and Drake, 2012), these criteria had previously been accounted for in the initial scoping stage of the IPF, and therefore, the socioeconomic assessment did not contribute to any further enhancements towards suggested spatial data layers. The reasoning behind this is essentially the lack of economic baseline data gathered and made publically available in the province. Howell and Drake's socioeconomic assessment is the first stage in a series of three stages that would be required to mimic theScottish SMPTE socioeconomic assessment of the sustainability appraisal, as the report provides a baseline of potential socioeconomic issues, while such issues need to be quantified in terms of their socioeconomic impacts, and such quantifications must further be assessed in order to spatially determine potential monetary losses to various other industries operating within the SMPTE management boundaries.

Perhaps the most insightful analysis put forth in the socioeconomic assessment was the adoption of MacDonald's (2011) promotion of MSP as a means to minimize barriers to tidal energy development in Nova Scotia. Regardless, it is recommended that a socioeconomic assessment that quantifies the spatial losses to other sectors utilizing the marine environment where initial POAs have been proposed emanating from the initial scoping stage of the IPF be undertaken by the DoE as the MSP CA following Phase 1 of the SMPTE. In doing so, the DoE should identify criteria in greater depth in relation to the established regional marine planning areas, producing a published report of the socioeconomic assessment which would be made publically available for comment for a minimum period of 16 weeks, in accordance with best practices demonstrated in Scotland. 
Table 12: Sustainability appraisal data layers in Nova Scotia

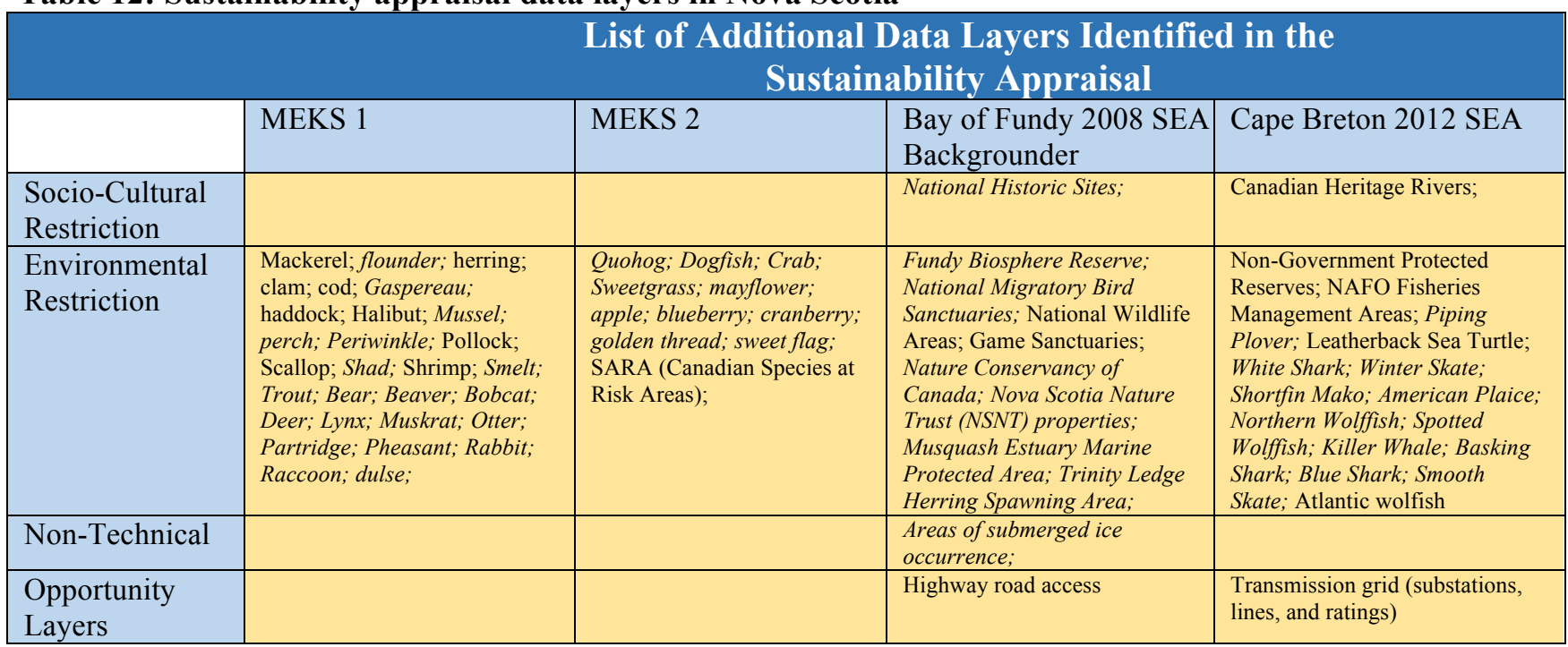

Industry Restriction non-applicable (data layers identified but not obtained in italics)

\subsection{Strategic environmental assessment}

Three SEA reports were produced for the Nova Scotia with regards to tidal energy development, two of which were for for the Bay of Fundy, the first being published in 2008 consisted of a backgrounder report undertaken by the Jacques Whitford (2008) consultant agency for the OEERA (2008) in order to inform a final draft that incorporated public input into the SEA through a series of community engagement initiatives. The 2008 Bay of Fundy SEA backgrounder identifies key environmental issues (KEIs) critical physical processes, fisheries, fish and fish habitat, marine habitat and benthic communities, pelagic communities, marine mammals, marine birds in relation to tidal energy development phases ranging from seabed preparation to decommissioning (Whitford, 2008). In compliance with the CEA Act 2012, a cumulative effects assessment was undertaken with regards to effects concerning energy extraction, common infrastructure, exclusion zones, other developments, other ecosystem changes, and site preparation. A number of recommendations were then put forth, including that of a coordinated planning approach towards management of Nova Scotia's marine environment. The information presented in the 2008 Bay of Fundy SEA backgrounder report contributed to the initial list of data layers emanating from Phase 1 of the SMPTE process that would further inform the identification of suitable POAs primarily in the environmental constraint category of the spatial overlay model, particularly with regards to biologically significant areas of ecological diversity including Fundy Biosphere Reserve, National Migratory Bird Sanctuaries, Nature Conservancy of Canada, Nova Scotia Nature Trust (NSNT) properties, Musquash Estuary Marine Protected Area, the Trinity Ledge Herring Spawning Area, National Wildlife Areas, and game sanctuaries. However, only the later two data layers could be obtained. In conformity with ecologically and biologically significant areas and significant habitat identified in Phase 1, these data layers received a ranking of 1,000 respectively. National Historic Sites were also identified as a new data layer within the socio-cultural restriction category, although such data could not be obtained. Primary terrestrial transportation highways were also identified and inputted into the opportunity layer with a score of 700 when demonstrating a $5 \mathrm{~km}$ buffer in relation to ports, wharves, and slipways, as this would facilitate the movement of technology, equipment, and 
people to and from the port for purposes concerning installation, operation, maintenance, and decommissioning.

OEERA (2008) then released a final report later that year where public stakeholder input from the 2008 backgrounder was gathered through community forums, workshops, and written submissions, with the purposes of exploring whether TCT deployment in the Bay of Fundy can proceed without impact on the marine environment and economy of the province, as well as facilitate communal economic benefit to the region, and inform the Nova Scotia government on the conditions required in order to issue permits, increased necessities of research and monitoring, and criteria concerning whether, where and how commercial projects should be developed, regulated, and managed. Furthermore, a Stakeholder Roundtable comprised of 24 members was created in order to provide greater representation of public perspectives regarding tidal energy development in the Bay of Fundy.

The Stakeholder Roundtable suggested the need to develop general sustainability principles to guide tidal energy development within provincial waters in order to ensure communal benefit, thereby mimicking the underlining purpose of MSP as a tool to spatially allocate various uses of the marine environment with the intent of facilitating economic gain while upholding environmental sustainability (Douvere, 2008), as well as adopting best practices of overarching ecosystem approach to MSP policies demonstrated in Scotland's NMP GES policies in which the SMPTE, as well as the other 10 identified sectors, must be in conformance with (Marine Scotland, 2014). This document upheld the transparency and public engagement principles suggested in best practice MSP, although no new spatial data was produced following the backgrounder report to take into consideration.

Table 13: Sustainability data layer weightings

\begin{tabular}{|c|c|c|c|c|c|}
\hline \multicolumn{6}{|c|}{$\begin{array}{r}\text { Weightings for Constraint Sustainability } \\
\text { Nova Scotia }\end{array}$} \\
\hline & Data Layer & Weight & $\begin{array}{l}\text { Maximum } \\
\text { Score }\end{array}$ & $\begin{array}{l}\text { Potential Relative } \\
\text { Influence }\end{array}$ & $\begin{array}{l}\text { Scaled Weightings } \\
\text { (out of } 1 \text { ) }\end{array}$ \\
\hline $\begin{array}{l}\text { Socio-Cultural } \\
\text { Restriction Model }\end{array}$ & Canadian Heritage Rivers & 800 & 80 & 64,000 & 0.06 \\
\hline \multirow{15}{*}{$\begin{array}{l}\text { Environmental } \\
\text { Restriction Model }\end{array}$} & $\begin{array}{l}\text { National Migratory Bird } \\
\text { Sanctuaries }\end{array}$ & 800 & 80 & 64,000 & 0.06 \\
\hline & $\begin{array}{l}\text { Trinity Ledge Herring } \\
\text { Spawning Area }\end{array}$ & 800 & 80 & 64,000 & 0.06 \\
\hline & $\begin{array}{l}\text { Musquash Estuary Marine } \\
\text { Protected Area }\end{array}$ & 800 & 80 & 64,000 & 0.06 \\
\hline & Mackerel & 800 & 145 & 116,000 & 0.06 \\
\hline & Herring & 800 & 145 & 116,000 & 0.06 \\
\hline & Cod & 700 & 70 & 49,000 & 0.05 \\
\hline & Haddock & 700 & 70 & 49,000 & 0.05 \\
\hline & Halibut & 700 & 70 & 49,000 & 0.05 \\
\hline & Pollock & 700 & 70 & 49,000 & 0.05 \\
\hline & Scallop & 700 & 70 & 49,000 & 0.05 \\
\hline & Shrimp & 700 & 70 & 49,000 & 0.05 \\
\hline & National Wildlife Areas & 1,000 & 180 & 180,000 & 0.08 \\
\hline & $\begin{array}{l}\text { NAFO Fisheries } \\
\text { Management Areas }\end{array}$ & 800 & 145 & 116,000 & 0.06 \\
\hline & Leatherback Sea Turtle & 700 & 70 & 49,000 & 0.05 \\
\hline & Wolfish & 700 & 70 & 49,000 & 0.05 \\
\hline \multirow{2}{*}{ Opportunity Layers } & Highway road access & +700 & +127 & $+88,900$ & 0.04 \\
\hline & $\begin{array}{l}\text { Transmission grid } \\
\text { (substations, lines, and } \\
\text { ratings) }\end{array}$ & +700 & +127 & $+88,900$ & 0.04 \\
\hline
\end{tabular}

Industry Restrictions Model and non-technical Exclusion Model non-applicable 
A second SEA for the Bay of Fundy was published in 2014 by AECOM (2014) for OERA with the purposes of building upon the issues raised by the Stakeholder Roundtable identified five years prior. The report detailed how the previous recommendations made were dealt with to date, and the current gaps remaining, one of which was the construction and implementation of a coordinated planning approach towards management of Nova Scotia's marine environment. The objectives of the SEA were to describe the status of the tidal energy industry both globally and regionally, as well as present the current scientific and community knowledge in place in relation to the industry in the Bay of Fundy. Gathering information of best practices and forefront knowledge and applying it to Nova Scotia, the report identified three criteria that were not previously considered in the initial scoping stage of the IPF, including the exclusion of development zones that demonstrate a propensity towards drifting submerged ice, and the emphasis of wet ports over dry ports to avoid costly construction charged associated with wharf expansion of dry ports further out into the bay. However, data on both of these findings could not be obtained.

In 2012, AECOM (2012) published a background report for the Cape Breton Region for OERA. The report summarized the status, validity, and applicability of the Bay of Fundy SEA final 2008 recommendations to the Cape Breton/Bras d'Or Region. The report acknowledged the same KEIs as the Bay of Fundy Backgrounder report. Amongst the data gaps identified, particular emphasis was placed on the lack of suitable resource analysis undertaken in regional waters, a theme reaffirmed by Karsten's (2012) resource assessment, which is the most recent assessment published to date and will be held as the standard towards identifying tidal current speeds in provincial waters. Due to the low current speeds of the region, the tidal sites in Cape Breton/Bras d'Or have been excluded from the SMPTE following the initial scoping stage of the IPF as demonstrated in section 5.2.1.2. The methodology employed by this paper in excluding areas with a Vmsp of $<1.5 \mathrm{~m} / \mathrm{s}$, based off of technical TCT parameters of installed, commercially viable TCTs, and in unison with the Scottish scoping methodology, is reaffirmed in the SEA through the promotion of EPRIs (2006) statement on the matter of resource requirements to host commercial TCT implementation.

Nevertheless, for purposes of future iterations of the SMPTE as a part of a quality management framework, and in line with best practices witnessed in Scotland, additional data layers have been identified and will be inputted into the weighted overlay model for the Phase 2 of the SMPTE process in the instance that future resource characterization demonstrates economically viable tidal current speeds in the Cape Breton Region, and/or TCT technology develops further to employ lower current speeds as a fuel source. However, it is worthy to note that data layers demonstrated inconsistency in their spatial persistence throughout established provincial waters, with the Cape Breton Region in particular demonstrating a lower availability of marine spatial data than the Bay of Fundy and the east coast of Nova Scotia.

Regardless, the additional data layers identified include Canadian Heritage Rivers, which was inputted into the socio-cultural restriction category with a weighting of 800 , in unison with legacy sites identified in Phase 1. New data related to the environmental restriction model included non-government protected reserves, North Atlantic Fisheries Organization (NAFO) Fisheries Management Areas, piping plover, leatherback sea turtle, white shark, winter skate, shortfin mako, American plaice, northern wolfish, spotted wolfish, killer whale, basking shark, blue shark, smooth skate, and Atlantic wolfish. Non-government protected reserves and NAFO Fisheries Management Areas were inputted into the environmental restriction model with a weighting of 800 , in unison with ecologically and biologically significant areas identified in 
Phase 1, while leatherback sea turtle and Atlantic wolfish were attributed a weighting of 700, in unison with other aquatic non-mammal species identified in Phase 1. Furthermore, transmission grid components including substations, lines, and associated power ratings, were identified and inputted into the opportunities category with a uniform rank of 700 in unison with previously identified opportunity data layers.

Figure 16: Initial plan framework and sustainability appraisal aggregate environmental data projection Environmental Constraint Data regions

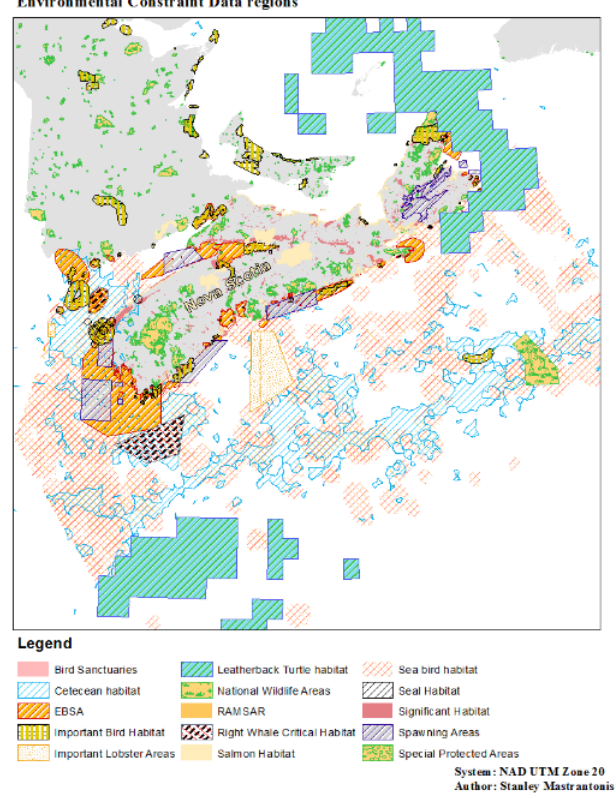

Figure 17: Initial plan framework and sustainability appraisal aggregate opportunity data projection

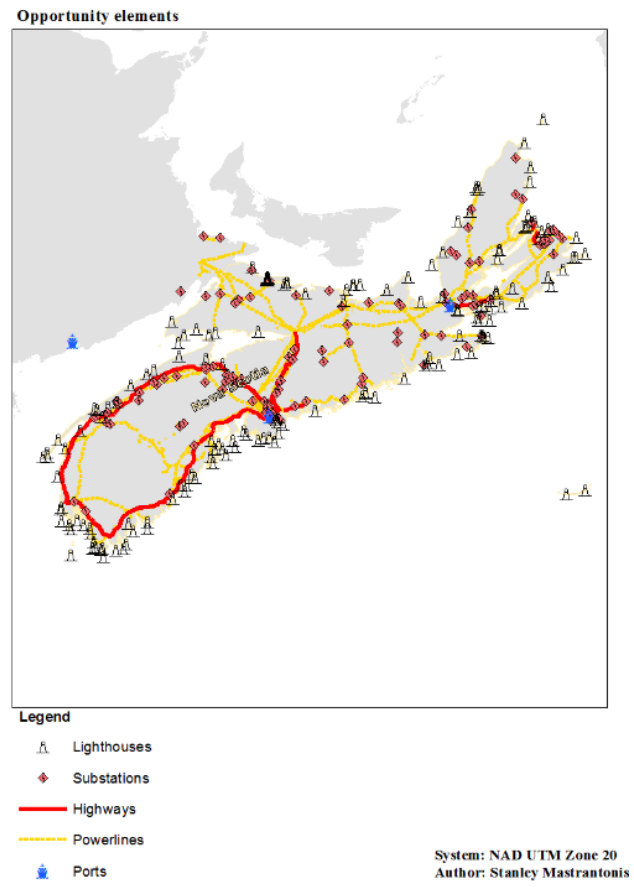


In 2014, Stantec (2014) published a community response report to the 2012 SEA undertaken in the Cape Breton Region, similar to the Bay of Fundy SEA framework, for OERA. The report summarizes the outcomes of community and Mi'kmaq engagement with the SEA backgrounder, which was undertaken with the strategic objectives of increasing awareness and knowledge of tidal energy development in the region to associated communities, providing public access to the backgrounder report, generating dialogue, providing opportunities for input, and gather record and analyze information, knowledge and concerns through the engagement process in a transparent manner. This document upheld the transparency and public engagement principles suggested in best practice MSP, although no new spatial data was produced following the backgrounder report to take into consideration.

Ideally, it is recommended that a single SEA with a study area incorporating the entirety of provincial planning boundaries established in this paper be undertaken by the DoE as the MSP CA following Phase 1 of the SMPTE, identifying criteria in greater depth in relation to the established regional marine planning areas, with the DoE producing a published report of the provincial MEKS which would be made publicly available for comment for a minimum period of 16 weeks, in accordance with best practices demonstrated in Scotland.

Figure 18: Sustainability appraisal aggregate constraint model

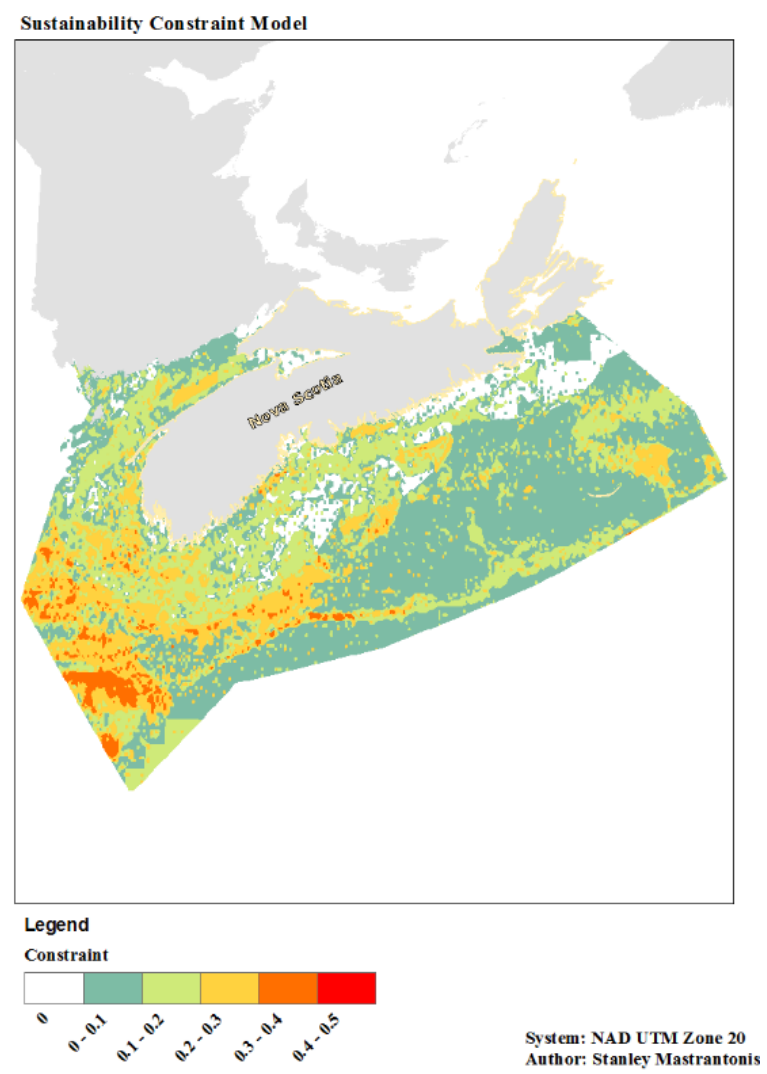




\subsubsection{Sustainability appraisal review}

In accordance with Scotland's best practices, it is suggested that a round of RLG initiated by the DoE be undertaken in relation to the three documents comprising the sustainability appraisal, with added inputs to original POAs produced from the initial scoping stage of the IPF being mapped out to create draft POAs. This process should result in the publication of a sustainability appraisal report which presents the key findings produced from the MEKS, socioeconomic assessment, and SEA, identifying criteria in greater depth in relation to the established regional marine planning areas, and be made publically available for comment for a minimum period of 16 weeks, in accordance with best practices demonstrated in Scotland. Running in parallel with the public consultation period, the sustainability appraisal report should be released to the CEAA and NSE, who are the ecosystem CAs and thus the statutory authorities over the SEA, and the Nova Scotia DNR, who is the other CA with jurisdiction over submerged provincial lands, and thus may review all three documents of the sustainability appraisal in order to make decisions regarding consent for authorization, in accordance with Section 5(d) of the MRE Act 2015 as a part of statutory consultation procedures.

At this stage, a consultation analysis report should be drafted detailing the key issues raised by key stakeholders identified in the SMPTE process, demonstrating how such issues have been taken into account throughout the sustainability appraisal report and inclusive of draft POAs. If statutory consultation determines that considerable alterations to the draft plan are required in order to better account for stakeholder input, economic sustainability, and/or environmental consideration, further research and amendments must be undertaken for the MEKS, socioeconomic assessment, and/or SEA until the legislated statutory consultation bodies accept the draft POAs under proposed conditions. If the draft SMPTE is accepted, it is then put forth to Phase 3.

\subsubsection{Phase 3 - Final plan option areas}

\subsubsection{Ministerial adoption}

At this stage, final POAs should undergo another round of RLG by in order to further determine areas of constraint and opportunity. Following the RLG exercise, final POAs should be put forth to the applicable provincial and federal ministers that make up the OWSC. If ministerial adoption is granted, a post-adoption statement justifying the reasons for adopting the current iteration of the SMPTE and how environmental and stakeholder concerns, socioeconomic assessment, and the MEKS were taken into consideration should be published, with amendments to the MRE Act 2015 being made to legislate this process, thereby mimicking the statutory obligation set out it the Environmental Assessment (Scotland) Act 2005 (Marine Scotland, 2013a).

In accordance with best practices emanating from Scotland, it is recommended that a SPRG be established within the DoE in order to oversee the implementation of SMPTE and undertake strategic monitoring and research to fill information gaps identified in the sustainability appraisal report. Furthermore, at the initial early stages of construction and implementation, it is suggested that the SMPTE is reviewed every two years, as suggested in the Scottish SMPTE consultation draft, with five-year set review periods thereafter legislated via an amendment to the MRE Act 2015 in conformity to the policies set out in the Scottish NMP and legislated under the Marine and Coastal Access Act 2009 and the Marine Scotland Act 2010 (Marine Scotland, 2014). 


\subsubsection{Marine renewable-energy areas vs. plan option areas}

Following the application of the SMPTE process detailed throughout this paper, five POAs have been produced based on their suitability ranking of $=>0.45 / 1$, one in the Minas Basin, inclusive of the Minas Channel in the established Minas ecoregion, measuring $242.148 \mathrm{~km} 2$, one in Petit Passage in the established Fundy ecoregion, measuring $0.210 \mathrm{~km} 2$, and three in Grand Passage in the established Acadia ecoregion, with an aggregate measurement of $0.608 \mathrm{~km} 2$, with a combined total area of $242.966 \mathrm{~km} 2$. When analyzing the resulting POAs against the marine renewable-energy priority areas and MREAs identified in the MRE Act 2015 which did not undergo a strategic siting methodology inclusive of the identification sufficient Vmsps, user - user and user - environment conflicts, as well as opportunities, a number of inconsistencies emerge. Firstly, the marine renewable-energy priority area of Cape Breton prescribed in schedule A, measuring $1069.872 \mathrm{~km} 2$ has been eliminated due to insufficient Vmsps.

Figure 19: Final plan option areas

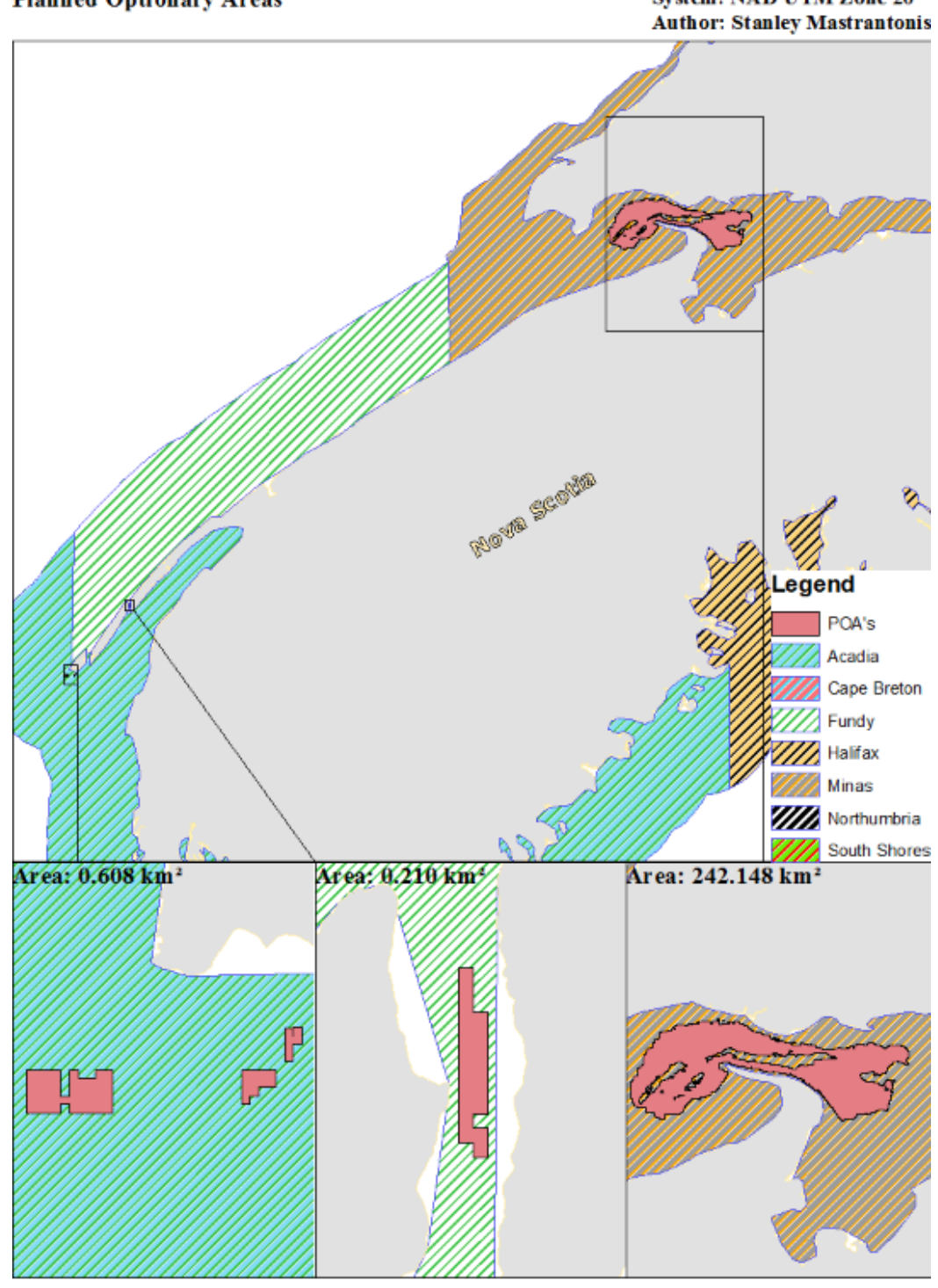


The FORCE MREA, which encompasses the greater Minas Basin region has been legislated under schedules C-A with an area of $1.599 \mathrm{~km} 2$ and C-B with area of $0.5 \mathrm{~km} 2$, with an aggregate area of $2.099 \mathrm{~km} 2,240.867 \mathrm{~km} 2$ less than the resulting POAs. This is primarily due to the extraordinary Vmsps characteristic of the area in conjunction with the lack of spatial conflict in the Minas ecoregion, with commercial fishing posing the only potential conflict just south of the Minas Passage POA. The Digby Gut MREA legislated in schedule D, and measuring $0.963 \mathrm{~km} 2$, has been eliminated in its entirety in relation to resulting POAs due to an insufficient Vmsp and heavy constraint emanating from heavy aggregation of marine mammal habitat, commercial shipping in relatively shallow waters, and prominence of indigenous cultural use.

Figure 20: Marine renewable-energy areas

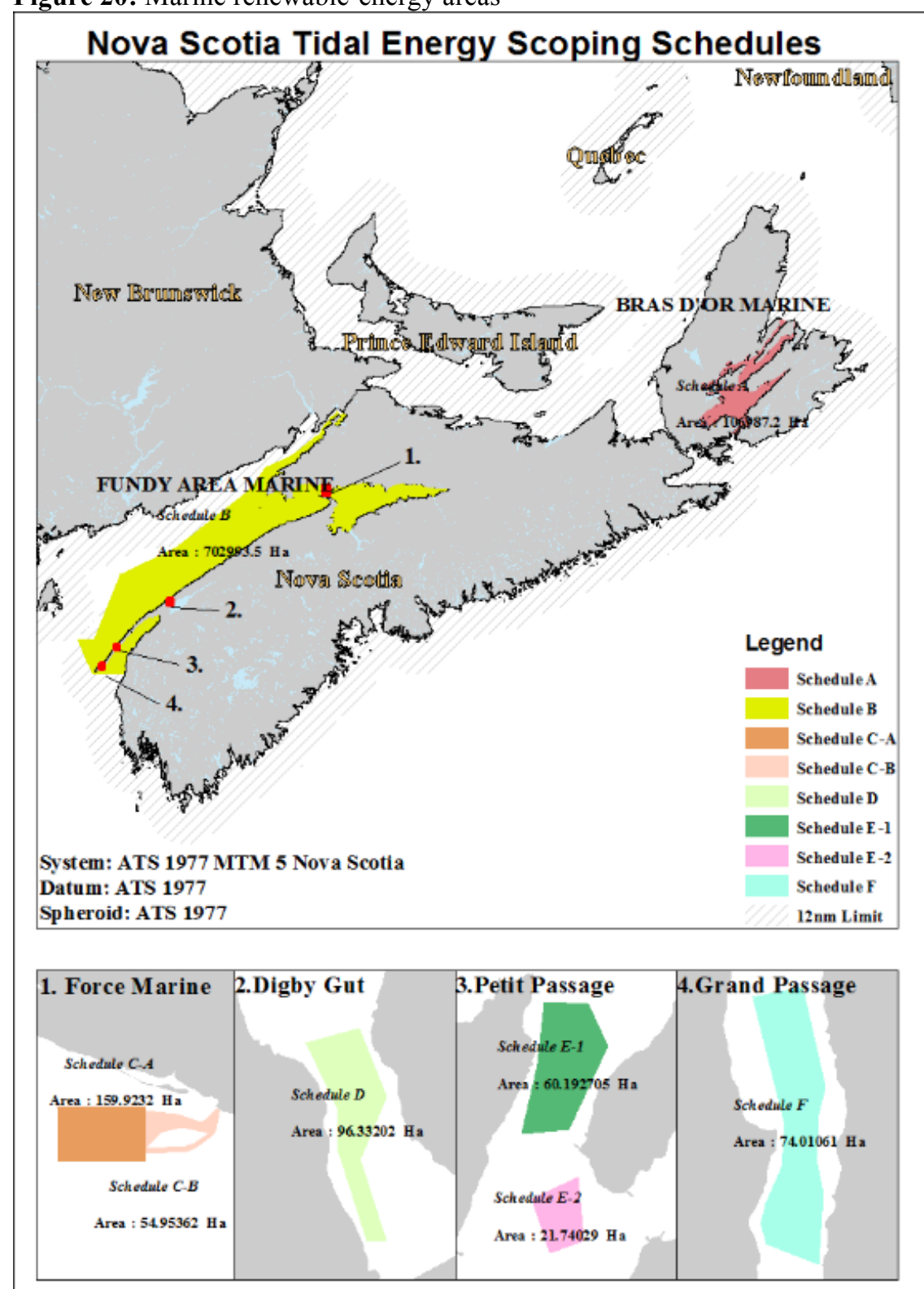

Author: Stanley Mastrantonis 
The Petit Passage MREAs legislated under schedules E1, measuring 0.602km2, and E2, measuring $0.217 \mathrm{~km} 2$, with an aggregate measurement of $0.819 \mathrm{~km} 2$, is $0.609 \mathrm{~km} 2$ greater than the resulting single POA due to moderate to heavy constrain associated with shipping, commercial fishing, tourism and recreational use, and indigenous cultural use. Finally, the single Grand Passage MREA legislated under schedule F, measuring $0.74 \mathrm{~km} 2$, is $132 \mathrm{~km} 2$ larger than the three resulting POAs due primarily to important bird habitat, national scenic areas, tourism and recreational use, and indigenous cultural use. In summation, although the Great Bras d'Or Lakes and Barra Straight site of the Cape Breton Region and Digby Gut have been eliminated as viable tidal energy deployment sites following the employment of the SMPTE process, the six MREAs have an aggregate area of $4.621 \mathrm{~km} 2$, which is $238.345 \mathrm{~km} 2(98.1 \%)$ less than the five POAs, primarily due to the Minas Basin POA, which accounts for $99.6 \%$ of the POA aggregate areas.

Rather than applying Karsten's (2012) levels of sustainable energy extraction presented in section 5.2.1.2. as the sole parameter to assess the development scenarios in either MREAs or POAs, potential installed TCT capacity will be determined by analyzing layout optimization parameters in which TCT arrays have been suggested require based on technological operation characteristics. Two layout optimization parameters will be analyzed initially, one proposed by AECOM (2010) in the 2014 Bay of Fundy SEA (AECOM, 2014), and one proposed by Myers and Bahaj (2012) through their layout optimization downscaled modeling test results. In order to decrease structural loading on TCT devises, allow for sufficient wake formation after the current passes around a TCT, and optimize the kinetic energy available to individual devises, the AECOM (2010) method suggests that a TCT array requires a 2.5Rd lateral separation perpendicular to the tidal flow and 10Rd separation between TCTs parallel to incoming tidal flows, while Myers and Bahaj (2012) suggest that a 1.5Rd lateral separation and $3^{\text {Rd }}$ downstream separation, which also facilitates benefits of increasing power available to downstream TCTs by $22 \%$.

Since the primary suitability parameters utilized in section 5.2.1.2. dictate that no smallscale TCTs can be deployed in Nova Scotia waters based on correlations between a Vmsp of $=>1.5 \mathrm{~m} / \mathrm{s}$ occurring between $10-30 \mathrm{~m}$ of depth, the largest Rd of a commercially viable largescale 1.5MW TCT of $18 \mathrm{~m}$ presented in section 5.2.1.2. will be utilized as a conservative buffer to account for large-scale TCTs with smaller Rds. Utilizing the layout optimization methodology suggested by AECOM (2010), each individual TCT within an array would require an area of $8.1 \mathrm{~km} 2$, while utilizing the layout optimization methodology suggested by Myers and Bahaj (2012), each individual TCT within an array would require an area of $1.458 \mathrm{~km} 2$. Based on the necessity to employ an array of TCTs in order to maximize economically viable returns for an emerging renewable energy technology, Myers and Bahajs layout optimization methodology will be employed to determine installed deployment capacity for each MREA and POA.

The application of the employed layout optimization methodology presented above to POAs would suggest that the Minas Basin POA could accommodate an installed capacity of 250MW, while the Petit Passage POA and the Grand Passage area could accommodate an installed capacity of $1.5 \mathrm{MW}$ each, resulting in an aggregate installed capacity of $253 \mathrm{MW}$. The application of the employed layout optimization methodology to MREAs would suggest that the Minas Basin MREAs legislated under schedule C-A could accommodate an installed capacity of $3 \mathrm{MW}$, while schedule $\mathrm{C}-\mathrm{B}$ could accommodate an installed capacity of $1.5 \mathrm{MW}$, together accounting for $4.5 \mathrm{MW}$. The Digby Gut MREA legislated under schedule D could accommodate an installed capacity of $1.5 \mathrm{MW}$, although sufficient Vmsps are not demonstrated in the region, and therefore will be excluded from the aggregate installed capacity analysis. The Petit Passage 
MREAs legislated under schedules E1 and E2 could accommodate an installed capacity of 1.5MW each, together accounting for 3MW. The Grand Passage MREA legislated under schedule F could accommodate an installed capacity of 1.5MW. All together, the MREAs legislated under the MRE Act 2015 could accommodate an installed TCT capacity of 9MW, 244MW less than the POAs.

Table 14: Marine renewable-energy areas vs plan option areas

\begin{tabular}{|l|l|l|l|l|l|}
\hline \multicolumn{2}{|c|}{} & \multicolumn{3}{c|}{ MREA } & \multicolumn{2}{c|}{ POA } \\
\cline { 3 - 8 } Ecoregion & Site & Area (km2) & $\begin{array}{c}\text { Installed Capacity } \\
\text { (MW) }\end{array}$ & Area (km2) & $\begin{array}{c}\text { Installed Capacity } \\
\text { (MW) }\end{array}$ \\
\hline Minas & Minas Basin & 2.099 & 4.5 & 242.148 & 250 \\
\hline \multirow{2}{*}{ Fundy } & Digby Gut & 0.963 & N/A (1.5) & N/A & N/A \\
\cline { 2 - 8 } & Petit Passage & 0.819 & 3 & 0.210 & 1.5 \\
\hline \multirow{2}{*}{ Acadia } & Grand Passage & 0.74 & 1.5 & 0.608 & 1.5 \\
\cline { 2 - 8 } & Total & $\mathbf{4 . 6 2 1}$ & $\mathbf{2 4 2 . 9 6 6}$ & \\
\hline
\end{tabular}

\subsubsection{Phase 4-Licencing}

The three proceeding process Phases are undertaken in fulfillment of the key driver of the SMPTE of marine planning in order to meet the key driver of marine licensing, the output Phase of the SMPTE, thereby facilitating a streamlined licensing and consenting process of TCT testing and development. A broad review of different licensing procedures from different nations suggests that administrative barriers characterized by a large number of legislative authorities required to grant consent for permits often promote an uncoordinated licensing regime that results in overdrawn approval timelines (Doelle et al., 2006), thereby deterring developers, community members, and investors from seeking licenses as such timeframes drive up costs and slow down project timelines (Fournier, 2011).

A case study of the lack of coordination emanating from a multiplicity of legislative jurisdictional and regulatory authorities can be witnessed in the offshore wind energy industry in the USA, as regulation was conducted under existing legislation, thereby resulting in regulatory conflict and overlap between the Federal Energy Regulatory Commission (FERC) and the Bureau of Ocean Energy Management (BOEM). This issue has only been resolved in recent years and subsequently, the first and only commercial-scale offshore wind turbine in the USA has been implemented off of Block Island, Rhode Island, which is also worthy to note that Rhode Island is one of the, if not the most progressive state in regards to MSP research and implementation.

Due to the political structure of Canada, it is very conceivable that such regulatory conflicts may arise between jurisdictionally overlapping provincial and federal governmental bodies in Nova Scotia, particularly the four provincial and five federal bodies that make up the OWSC due to their relative legislative authority over particular aspects of tidal energy development in the province, a factor further mirrored by the complexity of CAs operating in relation to the SMPTE under various statutes established in this paper, particularly in comparison to the Scottish context. In line with the SMPTEs key driver of developing a streamlined licensing and consenting process of TCT testing and development, the European Community (EC) decided to eliminate uncoordinated and complex administrative licensing procedures in relation to offshore wind development by recommending the adoption of one-stop-shops for application 
processing, providing assistance to applicants, issuing clear guidelines for authorization procedures with clear attribution of responsibilities, disseminating guidance on the interactive functionality of associated environmental legislation, and establishing pre-planning mechanisms that spatially allocate areas of renewable energy specific deployment (Fournier, 2011).

Table 15: One-window standing committee governmental bodies

\begin{tabular}{|l|l|}
\hline \multicolumn{2}{|c|}{ PWSC Members on Tidal Energy Development in Nova Scotia } \\
\hline \multicolumn{1}{|c|}{ Provincial Authorities } & \multicolumn{1}{c|}{ Federal Authorities } \\
\hline Department of Energy (lead) & Natural Resources Canada \\
\hline Department of Environment & Environment Canada \\
\hline Department of Labour & Fisheries and Oceans Canada \\
\cline { 1 - 2 } Department of Fisheries and Aquaculture & Canadian Environmental Assessment Agency \\
\cline { 1 - 2 } Department of Natural Resources & Transport Canada \\
\cline { 1 - 2 } Office of Aboriginal Affairs & \\
\hline
\end{tabular}

The DoE has applied such best practices proposed by the EC, thereby mimicking the MSLOT. Although several governmental bodies are required to give consent to a permit application, under Section 25 of the MRE Act 2015, the DoE acts as a one-stop-shop to facilitate communication of approvals between applicants and the necessary regulatory authorities, thereby providing for a coordinated, accountable, and transparent licensing regime. While the MREAs set out in the MRE Act 2015 provide for pre-planned areas of TCT deployment, thereby meeting the EC recommendation criteria in full, the implementation of a SMPTE would further determine the prime economic, environmental, ecological, political, social, and cultural suitability of such areas and thereby demonstrate governance support and risk reduction which would work in conjunction with the DoE licensing system in order to attract investors and developers in a streamlined development process.

Although POAs identified in the SMPTE are chosen due to their overall suitability to host commercial scale tidal energy project developments, given the complexity of the marine environment in conjunction with the distinct risks associated with different project developments, there is no guarantee that a project within a POA will receive consent to obtain a license. If deemed necessary, commercial developments will be required to undertake projectlevel assessments that take into account issues raised during plan adoption, SEA, socio-economic assessment, and MEKS during screening and scoping stages for EIAs under the NSEA 1995 in projects $>2 \mathrm{MW}-<50 \mathrm{MW}$ and the NSEA and CEAA under the CEA Act 2012 in projects $>50 \mathrm{MW}$. In unison with the Scottish context, projects should also be considered for consent in areas outside POAs if an applicant can demonstrate that the project is economically viable and ecologically sustainable upon producing an agreed upon series of assessment reports (Marine Scotland, 2013a).

\subsection{Quality management review}

The practice of MSP construction and implementation is relatively new in and of itself, while the process of creating SMPs is even more infant, with Scotland being the first and only nation to devise a SMPTE under the broader policy and legislative context of their NMP. Due to the Scottish SMPTE's status as the first MSP of its kind, in conjunction with the infancy of commercial TCT deployment and the sensitivity of the marine environment, it is important that Scotland's SMPTE be constructed and updated with an effective QMS. In light of such contexts, Marine Scotland undertook a quality management review of their SMPTE against criteria set out 
in the ICES MSP QMS (Sangiuliano, 2016). The review demonstrated that the Scottish SMPTE scored 140/178, a 78.7\% conformity ranking against the ICES MSP QMS, suggesting a well established internal context, risk analysis and evaluation, and monitoring and review framework, translating into a MSP with a well defined overarching governance structure, mitigation measures accountability, and adaptive management framework. However, the establishment of the external context, and risk identification and treatment components ranked comparatively lower in conformity to the ICES MSP QMS, translating into gaps in key stakeholder consultation, potentially unidentified risks pertaining to the ecosystem approach to MSP, and untreated traditional, cultural, social, and economic risk. The recommendations put forth from the analysis are summarized in Table 14.

Due to the requirement for a strong quality management framework for MSPs proposing to deploy new technology in a sensitive and already stressed marine environment, this paper undertook a quality review of Nova Scotia's SMPTE in conformity to the ICES MSP QMS and in comparison to the Scottish SMPTE quality management review in order to define existing gaps in the regulatory regime stemming from current research within the province and inform areas where a newly constructed SMPTE for the province can start fresh and learn off of the quality management gaps demonstrated in the Scottish SMPTE. Overall, the proposed Nova Scotia SMPTE scored $154 / 178$, an $86.5 \%$ conformity ranking, 14 points and a $7.8 \%$ increase in relation to Scotland's review. Since criteria under the seven components structured in the quality management review that demonstrated conformity to the ICES MSP QMS are presented in Appendix B, the following sub-sections of the paper focus on the persisting gaps identified and the areas improved upon in relation to the Scottish quality management review.

Table 16: Scottish SMPTE quality management review recommendations adapted from Sangiuliano (2016)

Scottish SMPTE Quality Management Review Recommendations

1. Industry and community stakeholder goals and objectives should be established and published at the beginning of the engagement process under a set timeframe.

2. A formalized consultation, feedback, communication, and decision making regime internal to MS should be established with regards to the SMPTE process.

3. The SMPTE should strengthen its ecosystem protection agenda so that internal and external stakeholders can work together to define significant ecosystem components, and therefore potential ecological interactions between marine species and functions with commercial-scale TCT deployment will be better understood by the public.

4. The SMPTE should quantify ecosystem services and identify ecosystem boundaries while establishing criteria to determine the significance allotted to significant drivers and determine the spatial, temporal, and magnitude of driver activities within and outside the management area that may compromise such ecosystem services within ecosystem boundaries.

5. Components of the cause and effect analysis should be quantified in order to better inform ecosystem services, impacts and consequences, economic consequences, driver conflicts, and legal repercussions, and subsequently the risk profile and significant driver activities and pressures in which cause and effect analysis components directly feed in to, as the SMPTE and the tidal energy industry develops in the near future.

6. An individual or group of individual MS employees should be delegated responsibility to review the risk register in order to provide for a more structured and accountable SMPTE process.

7. The SMPTE should establish criteria to identify economic, technical, financial, social, traditional, and cultural management options pertaining to the treatment of risk, and the associated consultation measures to inform such criteria, in order to effectively alleviate and/or mitigate the potential for risk in relation to tidal energy development within and outside the SMPTE management area.

8. It is recommended that criteria be established to identify cultural and socio-economic monitoring measures, and the associated human and financial resources required to implement such measures as the SMPTE and tidal energy industry develop in the near future. 
As referenced in Appendix B, boxes hosting component heading shaded in light blue denote the components relation to the marine development agenda of the SMPTE, boxes hosting component heading shaded in light green denote the components relation to the ecosystem protection agenda of the SMPTE, and boxes hosting component heading shaded in beige denote the components relation to the the general regulatory framework of the SMPTE. Furthermore, criteria was considered to be in conformity with the ICE MSP QMS if the appropriate functions and processes were either already in place are denoted by black text, or could easily be suggested as amendments to current regulatory frameworks are denoted in purple text, while areas where suggested quality management criteria could improve upon gaps in Scotland's quality management review are denoted in gold text, and areas where there was no such process in place, for the Scottish context, and not enough research has been conducted to easily allow for a conformity allocation, in the Nova Scotia context, are denoted in red text.

\subsubsection{The establishment of the external context}

The establishment of the external context component scored $4 / 6$, a $66.7 \%$ conformity ranking, one point (16.7\%) greater than the Scottish SMPTE. Gaps were identified in the marine development agenda of the SMPTE in relation to the absence of the identification of goals and objectives of industry and community stakeholders, similar to the Scottish context. Therefore, it is recommended that goals and objectives of industry and community stakeholders be identified through a series of workshops and in consultation with governmental organizations listed in the OWSC. The ecosystem protection agenda demonstrated gaps in relation to the absence of ecosystem management outcome indicators and targets to be achieved, in unison with the Scottish context. While broad ecosystem indictors, including biodiversity and seabed and coastal processes distinct to the Bay of Fundy and Cape Breton and the Bras d'Or region have been identified, consideration of ecosystem management outcomes and targets for the SMPTE itself have not been defined. It is therefore recommended that the quantification of ecosystem services be established through governmental, academic, and industry research in order to provide a baseline of the value that the provincial marine environment affords to both the provincial and national economy.

However, the Nova Scotia SMPTE has improved upon the Scottish SMPTE in the ecosystem protection agenda by establishing ecosystem boundaries in conformity to suggested best practices of applying an ecosystem approach to MSP (Douvere, 2008). While regional boundaries employed in Scotland's SMPTE conform to the six marine planning regions established in the NMP for purposes of further detailed evaluation in relation to sectoral planning, which follow no set criteria for their establishment in relation to the dynamic ecological complexities of the natural marine environment, ecosystem boundaries have been established in relation to the planning boundaries of the Nova Scotia SMPTE based on the identification of spatially persisting occurrence rates of various flora, fauna, and oceanographic processes within and outside the established provincial marine management boundaries.

\subsubsection{The establishment of the internal context}

The establishment of the internal context component scored 72/73, a $98.6 \%$ conformity ranking, 12 points $(14.1 \%)$ greater than the Scottish SMPTE. Gaps were identified in the general regulatory framework of the SMPTE in relation to the absence of a formal appeal process where a decision is not being understood, accepted, and/or tolerated by the public, in unison with the Scottish context. Although community stakeholders can ask the DoE questions about and provide feedback into the SMPTE process, the lack of a legislative appeal process under the 
overriding MRE Act 2015 can lead to lengthy and costly legal disputes. It is recommended that the MRE Act 2015 be revised to incorporate such an appeal process.

However, the Nova Scotia SMPTE has improved upon the Scottish SMPTE in the general regulatory framework by strengthening the consultation and feedback process through a proposed formal structure for consultation procedures for members of the governance body in order to mimic best practices and facilitate a more concise method of disseminating information to avoid the potential for confusion, lack of accountability and reliability, and subsequently affect the external engagement procedures with industry and community stakeholders (Cormier et al., 2015). The OWSC involved in the SMPTE process should engage in a minimum of one formal mandatory meeting for each stage within each phase of the SMPTE process to review the achievement of desired outputs and alter trajectories of the process in light of data gaps, with ancillary meetings held as needed. After the scoping meeting, which initiates the first outputs SMPTE process, all other meetings should consist of two agendas; a review of the completed stage and a development of the agenda for the next stage. It is also recommended that meetings be held to both develop and review the entirety of each of the three process phases and the resulting licensing output phase to establish and analyze the goals and objectives of each phase in relation to the key drivers and strategic aims established in the SMPTE. Such meetings facilitate communicate between the governance structure with senior MSP management, thereby promoting cohesion of goals, objectives, and strategies throughout the regulatory regime. It is recommended that 9 members, one representative from each governmental department delegated to the OWSC, be required to form a quorum for decision-making or to reach a consensus on recommendations.

It is also advised that the DoE develop a formally structured consultation and feedback process internal to the DoE, granting access to the OWSC as applicable, where filing systems and communication tools (e.g. secure forums) are specific to the SMPTE process. Formal mandatory meetings developed to strengthen the consultation and feedback process should discuss and document how and why/why not advice emanating internally within the governance structure was incorporated, with such communication tools utilized to disseminate the formulated document. An individual internal to the DoE and employed in the SMPTE process should be delegated responsibility for managing information related to the SMPTE process stored in the suggested electronic records management system to be constructed by the DoE specific to the SMPTE, accessible internally to DoE members involved in the SMPTE process, and maintained and controlled by the DoE in accordance with existing practices employed within DoE. In order to provide quality assurance of the competencies of those working within the general governance framework, it is recommended that professional designations for scientific and technical experts delegated as a part of the SMPTE process possess professional accreditation in their field of expertise (e.g. planners should hold CIP accreditation), particularly those working within the DoE, as the acting MSP CA, the NSE and CEAA, as the joint ecosystem CAs with the DoE, and the DNR, as the other CA.

The Nova Scotia SMPTE has improved upon the Scottish SMPTE in the ecosystem protection agenda by strengthening ecosystem management outcomes through aligning them with established ecosystem boundaries and significant ecosystem features and services and safeguarding them through various policies set out in the SMPTE in relation to an ecosystem approach to MSP and the overarching legislation listed in the SMPTEs public policy agenda informing such policies. When applying such improvements to the ecosystem protection agenda, particularly in relation to improvements in the consultation and feedback process of the general 
regulatory framework within the establishment of the internal context, an overarching improvement in the SMPTE process materializes through enhanced cooperation between internal and external stakeholders and the governance structure through continual interactions that better define significant ecosystem components. This materialization has the potential to promote public understanding of potential ecological interactions between marine species and functions with TCT lifecycles, thereby working to reduce the potential for public backlash and subsequent delays in the SMPTE and TCT implementation process (Alexander et al., 2012).

\subsubsection{Risk identification}

The risk identification component scored 17/23, a 73.9\% conformity ranking, one point (4.3\%) greater than the Scottish SMPTE. Gaps were identified in the marine development agenda of the SMPTE in relation to management area regulatory requirements as the occupation rate and location of the drivers operating in the management area has not been quantified, in unison with the Scottish context. This dilemma is further exacerbated in the general regulatory framework as no quantifiable criteria has been employed to select significant drivers within the SMPTE management area to begin with. These gaps are due to the lack of baseline data within the province, the absence of a central governance structure currently in place, and a comprehensive Maritime Regional MSP or Canadian NMP, while the current state of research in the province reveals that the quantity of such metadata is lacking substantially in comparison to European nations with MSPs, while any data collected is either not publically available and/or not organized by an individual government department or agency. Is is ideally recommended that the above deficiencies be implemented in order to strengthen the identification of risk for the proposal of POAs emanating from the SMPTE process.

Such gaps are intrinsically linked to the ecosystem protection agenda as drivers operating outside the SMPTE management areas are not specified in detail within the SMPTE due to the lack of baseline data within the province, as well as the absence of a central governance structure currently in place and comprehensive MSP, thus exact judgements concerning the activities of drivers operating outside the SMPTE management area impacting the ecosystem integrity within the SMPTE management area cannot be made. This evokes the potential to jeopardize the integrity of the marine environment throughout the SMPTE process, as any risks left out of the risk register will eliminate them from the entire resulting risk management process (Cormier et al., 2015), which could have repercussions on public acceptability, financial investment, and ecosystem integrity, potentially leading to ongoing iterations of Phase 2 of the SMPTE process that can withhold the development of a strategic plan, the deployment of TCT, and GHG mitigation and renewable energy deployment targets.

While the Nova Scotia SMPTE has improved upon the Scottish SMPTE in the ecosystem protection agenda by establishing ecosystem boundaries for the SMPTE based on the identification of spatially persisting occurrence rates of various flora, fauna, and oceanographic processes within and outside provincial management boundaries, in unison with the Scottish context, ecosystem services have not been quantified, and therefore their validation can not be solidified in the SMPTE process in an in depth ecological and economic context. Furthermore, since drivers operating outside the management boundaries have not formally been identified and taken into consideration due to the lack of a comprehensive Maritime Regional MSP or Canadian NMP in place which would identify drivers from all sectors operating within the marine environment of the Canadian EEZ, as is the case in Scotland, the vulnerability of ecosystem services becomes enhanced. 
Taking all the gaps identified in the risk identification component in relation to the general regulatory framework, marine development agenda, and ecosystem protection agenda into consideration, it is recommended that research be undertaken in the province, as well as the nation, to quantify ecosystem services while establishing criteria to determine the significance allotted to significant drivers and determine the spatial, temporal, and magnitude of driver activities within and outside the management area that may compromise such ecosystem services. It is also recommended that the data emanating from such research be gathered in one server and be made publically available, as is the case with Scotland's NMPi. An overarching recommendation to such dilemmas is that Canada devise a NMP that sets out a list of policies in which a Regional Martime MSP, which would further inform a Nova Scotia provincial MSP that hosts the SMPTE, must conform with, as witnessed in Scotland.

\subsubsection{Risk analysis}

The risk analysis component scored $9 / 15$, a $60 \%$ conformity ranking, 2 points $(13.3 \%)$ lesser than the Scottish SMPTE. Gaps were identified in the general regulatory framework of the SMPTE in relation to potential impacts, consequences, and repercussions, as the potential economic losses or liabilities if activities are displaced or encroached on by the activities of other drivers occurring in the management area have not been quantified. Furthermore, while environmental and ecological risk criteria are integrated in the classification of the likelihood and extent of the events and consequences in Karsten's (2012) Tidal energy resource assessment map for Nova Scotia, with hydrology alterations in specific tidal current resource areas quantified as acceptable or unacceptable, and maximum sustainable deployment targets suggested in relation to such calculations, socioeconomic quantification of potential monetary changes incurred to other drivers operating in the SMPTE management boundary has not been undertaken due to the lack of quantitative economic baseline data within the province, as well as the absence of a central governance structure currently in place and comprehensive MSP, thereby hindering the overall assessment of sustainability of risk criteria. In accordance with best practice emanating from the Scottish SMPTE process, it is recommended that environmental and ecological risk criteria be measured in likelihood and magnitude per planning region within the SMPTE through an updated SEA, while social and economic risk criteria be measured in likelihood and magnitude per planning region within the SMPTE through an updated socioeconomic assessment within the sustainability appraisal.

Gaps were also identified in the ecosystem protection agenda of the SMPTE in relation to cause and effect analysis, in unison with the Scottish context. The pressure-activity-state changeimpact chain has yet to be defined as the SMPTE process undertook an opportunities and constraints approach rather than a pressures and impacts approach to assess the severity of impacts in accordance to the Scottish SMPTE. However, it is recommended that a pressureactivity-state change-impact chain be defined for relevant developments in accordance with the ecosystem approach to MSP, although this is not feasible with the current state of knowledge in the province due to the lack of baseline data within the province, as well as the absence of a central governance structure currently in place and comprehensive MSP.

The absence of the employment of a pressures and impacts approach working in conjunction with an opportunities and constraints approach leaves the analysis of the duration and trajectory or trajectories of the recovery and the feasibility of the mitigation or restoration strategies that could be implemented if natural recovery is not possible uninformed, and thereby absent from the risk matrix that would be inputted into the risk treatment component of a QMS 
(Cormier et al., 2015). Therefore, in unison with the quality management review recommendation made for Scotland's SMPTE, it is recommended that criteria of the cause and effect analysis be quantified in order to better inform ecosystem services, impacts and consequences, economic consequences, driver conflicts, and legal repercussions, and subsequently the risk profile and significant driver activities and pressures in which cause and effect analysis components directly feed in to (Sangiuliano 2016).

\subsubsection{Risk evaluation}

The risk evaluation component scored $15 / 15$, a 100\% conformity ranking, 1 point $(6.7 \%)$ greater than the Scottish SMPTE. The Nova Scotia SMPTE has improved upon the Scottish SMPTE in the marine development agenda by suggested that one member of the DoE involved in the SMPTE process be delegated the responsibility to review and keep the risk register up-todate as decisions to develop new or enhanced management measures are made to provide for a more structured and accountable regulatory governance structure.

\subsubsection{Risk treatment}

The risk treatment component scored $12 / 16$, a $75 \%$ conformity ranking, 2 points $(12.5 \%)$ greater than the Scottish SMPTE. Gaps were identified in the general regulatory framework of the SMPTE in relation to management options costs, benefits, and feasibility, in unison with the Scottish context. The costs of implementing the management options such as training, equipment acquisition, changes to procedures, and impacts on production efficiency have not been quantified for the SMPTE due to the lack of baseline data on environmental, ecological, social, economic, cultural, legal, and industry procedures and processes within the province that would inform the scale of cooperation within and between government and stakeholders to apply the SMPTE process.

This dilemma runs in parallel with the absence of criteria established to assess and classify the level of social demand, acceptance and/or tolerance and consultation processes used to demonstrate how the management measures reduce risks to traditional, cultural, social, and economic ecosystem services. Therefore, in unison with the quality management review recommendation made for Scotland's SMPTE, it is recommended that the SMPTE establish criteria to identify economic, technical, financial, social, traditional, and cultural management options pertaining to the treatment of risk, and the associated consultation measures to inform such criteria, in order to effectively alleviate and/or mitigate the potential for risk in relation to tidal energy development within and outside the SMPTE management area (Sangiuliano, 2016). However, the Nova Scotia SMPTE has improved upon the Scottish SMPTE in the general governance framework through identifying the statutes delegating the structure of the SMPTEs public policy agenda and associated policy and programs of the CA that will need to be updated or changed as a result of implementing the management measures as the Oceans Act 1996 and the MRE Act 2015.

Gaps were identified in the marine development agenda of the SMPTE in relation to spatial and temporal management options, in unison with the Scottish context. The economic and technical feasibility of the proposed management options in terms of implementation, enforcement, and integration into operational activities has not been quantified by the SMPTE process due to the lack of quantitative economic baseline data within the province, as well as the absence of a central governance structure currently in place and comprehensive MSP. However, the Nova Scotia SMPTE has improved upon the Scottish SMPTE in the marine development 
agenda by achieving management measures that were SMART (Specific, Measurable, Achievable, Realistic, Time-bound).

While the Scottish SMPTE accounts for a monitoring and review period in two-year time intervals suggested in the SMPTE consultation draft, with the discovery of any criteria evoking a change in the SMPTE becoming subject to formal consultation and reporting, there is a lack of clarity and solidity on how management measures will be undertaken, the quantification of detrimental impacts that will deem tidal development projects no longer sustainable and acceptable, and the quantification of development objectives to be achieved. Adopting the monitoring and review framework set out in Scotland, the Nova Scotia SMPTE can improve to meet all of the SMART management objectives via the utilization of quantified limits of acceptable levels of energy extraction put forth by Karsten (2012) being formally adopted by the plan conditional to ongoing research and monitoring in relation to proposed objective targets for maximum sustainable development.

\subsubsection{Monitoring and review}

The monitoring and review component scored $25 / 30$, an $83.3 \%$ conformity ranking, 1 point $(3.4 \%)$ lesser than the Scottish SMPTE. Gaps were identified in the marine development agenda of the SMPTE in relation to cultural and socioeconomic monitoring, in unison to the Scottish context. No indicators of socio-economic performance monitoring have been developed and finalized at the moment due to the lack of quantitative economic baseline data within the province, as well as the absence of a central governance structure currently in place and comprehensive MSP, therefore negating the possibility to develop and finalize an agenda for the allotment of human and financial resources. It is recommended that criteria be established to identify socio-economic monitoring measures in an updated socioeconomic assessment within the sustainability appraisal of the SMPTE in order to inform the associated human and financial resources required to implement such measures.

Gaps were also identified in the ecosystem protection agenda of the SMPTE in relation to ecosystem status and trends monitoring, in unison to the Scottish context. Thresholds and criteria to ascertain the effectiveness of the management measures of the SMPTE in achieving the management outcomes have yet to be determined due to the lack of baseline data within the province, as well as the absence of a central governance structure currently in place and comprehensive MSP, and therefore resources available to conduct the ecosystem monitoring program have not been quantified.

Furthermore, in relation to the Scottish context, there is an insufficient amount of baseline ecosystem data for the province, thus making it difficult to establish such thresholds and subsequently conduct effective monitoring and review post TCT deployment. It is therefore recommended that baseline ecosystem data be collected and quantified for the SEA post-Phase 1 of the SMPTE process under categories pertaining to critical physical processes, fisheries, fish and fish habitat, benthic communities, pelagic communities, marine mammals, marine birds, species at risk as listed in the the previously completed Bay of Fundy and Cape Breton/Bras d'Or SEAs. It is also recommended that such data is utilized to establish environmental and ecological thresholds in an updated SEA covering the entirety of provincial waters within the sustainability appraisal of the SMPTE in order to inform the associated human and financial resources required to conduct the ecosystem monitoring program. 


\subsubsection{Summary}

Overall, the additions to the quality management framework of Nova Scotia's SMPTE suggested pre-emptively in relation to its construction have allowed for an enhanced QMS over the already established Scottish SMPTE, scoring 154/178, an 86.5\% conformity ranking, 14 points and a $7.8 \%$ increase in relation to Scotland's review. Slight improvements have been addressed in the risk evaluation and treatment components of the marine development agenda, via the delegation to responsibility to a DoE employee involved in the SMPTE process to maintain the risk register in order to ensure accountability and the quantification of detrimental impacts set out in the spatial and temporal management options derived from the risk register. The general regulatory framework has demonstrated significant improvements with regards to the establishment of the internal context, particularly with regards to the consultation and feedback processes set in place, thereby providing for a more organized and accountable governance structure with enhanced quality assurance in relation to the construction and execution of management measures. However, the risk analysis component of the Nova Scotia SMPTE demonstrated a lower conformity ranking in comparison to the Scottish SMPTE as economic impacts, consequences, and repercussions emanating from user - user conflicts could not be quantified due to the absence of baseline data which would inform a further iteration of the socioeconomic assessment portion of the sustainability appraisal, as was undertaken for Scotland's SMPTE (Marine Scotland, 2015a).

Table 17: ICES Marine Spatial Planning Quality Management System Conformity Comparison

\begin{tabular}{|c|c|c|c|c|}
\hline \multirow[b]{2}{*}{ QMS Components } & \multicolumn{2}{|c|}{$\begin{array}{r}\text { ICES MSP ( } \\
\text { Scotland } \\
\end{array}$} & \multicolumn{2}{|c|}{ Nova Scotia } \\
\hline & Score & $\begin{array}{c}\text { Conformity } \\
\%\end{array}$ & Score & $\begin{array}{c}\text { Conformity } \\
\%\end{array}$ \\
\hline Establishing the External Context & $3 / 6$ & 50 & $4 / 6$ & 66.7 \\
\hline Marine Development Public Policy Agenda & $2 / 3$ & 66.7 & $2 / 3$ & 66.7 \\
\hline Ecosystem Protection Public Policy Agenda & $1 / 3$ & 33.3 & $2 / 3$ & 66.7 \\
\hline Establishing the Internal Context & $61 / 73$ & 84 & $72 / 73$ & 98.6 \\
\hline $\begin{array}{l}\text { Marine Planning Legislation, Policies and } \\
\text { Authorities }\end{array}$ & $5 / 5$ & 100 & $5 / 5$ & 100 \\
\hline $\begin{array}{l}\text { Ecosystem Legislation, Policies and } \\
\text { Authorities }\end{array}$ & $5 / 5$ & 100 & $5 / 5$ & 100 \\
\hline Competent Authorities & $2 / 2$ & 100 & $2 / 2$ & 100 \\
\hline Industry Stakeholders & $3 / 3$ & 100 & $3 / 3$ & 100 \\
\hline Communities of Interest & $3 / 3$ & 100 & $3 / 3$ & 100 \\
\hline Consultation and Feedback Process & $0 / 4$ & 0 & $4 / 4$ & 100 \\
\hline Public & $1 / 1$ & 100 & $1 / 1$ & 100 \\
\hline Public Communication Procedures & $3 / 4$ & 75 & $3 / 4$ & 75 \\
\hline Scientific and Technical Advisory Bodies & $4 / 5$ & 80 & $5 / 5$ & 100 \\
\hline Scientific and Technical Advisory Process & $4 / 4$ & 100 & $4 / 4$ & 100 \\
\hline Governance Body & $2 / 2$ & 100 & $2 / 2$ & 100 \\
\hline Governance Terms of References & $2 / 6$ & 33.3 & $6 / 6$ & 100 \\
\hline Governance Business Rules & $5 / 5$ & 100 & $5 / 5$ & 100 \\
\hline Marine Spatial Planning Risk Criteria & $4 / 4$ & 100 & $4 / 4$ & 100 \\
\hline Ecosystem Management Outcomes & $3 / 4$ & 75 & $4 / 4$ & 100 \\
\hline MSP Management Outcomes & $5 / 5$ & 100 & $5 / 5$ & 100 \\
\hline MSP Secretariat & $10 / 11$ & 90.9 & $11 / 11$ & 100 \\
\hline Risk Identification & $16 / 23$ & 69.6 & $17 / 23$ & 73.9 \\
\hline Significant Ecosystem Components & $4 / 7$ & 57.1 & $6 / 7$ & 85.7 \\
\hline
\end{tabular}




\begin{tabular}{|l|c|c|c|c|}
\hline Significant Ecosystem Services & $3 / 5$ & 60 & $2 / 5$ & 40 \\
\hline Significant Driver Activities and Pressures & $3 / 4$ & 75 & $3 / 4$ & 75 \\
\hline $\begin{array}{l}\text { Management Area Regulatory } \\
\text { Requirements }\end{array}$ & $3 / 4$ & 75 & $3 / 4$ & 75 \\
\hline Risk Profile & $3 / 3$ & 100 & $3 / 3$ & 100 \\
\hline Risk Analysis & $\mathbf{1 1 / 1 5}$ & $\mathbf{7 3 . 3}$ & $\mathbf{9 / 1 5}$ & $\mathbf{6 0}$ \\
\hline Cause and Effect Analysis & $1 / 5$ & 20 & $1 / 5$ & 20 \\
\hline Impacts Consequences and Repercussions & $7 / 7$ & 100 & $6 / 7$ & 85.7 \\
\hline Risk Matrix & $3 / 3$ & 100 & $2 / 3$ & 66.7 \\
\hline Risk Evaluation & $\mathbf{1 4 / 1 5}$ & $\mathbf{9 3 . 3}$ & $\mathbf{1 5 / 1 5}$ & $\mathbf{1 0 0}$ \\
\hline Management Measures Evaluations & $4 / 4$ & 100 & $4 / 4$ & 100 \\
\hline $\begin{array}{l}\text { Existing Management Measures Acceptable } \\
\text { for the Marine Spatial Plan }\end{array}$ & $3 / 3$ & 100 & $3 / 3$ & 100 \\
\hline $\begin{array}{l}\text { New or Enhanced Management Measures } \\
\text { Needed for the Marine Spatial Plan }\end{array}$ & $5 / 5$ & 100 & $5 / 5$ & 100 \\
\hline Marine Spatial Risk Register & $2 / 3$ & 66.7 & $3 / 3$ & 100 \\
\hline Risk Treatment & $\mathbf{1 0 / 1 6}$ & $\mathbf{6 2 . 5}$ & $\mathbf{1 2 / 1 6}$ & $\mathbf{7 5}$ \\
\hline Spatial and Temporal Management Options & $1 / 3$ & 33.3 & $2 / 3$ & 66.7 \\
\hline Management Options Costs, Benefits and & $3 / 7$ & 42.9 & $4 / 7$ & 57.1 \\
Feasibility & & & & \\
\hline Marine Spatial Plan & $6 / 6$ & 100 & $6 / 6$ & 100 \\
\hline Monitoring and Review & $\mathbf{2 6 / 3 0}$ & $\mathbf{8 6 . 7}$ & $\mathbf{2 5 / 3 0}$ & $\mathbf{8 3 . 3}$ \\
\hline Marine Spatial Plan Implementation & $2 / 2$ & 100 & $2 / 2$ & 100 \\
\hline Compliance Verification and Auditing & $9 / 9$ & 100 & $9 / 9$ & 100 \\
\hline Ecosystem Status and Trends Monitoring & $6 / 8$ & 75 & $5 / 8$ & 62.5 \\
\hline Cultural and Socio-Economic Monitoring & $3 / 5$ & 60 & $3 / 5$ & 60 \\
\hline Marine Spatial Plan Periodic Review & $6 / 6$ & 100 & $6 / 6$ & 100 \\
\hline Total & $\mathbf{1 4 0 / 1 7 8}$ & $\mathbf{7 8 . 7}$ & $\mathbf{1 5 4 / 1 7 8}$ & $\mathbf{8 6 . 5}$ \\
\hline
\end{tabular}

\begin{tabular}{|l|l|}
\hline $\begin{array}{c}\text { Conformity } \\
\text { with ICES } \\
\text { MSP QMS (\%) }\end{array}$ & $\begin{array}{c}\text { Colour } \\
\text { Legend }\end{array}$ \\
\hline $0-9.9$ & \\
\hline $10-19.9$ & \\
\hline $20-29.9$ & \\
\hline $30-39.9$ & \\
\hline $40-49.9$ & \\
\hline $50-59.9$ & \\
\hline $60-69.9$ & \\
\hline $70-79.9$ & \\
\hline $80-89.9$ & \\
\hline $90-100$ & \\
\hline
\end{tabular}

Marine development agenda Ecosystem protection agenda General regulatory framework 
Although some improvements have been made to the ecosystem protection agenda for the Nova Scotia SMPTE in comparison to the Scottish SMPTE, particularly in relation to the establishment of ecosystem boundaries to further inform ecosystem management outcomes (Cormier et al., 2015), in compliance with best practices advocating for an ecosystem approach to MSP (Douvere, 2008), the ecosystem protection agenda remains an outstanding weak component, ranking $24 \%$ points lower than the general regulatory framework, and $22.1 \%$ points lower than the marine development agenda, thereby suggesting its absence in the SMPTE process.

The ecosystem protection agenda demonstrates considerable weakness in relation to the risk analysis component, particularly with regards to cause and effect analysis, in unison with the Scottish context. This is due in part to the infancy of the the tidal energy industry and SMPTEs, however, failure to define the consequences of risk are greatly attributable to the lack of quantification of ecosystem services world wide. If ecosystem service quantification work becomes a greater research field, decisions made pertaining to planning in a marine environment can be greatly informed with regards to the weight of significance place of particular ecosystem functions and species, as well as the monetary relationship they have with coastal communities and regional economies.

Table 18: ICES MSP QMS public policy agenda \& component conformity comparison

\begin{tabular}{|c|c|c|c|c|c|c|c|c|c|}
\hline \multicolumn{10}{|c|}{\begin{tabular}{l|}
\multicolumn{1}{|c}{ ICES MSP QMS } \\
\end{tabular}} \\
\hline $\begin{array}{l}\text { Public Policy } \\
\text { Agendas }\end{array}$ & Score & $\begin{array}{c}\text { Conformity } \\
\%\end{array}$ & Score & $\begin{array}{c}\text { Conform } \\
\text { ity } \%\end{array}$ & $\begin{array}{c}\text { QMS } \\
\text { Componen } \\
\text { ts }\end{array}$ & Score & $\begin{array}{c}\text { Conformity } \\
\%\end{array}$ & Score & $\begin{array}{c}\text { Conformity } \\
\%\end{array}$ \\
\hline $\begin{array}{l}\text { Marine } \\
\text { Developme } \\
\text { nt Agenda }\end{array}$ & $48 / 55$ & 82.3 & $50 / 55$ & 90.1 & & & & & \\
\hline $\begin{array}{l}\text { Marine } \\
\text { Development } \\
\text { Public Policy } \\
\text { Agenda }\end{array}$ & $2 / 3$ & 66.7 & $2 / 3$ & 66.7 & $\begin{array}{l}\text { External } \\
\text { Context }\end{array}$ & $2 / 3$ & 66.7 & $2 / 3$ & 66.7 \\
\hline $\begin{array}{l}\text { Marine } \\
\text { Planning } \\
\text { Legislation, } \\
\text { Policies and } \\
\text { Authorities }\end{array}$ & $5 / 5$ & 100 & $5 / 5$ & 100 & $\begin{array}{l}\text { Internal } \\
\text { Context }\end{array}$ & $10 / 10$ & 100 & $10 / 10$ & 100 \\
\hline $\begin{array}{l}\text { MSP } \\
\text { Management } \\
\text { Outcomes } \\
\end{array}$ & $5 / 5$ & 100 & $5 / 5$ & 100 & & & & & \\
\hline $\begin{array}{l}\text { Management } \\
\text { Area } \\
\text { Regulatory }\end{array}$ & $3 / 4$ & 75 & $3 / 4$ & 75 & $\begin{array}{l}\text { Risk } \\
\text { Identificati } \\
\text { on }\end{array}$ & $3 / 4$ & 75 & $3 / 4$ & 75 \\
\hline Requirements & & & & & $\begin{array}{l}\text { Risk } \\
\text { Analysis }\end{array}$ & & & & $\overline{\mathrm{T} / \mathrm{A}}$ \\
\hline $\begin{array}{l}\text { Management } \\
\text { Measures } \\
\text { Evaluations }\end{array}$ & $4 / 4$ & 100 & $\overline{4 / 4}$ & 100 & $\begin{array}{l}\text { Risk } \\
\text { Evaluation }\end{array}$ & $6 / 7$ & 85.7 & $7 / 7$ & 100 \\
\hline $\begin{array}{l}\text { Marine Spatial } \\
\text { Risk Register }\end{array}$ & $2 / 3$ & 66.7 & $3 / 3$ & 100 & & & & & \\
\hline $\begin{array}{l}\text { Spatial and } \\
\text { Temporal } \\
\text { Management } \\
\text { Options }\end{array}$ & $1 / 3$ & 33.3 & $2 / 3$ & 66.7 & $\begin{array}{l}\text { Risk } \\
\text { Treatment }\end{array}$ & $7 / 9$ & 77.8 & $8 / 9$ & 88.9 \\
\hline $\begin{array}{l}\text { Marine Spatial } \\
\text { Plan }\end{array}$ & $6 / 6$ & 100 & $6 / 6$ & 100 & & & & & \\
\hline $\begin{array}{l}\text { Marine Spatial } \\
\text { Plan } \\
\text { Implementatio }\end{array}$ & $2 / 2$ & 100 & $2 / 2$ & 100 & $\begin{array}{l}\text { Monitoring } \\
\text { \& Review }\end{array}$ & $20 / 22$ & 90.9 & $20 / 22$ & 90.9 \\
\hline
\end{tabular}




\begin{tabular}{|c|c|c|c|c|c|c|c|c|c|}
\hline $\mathrm{n}$ & & & & & & & & & \\
\hline $\begin{array}{l}\text { Compliance } \\
\text { Verification } \\
\text { and Auditing }\end{array}$ & $9 / 9$ & 100 & $9 / 9$ & 100 & & & & & \\
\hline $\begin{array}{l}\text { Cultural and } \\
\text { Socio- } \\
\text { Economic } \\
\text { Monitoring } \\
\end{array}$ & $3 / 5$ & 60 & $3 / 5$ & 60 & & & & & \\
\hline $\begin{array}{l}\text { Marine Spatial } \\
\text { Plan Periodic } \\
\text { Review }\end{array}$ & $6 / 6$ & 100 & $6 / 6$ & 100 & & & & & \\
\hline $\begin{array}{l}\text { Marine } \\
\text { Developme } \\
\text { nt Agenda }\end{array}$ & $23 / 37$ & 62.2 & $25 / 37$ & 68 & & & & & \\
\hline $\begin{array}{l}\text { Ecosystem } \\
\text { Protection } \\
\text { Public Policy } \\
\text { Agenda }\end{array}$ & $1 / 3$ & 33.3 & $2 / 3$ & 66.7 & $\begin{array}{l}\text { External } \\
\text { Context }\end{array}$ & $1 / 3$ & 33.3 & $2 / 3$ & 66.7 \\
\hline $\begin{array}{l}\text { Ecosystem } \\
\text { Legislation, } \\
\text { Policies and } \\
\text { Authorities }\end{array}$ & $5 / 5$ & 100 & $5 / 5$ & 100 & $\begin{array}{l}\text { Internal } \\
\text { Context }\end{array}$ & $8 / 9$ & 88.9 & $9 / 9$ & 100 \\
\hline $\begin{array}{l}\text { Ecosystem } \\
\text { Management } \\
\text { Outcomes }\end{array}$ & $3 / 4$ & 75 & $4 / 4$ & 100 & & & & & \\
\hline $\begin{array}{l}\text { Significant } \\
\text { Ecosystem } \\
\text { Components }\end{array}$ & $4 / 7$ & 57.1 & $6 / 7$ & 85.7 & \multirow[t]{2}{*}{$\begin{array}{l}\text { Risk } \\
\text { Identificati } \\
\text { on }\end{array}$} & \multirow[t]{2}{*}{$7 / 12$} & \multirow[t]{2}{*}{58.3} & \multirow[t]{2}{*}{$8 / 12$} & \multirow[t]{2}{*}{66.7} \\
\hline $\begin{array}{l}\text { Significant } \\
\text { Ecosystem } \\
\text { Services } \\
\end{array}$ & $3 / 5$ & 60 & $2 / 5$ & 40 & & & & & \\
\hline \multirow[t]{3}{*}{$\begin{array}{l}\text { Cause and } \\
\text { Effect Analysis }\end{array}$} & \multirow[t]{3}{*}{$1 / 5$} & \multirow[t]{3}{*}{20} & \multirow[t]{3}{*}{$1 / 5$} & \multirow[t]{3}{*}{20} & $\begin{array}{l}\text { Risk } \\
\text { Analysis } \\
\end{array}$ & $1 / 5$ & 20 & $1 / 5$ & 20 \\
\hline & & & & & $\begin{array}{l}\text { Risk } \\
\text { Evaluation }\end{array}$ & \multicolumn{2}{|c|}{$\mathrm{N} / \mathrm{A}$} & \multicolumn{2}{|c|}{ N/A } \\
\hline & & & & & $\begin{array}{l}\text { Risk } \\
\text { Treatment } \\
\end{array}$ & \multicolumn{2}{|c|}{ N/A } & \multicolumn{2}{|c|}{ N/A } \\
\hline $\begin{array}{l}\text { Ecosystem } \\
\text { Status and } \\
\text { Trends } \\
\text { Monitoring }\end{array}$ & $6 / 8$ & 75 & $5 / 8$ & 62.5 & $\begin{array}{l}\text { Monitoring } \\
\text { \& Review }\end{array}$ & $6 / 8$ & 75 & $5 / 8$ & 62.5 \\
\hline $\begin{array}{l}\text { General } \\
\text { Regulatory } \\
\text { Framework } \\
\end{array}$ & $70 / 86$ & 83.4 & $79 / 86$ & 92 & & & & & \\
\hline Competent & $2 / 2$ & 100 & $2 / 2$ & 100 & $\begin{array}{l}\text { External } \\
\text { Context }\end{array}$ & & & & \\
\hline Authorities & & & & & Internal & $43 / 53$ & 81.1 & $52 / 53$ & 98.1 \\
\hline $\begin{array}{l}\text { Industry } \\
\text { Stakeholders }\end{array}$ & $3 / 3$ & 100 & $3 / 3$ & 100 & Context & & & & \\
\hline $\begin{array}{l}\text { Communities } \\
\text { of Interest }\end{array}$ & $3 / 3$ & 100 & $3 / 3$ & 100 & & & & & \\
\hline $\begin{array}{l}\text { Consultation } \\
\text { and Feedback } \\
\text { Process }\end{array}$ & $0 / 4$ & 0 & $4 / 4$ & 100 & & & & & \\
\hline Public & $1 / 1$ & 100 & $1 / 1$ & 100 & & & & & \\
\hline $\begin{array}{l}\text { Public } \\
\text { Communicatio } \\
\text { n Procedures }\end{array}$ & $3 / 4$ & 75 & $3 / 4$ & 75 & & & & & \\
\hline $\begin{array}{l}\text { Scientific and } \\
\text { Technical } \\
\text { Advisory } \\
\text { Bodies }\end{array}$ & $4 / 5$ & 80 & $5 / 5$ & 100 & & & & & \\
\hline $\begin{array}{l}\text { Scientific and } \\
\text { Technical } \\
\text { Advisory } \\
\text { Process } \\
\end{array}$ & $4 / 4$ & 100 & $4 / 4$ & 100 & & & & & \\
\hline $\begin{array}{l}\text { Governance } \\
\text { Body }\end{array}$ & $2 / 2$ & 100 & $2 / 2$ & 100 & & & & & \\
\hline $\begin{array}{l}\text { Governance } \\
\text { Terms of } \\
\text { References }\end{array}$ & $2 / 6$ & 33.3 & $6 / 6$ & 100 & & & & & \\
\hline Governance & $5 / 5$ & 100 & $5 / 5$ & 100 & & & & & \\
\hline
\end{tabular}




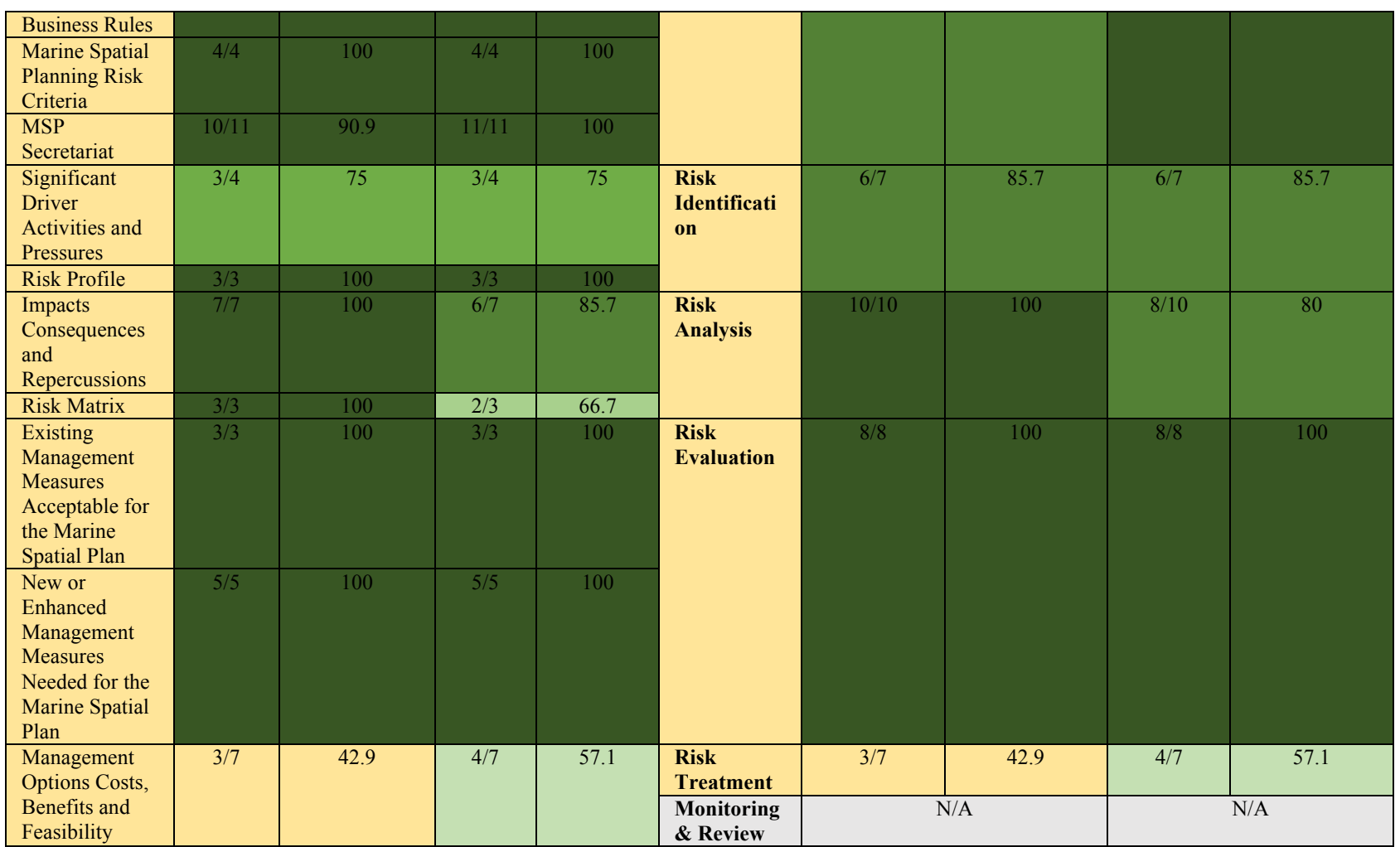

Table 19: Scottish sectoral marine plan for tidal energy quality management review recommendations

\begin{tabular}{|c|c|}
\hline & ICES MSP QMS Recommendations \\
\hline $\begin{array}{l}\text { QMS } \\
\text { Components }\end{array}$ & Public Policy Agenda \\
\hline \multirow[t]{2}{*}{$\begin{array}{l}\text { Establishing } \\
\text { the External } \\
\text { Context }\end{array}$} & $\begin{array}{l}\text { 1. it is recommended that goals and objectives of industry and community stakeholders be } \\
\text { identified through a series of workshops and in consultation with governmental organizations } \\
\text { listed in the OWSC }\end{array}$ \\
\hline & $\begin{array}{l}\text { 2. It is recommended that the quantification of ecosystem services be established through } \\
\text { governmental, academic, and industry research in order to provide a baseline of the value that the } \\
\text { provincial marine environment affords to both the provincial and national economy }\end{array}$ \\
\hline $\begin{array}{l}\text { Establishing } \\
\text { the Internal } \\
\text { Context }\end{array}$ & $\begin{array}{l}\text { 3. It is recommended that the MRE Act be revised to incorporate a formal appeal process where a } \\
\text { decision is not being understood, accepted, and/or tolerated by the public }\end{array}$ \\
\hline \multirow[t]{3}{*}{$\begin{array}{l}\text { Risk } \\
\text { Identification }\end{array}$} & $\begin{array}{l}\text { 4. it is recommended that research be undertaken in the province, as well as the nation, to quantify } \\
\text { ecosystem services while establishing criteria to determine the significance allotted to significant } \\
\text { drivers and determine the spatial, temporal, and magnitude of driver activities within and outside } \\
\text { the management area that may compromise such ecosystem services }\end{array}$ \\
\hline & $\begin{array}{l}\text { 5. It is recommended that the data emanating from such research be gathered in one server and be } \\
\text { made publically available }\end{array}$ \\
\hline & $\begin{array}{l}\text { 6. It is recommended that Canada devise a NMP that sets out a list of policies in which a regional } \\
\text { Martime MSP, which would further inform a Nova Scotia provincial MSP that hosts the SMPTE, } \\
\text { must conform with }\end{array}$ \\
\hline \multirow[t]{3}{*}{ Risk Analysis } & $\begin{array}{l}\text { 7. It is recommended that environmental and ecological risk criteria be measured in likelihood and } \\
\text { magnitude per planning region within the SMPTE through an updated SEA }\end{array}$ \\
\hline & $\begin{array}{l}\text { 8. It is recommended that social and economic risk criteria be measured in likelihood and } \\
\text { magnitude per planning region within the SMPTE through an updated socioeconomic assessment } \\
\text { within the sustainability appraisal }\end{array}$ \\
\hline & 9. It is recommended that a pressure-activity-state change-impact chain be defined for relevant \\
\hline
\end{tabular}




\begin{tabular}{|l|l|}
\hline \multirow{2}{*}{$\begin{array}{l}\text { Eisk } \\
\text { Evaluation }\end{array}$} & $\begin{array}{l}\text { 10. It is recommended that criteria of the cause and effect analysis should be quantified in order to } \\
\text { better inform ecosystem services, impacts and consequences, economic consequences, driver } \\
\text { conflicts, and legal repercussions, and subsequently the risk profile and significant driver activities } \\
\text { and pressures in which cause and effect analysis components directly feed in to }\end{array}$ \\
\hline $\begin{array}{l}\text { Risk } \\
\text { Treatment }\end{array}$ & $\begin{array}{l}\text { N/A } \\
\text { financial, social, traditional, and cultural management options pertaining to the treatment of risk, } \\
\text { and the associated consultation measures to inform such criteria, in order to effectively alleviate } \\
\text { and/or mitigate the potential for risk in relation to tidal energy development within and outside the } \\
\text { SMPTE management area }\end{array}$ \\
\hline $\begin{array}{l}\text { Monitoring } \\
\text { and Review }\end{array}$ & $\begin{array}{l}\text { 12. It is recommended that criteria be established to identify socio-economic monitoring measures } \\
\text { in an updated socioeconomic assessment within the sustainability appraisal of the SMPTE in order } \\
\text { to inform the associated human and financial resources required to implement such measures }\end{array}$ \\
\cline { 2 - 3 } $\begin{array}{l}\text { 13. It is recommended that baseline ecosystem data should be collected and quantified for the SEA } \\
\text { post-Phase 1 of the SMPTE process under categories pertaining to critical physical processes, } \\
\text { fisheries, fish and fish habitat, benthic communities, pelagic communities, marine mammals, } \\
\text { marine birds, species at risk as listed in the the previously completed Bay of Fundy and Cape } \\
\text { Breton/Bras d'Or SEAs }\end{array}$ \\
\cline { 2 - 3 } & $\begin{array}{l}\text { 14. It is recommended that baseline ecosystem data be utilized to establish environmental and } \\
\text { ecological thresholds in an updated SEA covering the entirety of provincial waters within the } \\
\text { sustainability appraisal of the SMPTE in order to inform the associated human and financial } \\
\text { resources required to conduct the ecosystem monitoring program }\end{array}$ \\
\hline
\end{tabular}

Finally, the overarching absences in the SMPTE process, extending to the marine development agenda, ecosystem protection agenda, and general regulatory framework for both Nova Scotia and Scotland first arise in the risk identification component of the QMS, and remain persistent throughout the quality management review up to and including the monitoring and review component. These overarching absences are in relation to to the lack of baseline data within the province and the implementation of a comprehensive Maritime Regional MSP or Canadian NMP. Without baseline data from which to draw upon, it becomes difficult to make informed decisions backed by measurable benchmarks (Kahraman and Kaya, 2010). This dilemma is further exacerbated in the Nova Scotia and Canadian contexts as any data available is either not aggregated into one database, and normalized as such, and/or is not publically accessible. This runs in contrast with the best practice approach undertaken by Scotland, where all data layers utilized for the SMPTE process are organized and made publically available under the National Marine Plan Index (NMPi) (Marine Scotland, 2014).

Moreover, despite recommendations pertaining to an enhanced research focus on data collection, specifically with regards to ecosystem services and economic baselines, in conjunction with the development of a centrally aggregated and accessible database similar to the NMPi, the lack of overarching MSP policies established at a federal level to structure regional MSPs containing provincial MSPs and SMPs diminishes the ability for streamlined trans-governmental cooperation, legislative and jurisdictional authority, and associated accountability. Until such a framework is in place, disaggregation and lack of communication between various vertically and laterally stratified government agencies and departments will persist, thereby hindering a uniform initiative with the strategic goal of promoting a sustainable economy while upholding ecosystem integrity, which are essentially the core principals to an 
ecosystem approach towards MSP (Douvere, 2008). A complete list of recommendations emanating from the quality management review are presented in Table 17.

\section{Key Recommendations}

Given vast vast tidal current resource potential of the Bay of Fundy, in conjunction with the capacity building in place in Nova Scotia, supply chain capabilities, potential for an industry cluster in the province, the amount of money that the provincial and federal government have allocated in the industry, and the heavy reliance on fossil fuels as an electricity source, it would be a shame if the industry never takes off in the province. Throughout all of the interrelated processes analyzed in this paper related to the construction of a strategic plan with the goal of organizing jurisdictional boundaries to legislated authorities to producing a SMPTE that identifies a plethora of user - user and user - environment conflicts in order to allocate the most suitable areas of TCT deployment in provincial TZ waters through the identification of POAs, a number of recommendations can be made in response to data gaps and an absence of regulatory structure.

First and foremost, the organizations currently engaged in the tidal energy industry in Nova Scotia, many of which were encouraged to participate as a part of the STAP for this paper, should follow through with the recommendations emanating from the reports produced either directly from their research or for their organization. Marine Renewable Energy Legislation (Fournier, 2011), Marine Renewable Energy Strategy (Department of Energy, 2012), Scoping Study on Socio-Economic Impacts of Tidal Energy Development in Nova Scotia (Howell and Drake, 2012), Community and Business Toolkit for Tidal Energy Development (ATEI, 2013), Background Report for the Fundy Tidal Energy Strategic Environmental Assessment (Jacques Whitford, 2008), Fundy Tidal Energy Strategic Environmental Assessment Final Report (OEERA, 2008), Strategic Environmental Assessment Update (AECOM, 2014), Background Report to Support a Strategic Environmental Assessment for the Cape Breton Coastal Region, Inclusive of the Bras D'Or Lakes (AECOM, 2012), and OERA Marine Renewable Energy Strategic Environmental Assessment Cape Breton Coastal Region and Bras d'Or Lakes Phase II - Community Response Report (Stantec, 2014) are just some publications employing the involvement of some of the STAP members that advocate for the need for a strategic plan of sorts in order to move the tidal energy industry in the province into the commercial-deployment stage. In the case of TCTs operating in the marine environment, this strategic plan would manifest most directly with the construction and implementation of a provincial SMPTE.

However, the lack of interest demonstrated on behalf of the STAP, subsequently leading to their informal withdrawal from the project, demonstrates either a lack of desire to followthrough on their recommendation of constructing a strategic plan and/or a misunderstanding of what MSP actually is. Regardless, there several other governmental factors inhibiting the construction and implementation of a MSP of sorts. While a SMPTE is a strategic way to facilitate a regulatory regime that streamlines licensing and consenting procedures, and subsequently promotes the sustainable commercial-scale deployment of TCTs via a reduction in financial risk to government, communities, developers, and investors, and an increase in government and community support through the identification of POAs which takes into consideration technological, political, legal, environmental, ecological, social, cultural, and economic factors, ideally a SMPTE should reside within the context of an overarching provincial MSP. 
Moreover, given the geographical size of Canada and the resulting variation of ecosystem complexities, a Maritime Regional MSP should be drafted which takes into account drivers operating within the management boundaries of the Maritime Region in order to inform policies set out in the provincial Nova Scotia MSP, and the resulting SMPTE, which would represent only one industry operating within established provincial marine planning boundaries. Ideally, and in conformity to best practices witnessed in Europe, the provincial MSP would regulate spatial uses within provincial boundaries for various sectors identified in the province, such as aquaculture, shipping, commercial fishing, etc. These identified industries, whose data was incorporated into the SMPTE scoping analysis, could draw upon the same data and SMP process utilized in this paper in order to construct their own sectoral plans which attribute constraint weightings to other users and uses of the marine environment within the context of their industry operations.

Such a sectoral exercise can then either overlay constraint layers with attributed weightings fin order to identify a provincial MSP which can include separate sectoral plans under the provincial banner, in unison with the framework utilized in Scotland (Marine Scotland, 2014) or just employ a non-sectoral based overarching provincial MSP, in unison with the framework utilized in Germany (German Federal Agency for Marine Conservation, 2006). In order to account for an ecosystem approach to MSP, the Regional Maritime MSP would provide policies and data on the drivers operating and marine functions persisting outside of the provincial marine planning boundaries, and therefore SMPs which are in conformity with the policies set out in the Nova Scotia MSP can take into account impacts that developments internal to Nova Scotia waters has on industries and ecosystem functions located outside of provincial planning boundaries either in the Canadian EEZ or the MSP boundaries or bordering provinces such as New Brunswick and Prince Edward Island. Finally, a Canadian National MSP should be implemented that established a number of policies in which the Maritime Regional MSP must be in conformance with, thereby informing the policies of the Provincial MSP that hosts the SMPTE.

The public policy agenda of the SMPTE presented in this paper was based off of the restructuring of current legislation and policies in place in Nova Scotia and Canada, and therefore, in order to devolve powers to plan for the marine environment from Transport Canada and the DFO in relation to issues that may impede or obstruct marine transport the public right to fish (Fournier, 2011), to the DoE as the MSP CA, it was recommended that the federal government delegate administrative authority with regards to TCT projects to the province via the establishment of prescribed regulations under the Oceans Act 1996. However, in the absence of immediate necessities to facilitate transition Nova Scotia's tidal energy industry from the precommercial to the commercial stage, it is ideally recommended that new legislation be written that provides for jurisdictional provincial planning boundaries as well as an established provincial regulatory authority, in order to establish a more concrete regulatory framework backed by a single comprehensive piece of legislation, thereby avoiding regulatory issues demonstrated in the USA case study presented in section 5.2.3.1., and as is currently the case in the Nova Scotia and Canadian contexts. This method has been utilized in Scotland via the Marine and Coastal Access Act 2009, which devolved powers to plan for the Scottish EEZ from the UK government to Marine Scotland, and the Marine Scotland (2014) Act 2010, which legislated Marine Scotland as the CA for the Scottish TZ.

Running in parallel with the above recommendation, it is suggested that a new governmental department be created and authorized with powers to plan for Nova Scotia's TZ 
under the newly created legislation. The DoE was recommended as the MSP CA for this paper due to the establishment of the MRE Act 2015 which loosely provides for such powers in relation to tidal energy development. However, in the establishment of the recommended overarching provincial MSP, which would identify and plan for other sectors operating within the legislated TZ, either by sectors or uniformly, and therefore a substantial amount of provincial legislation would inhibit the DoE from planning for aquaculture, shipping, commercial fishing, and other sectors. A newly created governing body legislated under a new MSP specific statute would not only account for the regulatory and authoritative complexities associated with the involvement of various sectors, it would also establish a single CA rather than two separate ecosystem CAs in the NSE and CEAA whose joint involvement is predicated on deployment capacity under the NSEA 1995 and CEA Act 2012, as well as the DNR as the other CA via the Crown Lands Act 2012. This system of a single responsible and accountable regulatory authority under MSP specific legislation is once again demonstrated in the Scottish context with Marine Scotland acting as the sole CA.

In order to properly inform the strategic siting of TCTs, as well as MSP in general throughout the province and nation, it is recommended that greater data analysis be undertaken and mapped to enhance spatial decision making procedures. Tidal current resource assessments have to be carried out in more depth, particularly in the Cape Breton region, as they provide for the initial analysis of TCT deployment suitability. Prior to conducting such resource assessments, no decisions should be made regarding the legislation of MREAs and allocation of FITs and COMFITSs as has been demonstrated through an analysis of the timeline of the industry in Nova Scotia, as such decisions provide information on potential suitability to the public where no suitability is apparent, thereby facilitating distrust in government amongst community members, investors, and developers in the competencies of regulators, research organizations, and advocates for the tidal energy industry. The analysis on this paper demonstrated from the initial scoping stage that there was insufficient Vmsp in Digby Gut, Great Bras d'Or Channel, and Barra Straight, all of which were either designated as Marine Renewable-energy Priority Areas and MREAs or awarded FITs and COMFITs.

Once appropriate resource assessment is undertaken, the data should be mapped and made publically available through a central database which normalizes all data applicable to MSP in the province, as is the case with Scotland's NMPi (Marine Scotland, 2014). This data would have informed this paper to a greater degree of clarity as opposed to having to devise a linear correlation between power density maps and proposed current speeds presented in Karsten's (2012) Tidal energy resource assessment map for Nova Scotia. Furthermore, data pertaining to other aspects of the marine environment should be collated and mapped in their entirety, such as sediment data, which would have provided for another parameter of suitability assessment for this paper, instead, sediment information was restricted to the immediate coastal regions of Nova Scotia. Other areas of data pertaining to the marine environment require further research as well, which would have made it possible to map out the entire provincial marine boundary in one model as opposed to separate models employed in this paper for the southern Nova Scotia and Cape Breton. In particular, economic assessments of marine industries operating in Nova Scotia and the natural capital from which such industries draw upon should be studied further in depth prior to making concrete decisions pertaining to the suitability of tidal energy development.

While Nova Scotia seems to have the perfect resource availability, supply chai industries, scientific and technical expertise, and political climate to situate the province as a global leader 
in tidal energy development from an outsider's perspective, an in depth analysis undertaken in this paper suggests that the tidal energy industry requires further research and a solidified regulatory regime both provincially and federally in order to establish the province as an industry leader. In unison with the recommendations of various research publications, this paper advocates for the construction and implementation of a strategic plan in the form of a SMPTE which draws its policies from overarching comprehensive provincial, regional, and national MSPs. Whether it be a case of correlation or causation, European nations who have constructed and implemented MSPs have also implemented offshore renewable energy systems. In the case of Scotland, the implementation of a SMPTE within their NMP has established a concrete regulatory regime and strategic siting process which gives consideration to all industries and ecosystem functions persisting within their TZ and EEZ, and has subsequently facilitated and/or supported the first commercial-scale TCT array in the world. From Scotland to New Scotland, the younger province of Nova Scotia can learn from the best practices employed by its paternal figurehead nation via the construction and implementation of a SMPTE to meet renewable energy deployment and GHG emissions reductions targets.

\section{References}

AECOM. (2010). Strategic Environmental Assessment of the Offshore Renewable Energy Development Plan (OREDP) in the Republic of Ireland. Environmental Report Volume 2: Main Report. October 2010.

AECOM. (2012). Marine Renewable Energy: Background Report to Support a Strategic Environmental Assessment (SEA) for the Cape Breton Coastal Region, inclusive of the Bras D'Or Lakes. Retrieved from http://www.oera.ca/marine-renewable-energy/strategicenvironmental-assessment/sea-phase-ii-cape-breton-coastal-region/

AECOM. (2014). Tidal Energy: Strategic Environmental Assessment (SEA) Update for the Bay of Fundy. Retrieved from http://www.oera.ca/marine-renewable-energy/strategicenvironmental-assessment/sea-phase-ii-bay-of-fundy-update/

Acadia Tidal Energy Institute ATEI. (2013). Community and business toolkit for tidal energy development. Wolfville, Nova Scotia, Canada

Acadia Tidal Energy Institute ATEI. (2016). Nova Scotia tidal energy atlas v1.0: Tidal energy related data for the Bay of Fundy. Retrieved from http://tidalenergyatlas.acadiau.ca/

Alexander, K. A., Janssen, R., Arciniegas, G., O'Higgins, T. G., Eikelboom, T., and Wilding, T. A. (2012). Interactive marine spatial planning: Siting tidal energy arrays around the Mull of Kintyre. PLoS One, 7(1), e30031.

Atlantis Resources Ltd. (2015). Turbine Construction Contract with Lockheed Martin. Retrieved from http://atlantisresourcesltd.com/media-centre/atlantis-annoucements/79-atlantisannouncements/2015-annoucements/359-turbine-construction-contract-with-lockheedmartin.html

Ben Elghali, S. E., Benbouzid, M. E. H., and Charpentier, J. F. (2007, May). Marine tidal current electric power generation technology: State of the art and current status. In Electric Machines \& Drives Conference, 2007. IEMDC'07. IEEE International (Vol. 2, pp. 1407-1412). IEEE.

Bronfman, N. C., Jiménez, R. B., Arévalo, P. C., and Cifuentes, L. A. (2012). Understanding social acceptance of electricity generation sources. Energy Policy, 46, 246-252. 
Bryden, I. G., Couch, S. J., Owen, A., and Melville, G. (2007). Tidal current resource assessment. Proceedings of the Institution of Mechanical Engineers, Part A: Journal of Power and Energy, 221(2), 125-135.

Bryden, I. G., and Macfarlane, D. M. (2000). The utilisation of short term energy storage with tidal

Bryden, I., and Melville, G. T. (2004). Choosing and evaluating sites for tidal current development. Proceedings of the Institution of Mechanical Engineers, Part A: Journal of Power and Energy, 218(8), 567-577.

CBC Radio. (June 15, 2016). Bay of Fundy tidal turbines on hold over environmental concerns. Retrieved from http:/www.cbc.ca/radio/thecurrent/the-current-for-june-15-20161.3635918/bay-of-fundy-tidal-turbines-on-hold-over-environmental-concerns-1.3636006

Charlier, R. H. (2003). A "sleeper" awakes: tidal current power. Renewable and Sustainable Energy Reviews, 7(6), 515-529.

Clark, R. H. (2007). Elements of tidal-electric engineering (Vol. 33). John Wiley and Sons.

Cormier, R., Kannen, A., Elliott, M., and Hall, P. (2015). Marine Spatial Planning Quality Management System. ICES Cooperative Research Report, (327), 106.

Crown Estate, (2012). UK Wave and Tidal Key Resource areas project-Summary report. http://www.thecrownestate.co.uk/media/5478/u n -wave-and-tidal-key-resource-areastechnological-report.pdf

Daborn, G. R. (2016). Research tidal energy - marine life: The Nova Scotia experience.

Danish Energy Authority. (2005). Copenhagen strategy on offshore wind power deployment. Retrieved from http://www.ewea.org/index.php?id=203

Davies, I. M., Gubbins, M., and Watret, R. (2012). Scoping study for tidal stream energy development in Scottish waters. Scottish Government.

Department of Energy, N. S. (2010a). Final report - Renewable energy opportunities and competitiveness assessment study. Halifax, Nova Scotia.

Department of Energy, N. S. (2010b). Our electricity future: Nova Scotia's electricity plan 20152040. Retrieved from http://energy.novascotia.ca/electricity

Department of Energy, N. S. (2012). Marine Renewable Energy Strategy.

Department of Energy, N. S. (2016). Defined by the sea: Nova Scotia's ocean technology sector present and future.

Deutsch, L., Folke, C., and Skånberg, K. (2003). The critical natural capital of ecosystem performance as insurance for human well-being. Ecological Economics, 44(2), 205-217.

Doelle, M., Russell, D., Saunders, P., VanderZwaag, D., and Wright, D. (2006). Tidal Energy: Governance Options for NS. Agenda, 21, 6.

Douvere, F. (2008). The importance of marine spatial planning in advancing ecosystem-based sea use management. Marine policy, 32(5), 762-771.

Douvere, F., and Ehler, C. N. (2009). New perspectives on sea use management: initial findings from European experience with marine spatial planning. Journal of environmental management, 90(1), 77-88.

Douvere, F., Maes, F., Vanhulle, A., and Schrijvers, J. (2007). The role of marine spatial planning in sea use management: the Belgian case. Marine Policy, 31(2), 182-191.

Elghali, S. B., Benbouzid, M. E. H., and Charpentier, J. F. (2007, May). Marine tidal current electric power generation technology: State of the art and current status. In 2007 IEEE International Electric Machines and Drives Conference (Vol. 2, pp. 1407-1412). IEEE. 
EMEC. (2016). Grid-connected tidal test sites. Retrieved from http://www.emec.org.uk/facilities/tidal-test-site/

EPRI: Electric Power Research Institute. 2006. Nova Scotia Tidal In-Stream Energy Conversion (TISEC): Survey and Characterisation of Potential Project Sites.

Esteban, M., and Leary, D. (2012). Current developments and future prospects of offshore wind and ocean energy. Applied Energy, 90(1), 128-136.

EU. (2012). Blue Growth opportunities for marine and maritime sustainable growth. Communication from the commission to the European Parliament, the Council, the European Economic and Social Committee and the Committee on the Regions. COM (2012) 494 final.

Everett, R., Boyle, G., Peake, S., and Ramage, J. (2012). Energy systems and sustainability: power for a sustainable future. Oxford Univerity Press.

Foley, M. M., Halpern, B. S., Micheli, F., Armsby, M. H., Caldwell, M. R., Crain, C. M., Prahler, E., Rohr, N., Sivas, D., Beck, M. W., Carr, M. H., Crowder, L. B., Duffy, E. J., Hacker, S. D., McLeod, K. L., Palumbi, S. R., Peterson, C. H., Regan, H. M., Ruckelshaus, M. H., Sandifer, P. A., and Steneck, R. S. (2010). Guiding ecological principles for marine spatial planning. Marine Policy, 34(5), 955-966.

FORCE Fundy Ocean Research Center for Energy. (2013). Environmental effects monitoring report 2011-2013. Retrieved fromhttp://fundyforce.ca/environment/monitoring/

FORCE Fundy Ocean Research Center for Energy. (2013). Technology. Retrieved from http://fundyforce.ca/technology/

Fournier, R. (2011). Marine Renewable Energy Legislation: A Consultative Process. Report to the Government of Nova Scotia.

Fraenkel, P. L. (2002). Power from marine currents. Proceedings of the Institution of Mechanical Engineers, Part A: Journal of Power and Energy,216(1), 1-14.

Fraenkel, P. L. (2006). Tidal current energy technologies. Ibis, 148(s1), 145-151.

Fraenkel, P. L. (2010, October). Development and testing of Marine Current Turbine's SeaGen 1.2 MW tidal stream turbine. In Proc. 3rd International Conference on Ocean Energy.

Gee, K., Kannen, A., Glaeser, B., and Sterr, H. (2004). National ICZM strategies in Germany: A spatial planning approach. Managing the Baltic Sea (Schernewski, G., and N. Loser, eds.). Coastline Reports, 2, 23-33.

German Federal Agency for Marine Conservation. (2006). Marine Spatial Planning in the German Exclusive Economic Zone of the North and Baltic Seas: Nature Conservation Objectives and Principles. from https://www.bfn.de/fileadmin/MDB/documents/themen/meeresundkuestenschutz/downloads /Raumordnung-in-der-deutschen-AWZ/Marine_Conservation_MSP_EEZ.pdf

Grabbe, M., Lalander, E., Lundin, S., and Leijon, M. (2009). A review of the tidal current energy resource in Norway. Renewable and Sustainable Energy Reviews, 13(8), 1898-1909.

Griffiths, N. E. (1992). Contexts of Acadian history, 1686-1784. McGill-Queen's Press-MQUP.

Howell, A., and Drake, C. (2012). Scoping Study on Socio-Economic Impacts of Tidal Energy Development in Nova Scotia: A Research Synthesis and Priorities for Future Action. Fundy Energy Research Network: Wolfville, Canada.

Integrated Management Plan for the North Sea 2015 IMPNS2015, (2005). Interdepartmental Directors Consultative Committee. The Netherlands.

IPCC Intergovernmental Panel on Climate Change. (2014). Summary for policymakers. IPCC 5th Assessment Report. 
Jacques Whitford. (2008). Final Report: Background Report for the Fundy Tidal Energy Strategic Environmental Assessment. Retrieved from http:/www.oera.ca/marine-renewableenergy/strategic-environmental-assessment/

Johnson, K., Kerr, S., and Side, J. (2012). Accommodating wave and tidal energy-Control and decision in Scotland. Ocean and coastal management, 65, 26-33.

Kahraman, C., and Kaya, İ. (2010). A fuzzy multicriteria methodology for selection among energy alternatives. Expert Systems with Applications, 37(9), 6270-6281.

Karsten, R. (2012). Tidal energy resource assessment map for Nova Scotia. Acadia Tidal Energy Institute. Retrieved from http://www.oera.ca/marine-renewable-energy/tidal-researchprojects/resource-characterization/

Khan, M. J., Bhuyan, G., Iqbal, M. T., and Quaicoe, J. E. (2009). Hydrokinetic energy conversion systems and assessment of horizontal and vertical axis turbines for river and tidal applications: A technology status review. Applied Energy, 86(10), 1823-1835.

Lester, S. E., Costello, C., Halpern, B. S., Gaines, S. D., White, C., and Barth, J. A. (2013). Evaluating tradeoffs among ecosystem services to inform marine spatial planning. Marine Policy, 38, 80-89.

Li, Y., and Florig, H. K. (2006, September). Modeling the operation and maintenance costs of a large scale tidal current turbine farm. In OCEANS 2006 (pp. 1-6). IEEE.

MacDonald, M. (2011). Accelerating the deployment of offshore renewable energy technologies: final report.

Marine Renewable-energy Act. (2015). Retrieved from http://energy.novascotia.ca/ renewables/marine-renewable-energy/marine-renewable-energy-legislation

Marine Scotland (UK). (2013a). Planning Scotland's seas: Sectoral marine plans for offshore wind, wave, and tidal energy in Scottish waters consultation draft. http://www.gov.scot/Publications/2013/07/8702

Marine Scotland (UK). (2013b). Planning Scotland's seas: Sustainability appraisal for sectoral plans for offshore renewable energy in Scottish waters. http://www.gov.scot/Publications/2013/07/2403

Marine Scotland. (2013c). Tidal - regional locational guidance. Retrieved from http://www.gov.scot/Topics/marine/marineenergy/Planning/tidalrlg

Marine Scotland (UK). (2014). Scotland's national marine plan. Marine Scotland, Edinburgh(UK).

Marine Scotland (UK). (2015a). Planning Scotland's seas: Developing the socio-economic evidence base for offshore renewable sectoral marine plans in Scottish waters; Final report. http://www.gov.scot/Publications/2013/07/5841

Marine Scotland (UK). (2015b). Planning Scotland's seas: Habitats regulations appraisal of the sectoral marine plans for offshore renewable energy in Scottish waters; Draft summary report. http://www.gov.scot/Topics/marine/marineenergy/Planning/drafthra

Marine Scotland (UK). (2015c). Planning Scotland's seas: SEA of plans for wind, wave, and tidal power in Scottish marine waters; Environmental Report. http://www.gov.scot/Publications/2013/07/2403

Membertou Geomatics Consultants. (2009). Phase 1 - Bay of Fundy, Nova Scotia including the Fundy Tidal Energy Demonstration Project Site: Mi'kmaq ecological knowledge study

Membertou Geomatics Consultants. (2012). Phase 2 - Bay of Fundy, Nova Scotia including the Outer Bay of Fundy Tidal Energy Project Site Mi'kmaq Ecological Knowledge Study

MeyGen. (2016). Retrieved from www.meygen.com 
Myers, L. E., and Bahaj, A. S. (2012). An experimental investigation simulating flow effects in first generation marine current energy converter arrays. Renewable Energy, 37(1), 28-36.

Natural Resources Canada. (2016). Tidal energy project in the Bay of Fundy. Retrieved from http://www.nrcan.gc.ca/energy/funding/current-funding-programs/cef/4955

NOREL. (May, 2014). Under keel clearance - policy paper: Guidance to developers in assessing minimum water depth over tidal devises. Retrieved from https://www.gov.uk/government/uploads/system/uploads/attachment_data/file/373456/Unde r_Keel_Clearance_paper_May_14__FINAL.pdf

Offshore Energy Environmental Research Association. (2008). Fundy Tidal Energy Strategic Environmental Assessment Final Report. Retrieved from http://www.oera.ca/marinerenewable-energy/strategic-environmental-assessment/

O'Rourke, F., Boyle, F., and Reynolds, A. (2009). Renewable energy resources and technologies applicable to Ireland. Renewable and Sustainable Energy Reviews, 13(8), 1975-1984.

O'Rourke, F., Boyle, F., and Reynolds, A. (2010a). Tidal current energy resource assessment in Ireland: Current status and future update. Renewable and Sustainable Energy Reviews, 14(9), 3206-3212.

O'Rourke, F., Boyle, F., and Reynolds, A. (2010b). Tidal energy update 2009.Applied Energy, 87(2), 398-409.

OSPAR. 2010. Quality Status Report 2010: Regional Summaries. No. 154. OSPAR Commission. London. 176pp.

Pinfold, G. (2015). Value proposition for tidal energy development in Nova Scotia, Atlantic Canada and Canada. Report to OERA and ACOA

Pomeroy, R., and Douvere, F. (2008). The engagement of stakeholders in the marine spatial planning process. Marine Policy, 32(5), 816-822.

Sangiuliano, S. J. (2016). A quality management review of Scotland's sectoral marine plan for tidal energy. Scottish Marine and Freshwater Science. Vol 7 No 18

Stantec. (2014). OERA Marine Renewable Energy Strategic Environmental Assessment Cape Breton Coastal Region and Bras d'Or Lakes Phase II - Community Response Report. Retrieved from http://www.oera.ca/marine-renewable-energy/strategic-environmentalassessment/

Stelzenmüller, V., Lee, J., South, A., Foden, J., and Rogers, S. I. (2013). Practical tools to support marine spatial planning: a review and some prototype tools. Marine Policy, 38, 214227.

Tarbotton, M., and Larson, M. (2006). Canada ocean energy atlas (phase 1) potential tidal current energy resources analysis background. Report to Canadian Hydraulics Centre.

Tibbetts, J. (2002). Coastal cities: living on the edge. Environmental Health Perspectives, 110(11), A674.

Timmons, D., Harris, J. M., and Roach, B. (2014). The Economics of Renewable Energy. Global Development And Environment Institute, Tufts University, Medford, MA, 52.

Tougaard, J., Carstensen, J., Damsgaard Henriksen, O., and Teilmann, J. (2003). Short-term effects of the construction of wind turbines on harbour porpoises at Horns Reef. Hedeselskabet.

UN Atlas of the Oceans. (2010). Human settlements on the coast. Retrieved from http://www.oceansatlas.org/servlet/CDSServlet

Verdant Power. (2008, April). Overview: Marine Renewable Energy Technologies. Retrieved from http://dnr.alaska.gov/mlw/wslca/appendix_g/verdant_power_marine_renewables.pdf 
World Resource Institute. (2005). Millennium ecosystem assessment. Summary for decisionmakers, 2005.

Zhou, Z., Scuiller, F., Charpentier, J. F., Benbouzid, M., and Tang, T. (2014, November). An upto-date review of large marine tidal current turbine technologies. In 2014 International Power Electronics and Application Conference and Exposition (pp. 480-484). IEEE. 


\section{Appendix A}

Nova Scotia SMPTE Consultation Draft 


\section{NOVA SCOTIA \\ Department of Energy}

\section{Planning for Nova Scotia's \\ Marine Environment \\ Sectoral Marine Plan for Tidal Energy}

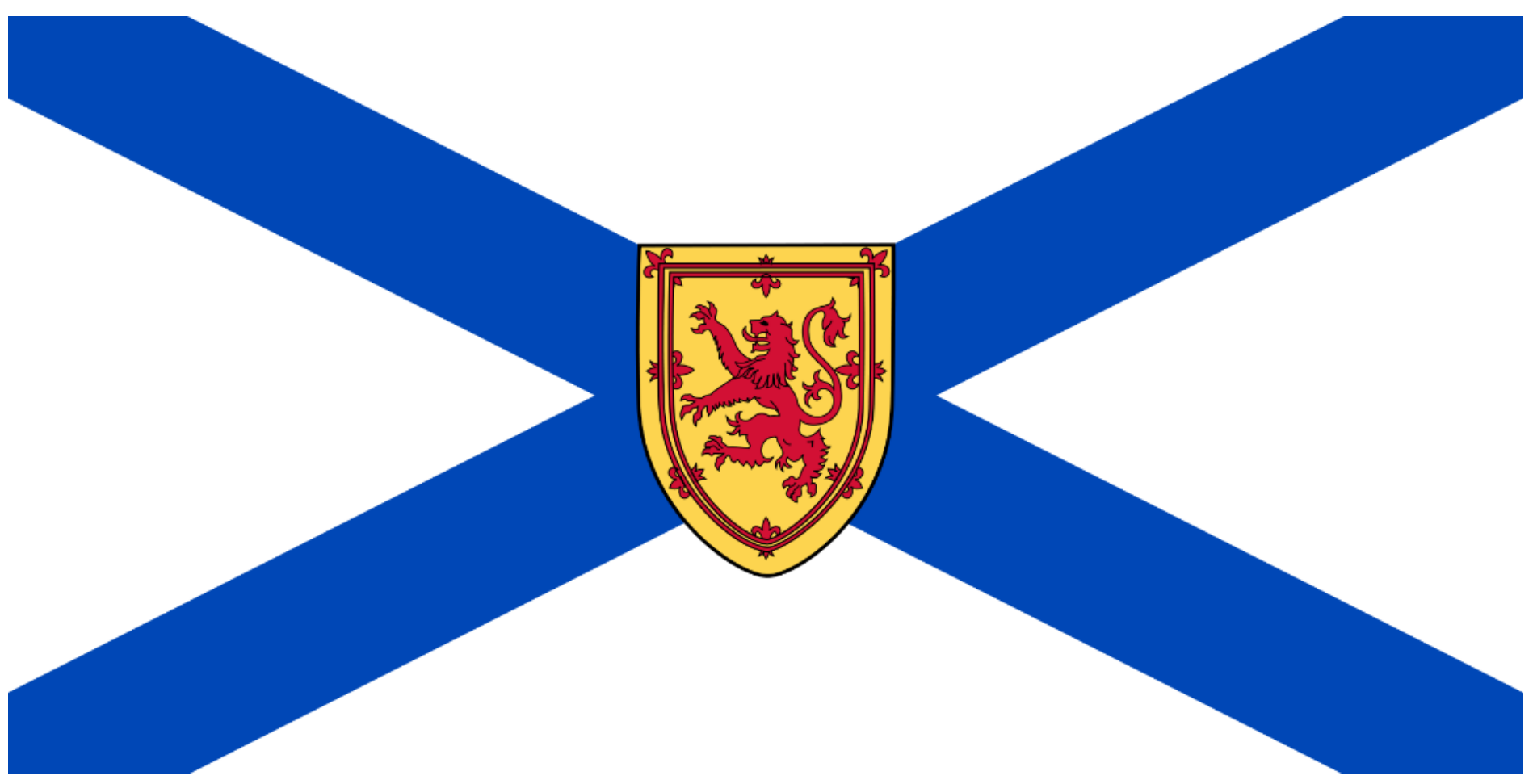


Stephen J. Sangiuliano

\section{Contents}

Executive Summary $\quad 80$

1. Introduction $\quad 81$

2. Vision $\quad 83$

3. Key Drivers $\quad 83$

4. Strategic Aims $\quad 84$

5. Key Stakeholders $\quad 84$

6. Sectoral Marine Planning Process $\quad 86$

7. Plan Option Areas (POAs) 90

List of Tables

- OWSC Members on Tidal Energy Development in Nova Scotia 82

- $\quad$ List of Stakeholders for Consultation in the SMPTE Process 84

- $\quad$ Adopted Plan Option Areas 90

List of Figures

- Nova Scotia Marine Planning Boundaries $\quad 82$

- Nova Scotia Ecoregions $\quad 83$

- $\quad$ Sectoral Marine Planning Process $\quad 87$

- $\quad$ Adopted POAs 91

- Minas Ecoregion Minas Passage POA 92

- Fundy Ecoregion Petit Passage POA 92

- Acadia Ecoregion Grand Passage POAs 93

\section{$\underline{\text { Executive Summary }}$}

The tidal current resource potential of Nova Scotia is enormous and is supported by local scientific and technical expertise and industry clusters that can proliferate the sustainable development of the tidal energy industry in the province, thereby facilitating the global export of such expertise and supply chains to other nations around the world with similar resource potential.

This Sectoral Marine Plan for Tidal Energy (SMPTE) demonstrates the next step in Nova Scotia's pursuit to harness the magnificent energy emanating from the Bay of Fundy by creating a solidified, accountable, and transparent governance structure that accounts for user - user and user - environment conflicts both within and outside of the marine planning boundaries of the province.

In accordance to best practices demonstrated in Europe, this SMPTE utilizes an ecosystem approach towards Marine Spatial Planning (MSP) in order to account for the enhanced and continued integrity of the marine ecosystem, thereby safeguarding the natural capital produced by healthy ecosystem functions that are intertwined with the provincial economy.

The SMPTE also takes into consideration technological, political, social, and cultural factors to further enhance the plausibility of meeting its strategic aims in a sustainable and inclusive framework. In line with such parameters, this SMPTE was constructed under a Quality Management System (QMS) to provide quality assurance to Nova Scotians that a plethora of factors were considered in constructing this SMPTE.

Public consultation is encouraged and incorporated throughout every stage of the SMPTE process both within and outside the province in order to account for potential far-field environmental effects of Tidal Current Turbine (TCT) deployment. Such public consultation is encouraged throughout the ongoing monitoring and review to account for further iterations of the SMPTE. 


\section{$\underline{\text { Introduction }}$}

1.1. The Nova Scotia Department of Energy (DoE), via the the establishment of prescribed regulations under the Oceans Act 1996 over the provincial 12nm territorial zone (TZ), retains regulatory authority to plan for Nova Scotia's marine jurisdiction. With the TZ, the DoE has constructed a SMPTE to identify POAs that demonstrate maximum suitability for TCT deployment by taking into consideration potential user - user and user - environment conflicts.

1.2. Through the identification of spatially persisting occurrence rates of various flora, fauna, and oceanographic processes within and outside the established provincial marine management boundaries, the SMPTE has established seven ecosystem boundaries which act as regional planning areas in compliance with the ecosystem approach to planning. These regional planning areas facilitate a more in depth analysis of ecosystem dynamics and associated coastal economies and community and heritage values to further inform TCT deployment suitability.

1.3. The SMPTE forms an integral part of a series of initiatives including but not limited to:

\subsubsection{Marine Renewable Energy Legislation: A Consultative Process}

\subsubsection{MRE Act 2015}

1.3.3. Environmental Goals and Sustainable Prosperity Act 2007

\subsubsection{Nova Scotia’s Electricity Plan}

\subsubsection{Marine Renewable Energy Strategy}

1.4. Under the Marine Renewable Energy (MRE) Act 2015, the DoE is the MSP Competent Authority (CA) for the construction and oversight of the planning process of the marine development agenda

1.5. Under the Nova Scotia Environment Act (NSEA) 1995, the Nova Scotia Department of Environment (NSE) jointly holds the position of Ecosystem CA with the DoE in tidal energy projects $>2 \mathrm{MW}-<50 \mathrm{MW}$

1.6. Under the Canadian Environmental Assessment (CEA) Act 2012, the Canadian Environmental Assessment Agency (CEAA) jointly holds the position of Ecosystem CA with the DoE and the NSE in tidal energy projects $=>50 \mathrm{MW}$

1.7. Under the Crown Lands 2012 Act, the Nova Scotia Department of Natural Resources (DNR) has proprietary rights over the seabed within provincial jurisdictional boundaries, and therefore is recognized as the Other CA

1.8. This SMPTE identifies _ POAs based on their resource potential, degree of suitability, and limited level of constraint with respect to persistent user - user and user - environment conflicts. A technical decision support making system, ArcGIS, was utilize to apply constraint and opportunity weightings and non-technical exclusion areas based on a proposed methodology, while Mi'kmaq Ecological Knowledge Studies (MEKSs), socioeconomic assessment, and Strategic Environmental Assessments (SEAs) further informed various fields that should be incorporated into further technical analysis with a sustainability appraisal. 
1.9. The assessment results emanating from the sustainability appraisal demonstrated identified strategic issues including but not limited to shipping, fishing, grid provision, habitat disruption, and hydrology alteration pertaining to TCT implementation. While the results don't necessarily demonstrate that adverse environmental, social, cultural, and economic impacts will materialized through development of proposed POAs, a lack of socio-economic baseline data within the province hindered the ability to incorporate spatially quantified monetary loses to other sectors operating within and outside the SMPTE management boundaries. It is therefore recommended that criteria be established to identify socio-economic monitoring measures in an updated socioeconomic assessment within the sustainability appraisal of the SMPTE.

1.10. Decisions concerning the construction of the general regulatory framework and decision making procedures of the SMPTE will involve four provincial and five federal bodies which make up the One-Window Standing Committee (OWSC) due to their relative legislative authority over particular aspects of tidal energy development in the province. The provisional regulatory members of the OWSC are as follows:

\begin{tabular}{|l|l|}
\hline \multicolumn{2}{|c|}{ OWSC Members on Tidal Energy Development in Nova Scotia } \\
\hline \multicolumn{1}{|c|}{ Provincial Authorities } & \multicolumn{1}{c|}{ Federal Authorities } \\
\hline Department of Energy (lead) & Natural Resources Canada \\
\hline Department of Environment & Environment Canada \\
\hline Department of Labour & Fisheries and Oceans Canada \\
\hline Department of Fisheries and Aquaculture & Canadian Environmental Assessment Agency \\
\hline Department of Natural Resources & Transport Canada \\
\hline Office of Aboriginal Affairs & \\
\hline
\end{tabular}

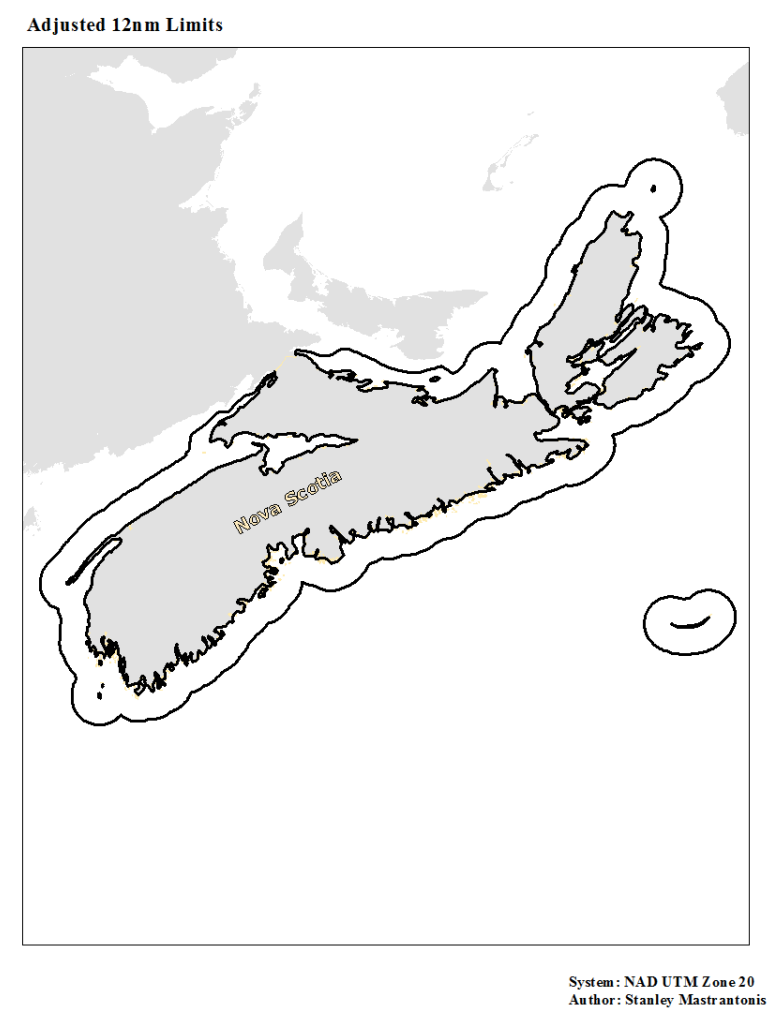




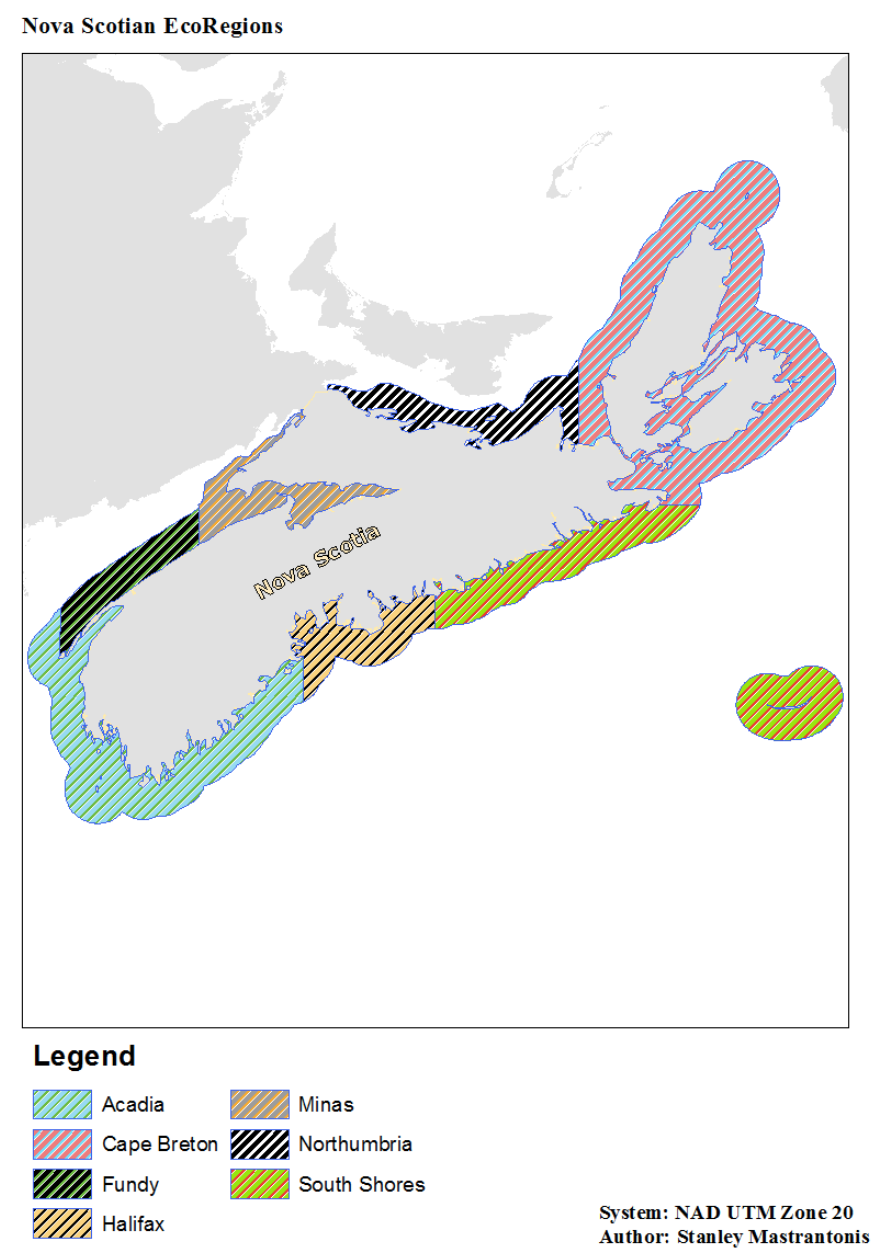

\section{$\underline{\text { Vision }}$}

2.2. A vision acts as a mission statement for the long-term aspirations of what the government believes it can achieve as a whole for the nation. The SMPTE was constructed with the following vision:

2.2.1. The Nova Scotia Government believes that Nova Scotia can become a global leader in the development of technology and systems that produce environmentally sustainable, competitively priced electricity from the ocean.

\section{$\underline{\text { Key Drivers }}$}

3.1. Key drivers are the political and governance context which is pushing the actions of the government through the construction of a plan to fulfill their vision. The SMPTE was constructed in response to the following key drivers:

3.1.1. Marine Planning - To assist with the development of a comprehensive policy framework for future decisions made at the project level

3.1.2. Marine Licensing - To streamline the licensing and consenting process of TCT testing and development 
3.1.3. Greenhouse Gas Emissions Reductions - To streamline the licensing and consenting process of TCT testing and development

3.1.4. Price Stability - To reduce provincial reliance on coal and inherent volatile prices and exchange it for indigenous resources, with TCTs contributing to a $40 \%$ renewable energy generation portfolio by 2020

\section{$\underline{\text { Strategic Aims }}$}

4.1. Strategic aims refer to the goals that the government has set out to achieve in response to the key drivers and towards the path to the government's vision. The SMPTE was constructed with to help achieve the following strategic aims:

4 1.1. Maximizing the aggregate installed capacity of tidal energy in Nova Scotia

4 1.2. Reducing imported electricity to increase the wealth within the province

4 1.3. Create a skilled labor force with industry expertise to be exportable internationally

4 1.4. Contribute to a more environmentally, economically, and socially sustainable Nova Scotia

\section{$\underline{\text { Key Stakeholders }}$}

5.1. Throughout the SMPTE process, the following key stakeholders will be sought out for consultation in order to provide for a transparent, inclusive, and participatory planning process.

5.2. It is worthy to note that this list of key stakeholders is by no means exhaustive or inclusive to those identified throughout the entirety of the SMPTE process as participation is encouraged by all for any stage of the SMPTE.

\begin{tabular}{|l|l|}
\hline \multicolumn{1}{|c|}{ List of Stakeholders for Consultation in the SMPTE Process } \\
\hline Fishing & Bay of Fundy Inshore Fishermans Association; Fundy Fixed Gear Council; Full Bay \\
Scallop Association; Striped Bass Association; Aquaculture Association of Nova Scotia; \\
Canadian Aquaculture Industry Alliance; 1688 Professional Lobster Fishermen \\
Assocation; 4Wd Gulf Tuna Association; 4Wd (Atlantic) Tuna Association; Acadia First \\
Nation; Annapolis County Clam Management Assoc; Area 18 Crab Fishermen's Assoc; \\
Area 19 Crab Fishermen's Association; Area 22 Offshore Crab; Area 23 Crab \\
Fishermen's Association; Area 24 Crab Fishermen's Association; Area 29-30 Fishermen's \\
Association; Area 30 Fishermen's Association; ASPANS Affiliation of Seafood \\
Producers Association of Nova Scotia; Atlantic Canadian Mobile Shrimp Association; \\
Atlantic Elver Fishery Association; Atlantic Groundfish Association; Atlantic Herring \\
Co-op; Atlantic Policy Congress of First Nations Chiefs; Atlantic Shark Association; \\
Bay of Fundy Inshore Fishermen's Association; Bay of Fundy Marine Resource Centre; \\
Big Bras D'Or Fishermen's Group; Canadian Association of Prawn Producers; Clam \\
Harvesting Area Two Clammers Association; Cold Water Lobster Association; \\
Commercial Fishers Holders of Yarmouth Co. Eel Licences Assoc.; Cumberland North \\
Fisherman's Assoc.; Digby/Annapolis/Kings Sea Urchin Mgmt Board; Digby County \\
Clam Diggers Association; East Cape Breton Fisherman's Association; East Cape Breton \\
Fishers Association; Eastern NS Mobile Gear Association; Eastern Shore Protective \\
Fishermans Assoc; Eastern Fishermen's Federation; ENS4X; Eskasoni Fish \& Wildlife \\
\hline
\end{tabular}




\begin{tabular}{|c|c|}
\hline & 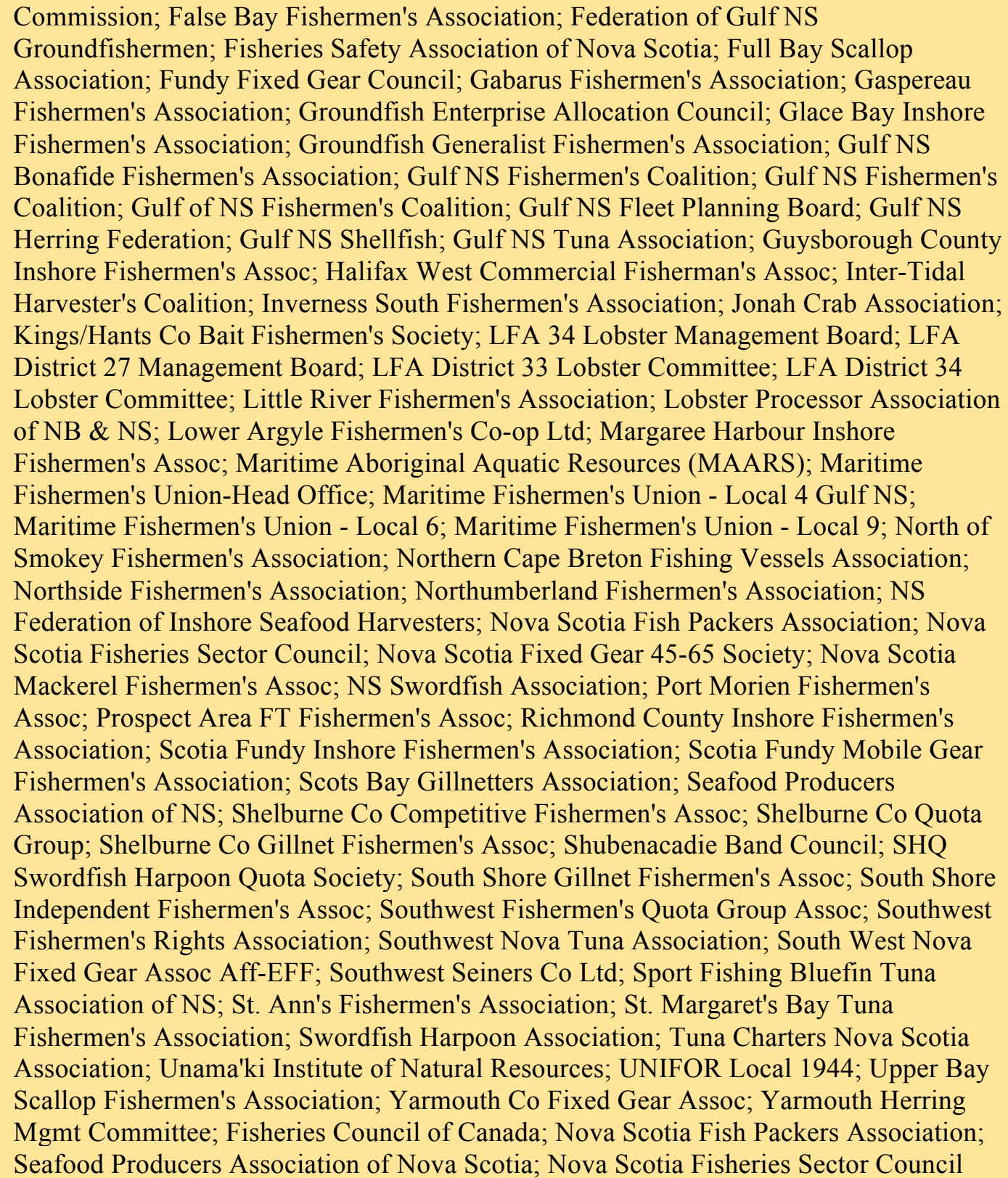 \\
\hline $\begin{array}{l}\text { Shipping/ } \\
\text { Navigation }\end{array}$ & $\begin{array}{l}\text { Nova Scotia Boat Builders Association; Canadian Coast Guard; Transport Canada; Saint } \\
\text { John Port Authority (biggest port in the Bay of Fundy), Halifax Port Authority (if this is } \\
\text { province wide), other port authorities }\end{array}$ \\
\hline Go & $\begin{array}{l}\text { NS Department of Energy (DoE); NS Department of Agriculture; NS Department of } \\
\text { Communities, Culture, and Heritage; Nova Scotia Environment (NSE); NS Department } \\
\text { of Fisheries and Aquaculture; NS Department of Justice; NS Department of Labor and } \\
\text { Advanced Education; NS Department of Natural Resources (DNR); NS Department of } \\
\text { Intergovernmental Affairs; Municipality of Digby; Department of Fisheries and Oceans } \\
\text { Canada (DFO); Natural Resources Canada; Environment Canada, New Brunswick (NB) } \\
\text { Department of Aboriginal Affairs; NB Department of Agriculture, Aquaculture, and } \\
\text { Fisheries; NB Emergency Measures Organization; NB Department of Energy and } \\
\text { Resource Development; NB Department of Intergovernmental Affairs; NB Department } \\
\text { of Justice and Public Safety; NB Office of the Attorney General; NB Department of } \\
\text { Post-Secondary Education, Training, and Labor; NB Department of Tourism, Heritage, }\end{array}$ \\
\hline
\end{tabular}




\begin{tabular}{|c|c|}
\hline & $\begin{array}{l}\text { and Culture; Prince Edward Island (PEI) Department of Agriculture and Fisheries; PEI } \\
\text { Department of Communities, Land, and Environment; PEI Department of Economic } \\
\text { Development and Tourism; PEI Department of Education, Early Learning, and Culture; } \\
\text { PEI Department of Justice and Public Safety; PEI Department of Transportation, } \\
\text { Infrastructure, and Energy; PEI Department of Workforce and AdvancedLearning; } \\
\text { Maine Department of Aquaculture, Conservation, and Forestry; Maine Department of the } \\
\text { Attorney General; Maine Department of Economic and Community Development; } \\
\text { Maine Emergency Management Agency (MEMA); Maine Governor's Office of Energy; } \\
\text { Maine Department of Environmental Protection; Maine Library of Geographic } \\
\text { Information; Maine Geological Survey; Maine Historic Preservation Commission; Maine } \\
\text { Department of Inland Fisheries and Wildlife (IFW); Maine Department of Resources; } \\
\text { USA National Oceanic and Atmospheric Association (NOAA) - U.S. Department of } \\
\text { Commerce; Municipality of the County of Cumberland; Cumberland Energy Authority; } \\
\text { WWF, Ecology Action Center, Oceana, CPAWS }\end{array}$ \\
\hline Industry & $\begin{array}{l}\text { Fundy Tidal Inc. (FTI); Fundy Ocean Research Association for Energy (FORCE); } \\
\text { Marine Renewables Canada (MRC); Nova Scotia Tourism Human Resource Council; } \\
\text { Offshore Energy Research Association (OERA); Cape Sharp Tidal; DP Energy; Atlantis } \\
\text { Resources; Minas Tidal; Black Rock Tidal }\end{array}$ \\
\hline Community & $\begin{array}{l}\text { Mi'kmaq Conservation Group; Native Council of Nova Scotia; Acadia Tidal Energy } \\
\text { Institute (ATEI); Assembly of First Nations (AFN); Native Women's Assoc. of Canada } \\
\text { (NWAC); Inuit Tapiriit Kanatami (ITK); Metis National Council (MNC); Congress of } \\
\text { Aboriginal People (CAP); Atlantic Policy Congress of First Nation Chiefs Secretariat } \\
\text { (APC); Ulnooweg Development Group (Financial/Business); Mi'kmaq Grand Council; } \\
\text { Mi'kmaq Rights Initiative (KMKNO); Confederacy of Mainland Mi'kmaq (CMM); } \\
\text { Union of Nova Scotia Indians (UNSI); Mi'kmaw Kina'matnewey (Education); Nova } \\
\text { Scotia Native Women's Association; Native Council of Nova Scotia (Non-status/off- } \\
\text { res.); Mi'kmaw Native Friendship Centre (Urban); Unama'ki Institute of Natural } \\
\text { Resources; Mi'kmaq Assoc. of Cultural Studies; Mi'kmaq Family \& Children's Services } \\
\text { (Social); Mi'kmaq Legal Support Network (Justice); Native Alcohol \& Drug Abuse } \\
\text { Counselling Assoc. (Addictions); Mi'kmaq Employment \& Training Secretariat } \\
\text { (Employment); Mi'kmaw Economic Benefits Office (Training/Employment); Aboriginal } \\
\text { Affairs Working Group (National: FPT+NAO); Mi'kmaq-Nova Scotia-Canada Tripartite } \\
\text { Forum; Made-in-Nova Scotia Process (Negotiations); Mi'kmaq Rights Initiative }\end{array}$ \\
\hline
\end{tabular}

\section{$\underline{\text { SMPTE Process }}$}

6.1. The following details the SMPTE process utilized in order to identify POAs and grants consents and seabed leases to prospectors within designated POAs

6.2. It is worthy to note that, although POAs identified are chosen due to their overall suitability to host tidal energy project developments, given the complexity of the marine environment in conjunction with the distinct risks associated with different project developments, there is no guarantee that a project within a plan option area will receive consent to obtain a license. If deemed necessary, commercial developments will be required to undertake project-level assessments that take into account issues raised during plan adoption, SEA, socio-economic assessment, and MEKS during screening and scoping stages for EIAs under the NSEA 1995 in projects $>2 \mathrm{MW}-<50 \mathrm{MW}$ and the NSEA and CEAA under the CEA Act 2012 in projects $>50 \mathrm{MW}$. Furthermore, projects should also be considered for consent in areas outside POAs if an applicant 
can demonstrate that the project is economically viable and ecologically sustainable upon producing an agreed upon series of assessment reports

\section{SMPTE Process}

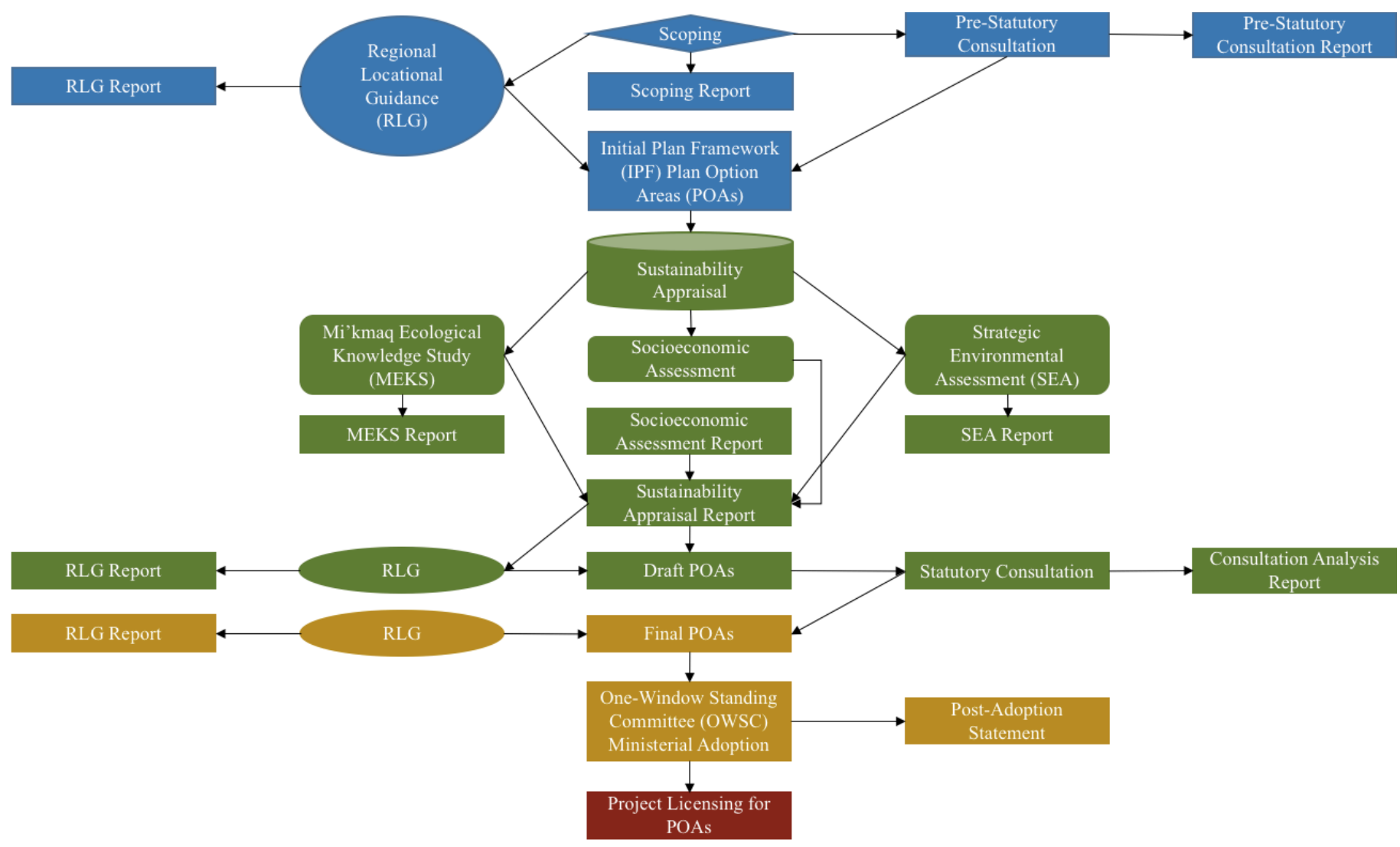

Phase 1 - Initial Plan Framework (IPF)

Phase 2 - Draft Plan Option Areas (POAs)

Phase 3 - Final POAs

Phase 4 - Licensing

\subsubsection{Phase 1 - IPF}

6.3.1.1. Scoping: The preliminary identification of POAs is undertaken during the scoping stage by selecting spatial data layers consisting of presently occurring and future designated uses of Nova Scotia waters, as well as culturally and ecologically significant areas, all of which were categorized as socio-cultural, environmental, industry, non-technical, and opportunity. Through informed consultation within the DoE, weightings regarding the level of constraint and opportunity are attributed to spatial data layers and was compiled into a weighted overlay spatial modeling tool that allocated gradients of suitability to area within provincial waters, which then produce maps suggesting the most suitable sites for tidal energy development. A scoping report detailing the methodology employed to produce the maps is then published.

6.3.1.2. RLG: Following the production of maps from the scoping exercise, RLG is employed by scientific and technical advisors of the DoE to further identify areas of suitable deployment based 
both on constraint and opportunity that are site specific to regions identified in the SMPTE, and thus more detailed. A Phase 1 RLG report detailing any changes to the maps emanating from the initial scoping exercise is then published.

6.3.1.3. Pre-Statutory Consultation: Running in parallel with RLG, maps produced from the scoping exercise are presented to key stakeholders via formal and informal consultation and workshops in order to further identify areas of constraint and opportunity based on local community and sector knowledge. A pre-statutory consultation analysis report detailing the the input emanating from consultation and workshops and how such input was employed to produce the maps is then published.

6.3.1.4. IPF POAs: The outputs from the scoping exercise, further informed by the RLG and prestatutory consultation stages, produce initial POAs.

\subsubsection{Phase 2 - Draft POAs}

6.3.2.1. Sustainability Appraisal: Initial POAs produced from the IPF are then subjected to a sustainability appraisal comprised of the following components:

6.3.2.1.1. MEKS: The purpose of the MEKS are to ensure that Mi'kmaq traditional knowledge and use of the tidal energy development study area incorporated in environmental management and monitoring plans. This target is met by engaging in consultations with the Mi'kmaq in order to identify traditional land uses and activities, as well as identifying others who possess such knowledge and undertake such activities, resulting in the identification of areas of spiritual use, and sustenance use, including fishing, hunting or medicinal gathering activities. A report detailing the methodology employed in the MEKS and the output produced is then published.

6.3.2.1.2. Socioeconomic Assessment: Howell and Drake's (2012) socioeconomic assessment is the first stage in a series of three stages that would be required to mimic best practices demonstrated in Scotland's SMPTE socioeconomic assessment, as the report provides a baseline of potential socioeconomic issues, while such issues need to be quantified in terms of their socioeconomic impacts, and such quantifications must further be assessed in order to spatially determine potential monetary losses to various other industries operating within the SMPTE management boundaries. Therefore, minimal socioeconomic characterizations were incorporated in this initial iteration of Nova Scotia's SMPTE due to the lack of baseline data within the province. However, as information becomes available, further socioeconomic data will be injected into the future iterations of the SMPTE. A report detailing the methodology employed in the socioeconomic assessment and the output produced will then be published.

6.3.2.1.3. SEA: The SEA identifies key environmental receptors that are likely to display degrees of sensitivity resulting from stressors produced from tidal energy developments. The results of the SEA are then used as a basis to inform detailed site specific environmental assessments (EAs) for both strategic review at a regional scale and individual project developments as applicable. However, due to the lack of baseline data within the province, the quantification of potential impacts and exploration of potential mitigation measures based of such information has not been incorporated into the SMPTE process. As information becomes available, further environmental data will be injected into the future iterations of the SMPTE. A report detailing the methodology employed in the SEA and the output produced is then published.

6.3.2.2. Sustainability Appraisal Report: Drawing upon key findings produced from the MEKS, socioeconomic assessment, and SEA, a sustainability appraisal report is published and subject to 
consultation with relevant sectoral and community stakeholders for a minimum period of 16 weeks.

6.3.2.3. RLG: Drawing from the information emanating from the sustainability appraisal, RLG further informs areas of constraint and opportunity, ultimately feeding into the mapping of draft POAs. A Phase 2 RLG report detailing any changes to the maps emanating from the sustainability appraisal is then published.

6.3.2.4. Draft POAs: Drawing upon key findings produced from the SEA, socioeconomic assessment, and MEKS presented in the sustainability appraisal report, in conjunction with knowledge obtained from RLG, formal draft POAs are developed and published. The draft SMPTE is subject to consultation with relevant sectoral and community stakeholders for a minimum period of 16 weeks.

6.3.2.5. Statutory Consultation: Running in parallel with the public consultation period and the RLG, the sustainability appraisal report is released to the CEAA and NSE, who are the ecosystem CAs and thus the statutory authorities over the SEA, and the Nova Scotia DNR, who is the other CA with jurisdiction over submerged provincial lands, and thus may review all three documents of the sustainability appraisal in order to make decisions regarding consent for authorization, in accordance with Section 5(d) of the MRE Act 2015 as a part of statutory consultation procedures.

6.3.2.6. Consultation Analysis Report: At this stage, a consultation analysis report should be drafted detailing the key issues raised by key stakeholders identified in the SMPTE process, demonstrating how such issues have been taken into account throughout the sustainability appraisal report and inclusive of draft POAs. If statutory consultation determines that considerable alterations to the draft plan are required in order to better account for stakeholder input, economic sustainability, and/or environmental consideration, further research and amendments must be undertaken for the MEKS, socioeconomic assessment, and/or SEA until the legislated statutory consultation bodies accept the draft POAs under proposed conditions. If the draft SMPTE is accepted, it is then put forth to Phase 3.

\subsubsection{Phase 3 - Final POAs}

6.3.3.1. RLG: Following any alterations emanating from statutory consultation, POAs will undergo a final round of RLG to further identify areas of constraint and opportunity in order to produce final POAs. A Phase 3 RLG report detailing any changes to the maps emanating from statutory consultation is then published.

6.3.3.2. OWSC Ministerial Adoption: Following the RLG exercise, final POAs are put forth to the OWSC for formal adoption.

6.3.3.3. Post-Adoption Statement: If ministerial adoption is granted, a post-adoption statement justifying the reasons for adopting the current iteration of the SMPTE and how environmental and stakeholder concerns, socio-economic assessment, and the MEKS were taken into consideration should be published, with amendments to the MRE Act 2015 being made to legislate this process

\subsubsection{Phase 4 - Licensing}

6.3.4.1. Project Licensing for Adopted POAs: Although several governmental bodies are required to give consent to a permit application, under Section 25 of the MRE Act 2015, the DoE acts as a 
one-stop-shop to facilitate communication of approvals between applicants and the necessary regulatory authorities, thereby providing for a coordinated, accountable, and transparent licensing regime.

6.3.5. Plan Review Process: In accordance with best practices emanating from Scotland, it is recommended that a SPRG be established within the DoE in order to oversee the implementation of SMPTE and undertake strategic monitoring and research to fill information gaps identified in the sustainability appraisal report. A two-year monitoring and review period to update the current iteration of the SMPTE is suggested in this consultation draft, with a mandatory five year monitoring and review period thereafter.

\section{POAs}

The SMPTE process detailed above produced the final POAs most suitable for tidal energy development in Nova Scotia waters. Although POAs identified in the SMPTE are chosen due to their overall suitability to host commercial scale tidal energy project developments, given the complexity of the marine environment in conjunction with the distinct risks associated with different project developments, there is no guarantee that a project within a POA will receive consent to obtain a license. If deemed necessary, commercial developments will be required to undertake project-level assessments that take into account issues raised during plan adoption, SEA, socio-economic assessment, and MEKS during screening and scoping stages for EIAs under the NSEA 1995 in projects $>2 \mathrm{MW}-<50 \mathrm{MW}$ and the NSEA and CEAA under the CEA Act 2012 in projects $>50 \mathrm{MW}$. In unison with the Scottish context, projects should also be considered for consent in areas outside POAs if an applicant can demonstrate that the project is economically viable and ecologically sustainable upon producing an agreed upon series of assessment reports.

Within the seven ecoregions established for provincial marine planning in Nova Scotia, three ecoregions demonstrate the level of suitability based off of constraint and suitability modelling to hosts sustainable TCT deployment. These ecoregions include Minas, with the greater Minas Basin hosting one POA measuring $242.148 \mathrm{~km} 2$ and hosting a conservative installation capacity of $250 \mathrm{MW}$; Fundy with Petit Passage hosting one POA measuring $0.210 \mathrm{~km} 2$ and hosting a conservative installation capacity of $1.5 \mathrm{MW}$; and Acadia, with Grand Passage hosting three POAs measuring $0.608 \mathrm{~km} 2$ combined and hosting am aggregate conservative installation capacity of $1.5 \mathrm{MW}$.

\begin{tabular}{|c|c|c|c|}
\hline \multicolumn{4}{|c|}{ POAs } \\
\hline Ecoregion & Site & Area $(\mathrm{km} 2)$ & $\begin{array}{c}\text { Installed Capacity } \\
\text { (MW) }\end{array}$ \\
\hline Minas & Minas Basin & 242.148 & 250 \\
\hline Fundy & Petit Passage & 0.210 & 1.5 \\
\hline Acadia & Grand Passage & 0.608 & 1.5 \\
\hline & Total & 242.966 & 253 \\
\hline
\end{tabular}




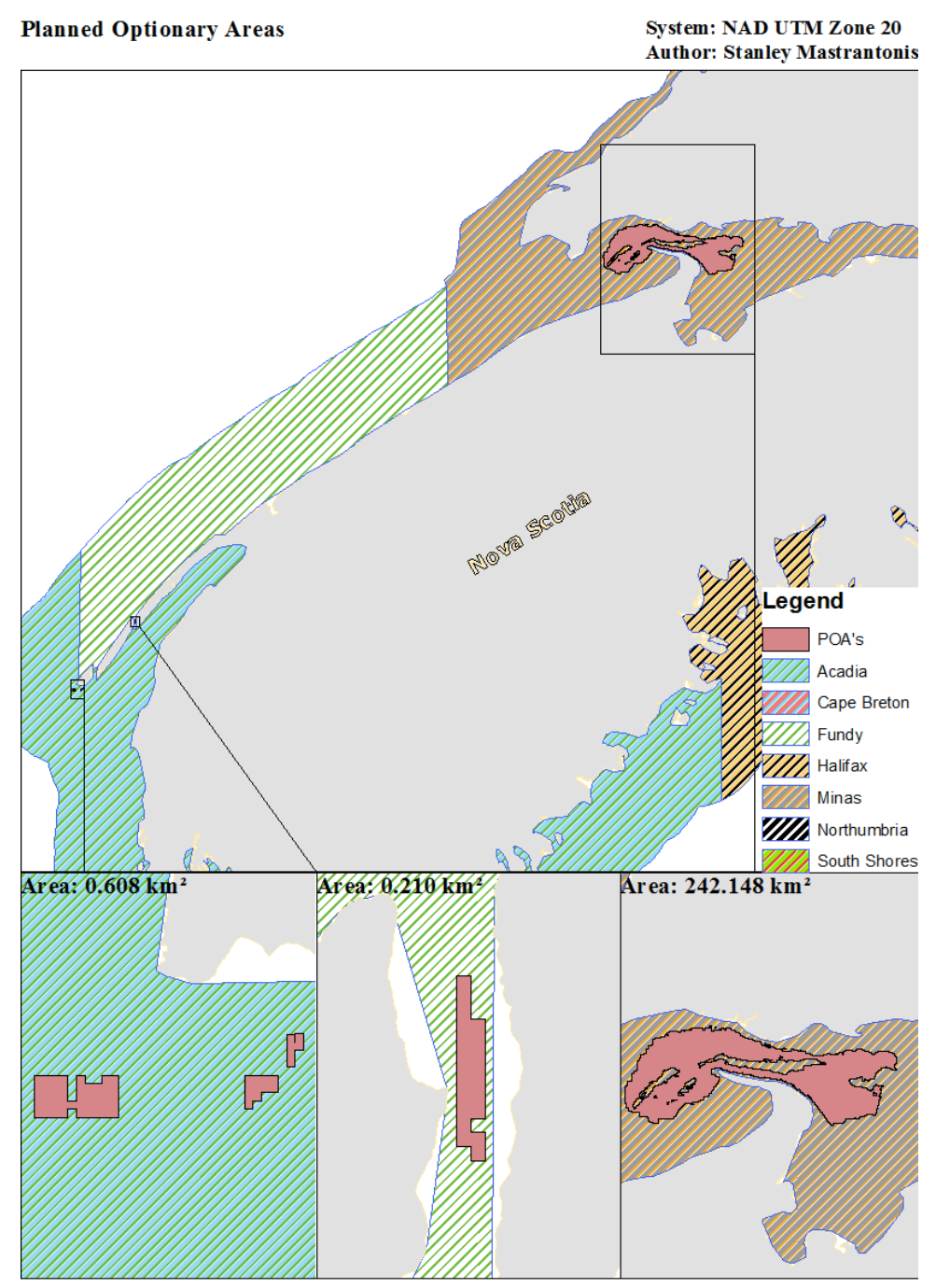

\section{Minas}

The Minas ecoregion POA is located in the greater Minas Basin. The POA has an area of $242.148 \mathrm{~km} 2$ and hosts a conservative installation capacity of $250 \mathrm{MW}$.

The SMPTE process identified the following constraints to be of particular importance to the Minas ecoregion POA, referenced as low, moderate, or high based on intensity of spatial occurrence:

- Moderate ecologically and biologically significant areas

- Moderate National parks areas

- Low to moderate commercial fishing

- Low to moderate traditional use

The SMPTE process identified the following constraints to be of particular importance to the Minas ecoregion POA:

- Lighthouses

- Power lines 


\section{Fundy}

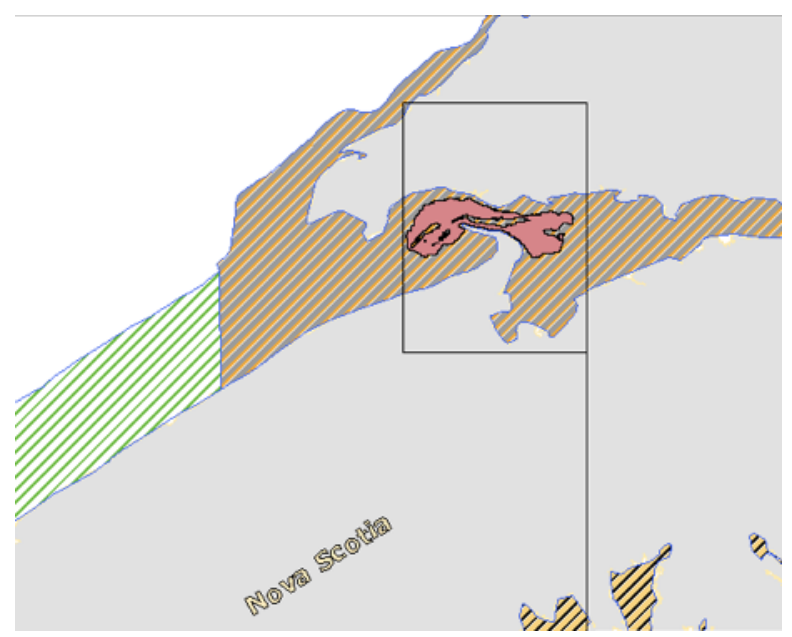

The Fundy ecoregion POA is located in Petit Passage. The POA has an area of $0.210 \mathrm{~km} 2$ and hosts a conservative installation capacity of $1.5 \mathrm{MW}$.

The SMPTE process identified the following constraints to be of particular importance to the Fundy ecoregion POA, referenced as low, moderate, or high based on intensity of spatial occurrence:

- High important bird habitat

- High National park areas

- Moderate to high spawning areas

- Moderate to high significant habitat

- Moderate to high seabird habitat

- Moderate to high traditional land use

- Moderate commercial fishing

- Moderate tourism

- Low to moderate cetacean habitat

- Low to moderate shipping density

The SMPTE process identified the following constraints to be of particular importance to the Fundy ecoregion POA:

- Lighthouses

\section{Acadia}

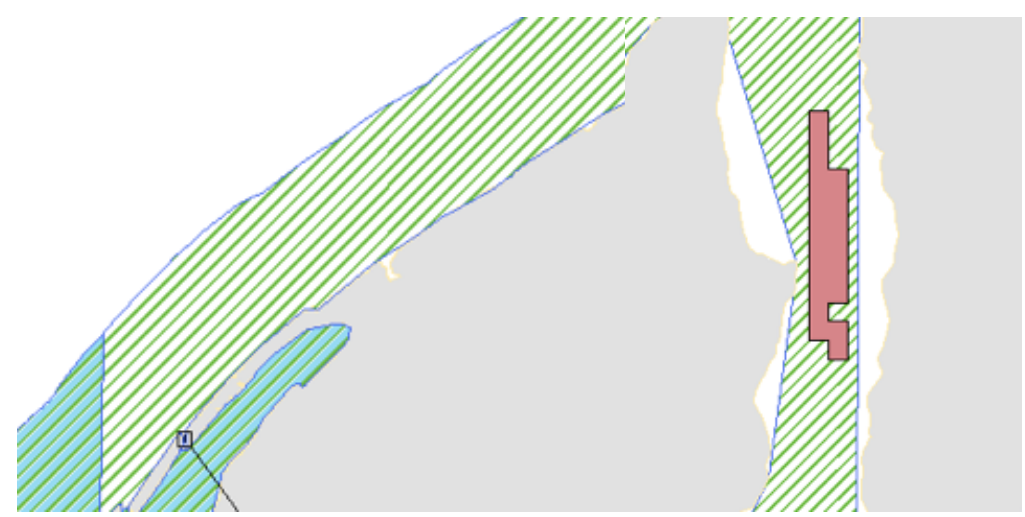

The three Acadia ecoregion POAs are located in Grand Passage. The POAs have a cumulative area of $0.608 \mathrm{~km} 2$ and host a conservative aggregate installation capacity of $1.5 \mathrm{MW}$. 
The SMPTE process identified the following constraints to be of particular importance to the Acadia ecoregion POAs, referenced as low, moderate, or high based on intensity of spatial occurrence:

- High important bird habitat

- High Ecologically and biological significant areas

- High National park areas

- Moderate to high spawning areas

- Moderate to high traditional land use

- Moderate to high shipping density

- Moderate to high significant habitat

- Moderate to high seabird habitat

- Moderate commercial fishing

- Moderate tourism

- Low to moderate cetacean habitat

The SMPTE process identified the following constraints to be of particular importance to the Acadia ecoregion POAs:

- Lighthouses

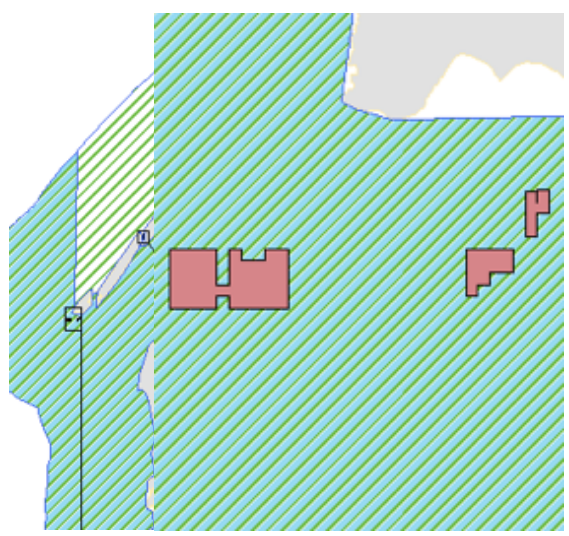




\section{Appendix B}

Quality Management Review 
The following material detail the questions and answers to the quality management checklist set out in the ICES MSP QMS for the Nova Scotia context in relation to the answers produced in the Scottish quality management review adopted from Sangiuliano's (2016) $A$ Quality Management Review of Scotland's Sectoral Marine Plan for Tidal Energy. Functions and processes were either already in place are denoted by black text, or could easily be suggested as amendments to current regulatory frameworks are denoted in purple text, while areas where suggested quality management criteria could improve upon gaps in Scotland's quality management review are denoted in gold text, and areas where there was no such process in place, for the Scottish context, and not enough research has been conducted to easily allow for a conformity allocation, in the Nova Scotia context, are denoted in red text.

\section{Public Policy Agenda}

Marine Development Public Policy Agenda

The SG's Economic Strategy, the Electricity Generation Policy Statement, and the Climate Change (Scotland) Act 2010, which work together to promote economic development while safeguarding the environment by meeting GHG emissions reduction targets

\section{What is the} marine public policy agenda that would trigger or support the need to initiate a planning process? development
The NS Electricity Plan, MRE Act 2015, EGSPA 2007, and the DoE's MRE Strategy, which work together to identify the need for TCT implementation to contribute to provincial and federal GHG emissions reductions targets while supporting and enhancing the environment and the economy.
Ecosystem Protection Public Policy Agenda \begin{tabular}{l|l|l} 
Natura 2000 biological & What is the public & The NSEA 1995 an
\end{tabular} conservation sites were $\quad$ policy $\quad$ CEA Act 2012 as \begin{tabular}{l|l} 
taken into consideration & agenda that sets
\end{tabular} \begin{tabular}{l|l|l} 
when scoping for & ecosystem & ensuring that ecosystem
\end{tabular} suitable tidal energy development sites for the SMPTE in order to safeguard the sensitive marine ecosystems and features while achieving the SMPTE's strategic aims

sustainability goals and timeframes for the implementation of protection and conservation measures? sustainability is not compromised through the implementation of TCTs via established installed capacity targets triggering environmenta assessments and monitoring and review protocols.
The strategic aims of the SMPTE process are listed, although the process itself did not follow a strict completion number of steps were undertaken to construct the SMPTE in chronological sectoral marine planning (SMP) process timeframe, rather, a defined order in conformity with the

\begin{tabular}{l|l}
$\begin{array}{l}\text { What are the } \\
\text { strategic goals, } \\
\text { socio- }\end{array}$ & $\begin{array}{l}\text { The strategic aims of the } \\
\text { SMPTE process are listed, } \\
\text { economic }\end{array}$ \\
although the process itself did not \\
completion & follow a strict completion timeframe, \\
timeframes & rather, a defined number of steps are \\
for the & SMPTE in chronological order in \\
proposed & conformity with the \\
planning & sectoral marine planning \\
process? & (SMP) process developed by MS \\
& suggested by this paper for adoption \\
& by the DoE
\end{tabular}

\begin{tabular}{|l|l|l|}
\hline \multicolumn{1}{|l|}{} & & by the DoE \\
& & \\
\hline $\begin{array}{l}\text { The goals and objectives of } \\
\text { industry and community } \\
\text { stakeholders are not formally } \\
\text { published as definitive targets }\end{array}$ & $\begin{array}{l}\text { What are the } \\
\text { goals, } \\
\text { objectives and } \\
\text { timeframes of } \\
\text { the industry } \\
\text { stakeholders }\end{array}$ & $\begin{array}{l}\text { The goals and objectives of industry } \\
\text { and community stakeholders are not in } \\
\text { through a series of workshops and in } \\
\text { consultation with governmental } \\
\text { organizations listed in the One- }\end{array}$ \\
\hline
\end{tabular}

\section{While broad ecosystem} indictors, including biodiversity and seabed and coastal processes distinct to each of the three regions where suitable tidal energy development sites have been allocated have been identified,

consideration of ecosystem management outcomes and targets fo the SMPTE itself have not been explicitly defined

\section{What are the} ecosystem management outcome indicators and targets to be achieved?
While broad ecosystem indictors, including biodiversity and seabed and coastal processes distinct to the Bay of Fundy and Cape Breton and the Bras d'Or region have been identified, consideration of ecosystem management outcomes and targets for the SMPTE itself have not been explicitly defined. It is suggested that the quantification of ecosystem services be established through governmental, academic, and industry research in order to provide a baseline of the value that the provincial marine environment affords to the provincial economy.

The SMPTE is divided into six regions; North, North East, East, South West, West, North West. These regions extend to the $200 \mathrm{~nm}$

\begin{tabular}{|c|c|}
\hline $\begin{array}{l}\text { What are the boundaries } \\
\text { of the ecosystem? }\end{array}$ & $\begin{array}{l}\text { Ecosystem boundaries } \\
\text { have been established in } \\
\text { relation to the planning } \\
\text { boundaries based } \\
\text { on the identification of } \\
\text { spatially persisting }\end{array}$ \\
\hline
\end{tabular}




\begin{tabular}{|c|c|c|c|c|c|}
\hline & $\begin{array}{l}\text { and } \\
\text { communities } \\
\text { of interest in } \\
\text { relation to the } \\
\text { planning area? }\end{array}$ & $\begin{array}{l}\text { Window Standing Committee } \\
\text { (OWSC) }\end{array}$ & \multicolumn{2}{|c|}{$\begin{array}{l}\text { EEZ and do not } \\
\text { explicitly take into } \\
\text { consideration ecosystem } \\
\text { boundaries in their } \\
\text { construction }\end{array}$} & $\begin{array}{l}\text { occurrence rates of } \\
\text { various flora, fauna, } \\
\text { and oceanographic } \\
\text { processes within and } \\
\text { outside of the } \\
\text { management boundaries } \\
\end{array}$ \\
\hline \multicolumn{3}{|c|}{1 Marine Planning Legislation, Policies and Authorities $>$} & \multicolumn{3}{|c|}{ Ecosystem Legislation, Policies and Authorities } \\
\hline $\begin{array}{l}\text { The Scottish NMP, bounded by } \\
\text { the Marine Scotland Act } 2010 \\
\text { within the TZ and the Marine and } \\
\text { Coastal Access Act } 2009 \text { within } \\
\text { the EEZ sets the scope for the } \\
\text { SMPTE }\end{array}$ & $\begin{array}{l}\text { What is the } \\
\text { marine spatial } \\
\text { planning } \\
\text { legislative and } \\
\text { policy } \\
\text { framework } \\
\text { that sets the } \\
\text { scope of the } \\
\text { planning } \\
\text { initiative? }\end{array}$ & $\begin{array}{l}\text { The MRE Act 2015, further informed } \\
\text { by the NS Electricity Plan and the } \\
\text { DoE's MRE Strategy sets the scope } \\
\text { for the SMPTE }\end{array}$ & $\begin{array}{l}\text { The Marine } \\
\text { Scotland } \\
\text { Act 2010, } \\
\text { Environmen } \\
\text { tal } \\
\text { Assessment } \\
\text { (Scotland) } \\
\text { Act 2005, } \\
\text { UK Marine } \\
\text { Policy } \\
\text { Statement, } \\
\text { Birds } \\
\text { Directive, } \\
\text { Habitats } \\
\text { Directive, } \\
\text { Habitats } \\
\text { Regulations, } \\
\text { etc }\end{array}$ & $\begin{array}{l}\text { What is } \\
\text { and polic } \\
\text { the ecolo } \\
\text { constrain } \\
\text { initiative }\end{array}$ & $\begin{array}{l}\text { The MRE Act 2015, } \\
\text { Oceans Act 1996, } \\
\text { EGSPA 2007, NWPA } \\
\text { 1985, Fisheries Act } \\
\text { 1985, CEA Act 2012, } \\
\text { NSEA 1995, etc. }\end{array}$ \\
\hline $\begin{array}{l}\text { The Marine Scotland Act 2010, } \\
\text { which provides the legislative and } \\
\text { management framework for the } \\
\text { marine environment, and the } \\
\text { Marine and Coastal Access Act } \\
\text { 2009, which provides the } \\
\text { legislative and management } \\
\text { framework for MSP within } \\
\text { Scottish waters }\end{array}$ & $\begin{array}{l}\text { What are the } \\
\text { agreements } \\
\text { and/or statutes } \\
\text { needed to } \\
\text { develop and } \\
\text { implement a } \\
\text { marine spatial } \\
\text { plan? }\end{array}$ & $\begin{array}{l}\text { The delegation of administrative } \\
\text { authority over identified provincial } \\
\text { marine planning boundaries from the } \\
\text { federal government to the DoE as the } \\
\text { MSP CA via the federal Oceans Act } \\
\text { 1996, with the identification of } \\
\text { MREAs requiring consultation with } \\
\text { the NS DNR under the Crown Lands } \\
\text { Act } 2012 \text { and the MRE Act } 2015\end{array}$ & $\begin{array}{l}\text { The Marine } \\
\text { Scotland } \\
\text { Act 2010, } \\
\text { Marine and } \\
\text { Coastal } \\
\text { Access Act } \\
2009 \text {, } \\
\text { Environmen } \\
\text { tal } \\
\text { Assessment } \\
\text { (Scotland) } \\
\text { Act 2005, } \\
\text { UK Marine } \\
\text { Policy } \\
\text { Statement, } \\
\text { Birds } \\
\text { Directive, } \\
\text { Habitats } \\
\text { Directive, } \\
\text { Habitats } \\
\text { Regulations, } \\
\text { etc }\end{array}$ & $\begin{array}{l}\text { What are } \\
\text { protectio } \\
\text { regulatio } \\
\text { planning } \\
\text { managen }\end{array}$ & $\begin{array}{l}\text { The MRE Act } 2015, \\
\text { Oceans Act 1996, } \\
\text { EGSPA 2007, NWPA } \\
\text { 1985, Fisheries Act } \\
\text { 1985, CEA Act 2012, } \\
\text { NSEA 1995, etc. }\end{array}$ \\
\hline $\begin{array}{l}\text { The Marine Scotland Act 2010, } \\
\text { Marine and Coastal Access Act } \\
\text { 2009, Environmental Assessment } \\
\text { (Scotland) Act 2005, UK Marine } \\
\text { Policy Statement, Birds } \\
\text { Directive, Habitats Directive, } \\
\text { Habitats Regulations, etc }\end{array}$ & $\begin{array}{l}\text { What are the } \\
\text { local or } \\
\text { regional } \\
\text { statutes or } \\
\text { international } \\
\text { agreements } \\
\text { that have to be } \\
\text { respected } \\
\text { within } \\
\text { boundaries of } \\
\text { the } \\
\text { management } \\
\text { area being } \\
\text { planned? }\end{array}$ & $\begin{array}{l}\text { The MRE Act 2015, Oceans Act 1996, } \\
\text { EGSPA 2007, NWPA 1985, Fisheries } \\
\text { Act 1985, CEA Act 2012, NSEA } \\
\text { 1995, etc. }\end{array}$ & $\begin{array}{l}\text { the Marine } \\
\text { Scotland } \\
\text { Act 2010, } \\
\text { Marine and } \\
\text { Coastal } \\
\text { Access Act } \\
2009 \text {, } \\
\text { Environmen } \\
\text { tal } \\
\text { Assessment } \\
\text { (Scotland) } \\
\text { Act 2005, } \\
\text { UK Marine } \\
\text { Policy } \\
\text { Statement, } \\
\text { Birds } \\
\text { Directive, } \\
\text { Habitats } \\
\text { Directive, } \\
\text { Habitats } \\
\text { Regulations, } \\
\text { etc }\end{array}$ & $\begin{array}{l}\text { What are } \\
\text { statutes } \\
\text { agreeme } \\
\text { respectec } \\
\text { of the ec }\end{array}$ & $\begin{array}{l}\text { The MRE Act } 2015, \\
\text { Oceans Act } 1996, \\
\text { EGSPA 2007, NWPA } \\
\text { 1985, Fisheries Act } \\
\text { 1985, CEA Act 2012, } \\
\text { NSEA 1995, etc. }\end{array}$ \\
\hline $\begin{array}{l}\text { MS is the MSP CA designated } \\
\text { under the Marine Scotland Act } \\
2010\end{array}$ & $\begin{array}{l}\text { Who is the } \\
\text { MSP } \\
\text { Competent }\end{array}$ & $\begin{array}{l}\text { The DoE is the MSP CA via the MRE } \\
\text { Act } 2015 \text { conditional on powers to } \\
\text { plan being delegated form the DFO }\end{array}$ & $\begin{array}{l}\text { MS is both } \\
\text { the MSP and } \\
\text { ecosystem }\end{array}$ & $\begin{array}{l}\text { Who is } t \\
\text { Authorit } \\
\text { the ecosy }\end{array}$ & $\begin{array}{l}\text { The NS DoE is the } \\
\text { ecosystem CA for the } \\
\text { SMPTE designated }\end{array}$ \\
\hline
\end{tabular}




\begin{tabular}{|c|c|c|c|c|c|}
\hline & $\begin{array}{l}\text { Authority that } \\
\text { is delegated } \\
\text { under the MSP } \\
\text { legislation or } \\
\text { under } \\
\text { agreement } \\
\text { from the } \\
\text { governance } \\
\text { structure? }\end{array}$ & under the Oceans Act 1996 & $\begin{array}{l}\text { CA } \\
\text { designated } \\
\text { under the } \\
\text { Marine } \\
\text { Scotland } \\
\text { Act } 2010\end{array}$ & $\begin{array}{l}\text { agreement from the governance } \\
\text { structure? }\end{array}$ & $\begin{array}{l}\text { under the MRE Act } \\
2015 \text { for projects under } \\
\text { 2MW of installed } \\
\text { capacity, with planning } \\
\text { authority held jointly } \\
\text { with the NSE for } \\
\text { projects over } 2 \mathrm{MW} \text { as } \\
\text { prescribed under the } \\
\text { NSEA } 1995 \text {, and the } \\
\text { NSE and CEAA in } \\
\text { projects over 50MW as } \\
\text { prescribed under the } \\
\text { CEA Act } 2012 \text {. }\end{array}$ \\
\hline $\begin{array}{l}\text { MS is responsible and } \\
\text { accountable for determining the } \\
\text { suitability of tidal energy } \\
\text { development sites within Scottish } \\
\text { waters, drafting the SMPTE, } \\
\text { issuing permits, granting consent, } \\
\text { engaging stakeholders, enforcing } \\
\text { management measures, and } \\
\text { monitoring and review of the } \\
\text { SMPTE }\end{array}$ & $\begin{array}{l}\text { What is the } \\
\text { span of } \\
\text { responsibility } \\
\text { and } \\
\text { accountability } \\
\text { of the MSP } \\
\text { Competent } \\
\text { Authority? }\end{array}$ & $\begin{array}{l}\text { DoE is responsible and accountable } \\
\text { for determining the suitability of tidal } \\
\text { energy development sites within NS } \\
\text { waters, drafting the SMPTE, issuing } \\
\text { permits and granting consent in } \\
\text { conjunction with the NS MNR, and } \\
\text { the NSE in projects over } 2 \mathrm{MW} \text {, and } \\
\text { the NSE and CEAA in projects over } \\
50 \mathrm{MW} \text {, engaging stakeholders, } \\
\text { enforcing management measures, and } \\
\text { monitoring and review of the SMPTE }\end{array}$ & $\begin{array}{l}\text { MS is } \\
\text { responsible } \\
\text { and } \\
\text { accountable } \\
\text { for } \\
\text { determining } \\
\text { the } \\
\text { suitability of } \\
\text { tidal energy } \\
\text { development } \\
\text { sites within } \\
\text { Scottish in } \\
\text { relation to } \\
\text { their } \\
\text { potential } \\
\text { interactions } \\
\text { with SACs } \\
\text { and SPAs, } \\
\text { undertaking } \\
\text { SEAs and } \\
\text { HRAs, } \\
\text { issuing } \\
\text { permits and } \\
\text { granting } \\
\text { consent to } \\
\text { project } \\
\text { leases that } \\
\text { are in } \\
\text { compliance } \\
\text { with } \\
\text { ecological } \\
\text { prohibitions, } \\
\text { protection or } \\
\text { conservation } \\
\text { regulations } \\
\text { and local } \\
\text { and regional } \\
\text { statutes and } \\
\text { international } \\
\text { agreements, } \\
\text { enforcing } \\
\text { ecosystem } \\
\text { management } \\
\text { measures, } \\
\text { and } \\
\text { monitoring } \\
\text { and review } \\
\text { of } \\
\text { ecosystem } \\
\text { conditions } \\
\text { within the } \\
\text { SMPTE } \\
\text { management } \\
\text { area } \\
\end{array}$ & $\begin{array}{l}\text { What is the span of responsibility } \\
\text { and accountability of the } \\
\text { Ecosystem Competent Authority? }\end{array}$ & $\begin{array}{l}\text { The DoE is responsible } \\
\text { and accountable under } \\
\text { the MRE Act } 2015 \text { for } \\
\text { initiating or causing the } \\
\text { initiation of } \\
\text { environmental } \\
\text { assessments in relation } \\
\text { to interactions between } \\
\text { TCTs and the marine } \\
\text { environment, consulting } \\
\text { with various provincial } \\
\text { and federal agencies and } \\
\text { departments on the } \\
\text { status of the marine } \\
\text { environment, and } \\
\text { issuing permits and } \\
\text { orders to stop work if } \\
\text { they deem that a } \\
\text { development can } \\
\text { compromise the } \\
\text { integrity of the } \\
\text { ecosystem in which it is } \\
\text { occurring or is } \\
\text { environmental } \\
\text { assessments undertaken } \\
\text { by the proponent are } \\
\text { unsatisfactory. The NSE } \\
\text { must jointly undertake } \\
\text { and determine if } \\
\text { environmental } \\
\text { assessments } \\
\text { demonstrate that a } \\
\text { development is } \\
\text { sustainable under the } \\
\text { NSEA in projects } \\
>2 \mathrm{MW}-<50 \mathrm{MW} \text {, while } \\
\text { the NSE and CEAA } \\
\text { must jointly undertake } \\
\text { and determine if } \\
\text { environmental } \\
\text { assessments } \\
\text { demonstrate that a } \\
\text { development is } \\
\text { sustainable under the } \\
\text { CEA Act } 2012 \text { in } \\
\text { projects }>50 \mathrm{MW} \\
\text { a }\end{array}$ \\
\hline MS is the only CA for the SMPTE & & \multicolumn{2}{|c|}{$\begin{array}{l}\text { What are the other competent authorities that have } \\
\text { legislative mandates related to the activities of the } \\
\text { drivers operating in the management area and that will } \\
\text { be managed by the marine spatial plan? }\end{array}$} & \multicolumn{2}{|c|}{$\begin{array}{l}\text { The other CA that does not fall directly under the marine } \\
\text { development and/or ecosystem protection public policy agendas as } \\
\text { having powers to plan is the NS MNR due to their status of having } \\
\text { proprietary jurisdiction over submerged Crown lands within } \\
\text { provincial boundaries under the Crown Lands Act, therefore }\end{array}$} \\
\hline
\end{tabular}




\begin{tabular}{|c|c|c|}
\hline & & $\begin{array}{l}\text { requiring their direct consultation in relation to the identification of } \\
\text { MREAs under the MRE Act 2015, as well as granting consents } \\
\text { and issuing seabed leases. }\end{array}$ \\
\hline $\begin{array}{l}\text { There are various relevant industry } \\
\text { agreements/statutes involving external or } \\
\text { international organizations that should be } \\
\text { included in the SMPTE process, all of which } \\
\text { are listed throughout the NMP, SEA Directive, } \\
\text { Marine Scotland Act 2010, and the Marine and } \\
\text { Coastal Access Act } 2009\end{array}$ & $\begin{array}{l}\text { Are there any relevant industry agreements/statutes } \\
\text { involving external or international organizations that } \\
\text { should be included in the planning process? }\end{array}$ & $\begin{array}{l}\text { There are various relevant industry agreements/statutes involving } \\
\text { external and laterally stratified intergovernmental organizations } \\
\text { that should be included in the SMPTE process, the majority of } \\
\text { which fall under the statutes referenced in the marine development } \\
\text { and ecosystem protection public policy agendas, which } \\
\text { recommendations to consult with USA Federal and State of Maine } \\
\text { international organizations due to the potential for far-field } \\
\text { ecosystem processes occurring between the Bay of Fundy and the } \\
\text { Gulf of Maine. }\end{array}$ \\
\hline \multicolumn{3}{|c|}{ Industry Stakeholders } \\
\hline $\begin{array}{l}\text { Key industry associations and organizations } \\
\text { that represent drivers operating in the } \\
\text { management area of the SMPTE specified in } \\
\text { the SMPTE are categorized under fishing, } \\
\text { shipping and navigation, grid, industry, and } \\
\text { tourism and recreation }\end{array}$ & $\begin{array}{l}\text { Who are the industry associations or organizations that } \\
\text { represent the drivers that are operating in the } \\
\text { management area and that will be managed by the } \\
\text { marine spatial plan? }\end{array}$ & $\begin{array}{l}\text { Key industry associations and organizations that represent drivers } \\
\text { operating in the management area of the SMPTE specified in the } \\
\text { SMPTE are categorized under fishing, shipping and navigation, } \\
\text { government, industry, and community }\end{array}$ \\
\hline $\begin{array}{l}\text { Under the policy framework of the NMP, which } \\
\text { draws its legitimacy from the Marine Scotland } \\
\text { Act } 2010 \text { and the Marine and Coastal Access } \\
\text { Act } 2009 \text {, early and ongoing engagement } \\
\text { with stakeholders should be undertaken in the } \\
\text { SMPTE process }\end{array}$ & $\begin{array}{l}\text { Under what legislation and policy framework are the } \\
\text { implicated industry sectors managed? }\end{array}$ & $\begin{array}{l}\text { The legislative and policy framework set in place to manage } \\
\text { implicated industry stakeholders are referenced in the marine } \\
\text { development and ecosystem protection public policy agendas, } \\
\text { while best practices emanating from Scotland and marine and } \\
\text { terrestrial planning in general suggesting that early and ongoing } \\
\text { engagement with stakeholders should be undertaken in the } \\
\text { SMPTE process }\end{array}$ \\
\hline $\begin{array}{l}\text { Industry sector representatives under each } \\
\text { industry category identified are specified within } \\
\text { the SMPTE. Industry sector representatives are } \\
\text { appointed by members of the industry in } \\
\text { question via stakeholder consultation events }\end{array}$ & $\begin{array}{l}\text { How is the industry sector delegate appointed to ensure } \\
\text { that they represent the views and concerns of their } \\
\text { sector? }\end{array}$ & $\begin{array}{l}\text { Industry sector representatives under each industry category } \\
\text { identified are specified within the SMPTE. Industry sector } \\
\text { representatives may be appointed by members of the industry in } \\
\text { question via stakeholder consultation events. }\end{array}$ \\
\hline \multicolumn{3}{|c|}{ Communities of Interest } \\
\hline $\begin{array}{l}\text { Communities of interest identified in the } \\
\text { SMPTE include fishers, natural environmental } \\
\text { organizations (both NGOs and statutory } \\
\text { bodies), local government, the local } \\
\text { community, and tourists }\end{array}$ & $\begin{array}{l}\text { Who are the communities of interest that depend on or } \\
\text { have a vested interest in the sustainability or integrity } \\
\text { of the ecosystem and its services that may be } \\
\text { influenced by the activities of the drivers managed } \\
\text { under the marine spatial plan? }\end{array}$ & $\begin{array}{l}\text { Communities of interest identified in the SMPTE include fishing, } \\
\text { shipping and navigation, government, industry, and community }\end{array}$ \\
\hline $\begin{array}{l}\text { Representative organizations of the fishing, } \\
\text { natural environment (both NGOs and statutory } \\
\text { bodies), local government, local community, } \\
\text { and tourism that are invited to events and } \\
\text { encouraged to provide feedback are specified in } \\
\text { the SMPTE. Representatives are appointed to } \\
\text { ensure that they represent their constituency by } \\
\text { members of the community of interest in } \\
\text { question via stakeholder consultation events. }\end{array}$ & $\begin{array}{l}\text { How is the community of interest delegate appointed } \\
\text { to ensure that they represent their constituency? }\end{array}$ & $\begin{array}{l}\text { Representative organizations of the fishing, shipping } \\
\text { and navigation, government, industry, and community that are } \\
\text { invited to events and encouraged to provide feedback are specified } \\
\text { in the SMPTE. Representatives are appointed to ensure that they } \\
\text { represent their constituency by members of the community of } \\
\text { interest in question via stakeholder consultation events proposed } \\
\text { by this paper }\end{array}$ \\
\hline $\begin{array}{l}\text { Yes, some communities of interest are located } \\
\text { outside the management area either } \\
\text { transnationally, such as the Welsh Assembly } \\
\text { Government, or in the context that they do not } \\
\text { directly interact with the marine management } \\
\text { area allocated in the SMPTE, such as Scottish } \\
\text { local terrestrial planning authorities }\end{array}$ & $\begin{array}{l}\text { Are the communities of interest located outside the } \\
\text { management area? }\end{array}$ & $\begin{array}{l}\text { Yes, some communities of interest are located outside the } \\
\text { management area either transnationally, such as the Maine } \\
\text { Department of Aquaculture, or in the context that they do not } \\
\text { directly interact with the marine management area allocated in the } \\
\text { SMPTE, such as the NB Department of Energy and Resource } \\
\text { Development }\end{array}$ \\
\hline \multicolumn{3}{|c|}{ Consultation and Feedback Process } \\
\hline $\begin{array}{l}\text { The consultation procedures for members of } \\
\text { MS are not formally structured, and therefore, } \\
\text { internal input occurs on an as needed basis to } \\
\text { inform the development of the SMPTE process }\end{array}$ & $\begin{array}{l}\text { What are the consultation procedures for the members } \\
\text { of the governance body? }\end{array}$ & $\begin{array}{l}\text { It is suggested that a formal structure for consultation procedures } \\
\text { for the members of the governance body be structured in order to } \\
\text { mimic best practices and facilitate a more concise method of } \\
\text { disseminating information (Cormier et al., 2015). Therefore, the } \\
\text { OWSC involved in the SMPTE process should engage in a } \\
\text { minimum of one formal mandatory meeting for each stage within } \\
\text { each phase of the SMPTE process to review the achievement of } \\
\text { desired outputs and alter trajectories of the process in light of data } \\
\text { gaps, with ancillary meetings held as needed. After the scoping } \\
\text { meeting, which initiates the first outputs SMPTE process, all other } \\
\text { meetings will consist of two agendas; a review of the completed } \\
\text { stage and a development of the agenda for the next stage. It is also } \\
\text { recommended that meetings be held to both develop and review } \\
\text { the entirety of each of the three process phases and the resulting } \\
\text { licensing output phase to establish and analyze the goals and } \\
\text { objectives of each phase in relation to the key drivers and strategic }\end{array}$ \\
\hline
\end{tabular}




\begin{tabular}{|c|c|c|}
\hline & & aims established in the SMPTE \\
\hline $\begin{array}{l}\text { The feedback procedures in place within MS to } \\
\text { inform members as to why and how advice was } \\
\text { either integrated or not integrated in the } \\
\text { SMPTE process are not formally structured, } \\
\text { rather, email chains and minutes for meeting } \\
\text { support this function on an as needed basis } \\
\text { determined by those internal to MS (Interview, } \\
\text { 2016a) }\end{array}$ & $\begin{array}{l}\text { What are the feedback procedures to inform members } \\
\text { as to why and how advice was either integrated or not } \\
\text { integrated in the planning process? }\end{array}$ & $\begin{array}{l}\text { It is advised that the DoE develop a formally structured } \\
\text { consultation and feedback process internal to the DoE, granting } \\
\text { access to the OWSC as applicable, where filing systems and } \\
\text { communication tools (e.g. secure forums) are specific to the } \\
\text { SMPTE process. Formal mandatory meetings developed to } \\
\text { strengthen the consultation and feedback process should discuss } \\
\text { and document how and why/why not advice emanating internally } \\
\text { within the governance structure was incorporated, with such } \\
\text { communication tools utilized to disseminate the formulated } \\
\text { document. }\end{array}$ \\
\hline $\begin{array}{l}\text { There are no formal requirements for record } \\
\text { keeping for communication products (beyond } \\
\text { standard public body filing systems) as well as } \\
\text { consultation and feedback documents received } \\
\text { by the members of MS in relation to the } \\
\text { SMPTE process }\end{array}$ & $\begin{array}{l}\text { What are the requirements for record keeping for } \\
\text { communication products as well as consultation and } \\
\text { feedback documents received by the members of the } \\
\text { governance body? }\end{array}$ & $\begin{array}{l}\text { It is advised that the DoE develop a formally structured } \\
\text { consultation and feedback process internal to the DoE, granting } \\
\text { access to the OWSC as applicable, where filing systems and } \\
\text { communication tools (e.g. secure forums) are specific to the } \\
\text { SMPTE process. }\end{array}$ \\
\hline $\begin{array}{l}\text { The appropriate language, fora and media for } \\
\text { communicating the material and views within MS } \\
\text { in relation to the SMPTE process is not formally } \\
\text { structured, rather, email chains and minutes for } \\
\text { meeting support this function on an as needed } \\
\text { basis determined by those internal to MS }\end{array}$ & $\begin{array}{l}\text { What is the most appropriate language, fora and media } \\
\text { for communicating the material and views? }\end{array}$ & $\begin{array}{l}\text { It is advised that the DoE develop a formally structured } \\
\text { consultation and feedback process internal to the DoE, granting } \\
\text { access to the OWSC as applicable, where filing systems and } \\
\text { communication tools (e.g. secure forums) are specific to the SMPTE } \\
\text { process. Formal mandatory meetings developed to strengthen the } \\
\text { consultation and feedback process should discuss and document how } \\
\text { and why/why not advice emanating internally within the governance } \\
\text { structure was incorporated, with such communication tools utilized } \\
\text { to disseminate the } \\
\text { formulated document. }\end{array}$ \\
\hline \multicolumn{3}{|c|}{ Public } \\
\hline $\begin{array}{l}\text { The SMPTE specifies that the CA must consult } \\
\text { with members of the general public such as } \\
\text { Local Community and Parish Councils, Local } \\
\text { Trusts, and any other interested parties or } \\
\text { groups }\end{array}$ & $\begin{array}{l}\text { What are the public constituencies that should be } \\
\text { consulted? }\end{array}$ & $\begin{array}{l}\text { The SMPTE specifies that the DoE must consult with members of } \\
\text { the general public such as Mi'kmaq Conservation Group, AETI } \\
\text { and any other interested parties or groups }\end{array}$ \\
\hline \multicolumn{3}{|c|}{ Public Communication Procedures } \\
\hline $\begin{array}{l}\text { MS makes available the draft plan, } \\
\text { sustainability appraisal report, SEA, socio- } \\
\text { economic report, and the RLG on the } \\
\text { government website where members of the } \\
\text { public can familiarize themselves with the } \\
\text { documents and the progression of the SMPTE }\end{array}$ & $\begin{array}{l}\text { What is the communication plan and tools used to } \\
\text { communicate key decisions? }\end{array}$ & $\begin{array}{l}\text { While documents already developed in relation to researching for } \\
\text { tidal energy development within Nova Scotia such as resource } \\
\text { assessments, socioeconomic assessments, MEKSs, and the BoF } \\
\text { and Cape Breton/Bras d'Or SEAs have been made publically } \\
\text { available on OERAs website, following suggestions made in this } \\
\text { paper to undertake studies incorporated in the SMPTE process } \\
\text { within the sustainability appraisal after phase } 1 \text { is complete, the } \\
\text { DoE should make available the draft plan, sustainability appraisal } \\
\text { report, SEA, MEKS, socio-economic report, and the RLG under } \\
\text { one banner on their government website where members of the } \\
\text { public can familiarize themselves with the documents and the } \\
\text { progression of the SMPTE. }\end{array}$ \\
\hline $\begin{array}{l}\text { Although community stakeholders can ask the } \\
\text { SG questions about and provide feedback into } \\
\text { the SMPTE process, there is no legislative right } \\
\text { to an appeal process where a decision is not } \\
\text { being understood, accepted, and/or tolerated by } \\
\text { the public }\end{array}$ & $\begin{array}{l}\text { Is there an appeal process where a decision is not being } \\
\text { understood/accepted/ tolerated by the public? }\end{array}$ & $\begin{array}{l}\text { Although community stakeholders can ask the DoE questions } \\
\text { about and provide feedback into the SMPTE process, there is no } \\
\text { legislative appeal process under the overriding MRE Act } 2015 \\
\text { where a decision is not being understood, accepted, and/or } \\
\text { tolerated by the public. It is suggested that the MRE Act } 2015 \text { be } \\
\text { revised to incorporate an appeal process for decisions } \\
\text { understood/accepted/tolerated by the public in order to avoid legal } \\
\text { disputes }\end{array}$ \\
\hline $\begin{array}{l}\text { The communication structure is approved by } \\
\text { Scottish Ministers and executed by MS as the } \\
\text { acting CA }\end{array}$ & Who approves the communication plan? & $\begin{array}{l}\text { The communication structure is approved by Nova Scotia and } \\
\text { Canadian Ministers involved in the OWSC and executed by the } \\
\text { DoE as the leading CA }\end{array}$ \\
\hline $\begin{array}{l}\text { MS makes available the draft plan, } \\
\text { sustainability appraisal report, SEA, and socio- } \\
\text { economic report on the government website } \\
\text { where members of the public can familiarize } \\
\text { themselves with the documents and the } \\
\text { progression of the SMPTE }\end{array}$ & $\begin{array}{l}\text { What controls exist on the dissemination of the key } \\
\text { decisions and products of the MSP? }\end{array}$ & $\begin{array}{l}\text { While documents already developed in relation to researching for } \\
\text { tidal energy development within Nova Scotia such as resource } \\
\text { assessments, socioeconomic assessments, MEKSs, and the BoF } \\
\text { and Cape Breton/Bras d'Or SEAs have been made publically } \\
\text { available on OERAs website, following suggestions made in this } \\
\text { paper to undertake studies incorporated in the SMPTE process } \\
\text { within the sustainability appraisal after phase } 1 \text { is complete, the } \\
\text { DoE should make available the draft plan, sustainability appraisal } \\
\text { report, SEA, MEKS, socio-economic report, and the RLG under } \\
\text { one banner on their government website where members of the } \\
\text { public can familiarize themselves with the documents and the } \\
\text { progression of the SMPTE. Furthermore, Nova Scotia and } \\
\text { Canadian Ministers involved in the OWSC should release a post } \\
\text { adoption statement detailing how and why/why not inputs from }\end{array}$ \\
\hline
\end{tabular}




\begin{tabular}{|c|c|c|}
\hline & & key stakeholders were incorporated into the SMPTE process \\
\hline \multicolumn{3}{|c|}{ Scientific and Technical Advisory Bodies } \\
\hline $\begin{array}{l}\text { The scientific and technical advisory bodies that } \\
\text { are internal to the SG that are called upon for } \\
\text { advise throughout the SMPTE process consist } \\
\text { of numerous experts categorized under the } \\
\text { learning and justice, enterprise, environment, } \\
\text { and innovation, health and social care, finance, } \\
\text { strategy and external affairs, and communities } \\
\text { divisions }\end{array}$ & $\begin{array}{l}\text { What are the scientific and technical advisory bodies } \\
\text { that the planning process will turn to for advice? }\end{array}$ & $\begin{array}{l}\text { The scientific and technical advisory bodies that are internal to the } \\
\text { DoE that are called upon for advise throughout the SMPTE } \\
\text { process consist of numerous experts categorized under the relevant } \\
\text { provincial and federal government departments and agencies } \\
\text { identified in the SMPTE under key stakeholders. }\end{array}$ \\
\hline $\begin{array}{l}\text { There is no standard for obligatory accreditation } \\
\text { regarding the employment of scientific and } \\
\text { technical expertise within MS }\end{array}$ & $\begin{array}{l}\text { What are the terms of reference or accreditation related } \\
\text { to their area of expertise for their organization or } \\
\text { association? }\end{array}$ & $\begin{array}{l}\text { It is recommended that professional designations for scientific and } \\
\text { technical experts delegated as a part of the SMPTE process } \\
\text { possess professional accreditation in their field in order to ensure } \\
\text { the competency of the individual (e.g. planners should hold CIP } \\
\text { accreditation) }\end{array}$ \\
\hline $\begin{array}{l}\text { Due to the pre-commercial stage in which TCTs } \\
\text { currently reside, resulting in the fact that } \\
\text { Scotland's SMPTE is the first of its kind, BATs } \\
\text { for ecosystem, social, economic, and policy } \\
\text { bodies have yet to be devised, therefore, } \\
\text { Scotland's SMPTE can pave the way to become } \\
\text { the standard for SMPTE processes }\end{array}$ & $\begin{array}{l}\text { What are the Best Available Techniques (BAT) that } \\
\text { are internationally recognized and accredited? }\end{array}$ & $\begin{array}{l}\text { Due to the pre-commercial stage in which TCTs currently reside, } \\
\text { resulting in the fact that Scotland's SMPTE is the first of its kind, } \\
\text { BATs for ecosystem, social, economic, and policy bodies have yet } \\
\text { to be devised, however, the Scottish SMPTE, informed by a } \\
\text { quality management review, can act as a BAT guideline to the } \\
\text { development of Nova Scotia's SMPTE as MS can constructed and } \\
\text { implemented the process, while Scotland is also the only nation in } \\
\text { the world to have granted consent and begun implementing a } \\
\text { commercial-scale TCT array }\end{array}$ \\
\hline $\begin{array}{l}\text { The SMPTE is designed not to have conflicts of } \\
\text { interest between experts and relevant } \\
\text { stakeholders. However, due to the intertwined } \\
\text { relationships between such actors, MS has } \\
\text { undergone judicial reviews undertaken by the } \\
\text { Royal Society for the Protection of Birds } \\
\text { (RSPB) in the past, although no significant } \\
\text { findings of malpractice has been identified and } \\
\text { confirmed }\end{array}$ & $\begin{array}{l}\text { Are there any conflicts of interest or link between the } \\
\text { experts and the stakeholders impacted by the proposed } \\
\text { MSP? }\end{array}$ & $\begin{array}{l}\text { The SMPTE is designed not to have conflicts of interest between } \\
\text { experts and relevant stakeholders. However, in accordance with } \\
\text { best practices observed in Scotland's SMPTE public policy } \\
\text { agenda, judicial reviews should be undertaken on an as needed } \\
\text { basis. }\end{array}$ \\
\hline $\begin{array}{l}\text { The legal advisors supporting the development } \\
\text { of the SMPTE process are internal to the SG }\end{array}$ & $\begin{array}{l}\text { Who are the legal advisors supporting the MSP } \\
\text { process? }\end{array}$ & $\begin{array}{l}\text { The legal advisors supporting the development of the SMPTE } \\
\text { process are internal to both the NS provincial government as per } \\
\text { the MRE Act } 2015 \text { and the NSEA 1995, as well as the Canadian } \\
\text { federal government as per the Crown Lands Act 2012, Fisheries } \\
\text { Act 1996, NWPA 1985, and CEA Act } 2012\end{array}$ \\
\hline \multicolumn{3}{|c|}{ Scientific and Technical Advisory Process } \\
\hline $\begin{array}{l}\text { Scientific and technical advice is garnered from } \\
\text { baseline and scoping assessments undertaken } \\
\text { by members internal to MS }\end{array}$ & $\begin{array}{l}\text { What is the source/reliability of the information used } \\
\text { to formulate the advice? }\end{array}$ & $\begin{array}{l}\text { Scientific and technical advice should be garnered from baseline } \\
\text { and scoping assessments undertaken by members internal to the } \\
\text { DoE, as well as the NSE in projects }>2 \mathrm{MW}-<50 \mathrm{MW} \text { and NSE and } \\
\text { CEAA in projects }>50 \mathrm{MW}\end{array}$ \\
\hline $\begin{array}{l}\text { An extensive amount of metadata is used } \\
\text { throughout the entire SMPTE ongoing process } \\
\text { to in order to be projected into decision support } \\
\text { system tools to validate if information is fit for } \\
\text { purpose in the formulation of scientific and } \\
\text { technical advice }\end{array}$ & $\begin{array}{l}\text { What is the metadata for the data used to validate if it } \\
\text { is fit for purpose in the formulation of the advice? }\end{array}$ & $\begin{array}{l}\text { An extensive amount of metadata should be used throughout the } \\
\text { entire SMPTE ongoing process to in order to be projected into } \\
\text { decision support system tools to validate if information is fit for } \\
\text { purpose in the formulation of scientific and technical advice. } \\
\text { However, the current state of research in the province reveals that } \\
\text { the quantity of such metadata is lacking substantially in } \\
\text { comparison to European nations with MSPs, while any data } \\
\text { collected is either not publically available and/or not organized by } \\
\text { an individual government department or agency. It is } \\
\text { recommended that the DoE resolve these issues by mimicking best } \\
\text { practices observed with Scotland's NMPi database. }\end{array}$ \\
\hline $\begin{array}{l}\text { The SG's Marine Strategy Forum (MSF), a } \\
\text { strategic oversight group comprised of relevant } \\
\text { stakeholders and scientific and technical } \\
\text { advisory bodies are encouraged to engage in the } \\
\text { development of the SEA and socio-economic } \\
\text { assessment processes that inform the } \\
\text { sustainability appraisal through to the statutory } \\
\text { consultation stage in order to set the terms of } \\
\text { references for the SMPTE process }\end{array}$ & $\begin{array}{l}\text { What is the process to set the terms of references and } \\
\text { questions to be answered by the advisory bodies? }\end{array}$ & $\begin{array}{l}\text { In accordance with best practices observed in Scotland, the DoE } \\
\text { should consult with the OWSC to create a a strategic oversight } \\
\text { group, much like the Scottish Marine Strategy Forum (MSF), } \\
\text { comprised of relevant stakeholders and scientific and technical } \\
\text { advisory bodies are encouraged to engage in the development of } \\
\text { the SEA and socio-economic assessment processes that inform the } \\
\text { sustainability appraisal through to the statutory consultation stage } \\
\text { in order to set the terms of references for the SMPTE process. } \\
\text { Essentially this would expand/readjust the delegated } \\
\text { responsibilities of the OWSC from their current role of reviewing } \\
\text { and coordinating permits and approvals required by provincial and } \\
\text { federal regulatory authorities. }\end{array}$ \\
\hline $\begin{array}{l}\text { The SMPTE process is approved by Scottish } \\
\text { Ministers and chaired by the relevant planning } \\
\text { Policy Lead in conjunction with scientific and } \\
\text { technical specialists applicable to specific } \\
\text { stages and processes of the SMPTE }\end{array}$ & $\begin{array}{l}\text { Who approves the process and who chairs to ensure } \\
\text { that advice reflects the questions asked and that the } \\
\text { advice is fit for the purpose of planning initiative? }\end{array}$ & $\begin{array}{l}\text { The SMPTE process is approved by Nova Scotia and Canadian } \\
\text { Ministers and chaired by the relevant planning Policy Lead in } \\
\text { conjunction with scientific and technical specialists applicable to } \\
\text { specific stages and processes of the SMPTE }\end{array}$ \\
\hline
\end{tabular}




\section{$\mathbf{x}$}

The Marine Scotland Act 2010, designating MS as the CA and therefore the governance body who structured the SMPTE process, from the scoping stage to the plan review process

\section{Governance Body}

What is the governance structure needed to address the legislative implications, ecological considerations, development priorities and community concerns as part of the scope of the planning initiative? the devolution of powers from UK Parliament to Scottish Parliament to plan the marine environment within the former UK EEZ bordering Scotland's TZ under the Marine and Coastal Access Act 2009
What are the agreements or memorandum of understandings needed to create the governance structure?

The DoE is the MSP CA via the MRE Act 2015 conditional on powers to plan being delegated form the DFO under the Oceans Act 1996, thereby designating the DoE as the governance body who structures the SMPTE process, from the scoping stage to the plan review process

The delegation of administrative authority over identified provincial marine planning boundaries from the federal government to the DoE as the MSP CA via the federal Oceans Act, with the identification of MREAs requiring consultation with the NS DNR under the Crown Lands Act 2012 and the MRE Act 2015, and environmental assessment and review process being held between the DoE and the NSE in projects $>2 \mathrm{MW}-<50 \mathrm{MW}$ under the NSEA 1995, and the NSE and CEAA in projects $>50 \mathrm{MW}$ under the CEA Act 2012.

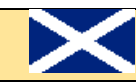

There are no formal obligations in the SG planning structure to incorporate a specified number of members within decision-making quorums or to reach a consensus on

recommendations

Members of MS communicate within the SMPTE governance structure in an informal manner via email chains and minutes for meetings on an as needed basis
Governance Terms of References

How many members are required to form a quorum for decision-making or to reach a consensus on recommendations?

ow do members communicate within the governance structure?

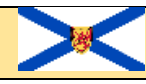

It is recommended that 11 members, one representative from each governmental department delegated to the OWSC, be required to form a quorum for decision-making or to reach a consensus on recommendations

It is advised that the DoE develop a formally structured consultation and feedback process internal to the DoE, granting access to the OWSC as applicable, where filing systems and communication tools (e.g. secure forums) are specific to the SMPTE process. Formal mandatory meetings developed to strengthen the consultation and feedback process should discuss and document how and why/why not advice emanating internally within the governance structure was incorporated, with such communication tools utilized to disseminate the formulated document and ancillary meetings held as needed.

There is no formal legislated expected response timeframe within the MS governance structure, rather, email chains and minutes for meeting support this function on an as needed basis, determined by those internal to MS
What is the expected response timeframe of the governance structure?
There is no formal senior SMPTE management communication protocol within the MS governance structure, rather, email chains and minutes for meeting support this function on an as needed basis

The SMPTE process itself requires the involvement and approval of Scottish Ministers through the final draft plan to the post-adoption statement

MS, as the sole acting CA, is identified in the terms of reference for the planning process
How does the governance structure communicate with senior MSP management?

How does the governance structure connect with the political leaders to demonstrate support from political leaders?

What are the competent authorities identified in the Terms of References for the planning process?

It is suggested that a formal structure for consultation procedure for the members of the governance body be structured in order to mimic best practices and facilitate a more concise method of disseminating information (Cormier et al., 2015). Therefore, the OWSC involved in the SMPTE process should engage in a minimum of one formal mandatory meeting for each stage within each phase of the SMPTE process to review the achievement of desired outputs and alter trajectories of the process in light of data gaps, with ancillary meetings held as needed. After the scoping meeting, which initiates the first outputs SMPTE process, all other meetings will consist of two agendas; a review of the completed stage and a development of the agenda for the next stage. It is also recommended that meetings be held to both develop and review the entirety of each of the three process phases and the resulting licensing output phase to establish and analyze the goals and objectives of each phase in relation to the key drivers and strategic aims established in the SMPTE

It is advised that the DoE develop a formally structured consultation and feedback process internal to the DoE, granting access to the OWSC as applicable, where filing systems and commu tools (e.g. secure forums) are specific to the

SMPTE process. Formal mandatory meetings should facilitate the communication between the governance structure with senior SMPTE management

The SMPTE process itself require the involvement and approval of Nova Scotia and Canadian Ministers through the final draft plan to the post-adoption statement

The DoE as the MSP CA, the NSE and CEAA as the ecosystem CAs joint with the DoE, and the NS DNR as the other CA are identified in the Terms of References for the SMPTE process

\section{Governance Business Rules}

Input from relevant industry and community stakeholders is taken into consideration in order to obtain sectoral and local knowledge and values when searching for potentially suitable tidal energy development sites during the prestatutory consultation stage, and continually updated during advancing stages of the SMPTE

\section{How is the advice and feedback from the industry} stakeholders and communities of interest taken into consideration in the governance and oversight of the planning initiative?

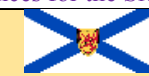

Input from relevant industry and community stakeholders is taken into consideration in order to obtain sectoral and local knowledge and values when searching for potentially suitable tidal energy development sites during the pre-statutory consultation stage, and continually updated during advancing stages of the SMPTE 


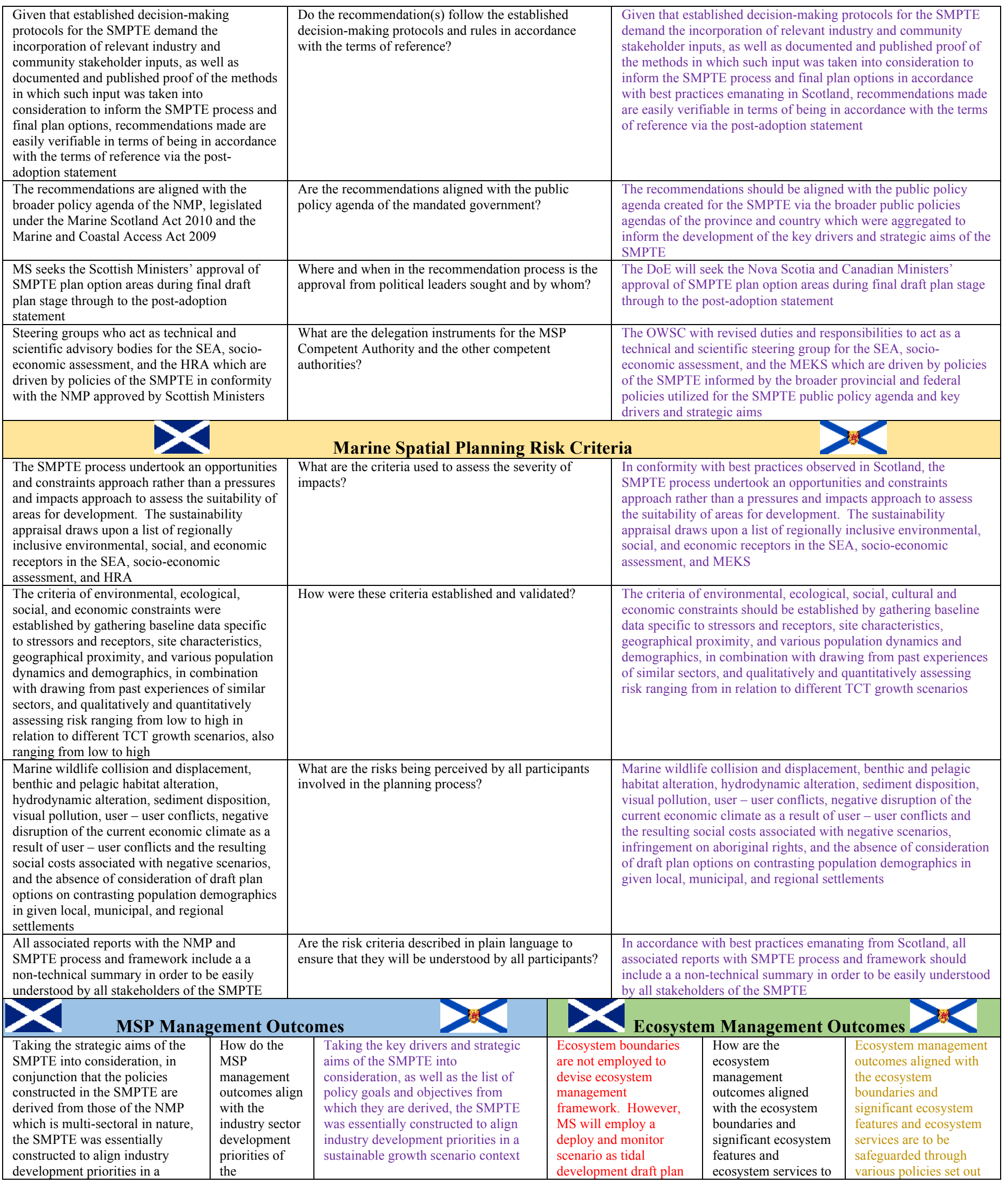




\begin{tabular}{|c|c|c|c|c|c|c|}
\hline $\begin{array}{l}\text { sustainable growth scenario } \\
\text { context }\end{array}$ & $\begin{array}{l}\text { management } \\
\text { area? }\end{array}$ & & \multirow{2}{*}{\multicolumn{2}{|c|}{$\begin{array}{l}\text { areas are given consent } \\
\text { in order to safeguard } \\
\text { significant ecosystem } \\
\text { features and services }\end{array}$}} & \multirow[t]{2}{*}{ be safeguarded? } & \multirow{2}{*}{$\begin{array}{l}\text { in the SMPTE in } \\
\text { relation to an ecosystem } \\
\text { approach to MSP and } \\
\text { the overarching } \\
\text { legislation listed in the } \\
\text { SMPTEs public policy } \\
\text { agenda informing such } \\
\text { policies }\end{array}$} \\
\hline $\begin{array}{l}\text { SMPTE outcomes reconcile the } \\
\text { needs of industry and community } \\
\text { stakeholders through the } \\
\text { engagement of such stakeholders } \\
\text { throughout the SMPTE process }\end{array}$ & $\begin{array}{l}\text { How do the } \\
\text { MSP outcomes } \\
\text { reconcile the } \\
\text { needs of } \\
\text { industry with } \\
\text { the public and } \\
\text { the } \\
\text { communities } \\
\text { of interests? }\end{array}$ & $\begin{array}{l}\text { SMPTE outcomes reconcile the needs } \\
\text { of industry and community } \\
\text { stakeholders through the proposed } \\
\text { structured engagement of such } \\
\text { stakeholders throughout the SMPTE } \\
\text { process }\end{array}$ & & & & \\
\hline $\begin{array}{l}\text { Given that the current iteration of } \\
\text { sustainability appraisal becomes } \\
\text { an ongoing process, in } \\
\text { conjunction with the low, } \\
\text { medium, and high growth } \\
\text { scenarios outlined in the NMP, it } \\
\text { is highly plausible that the } \\
\text { SMPTE will achieve ecosystem } \\
\text { management outcomes within the } \\
\text { management area }\end{array}$ & $\begin{array}{l}\text { Can the MSP } \\
\text { management } \\
\text { outcomes be } \\
\text { achieved with } \\
\text { the marine } \\
\text { spatial plan of } \\
\text { the } \\
\text { management } \\
\text { area? }\end{array}$ & $\begin{array}{l}\text { Given that the sustainability appraisal } \\
\text { becomes an ongoing process, } \\
\text { becoming further informed by } \\
\text { ongoing research and development in } \\
\text { the province as well as the country, it } \\
\text { is highly plausible that the SMPTE } \\
\text { will achieve ecosystem management } \\
\text { outcomes within the management area }\end{array}$ & \multicolumn{2}{|c|}{$\begin{array}{l}\text { Given that the current } \\
\text { iteration of SEA } \\
\text { becomes an ongoing } \\
\text { process, in conjunction } \\
\text { with the legislated } \\
\text { requirement of } \\
\text { undertaking project- } \\
\text { level EIAs for plan } \\
\text { areas put forward as a } \\
\text { mitigation measure } \\
\text { under the HRA, it is } \\
\text { highly plausible that the } \\
\text { SMPTE will achieve } \\
\text { ecosystem management } \\
\text { outcomes within the } \\
\text { management area }\end{array}$} & $\begin{array}{l}\text { Can the ecosystem } \\
\text { management } \\
\text { outcomes be achieved } \\
\text { from the marine } \\
\text { spatial plan within the } \\
\text { management area? }\end{array}$ & $\begin{array}{l}\text { Given that an ideal } \\
\text { iteration of SEA } \\
\text { becomes an ongoing } \\
\text { process, in conjunction } \\
\text { with the legislated } \\
\text { requirement of } \\
\text { undertaking project- } \\
\text { level EIAs for plan } \\
\text { areas put forward as a } \\
\text { mitigation measure } \\
\text { under the MRE Act } \\
\text { 2015, it is highly } \\
\text { plausible that the } \\
\text { SMPTE will achieve } \\
\text { ecosystem management } \\
\text { outcomes within the } \\
\text { management area }\end{array}$ \\
\hline $\begin{array}{l}\text { Potential conflicts and anticipated } \\
\text { interactions are taken into } \\
\text { consideration in the broader NMP } \\
\text { from which the SMPTE conforms } \\
\text { its policies must conform to }\end{array}$ & $\begin{array}{l}\text { Are some of } \\
\text { the MSP } \\
\text { management } \\
\text { outcomes } \\
\text { influenced by } \\
\text { activities } \\
\text { outside the } \\
\text { management } \\
\text { area or by } \\
\text { other } \\
\text { jurisdictions or } \\
\text { policies? }\end{array}$ & $\begin{array}{l}\text { Potential conflicts and anticipated } \\
\text { interactions are taken into } \\
\text { consideration in the SMPTE through } \\
\text { multi-secoral quantitative and } \\
\text { qualitative spatial analysis. However, } \\
\text { the further quantification of } \\
\text { environmental, social, and economic } \\
\text { factors in conjunction with a federal } \\
\text { MSP dictating policies in which } \\
\text { provincial MSPs must be in } \\
\text { conformity with, as witnessed in } \\
\text { Scotland, is recommended for greater } \\
\text { SMPTE management }\end{array}$ & \multicolumn{2}{|c|}{$\begin{array}{l}\text { Potential conflicts and } \\
\text { anticipated interactions } \\
\text { are taken into } \\
\text { consideration in the } \\
\text { broader NMP from } \\
\text { which the SMPTE } \\
\text { conforms its policies } \\
\text { must conform to }\end{array}$} & $\begin{array}{l}\text { Are some of the } \\
\text { ecosystem } \\
\text { management } \\
\text { outcomes dependent } \\
\text { on management } \\
\text { measures or marine } \\
\text { spatial plans that are } \\
\text { outside the } \\
\text { management area? }\end{array}$ & $\begin{array}{l}\text { Potential conflicts and } \\
\text { anticipated interactions } \\
\text { are taken into } \\
\text { consideration in the } \\
\text { SMPTE through multi- } \\
\text { secoral quantitative and } \\
\text { qualitative spatial } \\
\text { analysis. However, the } \\
\text { further quantification of } \\
\text { environmental, social, } \\
\text { and economic factors in } \\
\text { conjunction with a } \\
\text { federal MSP dictating } \\
\text { policies in which } \\
\text { provincial MSPs must } \\
\text { be in conformity with, } \\
\text { as witnessed in } \\
\text { Scotland, is } \\
\text { recommended for } \\
\text { greater SMPTE } \\
\text { management }\end{array}$ \\
\hline $\begin{array}{l}\text { All associated reports with the } \\
\text { NMP and SMPTE process and } \\
\text { framework include a non- } \\
\text { technical summary in order to be } \\
\text { easily understood by all } \\
\text { stakeholders of the SMPTE }\end{array}$ & $\begin{array}{l}\text { Are the MSP } \\
\text { management } \\
\text { outcomes } \\
\text { described in } \\
\text { plain language } \\
\text { that will be } \\
\text { understood by } \\
\text { all } \\
\text { participants? }\end{array}$ & $\begin{array}{l}\text { In conformity with best practices } \\
\text { observed in Scotland, it is suggested } \\
\text { that all associated reports with the } \\
\text { SMPTE process and framework } \\
\text { include a non-technical summary in } \\
\text { order to be easily understood by all } \\
\text { stakeholders of the SMPTE }\end{array}$ & \multicolumn{2}{|c|}{$\begin{array}{l}\text { All associated reports } \\
\text { with the NMP and } \\
\text { SMPTE process and } \\
\text { framework include a } \\
\text { non-technical summary } \\
\text { in order to be easily } \\
\text { understood by all } \\
\text { stakeholders of the } \\
\text { SMPTE }\end{array}$} & $\begin{array}{l}\text { Are the ecosystem } \\
\text { management } \\
\text { outcomes described in } \\
\text { plain language that } \\
\text { will be understood by } \\
\text { all participants? }\end{array}$ & $\begin{array}{l}\text { In conformity with best } \\
\text { practices observed in } \\
\text { Scotland, it is suggested } \\
\text { that all associated } \\
\text { reports with the SMPTE } \\
\text { process and framework } \\
\text { include a non-technical } \\
\text { summary in order to be } \\
\text { easily understood by all } \\
\text { stakeholders of the } \\
\text { SMPTE }\end{array}$ \\
\hline \multicolumn{7}{|c|}{ MSP Secretariat } \\
\hline \multicolumn{2}{|c|}{$\begin{array}{l}\text { All pertinent information related to the SMPTE } \\
\text { process is stored in the SGs electronic records } \\
\text { management system }\end{array}$} & \multicolumn{2}{|c|}{$\begin{array}{l}\text { How and where is information (e.g. data, records, } \\
\text { advice) stored? }\end{array}$} & \multicolumn{3}{|c|}{$\begin{array}{l}\text { All pertinent information related to the SMPTE process should be } \\
\text { stored in an electronic records management system constructed by } \\
\text { the DoE specific to the SMPTE and accessible internally to DoE } \\
\text { members involved in the SMPTE process }\end{array}$} \\
\hline \multicolumn{2}{|c|}{$\begin{array}{l}\text { The information and document management system } \\
\text { related to the SMPTE process is the SGs electronic } \\
\text { records management system }\end{array}$} & \multicolumn{2}{|l|}{$\begin{array}{l}\text { What is the information and document } \\
\text { management system? }\end{array}$} & \multicolumn{3}{|c|}{$\begin{array}{l}\text { The information and document management system related to the } \\
\text { SMPTE process should materialize in the form of an electronic } \\
\text { records management system constructed by the DoE specific to the } \\
\text { SMPTE and accessible internally to DoE members involved in the } \\
\text { SMPTE process }\end{array}$} \\
\hline \multicolumn{2}{|c|}{$\begin{array}{l}\text { The information and document management system } \\
\text { related to the SMPTE process is the SGs electronic } \\
\text { records management system }\end{array}$} & \multicolumn{2}{|c|}{ How are versions maintained and controlled? } & \multicolumn{3}{|c|}{$\begin{array}{l}\text { The information and document management system related to the } \\
\text { SMPTE process should materialize in the form of an electronic } \\
\text { records management system constructed by the DoE specific to the }\end{array}$} \\
\hline
\end{tabular}




\begin{tabular}{|c|c|c|}
\hline & & $\begin{array}{l}\text { SMPTE, accessible internally to DoE members involved in the } \\
\text { SMPTE process, and maintained and controlled by the DoE in } \\
\text { accordance with existing practices employed within DoE }\end{array}$ \\
\hline $\begin{array}{l}\text { Unpublished information pertaining to the SMPTE } \\
\text { in any manner can only be accessed by the SG and } \\
\text { are safeguarded through a secured built-in version } \\
\text { control SCOTS IT account system internal to SG } \\
\text { employees }\end{array}$ & $\begin{array}{l}\text { What are the security requirements to access and } \\
\text { safeguard information? }\end{array}$ & $\begin{array}{l}\text { Unpublished information pertaining to the SMPTE in any manner } \\
\text { can only be accessed by the DoE and are safeguarded through a } \\
\text { secured built-in version control account system internal to DoE } \\
\text { employees }\end{array}$ \\
\hline $\begin{array}{l}\text { There is no single member of MS who is responsible } \\
\text { for the management of information pertaining to the } \\
\text { SMPTE, rather, individual SG employees are } \\
\text { responsible for managing their own individual } \\
\text { information in which they produced }\end{array}$ & $\begin{array}{l}\text { Who, from the MSP secretariat, is responsible for } \\
\text { managing the information? }\end{array}$ & $\begin{array}{l}\text { An individual internal to the DoE and employed in the SMPTE } \\
\text { process should be delegated responsibility for managing } \\
\text { information related to the SMPTE process stored in the suggested } \\
\text { electronic records management system to be constructed by the } \\
\text { DoE specific to the SMPTE, accessible internally to DoE members } \\
\text { involved in the SMPTE process, and maintained and controlled by } \\
\text { the DoE in accordance with existing practices employed within } \\
\text { DoE }\end{array}$ \\
\hline $\begin{array}{l}\text { Yes, the MSP Secretariat is included in terms of } \\
\text { references of the Governance Body }\end{array}$ & $\begin{array}{l}\text { Is the MSP Secretariat included in terms of } \\
\text { references of the Governance Body? }\end{array}$ & $\begin{array}{l}\text { Yes, the MSP Secretariat will be included in terms of references of } \\
\text { the Governance Body }\end{array}$ \\
\hline $\begin{array}{l}\text { Any data and information created by MS in relation } \\
\text { the SMPTE and submitted to the advisory processes } \\
\text { is be copyrighted under the Crown Copyright } \\
\text { Marine Scotland. However, this does not necessarily } \\
\text { present any constraints to third party use, as most } \\
\text { information is available through the NMPi, and the } \\
\text { SG is subject to the provisions of the Freedom of } \\
\text { Information regulations }\end{array}$ & $\begin{array}{l}\text { What are the copyright or proprietary } \\
\text { requirements of the data and information } \\
\text { submitted to the advisory processes? }\end{array}$ & $\begin{array}{l}\text { Any data and information created by the DoE in relation the } \\
\text { SMPTE and submitted to the advisory processes is be copyrighted } \\
\text { under the Crown Copyright Province of Nova Scotia. However, } \\
\text { ideally this should not necessarily present any constraints to third } \\
\text { party use, as it is recommended, in conformity with best practices } \\
\text { emanating from Scotland's NMPi, that a central database be } \\
\text { constructed by the DoE and made publically accessible, with the } \\
\text { DoE being subject to the provisions of the Nova Scotia Freedom of } \\
\text { Information and Protection of Privacy Act (FOIPOP) } 1993\end{array}$ \\
\hline $\begin{array}{l}\text { The information and document management system } \\
\text { related to the SMPTE process is the SGs electronic } \\
\text { records management system }\end{array}$ & $\begin{array}{l}\text { What are the filing plans for all documents } \\
\text { produced during the planning and implementation } \\
\text { process? }\end{array}$ & $\begin{array}{l}\text { The information and document management system related to the } \\
\text { SMPTE process would be the proposed DoE electronic records } \\
\text { management system }\end{array}$ \\
\hline $\begin{array}{l}\text { All pertinent information related to the SMPTE } \\
\text { process is stored for relevant periods of time in } \\
\text { conformity with Freedom of } \\
\text { Information/Environmental Information regulations }\end{array}$ & $\begin{array}{l}\text { What is the file retention period and requirements } \\
\text { for the documents produced during the planning } \\
\text { and implementation process? }\end{array}$ & $\begin{array}{l}\text { All pertinent information related to the SMPTE process is stored } \\
\text { for relevant periods of time in conformity with Nova Scotia } \\
\text { FOIPOP regulations }\end{array}$ \\
\hline $\begin{array}{l}\text { The information produced by MS in relation to the } \\
\text { SMPTE is classified as official sensitive, as opposed } \\
\text { to secret or top secret, and can be accessed by an SG } \\
\text { employee via their secured built-in version control } \\
\text { Scots account system }\end{array}$ & $\begin{array}{l}\text { What are the privacy and accesses to information } \\
\text { requirements for the documents on file? }\end{array}$ & $\begin{array}{l}\text { In conformity to best practice emanating from Scotland, the } \\
\text { information produced by the DoE in relation to the SMPTE should } \\
\text { be classified as official sensitive, as opposed to secret or top secret, } \\
\text { and would only be accessed by a DoE employee via their proposed } \\
\text { secured built-in version control account system }\end{array}$ \\
\hline $\begin{array}{l}\text { The financing division of the SG within MS is the } \\
\text { responsible authority for tracking human and } \\
\text { financial resources in relation to the SMPTE } \\
\text { process. All relevant expenditures are recorded } \\
\text { under and traceable to the SG Enterprise Accounting } \\
\text { System }\end{array}$ & $\begin{array}{l}\text { What is the financial system used to track the } \\
\text { human and financial resources? }\end{array}$ & $\begin{array}{l}\text { The financing division of the DoE should be delegated as the } \\
\text { responsible authority for tracking human and financial resources in } \\
\text { relation to the SMPTE process. All relevant expenditures will be } \\
\text { recorded under and traceable to the proposed DoE electronic } \\
\text { records management system }\end{array}$ \\
\hline \multicolumn{3}{|c|}{ Risk Framework } \\
\hline \multicolumn{3}{|c|}{ Significant Ecosystem Components } \\
\hline Ecosystem boundaries have not been established & $\begin{array}{l}\text { What criteria are used to establish the ecosystem } \\
\text { boundaries? }\end{array}$ & $\begin{array}{l}\text { Ecosystem boundaries have been established in relation to the } \\
\text { planning boundaries based on the identification of spatially } \\
\text { persisting occurrence rates of various flora, fauna, and } \\
\text { oceanographic processes within and outside of the management } \\
\text { boundaries }\end{array}$ \\
\hline Ecosystem boundaries have not been established & $\begin{array}{l}\text { Are the boundaries drawn by topographical or } \\
\text { process-related criteria? }\end{array}$ & Ecosystem boundaries are drawn by process related criteria \\
\hline $\begin{array}{l}\text { The SMPTE placed high constraint levels on SACs, } \\
\text { SPAs, sites of scientific interest (SSSI), national } \\
\text { scenic areas (NSAs - areas of outstanding scenic } \\
\text { value from a national context) (Scottish National } \\
\text { Heritage, 2016), and European RAMSAR sites, } \\
\text { which are considered ecologically significant and } \\
\text { sensitive when evaluating suitable sites for tidal } \\
\text { energy development during the scoping stage }\end{array}$ & $\begin{array}{l}\text { What are the criteria to identify the significant } \\
\text { ecosystem features and processes that need to be } \\
\text { safeguarded to avoid ecosystem level } \\
\text { consequences? }\end{array}$ & $\begin{array}{l}\text { The initial scoping stage which drew upon the identification of } \\
\text { significant ecosystem features and process from a literature review } \\
\text { and consultation in accordance with best practices witnessed in } \\
\text { Scotland, like weightings of levels of constraint were attributed in } \\
\text { conformity with Scottish weighting based on similarities in marine } \\
\text { features following the dismantling of the STAP for this paper. } \\
\text { Current iterations of the MEKS, Bay of Fundy and Cape } \\
\text { Breton/Bras d'Or SEAs, and the socioeconomic assessment report } \\
\text { were then utilized to further identify the significant ecosystem } \\
\text { features and processes that need to be safeguarded to avoid } \\
\text { ecosystem level consequences during the sustainability appraisal } \\
\text { portion of Phase 2. Ideally, it is recommended that this process be } \\
\text { undertaken with greater MEKSs, SEAs, and socioeconomic } \\
\text { assessments under an overarching governance structure in } \\
\text { consultation with key stakeholders identified in the SMPTE and } \\
\text { scientific and technical experts from the DoE and, when necessary, } \\
\text { the OWSC }\end{array}$ \\
\hline
\end{tabular}


SACs and SPAs are established and evaluated under EU biological conservation legislation within Natura 2000. Together with some coastal SSSIs, SACs and SPAs combine with designated MPAs to form Scottish marine protected area network under the Marine Scotland Act 2010 and the Marine and Coastal Access Act 2009 (Marine Scotland, 2013a). NSAs are established by SNH and legislated under the Planning etc. (Scotland) Act 2006 (Scottish National Heritage, 2016), and European RAMSAR sites established by the JNCC and legislated under the Wildlife and Countryside Act 1981 and the Nature Conservation (Scotland) Act 2004 Drivers identified in the SMPTE as operating within the SMPTE management areas include potential tidal energy development and associated grid infrastructure, shipping and navigation, and recreation. Potential impacts are documented by the SEA as being site and technology specific, but generally of low overall risk to compromising ecosystem integrity (Marine Scotland, 2015c). Receptor pathways acknowledged in the SEA include fish, marine mammal, and diving sea bird collision risk with TCTs and alteration of hydrodynamics and associated interwoven coastal processes.

Drivers operating outside the SMPTE management areas are not specified in detail within the SMPTE, therefore, exact judgements concerning the activities of drivers operating outside the SMPTE

management area impacting the ecosystem integrity within the SMPTE management area cannot be made

The criteria used to identify risk to valued ecosystem components are presented in the SEA and the HRA
How were these criteria established and validated?

In terms of ecosystem integrity, what is the zone of influence of the activities of the drivers operating the management area?

In terms of ecosystem integrity, what is the zone of influence of the activities of drivers operating outside the management area?

What are methods used to conduct the risk identification?
These criteria were established and validated based mainly on legislative and policy requirements presented in the public policy agenda of the SMPTE and through the structuring of the SMPTE process based off of the best practice framework employed by MS in Scotland
Drivers identified in the SMPTE as operating within the SMPTE management areas include potential tidal energy development and associated grid infrastructure, shipping and navigation, and recreation. Key environmental issues (KEIs) acknowledged in the SEAs include critical physical processes, fisheries and aquaculture, fish and fish habitat, marine benthic habitat and communities, pelagic communities, marine mammals, marine birds, species at risk, marine transportation, tourism and recreation, marine and coastal resources, and economic development

\section{$\mathbf{x}$}

The socio-economic assessment identifies significan traditional, cultural, social and economic ecosystem services by drawing

from the EIAs and socio-economic impacts of past offshore renewable energy projects in order to qualitatively determine thesocio impacts and quantitatively measure the economic impacts of low of installed capacity, central, and high growth scenarios on different locations and population demographics within

Scotland

The ecosystem services, including the marine space, that support key stakeholders identified in the SMPT (fishing, shipping/navigation, natural environment, local government, grid,

national/devolved government, industry, community, and tourism/recreation) are potentially vulnerable to drivers occurring within the SMPTE management area, both from a user - user and user - environment conflict context

Drivers operating outside the SMPTE management area have been taken into consideration via weighting allotted to them within the constraints layer applied in the scoping and RLG stages

Ecosystem services have not been quantified by the SMPTE process, therefore, it is not possible to

determine whether the human capital exists in order to produce associated societal benefits

\section{Significant Ecosystem Services}

What criteria are used to identify the significant traditional, cultural, social and economic ecosystem services?

Drivers operating outside the SMPTE management areas are not specified in detail within the SMPTE due to the lack of baseline data within the province, as well as the absence of a central governance structure currently in place and comprehensive MSP, thus exact judgements concerning the activities of drivers operating outside the SMPTE management area impacting the ecosystem integrity within the SMPTE management area cannot be made

The criteria used to identify risk for the FORCE test site are the environmental monitoring and review assessments in relation to baseline data gathered in the Environmental Effects Monitoring Report 2011-2013. This initial gathering of baseline data, in conjunction with the incremental development approach promoted by the province and the adoption of a two-year monitoring and review of the SMPTE as witnessed in best practices emanating from Scotland is proposed for the entire provincial planning boundary.

The current iteration of the socioeconomic assessment and the MEKSs identify traditional, cultural, social and economic ecosystem services through aboriginal and key stakeholder consultation. However, it is recommended that, in accordance with the socioeconomic assessment released in Scotland for their SMPTE, future iterations of socioeconomic assessments and MEKSs quantitatively measure the economic impacts of TCT growth scenarios on different locations and population demographics within Nova Scotia

Are the ecosystem services vulnerabilities related to the activities of the drivers occurring within management area?
The ecosystem services identified in the MEKS, SEAs, and socioeconomic assessment are potentially vulnerable to drivers occurring within the SMPTE management area, both from a user user and user - environment conflict context
Are the ecosystem services vulnerabilities related to the activities of drivers occurring outside the management area

Does the human capital (complementary assets) exist to produce societal benefits from ecosystem services?
Drivers operating outside the SMPTE management area have not formally been identified and taken into consideration due to the lack of a Maritime regional MSP and Canadian NMP which would identify drivers from all sectors within the marine environment

Ecosystem services have not been quantified by the SMPTE process, therefore, it is not possible to determine whether the human capital exists in order to produce associated societal benefits 
Although valued ecosystem components were identified in the SEA and HRA, significant ecosystem services have not been quantified by the SMPTE process

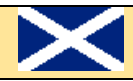

The current and future activities of drivers within the SMPTE management area are being identified and kept current through two-year monitoring and review periods of the SMPTE suggested in the consultation draft undertaken by MS

There are no quantifiable criteria employed to select significant drivers within the SMPTE management area

The marine development agenda is used to inform the SMPTE process and potential new emerging drivers through RLG and two-year time interval monitoring and review periods suggested in the consultation draft

The activities emanating from drivers specified within SMPTE plan option areas include fishing, shipping and navigation, grid, industry, tourism and recreation, and tidal energy development (Marine Scotland, 2013a). These drivers are projected to generate pressures related to the functioning and integrity of benthic habitats and species, nature conservation areas, priority marine features, seabirds, cetaceans, elasmobranchs, seals, protected fish, shellfish, water quality, sediments, soils, and bathymetry
What was the process to validate the findings of the significant ecosystem services with the relevant communities of interest?
Although valued ecosystem components were identified in the Current iterations of the Bay of Fundy and Cape Breton/Bras d'Or SEAs and the MEKSs, significant ecosystem services have not been quantified

\section{Significant Driver Activities and Pressures}

How are the current and future activities of drivers being identified and kept current?

What criteria are used to select the "significant" drivers in terms of the risks they introduce in the management area in relation to other drivers and the ecosystem?

\section{How is the marine development agenda used to} inform the marine spatial planning process and its plan of new / emerging drivers?

What are the activities emanating from those drivers and, subsequently, the pressures generated from those activities?
The current and future activities of drivers within the SMPTE management will be identified and kept current through two-year monitoring and review periods of the SMPTE suggested in the consultation draft undertaken by MS for Scotland's SMPTE

There are no quantifiable criteria employed to select significant drivers within the SMPTE management area due to the lack of baseline data within the province, as well as the absence of a central governance structure currently in place and comprehensive MSP

The marine development agenda is used to inform the SMPTE process and potential new emerging drivers through RLG and twoyear time interval monitoring and review periods suggested in the MS consultation draft

The activities emanating from drivers specified within SMPTE

POAs include fishing, shipping and navigation, government, industry, community, and tidal energy development. These drivers are projected to generate pressures related to the functioning and integrity of Critical physical processes, fisheries, fish and fish habitat, benthic communities, pelagic communities, marine mammals, marine birds, species at risk

\section{Management Area Regulatory Requirements}

The Marine Scotland Act 2010 provides the legislative and management framework for the marine environment within Scotland's TZ and the Marine and Coastal Access Act 2009 provides the legislative and management framework for MSP within Scottish waters out to Scotland's EEZ

What are the legislative statutes or agreements that are used to manage the activities of the drivers operating in the management area?

What is the occupation rate and location of the The location of drivers operating within the SMPTE management area are listed in the socio-economic assessment, however, further specifications related to the occupation rate and micro-siting of TCTs within plan area options in relation to the magnitude of spatial and temporal uses of drivers within the SMPTE management area will be undertaken in more detail as licenses for commercial scale development are issued

\section{The SEA Directive requires that a baseline of all} policies and legislation applicable to every stage of the SMPTE process is compiled by MS and listed in the SMP SEA

Transnational issues are handled by the UK government, which coordinates all EU Member States potentially affected or with an expressed interest in the SMPTE of the statutory consultation process in conformity with the SEA Directive

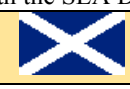

Consultation amongst the CA and relevant industry and community stakeholders is taken into consideration in order to obtain sectoral and local knowledge and values when searching for potentially suitable tidal energy development sites during the pre-statutory consultation stage, and

drivers operating in the management area?

How is the inventory of legislation and policies maintained current and up-to-date?

Are transnational issues handled and what is the relationship to regional bodies such as Regional Seas Commissions?
The legislative and regulatory framework that are used to manage the activities of the drivers operating in the management area stem from the recommended delegation of administrative authority over identified provincial marine planning boundaries from the federal government to the DoE as the MSP CA via the federal Oceans Act, with the identification of MREAs requiring consultation with the NS DNR under the Crown Lands Act and the MRE Act 2015, with involvement of the NSE in the environmental assessment and review process in projects $>2 \mathrm{MW}-<50 \mathrm{MW}$ legislated under the NSEA 1995 and the involvement of the NSE and CEAA in the environmental assessment and review process in projects $>50 \mathrm{MW}$ legislated under the CEA Act 2012

The occupation rate and location of the drivers operating in the management area has not been quantified due to the lack of baseline data within the province, the absence of a central governance structure currently in place, and a comprehensive Maritime regional MSP or Canadian NMP, while the current state of research in the province reveals that the quantity of such metadata is lacking substantially in comparison to European nations with MSPs, while any data collected is either not publically available and/or not organized by an individual government department or agency

In accordance with best practice witnessed in Scotland and the EU, a baseline of all policies and legislation listed in the public policy agenda of the SMPTE applicable to every stage of the SMPTE process should be compiled by the DoE and listed on their website In accordance with best practice witnessed in Scotland and the EU, transnational issues are to be handled by the Canadian federal government

\section{Risk Profile}

What were the consultation and feedback processes to ensure that competent authorities, industry stakeholders and communities of interest concur with the description of the risks in the risk profile?

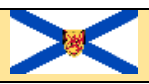

Consultation amongst the CA and relevant industry and community stakeholders and aboriginal groups is taken into consideration in order to obtain sectoral, local, and cultural knowledge and values when searching for potentially suitable tidal energy development sites during the pre-statutory consultation stage, and continually updated during advancing stages of the 


\begin{tabular}{|c|c|c|}
\hline $\begin{array}{l}\text { continually updated during advancing stages of the } \\
\text { SMPTE }\end{array}$ & & $\begin{array}{l}\text { SMPTE, with specific knowledge regarding historical and cultural } \\
\text { values occurring during the MEKS of the sustainability appraisal. }\end{array}$ \\
\hline $\begin{array}{l}\text { MS will employ a deploy and monitor scenario as } \\
\text { tidal development draft plan areas are given consent } \\
\text { in order to determine the impact of drivers on } \\
\text { ecosystem components and/or processes, } \\
\text { incrementally gathering information to inform } \\
\text { mitigation measures as appropriate in order to ensure } \\
\text { that SMPTE strategic aims are met }\end{array}$ & $\begin{array}{l}\text { What verification is being done to ensure that the } \\
\text { risk profile is linked to the MSP management } \\
\text { outcomes and the ecosystem management } \\
\text { outcomes? }\end{array}$ & $\begin{array}{l}\text { In conformity with best practices observed in Scotland, it is } \\
\text { suggested that the DoE employ a deploy and monitor scenario as } \\
\text { tidal development draft plan areas are given consent in order to } \\
\text { determine the impact of drivers on ecosystem components and/or } \\
\text { processes, incrementally gathering information to inform } \\
\text { mitigation measures as appropriate in order to ensure that SMPTE } \\
\text { strategic aims are met. }\end{array}$ \\
\hline $\begin{array}{l}\text { All associated reports with the NMP and SMPTE } \\
\text { process and framework include a non-technical } \\
\text { summary in order to be easily understood by all } \\
\text { stakeholders of the SMPTE }\end{array}$ & $\begin{array}{l}\text { Is the language, media and techniques used to } \\
\text { describe the risk profile adapted to the audience? }\end{array}$ & $\begin{array}{l}\text { In conformity with best practices observed in Scotland, it is } \\
\text { suggested that all associated reports with the SMPTE process and } \\
\text { framework include a non-technical summary in order to be easily } \\
\text { understood by all stakeholders of the SMPTE }\end{array}$ \\
\hline \multicolumn{3}{|c|}{ Cause and Effect Analysis } \\
\hline $\begin{array}{l}\text { Benthic habitats and species, nature conservation } \\
\text { areas, priority marine features, seabirds, cetaceans, } \\
\text { elasmobranchs, seals, protected fish, shellfish, water } \\
\text { quality, sediments, soils, and bathymetry }\end{array}$ & $\begin{array}{l}\text { What are the ecosystem components or processes } \\
\text { that would be altered or degraded as a result of the } \\
\text { pressures occurring from the activities of the } \\
\text { drivers? }\end{array}$ & $\begin{array}{l}\text { Critical physical processes, fisheries and aquaculture, fish and fish } \\
\text { habitat, marine benthic habitat and communities, pelagic } \\
\text { communities, marine mammals, marine birds, species at risk, and } \\
\text { marine and coastal resources }\end{array}$ \\
\hline $\begin{array}{l}\text { The pressure-activity-state change-impact chain has } \\
\text { yet to be defined as the SMPTE process undertook } \\
\text { an opportunities and constraints approach rather than } \\
\text { a pressures and impacts approach to assess the } \\
\text { severity of impacts }\end{array}$ & $\begin{array}{l}\text { Has the pressure-activity-state change-impact } \\
\text { chain been defined for relevant developments? }\end{array}$ & $\begin{array}{l}\text { The pressure-activity-state change-impact chain has yet to be } \\
\text { defined as the SMPTE process undertook an opportunities and } \\
\text { constraints approach rather than a pressures and impacts approach } \\
\text { to assess the severity of impacts in accordance to the Scottish } \\
\text { SMPTE. However, it is recommended that a pressure-activity-state } \\
\text { change-impact chain be defined for relevant developments in } \\
\text { accordance with the ecosystem approach to MSP, however, this is } \\
\text { not feasible with the current state of knowledge in the province } \\
\text { due to the lack of baseline data within the province, as well as the } \\
\text { absence of a central governance structure currently in place and } \\
\text { comprehensive MSP }\end{array}$ \\
\hline $\begin{array}{l}\text { The duration and trajectory of recovery to ecosystem } \\
\text { components or processes that would be altered or } \\
\text { degraded as a result of the pressures occurring from } \\
\text { the activities of the drivers within and outside the } \\
\text { SMPTE management area have not been estimated }\end{array}$ & $\begin{array}{l}\text { What would be the duration and trajectory or } \\
\text { trajectories of the recovery? }\end{array}$ & $\begin{array}{l}\text { The duration and trajectory of recovery to ecosystem components } \\
\text { or processes that would be altered or degraded as a result of the } \\
\text { pressures occurring from the activities of the drivers within and } \\
\text { outside the SMPTE management area have not been estimated due } \\
\text { to a lack of baseline data within the province, as well as the } \\
\text { absence of a central governance structure currently in place and } \\
\text { comprehensive MSP }\end{array}$ \\
\hline $\begin{array}{l}\text { The feasibility of mitigation and/or restoration } \\
\text { strategies have yet to be determined }\end{array}$ & $\begin{array}{l}\text { What is the feasibility of the mitigation or } \\
\text { restoration strategies that could be implemented if } \\
\text { natural recovery is not possible? }\end{array}$ & $\begin{array}{l}\text { The feasibility of mitigation and/or restoration strategies have yet } \\
\text { to be determined }\end{array}$ \\
\hline $\begin{array}{l}\text { The formulation of a cause and effect analysis is an } \\
\text { ongoing process }\end{array}$ & $\begin{array}{l}\text { What method was used to conduct the cause and } \\
\text { effect analysis? }\end{array}$ & $\begin{array}{l}\text { The formulation of a cause and effect analysis is an ongoing } \\
\text { process as only one TCT has been successfully deployed in Nova } \\
\text { Scotia waters for several years }\end{array}$ \\
\hline \multicolumn{3}{|c|}{ Impacts Consequences and Repercussions } \\
\hline $\begin{array}{l}\text { Benthic habitats and species, nature conservation } \\
\text { areas, priority marine features, seabirds, cetaceans, } \\
\text { elasmobranchs, seals, protected fish, shellfish, water } \\
\text { quality, sediments, soils, and bathymetry }\end{array}$ & $\begin{array}{l}\text { What are the ecosystem features and process that } \\
\text { may be altered or degraded as a result of the } \\
\text { pressures introduced by the activities of the } \\
\text { drivers operating in the management area? }\end{array}$ & $\begin{array}{l}\text { Critical physical processes, fisheries, fish and fish habitat, benthic } \\
\text { communities, pelagic communities, marine mammals, marine } \\
\text { birds, species at risk }\end{array}$ \\
\hline $\begin{array}{l}\text { The SMPTE socio-economic assessment report } \\
\text { estimates that the potential consequences } \\
\text { categorized under the "social" umbrella resulting } \\
\text { from the disruption of ecosystem services via the } \\
\text { deployment of tidal energy projects are limited to } \\
\text { commercial fisheries, recreational boaters, sea } \\
\text { kayakers, and sea anglers, but are deemed negligible }\end{array}$ & $\begin{array}{l}\text { What are the traditional, cultural and social } \\
\text { consequences if a given ecosystem service is } \\
\text { impacted by pressures or changes introduced by } \\
\text { the activities of the drivers operating in the } \\
\text { management area? }\end{array}$ & $\begin{array}{l}\text { The current iterations of the socio-economic assessment and } \\
\text { MEKSs identify the potential traditional, cultural and social } \\
\text { consequences resulting from the disruption of ecosystem services } \\
\text { via the deployment of tidal energy projects include aboriginal } \\
\text { ways of life and conflicts with industries operating within the } \\
\text { SMPTE management boundaries such as fishing, aquaculture, } \\
\text { shipping, etc. }\end{array}$ \\
\hline $\begin{array}{l}\text { The SMPTE socio-economic assessment report } \\
\text { estimates that the potential consequences } \\
\text { categorized under the "social" umbrella resulting } \\
\text { from the disruption of ecosystem services via the } \\
\text { deployment of tidal energy projects are limited to } \\
\text { commercial fisheries, recreational boaters, sea } \\
\text { kayakers, and sea anglers, but are deemed negligible }\end{array}$ & $\begin{array}{l}\text { What societal benefits would be impeded or } \\
\text { impacted by the ecosystem alteration and loss or } \\
\text { reduction of ecosystem services? }\end{array}$ & $\begin{array}{l}\text { The current iterations of the socio-economic assessment and } \\
\text { MEKSs identify the potential traditional, cultural and social } \\
\text { consequences resulting from the disruption of ecosystem services } \\
\text { via the deployment of tidal energy projects include aboriginal } \\
\text { ways of life and conflicts with industries operating within the } \\
\text { SMPTE management boundaries such as fishing, aquaculture, } \\
\text { shipping, etc. }\end{array}$ \\
\hline $\begin{array}{l}\text { Very minor affects are estimated on a local scale, } \\
\text { therefore local communities situated in close } \\
\text { proximity to plan option areas engaging in } \\
\text { commercial fishing, recreational boating, sea } \\
\text { kayaking, and sea angling may react to such } \\
\text { consequences of tidal energy development }\end{array}$ & $\begin{array}{l}\text { What is the size of the community or electorate } \\
\text { that would react to the consequences? }\end{array}$ & $\begin{array}{l}\text { Given the small political, geographic, and population size of Nova } \\
\text { Scotia, the size of the community or electorate that would react to } \\
\text { the consequences can be estimated to encompass the entire } \\
\text { province, with a list of key stakeholders who reside within the } \\
\text { province set out in the SMPTE }\end{array}$ \\
\hline $\begin{array}{l}\text { The potential economic loses produced from sectors } \\
\text { have been quantified in monetary terms under three } \\
\text { TCT growth scenarios, low }(0.5 \mathrm{GW}) \text {, central } \\
(1.25 \mathrm{GW}) \text {, and high }(2.5 \mathrm{GW}) \text {, for the three plan }\end{array}$ & $\begin{array}{l}\text { What are the potential economic losses or } \\
\text { liabilities if activities are displaced or encroached } \\
\text { on by the activities of other drivers occurring in } \\
\text { the management area? }\end{array}$ & $\begin{array}{l}\text { The potential economic losses or liabilities if activities are } \\
\text { displaced or encroached on by the activities of other drivers } \\
\text { occurring in the management area have not been quantified due to } \\
\text { the lack of quantitative economic baseline data within the }\end{array}$ \\
\hline
\end{tabular}




\begin{tabular}{|c|c|c|}
\hline option regions, southwest, west, and north & & $\begin{array}{l}\text { province, as well as the absence of a central governance structure } \\
\text { currently in place and comprehensive MSP }\end{array}$ \\
\hline $\begin{array}{l}\text { In the event that ecosystem management outcomes } \\
\text { of the NMP in management areas of the SMPTE are } \\
\text { compromised, EU marine legislation including the } \\
\text { MSFD and the MSP Directive set out the strategic } \\
\text { and/or international repercussions that are to ensue }\end{array}$ & $\begin{array}{l}\text { What strategic or international repercussions } \\
\text { could occur if the ecosystem management } \\
\text { outcomes are not achieved? }\end{array}$ & $\begin{array}{l}\text { In the event that ecosystem management outcomes of the SMPTE } \\
\text { are compromised, Section 58(1)(a) of the MRE Act } 2105 \text { explicitly } \\
\text { providing that the Minister may issue an order to cease work, } \\
\text { while the NSEA } 1995 \text { dictates that EAs must be completed for } \\
\text { tidal energy projects }>2 \mathrm{MW}-<50 \mathrm{MW} \text { with the NSE giving consent } \\
\text { to continue if impacts are deemed negligible and withhold consent } \\
\text { if they are not, and the CEA Act } 2012 \text { providing similar powers to } \\
\text { the NSE and CEAA in projects }>50 \mathrm{MW} \text {. No international } \\
\text { repercussions between the USA and Canada with respect to the } \\
\text { alteration of hydrology and thus significant ecosystem features and } \\
\text { process throughout the oceanographically interrelated large-scale } \\
\text { ecoregions of the Bay of Fundy and the Gulf of Maine. }\end{array}$ \\
\hline $\begin{array}{l}\text { In the event that ecosystem management outcomes } \\
\text { of the NMP in management areas of the SMPTE are } \\
\text { not achieved EU marine legislation including the } \\
\text { MSFD and the MSP Directive establish a framework } \\
\text { for a conflict resolution/appeal process }\end{array}$ & $\begin{array}{l}\text { Is there a conflict resolution / appeal process when } \\
\text { management outcome is not being achieved? }\end{array}$ & $\begin{array}{l}\text { The MRE Act sets out a conflict resolution / appeal process } \\
\text { when management outcome is not being achieved via Section } \\
58(1) \text { (a) of which explicitly providing that the Minister may issue } \\
\text { an order to cease work, while the NSEA } 1995 \text { dictates that EAs } \\
\text { must be completed for tidal energy projects }>2 \mathrm{MW}-<50 \mathrm{MW} \text { with } \\
\text { the NSE giving consent to continue if impacts are deemed } \\
\text { negligible and withhold consent if they are not, and the CEA Act } \\
2012 \text { providing similar powers to the NSE and CEAA in projects } \\
>50 \mathrm{MW} \text {. No international repercussions between the USA and } \\
\text { Canada with respect to the alteration of hydrology and thus } \\
\text { significant ecosystem features and process throughout the } \\
\text { oceanographically interrelated large-scale ecoregions of the Bay of } \\
\text { Fundy and the Gulf of Maine. }\end{array}$ \\
\hline \multicolumn{3}{|c|}{ Risk Matrix } \\
\hline $\begin{array}{l}\text { The contributions of various causes are integrated to } \\
\text { determine management priorities manifested as } \\
\text { strategic aims through the scoping stage all the way } \\
\text { through to the Scottish Ministers' approval of the } \\
\text { final draft plan, with contributions concerning } \\
\text { specific scientific and technical advisory exclusive } \\
\text { of the sustainability appraisal persistent throughout } \\
\text { the SMPTE process via RLG }\end{array}$ & $\begin{array}{l}\text { How are the contributions of the various causes } \\
\text { integrated to determine management priorities? }\end{array}$ & $\begin{array}{l}\text { The contributions of various causes are integrated to determine } \\
\text { management priorities manifested as strategic aims through the } \\
\text { scoping stage all the way through to the Nova Scotia and Canadian } \\
\text { Ministers' approval of the final draft plan, with contributions } \\
\text { concerning specific scientific and technical advisory form within } \\
\text { the DoE and the OWSC exclusive of the sustainability appraisal } \\
\text { persistent throughout the SMPTE process via RLG }\end{array}$ \\
\hline $\begin{array}{l}\text { The environmental and ecological, social, and } \\
\text { economic risk criteria are measured in likelihood } \\
\text { and magnitude of risk under probability of risk } \\
\text { occurring via the SEA and HRA, with social and } \\
\text { economic risk measured in relation to three growth } \\
\text { scenarios, low }(0.5 \mathrm{GW}) \text {, central ( } 1.25 \mathrm{GW}) \text {, and high } \\
(2.5 \mathrm{GW}) \text {, via the socio-economic assessment, } \\
\text { although only economic risk has been quantified }\end{array}$ & $\begin{array}{l}\text { Are the risk criteria integrated in the classification } \\
\text { of the likelihood and extent of the events and } \\
\text { consequences? }\end{array}$ & $\begin{array}{l}\text { The environmental and ecological risk criteria are integrated in the } \\
\text { classification of the likelihood and extent of the events and } \\
\text { consequences in Karsten's (2012) Tidal energy resource } \\
\text { assessment map for Nova Scotia, with hydrology alterations in } \\
\text { specific tidal current resource areas quantified as acceptable or } \\
\text { unacceptable, and maximum sustainable deployment targets } \\
\text { suggested in relation to such calculations. However, } \\
\text { socioeconomic quantification of potential monetary changes } \\
\text { incurred to other drivers operating in the SMPTE management } \\
\text { boundary has not been undertaken du to the lack of quantitative } \\
\text { economic baseline data within the province, as well as the absence } \\
\text { of a central governance structure currently in place and } \\
\text { comprehensive MSP, thereby hindering the overall assessment of } \\
\text { sustainability of risk criteria. }\end{array}$ \\
\hline $\begin{array}{l}\text { The likelihood and severity of environmental, } \\
\text { ecological, social, and economic risks are validated } \\
\text { internally within MS by measuring it against } \\
\text { baseline data and sharing results with external } \\
\text { stakeholders from the sustainability appraisal report } \\
\text { to the post-adoption statement }\end{array}$ & $\begin{array}{l}\text { How was the likelihood and severity of a risk } \\
\text { occurring described and validated with the } \\
\text { participants? }\end{array}$ & $\begin{array}{l}\text { The likelihood and severity of environmental, ecological, social, } \\
\text { and economic risks should be validated internally within the DoE } \\
\text { by measuring it against baseline data and sharing results with } \\
\text { external stakeholders from the sustainability appraisal report to the } \\
\text { post-adoption statement }\end{array}$ \\
\hline \multicolumn{3}{|c|}{ Management Measures Evaluations } \\
\hline $\begin{array}{l}\text { The criteria used to evaluate and classify the } \\
\text { effectiveness and feasibility of the management } \\
\text { options within SMPTE plan option areas are the } \\
\text { assessment of policy tools and objectives of the } \\
\text { NMP in which the SMPTE must be consistent with, } \\
\text { and will be undertaken when licenses for } \\
\text { commercial tidal energy developments have been } \\
\text { issued }\end{array}$ & $\begin{array}{l}\text { What are the criteria used to evaluate and classify } \\
\text { the effectiveness and feasibility of the } \\
\text { management options, given that information } \\
\text { obtained from competent authorities on the } \\
\text { effectiveness of selected management measures } \\
\text { may be confidential? }\end{array}$ & $\begin{array}{l}\text { The criteria used to evaluate and classify the effectiveness and } \\
\text { feasibility of the management options within SMPTE POAs are } \\
\text { the assessment of the conformity of the SMPTE in relation to the } \\
\text { legislation and policies from which the SMPTE draws form to } \\
\text { establish its key drivers and strategic aims, and will be undertaken } \\
\text { when licenses for commercial tidal energy developments have } \\
\text { been issued }\end{array}$ \\
\hline $\begin{array}{l}\text { Management measures were derived from the inputs } \\
\text { of MS staff, as the sole acting CA, through the } \\
\text { entirety of the SMPTE process, Scottish Ministers } \\
\text { from the final draft plan to the post adoption } \\
\text { statement, scientific and technical experts engaged } \\
\text { with steering groups such as the MSF to inform the }\end{array}$ & $\begin{array}{l}\text { Were the management measures derived from the } \\
\text { inputs of all relevant players? }\end{array}$ & $\begin{array}{l}\text { Management measures should be derived from the inputs of DoE } \\
\text { and OWSC staff through the entirety of the SMPTE process, Nova } \\
\text { Scotia and Canadian Ministers from the final draft plan to the post } \\
\text { adoption statement, governmental scientific and technical experts } \\
\text { identified as key stakeholders in the SMPTE to inform the } \\
\text { sustainability appraisal, and all relevant community and industry }\end{array}$ \\
\hline
\end{tabular}


sustainability appraisal, and all relevant community and industry stakeholders from the pre-statutory consultation stage through to the post-adoption statement

The methods used to identify the existing legislations, regulations, directives, policies, best management practices, standard operating procedures that may need to be implemented within SMPTE plan option areas are garnered from the assessment of policy tools and objectives of the NMP in which the SMPTE must be consistent with The evaluation of the management measures of the SMPTE are conducted through the assessment of policy tools and objectives of the NMP in which the SMPTE must be consistent with, and will be documented and stored in the SGs electronic records management system

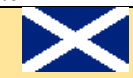

\section{Existing Managem}

In the event that ecosystem management outcomes of the NMP in management areas of the SMPTE are compromised, EU marine legislation including the MSFD and the MSP Directive establish the legal and policy liabilities and repercussions that are to ensue

In the event that ecosystem management outcomes of the NMP in management areas of the SMPTE are compromised, EU marine legislation including the MSFD and the MSP Directive set out strategic

stakeholders from the pre-statutory consultation stage through to the post-adoption statement

What are the existing legislations, regulations, directives, policies, best management practices, standard operating procedures that may need to be implemented for each management option being considered?
The existing legislations, regulations, directives, and policies that may need to be implemented within SMPTE POAs are garnered listed in the marine development and ecosystem protection public policy agendas, while best management practices and standard operating procedures are applied from the Scottish SMPTE and the ICES MSP QMS

How is the evaluation of the management measures being conducted (e.g. technique, qualifications of assessors, etc.) and documented?

The evaluation of management measures being conducted within SMPTE POAs are the assessment of the conformity of the SMPTE in relation to the legislation and policies from which the SMPTE draws form to establish its key drivers and strategic aims, and will be documented and stored in the DoEs electronic records management system and/or international repercussions that are to ensue

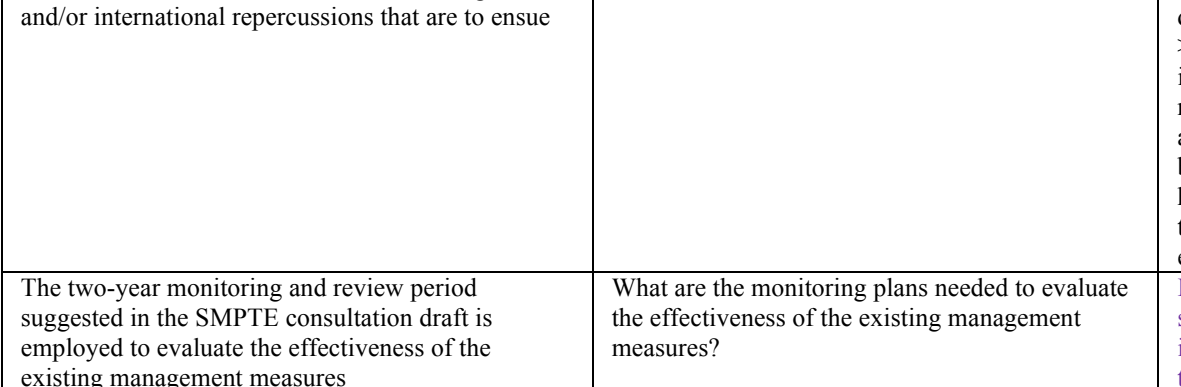

\section{New or Enhanced Management Measures Needed for the Marine Spatial Plan}

Input from relevant industry and community stakeholders is taken into consideration in order to obtain sectoral and local knowledge and values when searching for potentially suitable tidal energy development sites during the pre-statutory consultation stage, and continually updated during advancing stages of the SMPTE (RLG, IPF, SEA, socio-economic assessment, HRA, SA, consultation analysis report) (Marine Scotland, 2013a). Industry and community stakeholder input is then

documented and published in the pre-consultation analysis report, IFP, consultation analysis report, with the post-adoption statement detailing how such input was incorporated into the SMPTE final plan options

Given that established decision-making protocols for the SMPTE demand the incorporation of relevant industry and community stakeholder inputs, as well as documented and published proof of the methods in which such input was taken into consideration to inform the SMPTE process and final plan options, recommendations made are easily verifiable in terms of being in accordance with the terms of reference via the post-adoption statement (Marine Scotland, 2013a).

The two-year monitoring and review period
What could be the strategic or international repercussions if the MSP or ecosystem management outcomes are not achieved?
What could be the legal and policy liabilities and repercussions arising from not achieving the MSP or ecosystem management outcomes?

\section{How is the advice and feedback from the industry} stakeholders and communities of interest taken into consideration in the governance and oversight of the planning initiative?

Do the recommendation(s) follow the established decision-making protocols and rules in accordance with the terms of reference?

\section{ine Spatial Plan}

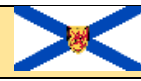

In the event that ecosystem management outcomes of the NMP in management areas of the SMPTE are compromised, Section 58(1)(a) of the MRE Act 2105 explicitly providing that the Minister may issue an order to cease work, while the NSEA 1995 dictates that EAs must be completed for tidal energy projects $>2 \mathrm{MW}-<50 \mathrm{MW}$ with the NSE giving consent to continue if impacts are deemed negligible and withhold consent if they are not, and the CEA Act 2012 providing similar powers to the NSE and CEAA in projects $>50 \mathrm{MW}$

In the event that ecosystem management outcomes of the NMP in management areas of the SMPTE are compromised, Section 58(1)(a) of the MRE Act 2105 explicitly providing that the Minister may issue an order to cease work, while the NSEA 1995 dictates that EAs must be completed for tidal energy projects $>2 \mathrm{MW}-<50 \mathrm{MW}$ with the NSE giving consent to continue if impacts are deemed negligible and withhold consent if they are not, and the CEA Act 2012 providing similar powers to the NSE and CEAA in projects $>50 \mathrm{MW}$. No international repercussions between the USA and Canada with respect to the alteration of hydrology and thus significant ecosystem features and process throughout the oceanographically interrelated large-scale ecoregions of the Bay of Fundy and the Gulf of Maine.

In accordance with best practices emanating from Scotland, it is suggested that a two-year monitoring and review period suggested in the Scottish SMPTE consultation draft be employed to evaluate the effectiveness of the existing management measures

\section{Input from relevant industry and community stakeholders will be} taken into consideration in order to obtain sectoral and local knowledge and values when searching for potentially suitable tidal energy development sites during the pre-statutory consultation stage, and continually updated during advancing stages of the SMPTE (MEKS, IPF, SEA, socio-economic assessment, HRA, sustainability appraisal, consultation analysis report). Industry and community stakeholder input will then be documented and published in the pre-consultation analysis report, IFP, consultation analysis report, with the post-adoption statement detailing how such input was incorporated into the SMPTE final POAs

Given that established decision-making protocols for the SMPTE demand the incorporation of relevant industry and community stakeholder inputs, as well as documented and published proof of the methods in which such input was taken into consideration to inform the SMPTE process and final POAs, recommendations made would be easily verifiable in terms of being in accordance with the terms of reference via the post-adoption statement. 


\begin{tabular}{|c|c|c|}
\hline $\begin{array}{l}\text { suggested in the SMPTE consultation draft is } \\
\text { employed to evaluate the effectiveness of the } \\
\text { existing, enhanced, or additional management } \\
\text { measures }\end{array}$ & policy agenda of the mandated government? & $\begin{array}{l}\text { Scottish SMPTE consultation draft should be applied by the Nova } \\
\text { Scotia SMPTE and employed to evaluate the effectiveness of the } \\
\text { existing, enhanced, or additional management measures }\end{array}$ \\
\hline $\begin{array}{l}\text { MS seeks the Scottish Ministers' approval of } \\
\text { SMPTE plan option areas during final draft plan } \\
\text { stage through to the post-adoption statement } \\
\text { (Interview, 2016b). }\end{array}$ & $\begin{array}{l}\text { Where and when in the recommendation process } \\
\text { is the approval from political leaders sought and } \\
\text { by whom? }\end{array}$ & $\begin{array}{l}\text { The DoE seeks the Nova Scotia and Canadian Ministers' approval } \\
\text { of SMPTE plan option areas during final draft plan stage through } \\
\text { to the post-adoption statement (Interview, 2016b). }\end{array}$ \\
\hline $\begin{array}{l}\text { Decisions concerning the evaluation of the } \\
\text { effectiveness of the SMPTE process and } \\
\text { management measures within its boundaries involve } \\
\text { the input of MS, relevant stakeholders and scientific } \\
\text { and technical advisory bodies apart of the SG's } \\
\text { Marine Strategy Forum (MSF), approved by } \\
\text { Scottish Ministers and chaired by the Policy Lead in } \\
\text { conjunction with scientific and technical specialists } \\
\text { applicable to specific stages and processes of the } \\
\text { SMPTE }\end{array}$ & $\begin{array}{l}\text { What are the delegation instruments for the MSP } \\
\text { Competent Authority and the other competent } \\
\text { authorities? }\end{array}$ & $\begin{array}{l}\text { Decisions concerning the evaluation of the effectiveness of the } \\
\text { SMPTE process and management measures within its boundaries } \\
\text { involve the input of the DoE, relevant stakeholders and scientific } \\
\text { and technical advisory bodies apart of the OWSC, approved by } \\
\text { Nova Scotia and Canadian Ministers and chaired by the Policy } \\
\text { Lead in conjunction with scientific and technical specialists } \\
\text { applicable to specific stages and processes of the SMPTE }\end{array}$ \\
\hline \multicolumn{3}{|c|}{ Marine Spatial Risk Register } \\
\hline $\begin{array}{l}\text { All responses emanating from the statutory } \\
\text { consultation stages of the SMPTE process are stored } \\
\text { in the SGs electronic records management system } \\
\text { and published in the post-adoption statement }\end{array}$ & $\begin{array}{l}\text { Where is the risk register maintained and filed and } \\
\text { how is its access controlled? }\end{array}$ & $\begin{array}{l}\text { All responses emanating from the statutory consultation stages of } \\
\text { the SMPTE process are stored in the DoEs established SMPTE } \\
\text { electronic records management system and published in the post- } \\
\text { adoption statement }\end{array}$ \\
\hline $\begin{array}{l}\text { All inputs and outputs used to inform and establish } \\
\text { the risk register are published online and justified } \\
\text { through the publication of the post-adoption } \\
\text { statement }\end{array}$ & $\begin{array}{l}\text { How is the risk register made available to all } \\
\text { participants for communication purposes? }\end{array}$ & $\begin{array}{l}\text { All inputs and outputs used to inform and establish the risk register } \\
\text { should be published online on the DoEs website and justified } \\
\text { through the publication of the post-adoption statement }\end{array}$ \\
\hline $\begin{array}{l}\text { There has not been a need as of yet to review the } \\
\text { risk register in order to develop new or enhanced } \\
\text { management measures based real-time commercial } \\
\text { deployment interaction data. Furthermore, no } \\
\text { individual MS employee has been delegated with the } \\
\text { responsibility of reviewing and updating the risk } \\
\text { register }\end{array}$ & $\begin{array}{l}\text { Who reviews and keeps the risk register up-to- } \\
\text { date as decisions to develop new or enhanced } \\
\text { management measures are made? }\end{array}$ & $\begin{array}{l}\text { It is suggested that one member of the DoE involved in the } \\
\text { SMPTE process reviews and keeps the risk register up-to-date as } \\
\text { decisions to develop new or enhanced management measures are } \\
\text { made to provide for a more structured and accountable regulatory } \\
\text { governance structure }\end{array}$ \\
\hline \multicolumn{3}{|c|}{ Spatial and Temporal Management Options } \\
\hline $\begin{array}{l}\text { Due to the strategic deploy and monitor management } \\
\text { protocol adopted by the SG in relation to TCT } \\
\text { implementation projects, the risks of ecosystem } \\
\text { stressors outlined in the SEA can be managed in the } \\
\text { SMPTE in accordance with the ALARP principal }\end{array}$ & $\begin{array}{l}\text { Are the proposed management options able to } \\
\text { reduce the risks of not achieving the MSP and } \\
\text { ecosystem management outcomes to a level as } \\
\text { low as reasonably practicable (ALARP)? }\end{array}$ & $\begin{array}{l}\text { Due to the strategic deploy and monitor management protocol } \\
\text { adopted by the SG in relation to TCT implementation projects and } \\
\text { suggested for application towards the Nova Scotia context, in } \\
\text { conjunction to the incremental development approach suggested } \\
\text { for adoption in the socio-economic assessment and the BoF and } \\
\text { Cape Breton/Bras d'Or SEAs, the risks of ecosystem stressors } \\
\text { outlined in the SEA can be managed in the SMPTE in accordance } \\
\text { with the ALARP principal }\end{array}$ \\
\hline $\begin{array}{l}\text { The economic and technical feasibility of the } \\
\text { proposed management options in terms of } \\
\text { implementation, enforcement and integration into } \\
\text { operational activities has not been quantified by the } \\
\text { SMPTE process }\end{array}$ & $\begin{array}{l}\text { What is the economic and technical feasibility of } \\
\text { the proposed management options in terms of } \\
\text { implementation, enforcement and integration into } \\
\text { operational activities? }\end{array}$ & $\begin{array}{l}\text { The economic and technical feasibility of the proposed } \\
\text { management options in terms of implementation, enforcement and } \\
\text { integration into operational activities has not been quantified by } \\
\text { the SMPTE process due to the lack of quantitative economic } \\
\text { baseline data within the province, as well as the absence of a } \\
\text { central governance structure currently in place and comprehensive } \\
\text { MSP }\end{array}$ \\
\hline $\begin{array}{l}\text { While the management measures are SMART } \\
\text { (Specific, Measurable, Achievable, Realistic, Time- } \\
\text { bound) in that they plan for a monitoring and review } \\
\text { period in two-year time intervals suggested in the } \\
\text { SMPTE consultation draft, with the discovery of any } \\
\text { criteria evoking a change in the SMPTE becoming } \\
\text { subject to formal consultation and reporting, there is } \\
\text { a lack of clarity and solidity on how management } \\
\text { measures will be undertaken, the quantification of } \\
\text { detrimental impacts that will deem tidal } \\
\text { development projects no longer sustainable and } \\
\text { acceptable, and the quantification of development } \\
\text { objectives to be achieved }\end{array}$ & Are the management measures SMART? & $\begin{array}{l}\text { The management measures are SMART (Specific, Measurable, } \\
\text { Achievable, Realistic, Time-bound) in that they will plan for a } \\
\text { monitoring and review period in two-year time intervals suggested } \\
\text { in the SMPTE consultation draft in Scotland, with the discovery of } \\
\text { any criteria evoking a change in the SMPTE becoming subject to } \\
\text { formal consultation and reporting, while the quantification of } \\
\text { detrimental impacts will employ quantified limits of acceptable } \\
\text { levels of energy extraction put forth by Karsten (2012) being } \\
\text { formally adopted by the plan conditional to ongoing research and } \\
\text { monitoring in relation to proposed objective targets for maximum } \\
\text { sustainable development }\end{array}$ \\
\hline \multicolumn{3}{|c|}{ Management Options Costs, Benefits and Feasibility } \\
\hline $\begin{array}{l}\text { The ecosystem benefits resulting from the } \\
\text { implementation of the SMPTE management options } \\
\text { include the assistance that TCT implementation will } \\
\text { provide in helping Scotland transition into a carbon- } \\
\text { free nation and therefore assisting in the mitigation } \\
\text { of global climate change (Marine Scotland, 2013a). }\end{array}$ & $\begin{array}{l}\text { What are the indicators and thresholds used to } \\
\text { forecast the ecosystem benefits as a result of } \\
\text { implementing the management options? }\end{array}$ & $\begin{array}{l}\text { The ecosystem benefits resulting from the implementation of the } \\
\text { SMPTE management options include the assistance that TCT } \\
\text { implementation will provide in helping Nova Scotia, as well as } \\
\text { Canada, transition into a carbon-free nation and therefore assisting } \\
\text { in the mitigation of global climate change. The criteria to indicate } \\
\text { this outcome consists of the amount of current GHG emission }\end{array}$ \\
\hline
\end{tabular}




\begin{tabular}{|c|c|c|}
\hline $\begin{array}{l}\text { The criteria to indicate this outcome consists of the } \\
\text { amount of current GHG emission reductions } \\
\text { displaced by the implementation of TCTs via the } \\
\text { aggregate electricity generated }\end{array}$ & & $\begin{array}{l}\text { reductions displaced by the implementation of TCTs via the } \\
\text { aggregate electricity generated, measured quantitatively against the } \\
\text { key drivers and qualitatively against the strategic aims set out in } \\
\text { the SMPTE }\end{array}$ \\
\hline $\begin{array}{l}\text { The two-year monitoring and review period } \\
\text { suggested in the SMPTE consultation draft will } \\
\text { inform the environmental, ecological, social, and } \\
\text { economic interactions arising from commercial- } \\
\text { scale TCT implementation and allow operating } \\
\text { procedures put in place for the current plan to be } \\
\text { updated as information becomes available }\end{array}$ & $\begin{array}{l}\text { What are the operating procedures and standards } \\
\text { that will need to be updated as a result of } \\
\text { implementing the management options? }\end{array}$ & $\begin{array}{l}\text { The two-year monitoring and review period suggested in the } \\
\text { Scottish SMPTE consultation draft and adopted as a best practice } \\
\text { for the Nova Scotia SMPTE will inform the environmental, } \\
\text { ecological, social, and economic interactions arising from } \\
\text { commercial-scale TCT implementation and allow operating } \\
\text { procedures put in place for the current plan to be updated as } \\
\text { information becomes available }\end{array}$ \\
\hline $\begin{array}{l}\text { The costs of implementing the management options } \\
\text { such as training, equipment acquisition, changes to } \\
\text { procedures, and impacts on production efficiency } \\
\text { have not been quantified for the SMPTE }\end{array}$ & $\begin{array}{l}\text { What are the costs of implementation as a result } \\
\text { of implementing the management options in terms } \\
\text { of training, equipment acquisition, changes to } \\
\text { procedures, and impacts on production efficiency? }\end{array}$ & $\begin{array}{l}\text { The costs of implementing the management options such as } \\
\text { training, equipment acquisition, changes to procedures, and } \\
\text { impacts on production efficiency have not been quantified for the } \\
\text { SMPTE due to the lack of baseline data within the province, as } \\
\text { well as the absence of a central governance structure currently in } \\
\text { place and comprehensive MSP }\end{array}$ \\
\hline $\begin{array}{l}\text { Social demand, acceptance, and/or tolerance have } \\
\text { not been classified to a discernable level }\end{array}$ & $\begin{array}{l}\text { What are the criteria used to assess and classify } \\
\text { the level of social demand, acceptance and/or } \\
\text { tolerance? }\end{array}$ & $\begin{array}{l}\text { Social demand, acceptance, and/or tolerance have not been } \\
\text { classified to a discernable level for the SMPTE due to the lack of } \\
\text { baseline data within the province, as well as the absence of a } \\
\text { central governance structure currently in place and comprehensive } \\
\text { MSP }\end{array}$ \\
\hline $\begin{array}{l}\text { Under the management framework stipulated in the } \\
\text { NMP, the SMPTE legislative and regulatory } \\
\text { framework is bounded by the Marine Scotland Act } \\
2010 \text { and the Marine and Coastal Access Act } 2009\end{array}$ & $\begin{array}{l}\text { What is the legislative and regulatory framework } \\
\text { under which the management options would be } \\
\text { implemented? }\end{array}$ & $\begin{array}{l}\text { The legislative and regulatory framework under which the } \\
\text { management options would be implemented stem from the } \\
\text { recommended delegation of administrative authority over } \\
\text { identified provincial marine planning boundaries from the federal } \\
\text { government to the DoE as the MSP CA via the federal Oceans Act, } \\
\text { with the identification of MREAs requiring consultation with the } \\
\text { NS DNR under the Crown Lands Act } 2012 \text { and the MRE Act } 2015\end{array}$ \\
\hline $\begin{array}{l}\text { The updating of policies and programs resulting } \\
\text { from the implementation of management measures } \\
\text { undertaken by MS can not yet be determine, } \\
\text { although the two-year monitoring and review period } \\
\text { will inform any necessary alterations required in the } \\
\text { political framework as information becomes } \\
\text { available }\end{array}$ & $\begin{array}{l}\text { What are the policy and program of the competent } \\
\text { authorities that will need to be updated or changed } \\
\text { as a result of implementing the management } \\
\text { measures? }\end{array}$ & $\begin{array}{l}\text { As an initial stage of SMPTE construction presented in this paper, } \\
\text { and therefore a conceptual and ideal policy and program in and of } \\
\text { itself, the statutes delegating the structure of the SMPTEs public } \\
\text { policy agenda and associated policy and programs of the } \\
\text { competent authorities that will need to be updated or changed as a } \\
\text { result of implementing the management measures include the } \\
\text { Oceans Act } 1996 \text { and the MRE Act } 2015\end{array}$ \\
\hline $\begin{array}{l}\text { The criteria and consultation processes used to } \\
\text { demonstrate how the management measures reduce } \\
\text { risks to traditional, cultural, social, and economic } \\
\text { ecosystem services has yet to be determined by the } \\
\text { SMPTE process }\end{array}$ & $\begin{array}{l}\text { What are the criteria and consultation processes } \\
\text { used to demonstrate how the management } \\
\text { measures reduce risks to traditional, cultural, } \\
\text { social, and economic ecosystem services? }\end{array}$ & $\begin{array}{l}\text { The criteria and consultation processes used to demonstrate how } \\
\text { the management measures reduce risks to traditional, cultural, } \\
\text { social, and economic ecosystem services has yet to be determined } \\
\text { by the SMPTE process due to the lack of baseline data within the } \\
\text { province, as well as the absence of a central governance structure } \\
\text { currently in place and comprehensive MSP }\end{array}$ \\
\hline \multicolumn{3}{|c|}{ Marine Spatial Plan } \\
\hline $\begin{array}{l}\text { As the acting CA, MS must follow the SMP process } \\
\text { in order to obtain approval from Scottish Ministers' } \\
\text { for the implementation of SMPTE final plan options }\end{array}$ & $\begin{array}{l}\text { What is the process that the MSP Competent } \\
\text { Authority must follow to obtain approval for the } \\
\text { implementation of the marine spatial plan? }\end{array}$ & $\begin{array}{l}\text { As the MSP CA, the DoE must follow the SMP process in order to } \\
\text { obtain approval from Nova Scotia and Canadian Ministers' for the } \\
\text { implementation of SMPTE final plan options }\end{array}$ \\
\hline MS is the sole CA for Scotland's SMPTE & $\begin{array}{l}\text { What is the process that the other competent } \\
\text { authority must follow to obtain approval for the } \\
\text { implementation of the marine spatial plan? }\end{array}$ & $\begin{array}{l}\text { The NS DNR as the other CA cannot implement the SMPTE, } \\
\text { however, they maintain proprietary jurisdiction over submerged } \\
\text { Crown lands within provincial boundaries under the Crown Lands } \\
\text { Act, thereby providing the legislative process required to provide } \\
\text { approval to the DoE for the identification of POAs produced from } \\
\text { the SMPTE process, as well as consent applications submitted to } \\
\text { the DoE by proponents for development leases }\end{array}$ \\
\hline $\begin{array}{l}\text { The legislative agreement required to implement the } \\
\text { SMPTE to ensure accountability of MS and industry } \\
\text { stakeholders is derived from the Marine Scotland } \\
\text { Act } 2010 \text { and the Marine and Coastal Access Act } \\
2009 \text { which delegate MS as the CA for the NMP and } \\
\text { devolve marine planning matters of UK's EEZ to } \\
\text { Scottish Parliament respectively. Together, these } \\
\text { legislative agreements coincide to formulate the } \\
\text { NMP, from which the SMPTE's policies must } \\
\text { conform to, which regulates the activities of industry } \\
\text { stakeholders in the management area and facilitates } \\
\text { engagement of industry stakeholders in the SMP } \\
\text { process }\end{array}$ & $\begin{array}{l}\text { What is the type of agreement needed to } \\
\text { implement the marine spatial plan to ensure } \\
\text { accountability of the competent authorities and } \\
\text { industry stakeholders? }\end{array}$ & $\begin{array}{l}\text { The legislative agreement required to implement the SMPTE to } \\
\text { ensure accountability of the DoE, NSE, CEAA, and DNR is } \\
\text { provided by the papers recommendation to delegate administrative } \\
\text { authority over identified provincial marine planning boundaries } \\
\text { from the federal government to the DoE as the MSP CA via the } \\
\text { federal Oceans Act, with the identification of MREAs requiring } \\
\text { consultation with the NS DNR under the Crown Lands Act } 2012 \\
\text { and the MRE Act 2015, with involvement of the NSE in the } \\
\text { environmental assessment and review process in projects }>2 \mathrm{MW-} \\
<50 \mathrm{MW} \text { legislated under the NSEA } 1995 \text { and the involvement of } \\
\text { the NSE and CEAA in the environmental assessment and review } \\
\text { process in projects }>50 \mathrm{MW} \text { legislated under the CEA Act } 2012\end{array}$ \\
\hline $\begin{array}{l}\text { MS, as the acting CA, is accountable for reporting } \\
\text { on the implementation of the SMPTE }\end{array}$ & $\begin{array}{l}\text { Who is accountable for reporting on the } \\
\text { implementation of the marine spatial plan? }\end{array}$ & $\begin{array}{l}\text { The DoE, as the MSP CA, is accountable for reporting on the } \\
\text { implementation of the SMPTE }\end{array}$ \\
\hline $\begin{array}{l}\text { The human and financial resources have been } \\
\text { quantified and documented by the financing division } \\
\text { of the SG within MS }\end{array}$ & $\begin{array}{l}\text { What are the human and financial resource } \\
\text { implications for the implementation of the marine } \\
\text { spatial plan from the perspective of the } \\
\text { governance structure, secretariat, competent }\end{array}$ & $\begin{array}{l}\text { The human and financial resources of the SMPTE process should } \\
\text { be quantified and documented by the financing team of the DoE }\end{array}$ \\
\hline
\end{tabular}




\begin{tabular}{|c|c|c|c|}
\hline & \multicolumn{2}{|c|}{ authorities and industry stakeholders? } & \\
\hline $\begin{array}{l}\text { Monitoring and review of the SMPTE will be } \\
\text { conducted in two-year time intervals as suggested in } \\
\text { the consultation draft, with the discovery of any } \\
\text { criteria evoking a change in the SMPTE becoming } \\
\text { subject to formal consultation and reporting being } \\
\text { published and made publically available, at which } \\
\text { point, MS will allow for all relevant stakeholder } \\
\text { input on the performance of the SMPTE }\end{array}$ & \multicolumn{2}{|c|}{$\begin{array}{l}\text { What are the complaints and feedback procedures } \\
\text { once the marine spatial plan has been } \\
\text { implemented? }\end{array}$} & $\begin{array}{l}\text { Monitoring and review of the SMPTE will be conducted in two- } \\
\text { year time intervals in accordance to best practices demonstrated in } \\
\text { the Scottish SMPTE consultation draft, with the discovery of any } \\
\text { criteria evoking a change in the SMPTE becoming subject to } \\
\text { formal consultation and reporting being published and made } \\
\text { publically available, at which point, the DoE should allow for all } \\
\text { relevant stakeholder input on the performance of the SMPTE }\end{array}$ \\
\hline \multicolumn{4}{|c|}{ Monitoring and Review } \\
\hline \multicolumn{4}{|c|}{ Marine Spatial Plan Implementation } \\
\hline $\begin{array}{l}\text { Following Scottish Ministers' adoption of the } \\
\text { finalized SMPTE, and the release of a post-adoption } \\
\text { statement, MS will implement project licensing for } \\
\text { tidal energy development proposals for adopted plan } \\
\text { options, as legislated under the Marine Scotland Act } \\
2010\end{array}$ & \multicolumn{2}{|c|}{$\begin{array}{l}\text { What is the work plan for the implementation of } \\
\text { the marine spatial plan? }\end{array}$} & $\begin{array}{l}\text { Following Nova Scotia and Canadian Ministers' adoption of the } \\
\text { finalized SMPTE, and the release of a post-adoption statement, the } \\
\text { DoE will implement project licensing for tidal energy development } \\
\text { proposals for adopted plan options, which prompts the } \\
\text { recommendation of legislative revision of the MRE Act } 2015 \text { for } \\
\text { incorporation of such a procedure }\end{array}$ \\
\hline $\begin{array}{l}\text { MS, as the acting CA, is responsible for oversight, } \\
\text { direction, and reporting regarding the } \\
\text { implementation of the SMPTE }\end{array}$ & \multicolumn{2}{|c|}{$\begin{array}{l}\text { Who is responsible for oversight, direction and } \\
\text { reporting as to the implementation of the marine } \\
\text { spatial plan? }\end{array}$} & $\begin{array}{l}\text { The DoE, as the MSP CA, is responsible for oversight, direction, } \\
\text { and reporting regarding the implementation of the SMPTE }\end{array}$ \\
\hline \multicolumn{4}{|c|}{ Compliance Verification and Auditing } \\
\hline $\begin{array}{l}\text { The compliance verification procedures employed to } \\
\text { determine compliance of the regulated parties with } \\
\text { respect to the SMPTE manifested through } \\
\text { compliance of the SMPTE with the policy tools and } \\
\text { objectives of the NMP in which the SMPTE must be } \\
\text { consistent with, in conjunction with the marine } \\
\text { licensing manual and any post-consent monitoring } \\
\text { strategies }\end{array}$ & $\begin{array}{l}\text { What are the compliance } \\
\text { verification procedures to } \\
\text { determine compliance of the } \\
\text { regulated parties? }\end{array}$ & \multicolumn{2}{|c|}{$\begin{array}{l}\text { The compliance verification procedures employed to determine compliance of the } \\
\text { regulated parties with respect to the SMPTE manifested through compliance of the } \\
\text { SMPTE with the policies and legislation presented in the public policy agenda of the } \\
\text { SMPTE, in conjunction with the licensing manual and any post-consent monitoring } \\
\text { strategies of the DoE }\end{array}$} \\
\hline $\begin{array}{l}\text { MS, as the sole acting CA, has the necessary } \\
\text { jurisdiction to conduct compliance verification for } \\
\text { the SMPTE }\end{array}$ & $\begin{array}{l}\text { Who are the competent } \\
\text { authorities that have the } \\
\text { necessary jurisdiction to } \\
\text { conduct compliance } \\
\text { verification? }\end{array}$ & \multicolumn{2}{|c|}{$\begin{array}{l}\text { The DoE, as the acting MSP CA, would have jurisdictional authority to conduct } \\
\text { compliance verification through the devolution of powers to plan the marine } \\
\text { environment from the DFO within established provincial marine planning boundaries } \\
\text { via the construction of necessary regulations in the Oceans Act legitimizing the DoEs } \\
\text { authority. }\end{array}$} \\
\hline $\begin{array}{l}\text { The regulated activities of drivers operating within } \\
\text { the SMPTE management area are regulated under } \\
\text { the NMP }\end{array}$ & $\begin{array}{l}\text { What are the regulated } \\
\text { activities of the drivers that are } \\
\text { regulated under the marine } \\
\text { spatial plan? }\end{array}$ & \multicolumn{2}{|c|}{$\begin{array}{l}\text { The regulated activities of drivers operating within the SMPTE management area are } \\
\text { bound to legislation referenced in the public policy agenda of the SMPTE }\end{array}$} \\
\hline $\begin{array}{l}\text { MS, as the sole acting CA, is accountable for } \\
\text { initiating conformity or performance audits of the } \\
\text { SMPTE under the framework of the NMP, with the } \\
\text { Scottish Ministers' post-adoption statement in } \\
\text { conjunction with the two-year review and } \\
\text { monitoring process suggested by the SMPTE } \\
\text { consultation draft acting as the defacto audit process }\end{array}$ & $\begin{array}{l}\text { Who is accountable for } \\
\text { initiating conformity or } \\
\text { performance audits? }\end{array}$ & \multicolumn{2}{|c|}{$\begin{array}{l}\text { The DoE, as the acting MSP CA, is accountable for initiating conformity or } \\
\text { performance audits of the SMPTE under the applicable policies and legislation } \\
\text { presented in the SMPTEs public policy agenda, with the Nova Scotia and Canadian } \\
\text { Ministers post-adoption statement in conjunction with the two-year review and } \\
\text { monitoring process suggested by the SMPTE consultation draft acting as the defacto } \\
\text { audit process }\end{array}$} \\
\hline $\begin{array}{l}\text { MS, as the sole acting CA, is accountable for } \\
\text { initiating conformity or performance audits of the } \\
\text { SMPTE under the framework of the NMP, with the } \\
\text { Scottish Ministers' post-adoption statement in } \\
\text { conjunction with the two-year review and } \\
\text { monitoring process suggested in the SMPTE } \\
\text { consultation draft acting as the defacto audit process. } \\
\text { Therefore, there are no joint audit processes for the } \\
\text { SMPTE }\end{array}$ & $\begin{array}{l}\text { How are joint audit process } \\
\text { initiated and under what } \\
\text { agreement? }\end{array}$ & \multicolumn{2}{|c|}{$\begin{array}{l}\text { The DoE, as the acting MSP CA, is accountable for initiating conformity or } \\
\text { performance audits of the SMPTE under the applicable policies and legislation } \\
\text { presented in the SMPTEs public policy agenda, with the Nova Scotia and Canadian } \\
\text { Ministers post-adoption statement in conjunction with the two-year review and } \\
\text { monitoring process suggested by the SMPTE consultation draft acting as the defacto } \\
\text { audit process }\end{array}$} \\
\hline $\begin{array}{l}\text { MS, as the sole acting CA, is accountable for } \\
\text { initiating conformity or performance audits of the } \\
\text { SMPTE under the framework of the NMP, with the } \\
\text { Scottish Ministers' post-adoption statement in } \\
\text { conjunction with the two-year review and } \\
\text { monitoring process suggested in the SMPTE } \\
\text { consultation draft acting as the defacto audit process }\end{array}$ & $\begin{array}{l}\text { What is the conformity and } \\
\text { performance audit framework? }\end{array}$ & \multicolumn{2}{|c|}{$\begin{array}{l}\text { The DoE, as the acting MSP CA, is accountable for preparing the audit report for the } \\
\text { SMPTE under the applicable policies and legislation presented in the SMPTEs public } \\
\text { policy agenda, with the Nova Scotia and Canadian Ministers post-adoption statement } \\
\text { in conjunction with the two-year review and monitoring process suggested by the } \\
\text { SMPTE consultation draft acting as the defacto audit process }\end{array}$} \\
\hline $\begin{array}{l}\text { MS, as the sole acting CA, is accountable for } \\
\text { preparing the audit report for the SMPTE and } \\
\text { responding to the findings under the framework of } \\
\text { the NMP, with the Scottish Ministers' post-adoption } \\
\text { statement in conjunction with the two-year review } \\
\text { and monitoring process acting as the defacto audit }\end{array}$ & $\begin{array}{l}\text { Who is accountable for } \\
\text { preparing the audit report and } \\
\text { responding to the findings? }\end{array}$ & \multicolumn{2}{|c|}{$\begin{array}{l}\text { The DoE, as the acting MSP CA, is accountable for preparing the audit report for the } \\
\text { SMPTE and responding to the findings under the applicable policies and legislation } \\
\text { presented in the SMPTEs public policy agenda, with the Nova Scotia and Canadian } \\
\text { Ministers post-adoption statement in conjunction with the two-year review and } \\
\text { monitoring process suggested by the SMPTE consultation draft acting as the defacto } \\
\text { audit process }\end{array}$} \\
\hline
\end{tabular}




\begin{tabular}{|c|c|c|c|c|c|}
\hline \multicolumn{6}{|l|}{ process } \\
\hline \multicolumn{2}{|c|}{$\begin{array}{l}\text { MS, as the sole acting CA, formally approves the } \\
\text { audit initiation process and request for corrective } \\
\text { action plans for the SMPTE under the framework of } \\
\text { the NMP, with the Scottish Ministers' post-adoption } \\
\text { statement in conjunction with the two-year review } \\
\text { and monitoring process acting suggested in the } \\
\text { SMPTE consultation draft as the defacto audit } \\
\text { process }\end{array}$} & $\begin{array}{l}\text { What is the formal approval } \\
\text { process to initiate an audit and } \\
\text { request corrective action plans? }\end{array}$ & \multicolumn{3}{|c|}{$\begin{array}{l}\text { The DoE, as the acting MSP CA, formally approves the audit initiation process and } \\
\text { request for corrective action plans for the SMPTE under the applicable policies and } \\
\text { legislation presented in the SMPTEs public policy agenda, with the Nova Scotia and } \\
\text { Canadian Ministers post-adoption statement in conjunction with the two-year review } \\
\text { and monitoring process suggested by the SMPTE consultation draft acting as the } \\
\text { defacto audit process }\end{array}$} \\
\hline \multicolumn{2}{|c|}{$\begin{array}{l}\text { Monitoring and review of the SMPTE will be } \\
\text { undertaken by MS in two-year time intervals AS } \\
\text { suggested in the consultation draft, with the } \\
\text { discovery of any criteria evoking a change in the } \\
\text { SMPTE becoming subject to formal consultation } \\
\text { and reporting being published and made publically } \\
\text { available }\end{array}$} & $\begin{array}{l}\text { How will the MSP } \\
\text { performance report be } \\
\text { communicated and made } \\
\text { available to all participants of } \\
\text { the MSP plan? }\end{array}$ & \multicolumn{3}{|c|}{$\begin{array}{l}\text { In conformity with best practices emanating from Scotland, it is suggested that } \\
\text { monitoring and review of the SMPTE will be undertaken by the DoE in two-year } \\
\text { time intervals AS suggested in the consultation draft, with the discovery of any } \\
\text { criteria evoking a change in the SMPTE becoming subject to formal consultation and } \\
\text { reporting being published and made publically available }\end{array}$} \\
\hline $\begin{array}{l}\text { MS, as the sole acting CA, } \\
\text { is accountable for } \\
\text { monitoring the cultural } \\
\text { and socio-performance of } \\
\text { the SMPTE }\end{array}$ & $\begin{array}{l}\text { Who is accountable } \\
\text { for monitoring the } \\
\text { cultural and socio- } \\
\text { performance of the } \\
\text { marine spatial plan? }\end{array}$ & $\begin{array}{l}\text { The DoE, as the sole acting } \\
\text { MSP CA, is accountable for } \\
\text { monitoring the cultural and } \\
\text { socio-performance of the } \\
\text { SMPTE }\end{array}$ & $\begin{array}{l}\text { MS, as the acting CA, is } \\
\text { accountable for implementing } \\
\text { the ecosystem monitoring } \\
\text { program and conducting the } \\
\text { data collection and analysis, } \\
\text { while individual project } \\
\text { developers are responsible for } \\
\text { conducting EIAs and } \\
\text { implementing site specific } \\
\text { monitoring programs for their } \\
\text { developments }\end{array}$ & $\begin{array}{l}\text { Who is accountable } \\
\text { for implementing the } \\
\text { ecosystem monitoring } \\
\text { program and } \\
\text { conducting the data } \\
\text { collection and } \\
\text { analysis? }\end{array}$ & $\begin{array}{l}\text { The DoE, as the acting } \\
\text { MSP CA, in conjunction } \\
\text { with the NSE in projects } \\
>2 \mathrm{MW}-<50 \mathrm{MW} \text { and the } \\
\text { NSE and CEAA in } \\
\text { projects }>50 \mathrm{MW} \text {, are } \\
\text { accountable for } \\
\text { implementing the } \\
\text { ecosystem monitoring } \\
\text { program and conducting } \\
\text { the data collection and } \\
\text { analysis, while } \\
\text { individual project } \\
\text { developers are } \\
\text { responsible for } \\
\text { conducting EIAs and } \\
\text { implementing site } \\
\text { specific monitoring } \\
\text { programs for their } \\
\text { developments }\end{array}$ \\
\hline \multirow[t]{2}{*}{$\begin{array}{l}\text { No socio-economic } \\
\text { assessment monitoring has } \\
\text { been constructed at the } \\
\text { moment, therefore, no } \\
\text { indicators of socio- } \\
\text { economic performance } \\
\text { monitoring have been } \\
\text { developed and finalized }\end{array}$} & \multirow[t]{2}{*}{$\begin{array}{l}\text { What are indicators } \\
\text { used to monitor the } \\
\text { cultural trends and the } \\
\text { socio-economic } \\
\text { performance of the } \\
\text { marine spatial plan? }\end{array}$} & \multirow{2}{*}{$\begin{array}{l}\text { No indicators of socio- } \\
\text { economic performance } \\
\text { monitoring have been } \\
\text { developed and finalized } \\
\text { moment due to the lack of } \\
\text { quantitative economic baseline } \\
\text { data within the province, as } \\
\text { well as the absence of a central } \\
\text { governance structure currently } \\
\text { in place and comprehensive } \\
\text { MSP }\end{array}$} & $\begin{array}{l}\text { Management measures of the } \\
\text { SMPTE are inherently } \\
\text { intertwined with ecosystem } \\
\text { monitoring activities, due to } \\
\text { the context of the strategic } \\
\text { aims of the SMPTE }\end{array}$ & $\begin{array}{l}\text { How are the } \\
\text { management } \\
\text { measures of the } \\
\text { marine spatial plan } \\
\text { linked to the } \\
\text { ecosystem monitoring } \\
\text { activities? }\end{array}$ & $\begin{array}{l}\text { Management measures } \\
\text { of the SMPTE are } \\
\text { inherently intertwined } \\
\text { with ecosystem } \\
\text { monitoring activities, } \\
\text { due to the context of the } \\
\text { strategic aims of the } \\
\text { SMPTE }\end{array}$ \\
\hline & & & $\begin{array}{l}\text { Baseline ecosystem data } \\
\text { collected for the SEA } \\
\text { categorized as biodiversity, } \\
\text { flora, and fauna, population } \\
\text { and human health, water and } \\
\text { the marine environment, } \\
\text { marine geology and coastal } \\
\text { processes, historic } \\
\text { environment, and landscape } \\
\text { and seascape }\end{array}$ & $\begin{array}{l}\text { What are indicators } \\
\text { used to monitor the } \\
\text { environmental effects } \\
\text { occurring at the } \\
\text { ecosystem level? }\end{array}$ & $\begin{array}{l}\text { Baseline ecosystem data } \\
\text { should be collected and } \\
\text { quantified or the SEA } \\
\text { post-Phase } 1 \text { of the } \\
\text { SMPTE process under } \\
\text { categories pertaining to } \\
\text { critical physical } \\
\text { processes, fisheries, fish } \\
\text { and fish habitat, benthic } \\
\text { communities, pelagic } \\
\text { communities, marine } \\
\text { mammals, marine birds, } \\
\text { species at risk as listed } \\
\text { in the the previously } \\
\text { completed Bay of } \\
\text { Fundy and Cape } \\
\text { Breton/Bras d'Or SEAs. }\end{array}$ \\
\hline $\begin{array}{l}\text { No socio-economic } \\
\text { assessment monitoring has } \\
\text { been constructed at the } \\
\text { moment, therefore no } \\
\text { agenda for the allotment of } \\
\text { human and financial } \\
\text { resources have been } \\
\text { developed and finalized }\end{array}$ & $\begin{array}{l}\text { What human and } \\
\text { financial resources } \\
\text { are available to } \\
\text { conduct these } \\
\text { analyses? }\end{array}$ & $\begin{array}{l}\text { No socio-economic assessment } \\
\text { monitoring has been } \\
\text { constructed at the moment due } \\
\text { to the lack of quantitative } \\
\text { economic baseline data within } \\
\text { the province, as well as the } \\
\text { absence of a central } \\
\text { governance structure currently } \\
\text { in place and comprehensive }\end{array}$ & $\begin{array}{l}\text { Thresholds and criteria to } \\
\text { ascertain the effectiveness of } \\
\text { the management measures of } \\
\text { the SMPTE in achieving the } \\
\text { management outcomes have } \\
\text { yet to be determined }\end{array}$ & $\begin{array}{l}\text { What are the } \\
\text { threshold and criteria } \\
\text { to ascertain the } \\
\text { effectiveness of the } \\
\text { management } \\
\text { measures of the } \\
\text { marine spatial plan at } \\
\text { achieving the } \\
\text { management }\end{array}$ & $\begin{array}{l}\text { Thresholds and criteria } \\
\text { to ascertain the } \\
\text { effectiveness of the } \\
\text { management measures } \\
\text { of the SMPTE in } \\
\text { achieving the } \\
\text { management outcomes } \\
\text { have yet to be } \\
\text { determined due to the }\end{array}$ \\
\hline
\end{tabular}




\begin{tabular}{|c|c|c|c|c|c|c|}
\hline & & $\begin{array}{l}\text { MSP, and therefore no agenda } \\
\text { for the allotment of human and } \\
\text { financial resources have been } \\
\text { developed and finalized }\end{array}$ & & & outcomes? & $\begin{array}{l}\text { lack of baseline data } \\
\text { within the province, as } \\
\text { well as the absence of a } \\
\text { central governance } \\
\text { structure currently in } \\
\text { place and } \\
\text { comprehensive MSP }\end{array}$ \\
\hline \multirow{2}{*}{$\begin{array}{l}\text { MS, as the sole acting CA, } \\
\text { is accountable for } \\
\text { preparing the cultural and } \\
\text { socio-economic reports } \\
\text { and responding to the } \\
\text { findings of the SMPTE }\end{array}$} & \multirow{2}{*}{$\begin{array}{l}\text { Who is accountable } \\
\text { for preparing the } \\
\text { cultural and socio- } \\
\text { economic reports and } \\
\text { responding to the } \\
\text { findings? }\end{array}$} & \multirow[b]{2}{*}{$\begin{array}{l}\text { The DoE, as the sole acting } \\
\text { CA, should be accountable for } \\
\text { preparing the cultural and } \\
\text { socio-economic reports and } \\
\text { responding to the findings of } \\
\text { the SMPTE. Currently, the } \\
\text { socio-economic report detailing } \\
\text { the the background context of } \\
\text { the province has been } \\
\text { undertaken by FERN for the } \\
\text { DoE and OERA. While the } \\
\text { scope of this report is a far cry } \\
\text { away from the level of } \\
\text { assessment required to } \\
\text { construct and implement an } \\
\text { economically viable and } \\
\text { ecologically sustainable } \\
\text { SMPTE for the province, } \\
\text { socio-economic reports in } \\
\text { general should be conducted by } \\
\text { the MSP CA rather than } \\
\text { contracted out in order to } \\
\text { provide for an accountable } \\
\text { governance structure }\end{array}$} & \multicolumn{2}{|c|}{$\begin{array}{l}\text { Resources available to conduct } \\
\text { the ecosystem monitoring } \\
\text { program have not been } \\
\text { quantified }\end{array}$} & $\begin{array}{l}\text { What resources are } \\
\text { available to conduct } \\
\text { the ecosystem } \\
\text { monitoring program? }\end{array}$ & $\begin{array}{l}\text { Resources available to } \\
\text { conduct the ecosystem } \\
\text { monitoring program } \\
\text { have not been quantified }\end{array}$ \\
\hline & & & \multicolumn{2}{|c|}{$\begin{array}{l}\text { The monitoring results of the } \\
\text { SMPTE are not formulated to } \\
\text { be biased toward any criterion, } \\
\text { rather, the environmental, } \\
\text { ecological, social, and } \\
\text { economic impacts outlined in } \\
\text { the sustainability appraisal } \\
\text { report are designed to be } \\
\text { weighted as appropriate to each } \\
\text { tidal energy development as } \\
\text { consent is granted and project } \\
\text { leases are permitted }\end{array}$} & $\begin{array}{l}\text { Are the results biased } \\
\text { by other sources of } \\
\text { risk not covered by } \\
\text { the marine spatial } \\
\text { plan or are they } \\
\text { biased by ecological } \\
\text { change? }\end{array}$ & $\begin{array}{l}\text { The monitoring results } \\
\text { of the SMPTE are not } \\
\text { formulated to be biased } \\
\text { toward any criterion, } \\
\text { rather, the } \\
\text { environmental, } \\
\text { ecological, social, and } \\
\text { economic impacts } \\
\text { outlined in the } \\
\text { sustainability appraisal } \\
\text { report are designed to be } \\
\text { weighted as appropriate } \\
\text { to each tidal energy } \\
\text { development as consent } \\
\text { is granted and project } \\
\text { leases are permitted }\end{array}$ \\
\hline \multirow[t]{3}{*}{$\begin{array}{l}\text { The final socio-economic } \\
\text { assessment report for the } \\
\text { SMPTE has been } \\
\text { published and made } \\
\text { publically available }\end{array}$} & \multirow[t]{2}{*}{$\begin{array}{l}\text { How will these } \\
\text { reports be } \\
\text { communicated and } \\
\text { made available to all } \\
\text { participants of the } \\
\text { MSP plan? }\end{array}$} & \multirow[t]{2}{*}{$\begin{array}{l}\text { The final socio-economic } \\
\text { assessment report for the } \\
\text { SMPTE should be published } \\
\text { and made publically available } \\
\text { on the DoE website }\end{array}$} & \multicolumn{2}{|c|}{$\begin{array}{l}\text { MS, as the acting CA, is } \\
\text { accountable for preparing the } \\
\text { ecosystem status and trends } \\
\text { report and responding to the } \\
\text { findings in two-year time } \\
\text { intervals suggested in the } \\
\text { SMPTE consultation draft }\end{array}$} & $\begin{array}{l}\text { Who is accountable } \\
\text { for preparing the } \\
\text { ecosystem status and } \\
\text { trends report and } \\
\text { responding to the } \\
\text { findings? }\end{array}$ & $\begin{array}{l}\text { Although the DoE must } \\
\text { work in conjunction } \\
\text { with the NSE in projects } \\
>2 \mathrm{MW}-<50 \mathrm{MW} \text { and the } \\
\text { NSE and CEAA in } \\
\text { projects }>50 \mathrm{MW} \text {, the } \\
\text { DoE, as the acting MSP } \\
\text { CA, is accountable for } \\
\text { preparing the ecosystem } \\
\text { status and trends report } \\
\text { and responding to the } \\
\text { findings in two-year } \\
\text { time intervals in } \\
\text { accordance with best } \\
\text { practices emanating } \\
\text { from the Scottish } \\
\text { SMPTE consultation } \\
\text { draft }\end{array}$ \\
\hline & & & \multicolumn{2}{|c|}{$\begin{array}{l}\text { Monitoring and review of the } \\
\text { SMPTE will be undertaken by } \\
\text { MS in two-year time intervals } \\
\text { as suggested in the SMPTE } \\
\text { consultation draft, with the } \\
\text { discovery of any criteria } \\
\text { evoking a change in the } \\
\text { SMPTE becoming subject to } \\
\text { formal consultation and } \\
\text { reporting being published and } \\
\text { made publically available }\end{array}$} & $\begin{array}{l}\text { How will the } \\
\text { ecosystem status and } \\
\text { trends reports be } \\
\text { communicated and } \\
\text { made available to all } \\
\text { participants of the } \\
\text { MSP plan? }\end{array}$ & $\begin{array}{l}\text { Monitoring and review } \\
\text { of the SMPTE will be } \\
\text { undertaken by the DoE } \\
\text { in two-year time } \\
\text { intervals in accordance } \\
\text { with best practices } \\
\text { emanating from the } \\
\text { Scottish SMPTE } \\
\text { consultation draft, with } \\
\text { the discovery of any } \\
\text { criteria evoking a } \\
\text { change in the SMPTE } \\
\text { becoming subject to } \\
\text { formal consultation and } \\
\text { reporting being } \\
\text { published and made } \\
\text { publically available }\end{array}$ \\
\hline & & \multicolumn{3}{|c|}{ Marine Spatial Plan Periodic Review } & & \\
\hline \multicolumn{2}{|c|}{$\begin{array}{l}\text { It is suggested that the SMPTE is reviewed every } \\
\text { two years as suggested in the consultation draft }\end{array}$} & \multicolumn{2}{|c|}{ What is the schedule for the review of the plan? } & \multicolumn{3}{|c|}{$\begin{array}{l}\text { It is suggested that the SMPTE is reviewed every two years in } \\
\text { conformity with the suggested timeframe proposed in the SGs } \\
\text { SMPTE consultation draft }\end{array}$} \\
\hline \multicolumn{2}{|c|}{$\begin{array}{l}\text { MS, as the acting CA, is accountable to initiate and } \\
\text { perform the review of the SMPTE }\end{array}$} & \multicolumn{2}{|c|}{$\begin{array}{l}\text { Is the MSP competent authority accountable to initiate } \\
\text { and perform the review? }\end{array}$} & \multicolumn{3}{|c|}{$\begin{array}{l}\text { The DoE, as the acting MSP CA, is accountable to initiate and } \\
\text { perform the review of the SMPTE }\end{array}$} \\
\hline \multicolumn{2}{|c|}{ The SMPTE suggests that a monitoring and review } & \multicolumn{2}{|c|}{ What is the formal approval process to initiate the } & \multicolumn{3}{|c|}{ It is suggested that the SMPTE is reviewed every two years in } \\
\hline
\end{tabular}




\begin{tabular}{|c|c|c|}
\hline $\begin{array}{l}\text { process be initiated by MS every two years with } \\
\text { demand from relevant stakeholders and Scottish } \\
\text { Ministers to undertake a further } \\
\text { process to identify new POAs }\end{array}$ & review? & $\begin{array}{l}\text { conformity with the suggested timeframe proposed in the SGs } \\
\text { SMPTE consultation draft, with demand from relevant } \\
\text { stakeholders and applicable federal and provincial Ministers } \\
\text { to undertake a further process to identify new POAs }\end{array}$ \\
\hline $\begin{array}{l}\text { MS, as the acting CA, has the authority to make } \\
\text { changes to the SMPTE }\end{array}$ & $\begin{array}{l}\text { Who has the authority to make changes to the marine } \\
\text { spatial plan? }\end{array}$ & $\begin{array}{l}\text { The DoE, as the acting MSP CA, has the authority to make } \\
\text { changes to the SMPTE }\end{array}$ \\
\hline $\begin{array}{l}\text { MS members appointed to the NMP monitoring and } \\
\text { review team are delegated as the monitoring and } \\
\text { review team for the SMPTE }\end{array}$ & $\begin{array}{l}\text { What is the selection process to identify a review } \\
\text { team? What are their qualifications? }\end{array}$ & $\begin{array}{l}\text { It is suggested that DoE members are appointed to the } \\
\text { SMPTE monitoring and review team based on internal } \\
\text { identification of relevant qualifications in conjunction with } \\
\text { prior scientific and technical advisory input into the SMPTE } \\
\text { process in conformity with best practices derived from the } \\
\text { Scottish SMPTE process }\end{array}$ \\
\hline $\begin{array}{l}\text { MS acts as the reviewers of the SMPTE while } \\
\text { approvers are Scottish Ministers, therefore, reviews } \\
\text { are approvers are independent bodies from one } \\
\text { another, thereby reducing biased and conflict of } \\
\text { interest }\end{array}$ & Are the reviewers "independent" from the approvers? & $\begin{array}{l}\text { The DoE acts as the reviewers of the SMPTE while approvers } \\
\text { are provincial and federal Ministers, therefore, reviews are } \\
\text { approvers are independent bodies from one another, thereby } \\
\text { reducing biased and conflict of interest }\end{array}$ \\
\hline
\end{tabular}




\section{Appendix C}

\begin{tabular}{|c|c|}
\hline \multicolumn{2}{|r|}{ List of Acronyms and Abbreviations } \\
\hline $\mathrm{AC}$ & Alternating current \\
\hline AHH & Andritz Hydro Hammerfest \\
\hline$\overline{\text { ARL }}$ & Atlantis Resources Ltd. \\
\hline ATEI & Acadia Tidal Energy Institute \\
\hline BOEM & Bureau of Ocean Energy Management \\
\hline BPNS & Belgium Part of the North Sea \\
\hline CA & Competent authority \\
\hline $\mathrm{CCS}$ & Carbon capture and storage \\
\hline CEAA & Canadian Environmental Assessment Agency \\
\hline CEA Act 2012 & Canadian Environmental Assessment Act 2012 \\
\hline COMFIT & Community feed-in tariff \\
\hline CVD & Charted vertical depth \\
\hline Dc & Vessel clearance depth \\
\hline $\mathrm{Dd}$ & Dynamic draught \\
\hline DFO & Department of Fisheries \& Oceans Canada \\
\hline $\mathrm{Dh}$ & Maximum devise design height \\
\hline DNR & Department of Natural Resources \\
\hline DoE & Department of Energy \\
\hline Ds & Draught \\
\hline DSC & Devise seabed clearance \\
\hline EA & Environmental assessment \\
\hline EC & European Community \\
\hline EGSPA 2007 & Environmental Goals and Sustainable Prosperity Act 2007 \\
\hline EMEC & European Marine Energy Centre \\
\hline EEZ & Exclusive economic zone \\
\hline EIA & Environmental impact assessment \\
\hline EQ & Equation \\
\hline FERC & Federal Energy Regulatory Commission \\
\hline FERN & Fundy Energy Research Network \\
\hline FIT & Feed-in tariff \\
\hline FORCE & Fundy Ocean Research Centre for Energy \\
\hline FTI & Fundy Tidal Inc. \\
\hline GDP & Gross domestic product \\
\hline GEN & General policy \\
\hline GES & Good environmental status \\
\hline GHG & Greenhouse gas \\
\hline GW & Gigawatt \\
\hline HAT & Highest astronomical tide \\
\hline HLMO & High-level marine objective \\
\hline HRA & Habitats regulation appraisal \\
\hline HS & Historic Scotland \\
\hline ICES & International Council for the Exploration of the Sea \\
\hline ICES MSP QMS & $\begin{array}{l}\text { International Council for the Exploration of the Sea's Marine } \\
\text { Spatial Planning Quality Management System }\end{array}$ \\
\hline IMPNS2015 & Netherlands' Integrated Management Plan for the North Sea 2015 \\
\hline IPF & Initial plan framework \\
\hline JNCC & Joint Nature Conservation Committee \\
\hline KEI & Key environmental issues \\
\hline
\end{tabular}




\begin{tabular}{|c|c|}
\hline KHPS & Kinetic Hydropower System \\
\hline Kms & Kilometers \\
\hline $\mathrm{kV}$ & Kilovolt \\
\hline $\mathrm{kW}$ & Kilowatt \\
\hline LAT & Lowest astronomical tide \\
\hline LOSC 1982 & Law of the Sea Convention 1982 \\
\hline $\mathrm{m}$ & Meters \\
\hline $\mathrm{M}$ & Minimum vertical distance \\
\hline $\mathrm{m} / \mathrm{s}$ & Meters per second \\
\hline MCT & Marine Current Turbines Ltd \\
\hline MEKS & Mi'kmaq ecological knowledge study \\
\hline MGC & Membertou Geomatics Consultants \\
\hline MRC & Marine Renewables Canada \\
\hline MRE Act 2015 & Marine Renewable-energy Act 2015 \\
\hline MS-LOT & Marine Scotland Licensing Operations Team \\
\hline MSFD & Marine Strategy Framework Directive \\
\hline MSP & Marine spatial planning \\
\hline MuZC & Multi-use zoning compatibility \\
\hline MW & Megawatt \\
\hline N-RIP & National Renewables Infrastructure Plan \\
\hline NAFO & North Atlantic Fisheries Organization \\
\hline $\mathrm{Nm}$ & Nautical miles \\
\hline NMP & National marine plan \\
\hline NMPi & National Marine Plan Index \\
\hline NSE & Nova Scotia Department of Environment \\
\hline NSEA 1995 & Nova Scotia Environment Act 1995 \\
\hline NSNT & Nova Scotia Nature Trust \\
\hline NWPA 1985 & Navigable Waters Protection Act 1985 \\
\hline OEERA & Offshore Energy Environmental Research Association \\
\hline OERA & Offshore Energy Research Association of North America \\
\hline OWSC & One-Window Standing Committee \\
\hline PFOW & Pentland Firth and Orkney Waters \\
\hline POA & Plan option area \\
\hline PV & Photovoltaic \\
\hline QMS & Quality management system \\
\hline $\mathrm{R} \& \mathrm{D}$ & Research and development \\
\hline $\mathrm{Rd}$ & Maximum rotor diameter \\
\hline RLG & Regional locational guidance \\
\hline SAC & Special area of conservation \\
\hline SARA & Canadian Species at Risk Areas \\
\hline SEA & Strategic environmental assessment \\
\hline SEPA & Scottish Environmental Protection Agency \\
\hline SMPTE & Sectoral marine plan for tidal energy \\
\hline SNH & Scottish Natural Heritage \\
\hline SPA & Special protection area \\
\hline SPRG & Sectoral plans review group \\
\hline STAP & Scientific and technical advisory panel \\
\hline TCT & Tidal current turbine \\
\hline $\mathrm{TWh} / \mathrm{yr}$ & Terawatt hours per year \\
\hline $\mathrm{TZ}$ & Territorial zone \\
\hline UKC & Under keel clearance \\
\hline Vmsp & Mean spring peak velocity \\
\hline WWF & World Wildlife Foundation \\
\hline
\end{tabular}


